Jenetic Witness: Forensic Uses of DNA Tests

July 1990

OTA-BA-438

NTIS order \#PB90-259110

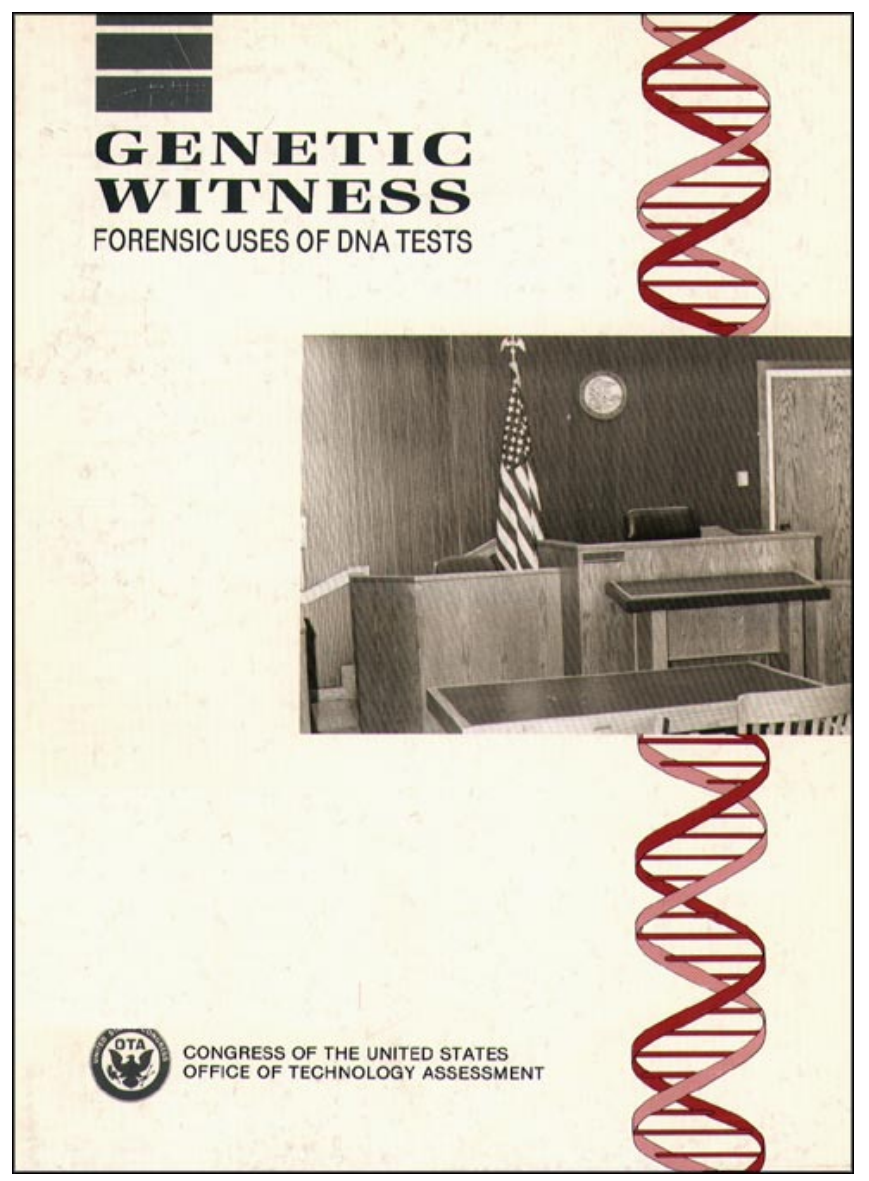




\section{Recommended Citation:}

U.S. Congress, Office of Technology Assessment, Genetic Witness: Forensic Uses of DNA Tests, OTA-BA-438 (Washington, DC: U.S. Government Printing Office, July 1990).

For sale by the Superintendent of Documents

U.S. Government Printing Office, Washington, DC 20402-9325

(Order form can be found in the back of this report.) 


\section{Foreword}

Many criminal and civil trials revolve around scientific evidence, but rarely does such evidence elicit the response received by DNA tests. Since November 1987, when a Florida criminal conviction based on DNA typing received national attention, interest in using DNA tests in crime laboratories throughout the country has soared, as have civil liberties concerns. Although forensic applications of DNA analysis involve technologies familiar in biological research laboratories and clinical practice, their transfer to forensic laboratories and the courts has just begun. This relatively quick movement of DNA typing into a public arena with life and death consequences, and its continuing, rapid evolution, spurred congressional interest in forensic DNA analysis.

Genetic Witness: Forensic Uses of DNA Tests was requested by the Senate Committee on Labor and Human Resources. It illustrates a range of options for action by the U.S. Congress on five policy issues:

. standards for forensic uses of DNA typing;

- funding of crime laboratories, forensic personnel training, and forensic research;

. the advisability of establishing computer databanks of DNA test results;

. standardization of DNA analysis for improved data collection; and

- privacy considerations of collecting, using, and storing DNA data or samples.

In gathering information for this study, OTA staff visited public and private laboratories in seven States and the District of Columbia. Hundreds of individuals representing the array of scientific, legal, and ethical interests assessed by this report cooperated with OTA through interviews, by providing written material, and by critiquing initial drafts. OTA prepared this report with the assistance of a panel of advisors and reviewers selected for their expertise and diverse points of view on the issues covered by the assessment. These authorities were drawn from academia, industry, and professional societies, as well as Federal, State, and local agencies. They included members of the scientific, law enforcement, forensic, and legal communities. OTA gratefully acknowledges the contribution of each of these individuals; as with all OTA reports, responsibility for the content is OTA's alone.

Highly touted initially and formerly used with limited scrutiny, DNA tests are now being subjected to closer inspection by scientific, legal, and law enforcement experts. Today's debate focuses on what standards and additional quality control may need to be used in forensic DNA testing, but no scientific doubt remains that technologies already available can accurately detect genetic differences between humans. Recombinant DNA technologies are new, powerful tools to clear the innocent and convict the guilty.

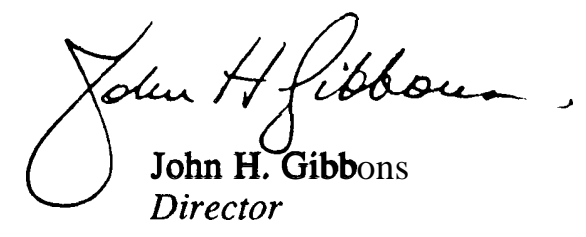




\title{
Genetic Witness: Forensic Uses of DNA Tests Advisory Panel
}

\author{
C. Thomas Caskey, Panel Chair \\ Baylor College of Medicine \\ Houston, TX
}

\author{
Michael L. Baird \\ Lifecodes Corp. \\ Valhalla, NY \\ W. Gray Buckley \\ Colorado Bureau of Investigation \\ Denver, CO \\ Robert L. Dean \\ Office of the State's Attorney \\ Montgomery County \\ Rockville, MD \\ Henry A. Erlich \\ Cetus Corp. \\ Emeryville, CA \\ Lisa Forman \\ Cellmark Diagnostics \\ Germantown, MD \\ Armando Garcia \\ Attorney-at-Law \\ Redwood City, CA \\ Janlori Goldman \\ American Civil Liberties Union \\ Washington, DC \\ Eric S. Lander \\ The Whitehead Institute for Biomedical Research \\ Cambridge, MA
}

Henry C. Lee

Forensic Science Laboratory

Connecticut State Police

Meriden, CT

Charles J. Ogletree

Harvard Law School

Cambridge, MA

The Honorable Haskell M. Pitluck

State of Illinois 19th Judicial Circuit

Woodstock, IL

Gloria H. Reynolds

Crime Laboratory

Detroit Department of Police

Detroit, MI

Douglas P. Rutnik

Office of the Public Defender

Albany County

Albany, NY

Robert E. Stevenson

American Type Culture Collection

Rockville, MD

Willard Carl Stuver

Crime Laboratory

Metro-Dade Police Department

Miami, FL

George B. Trubow

The John Marshall Law School

Chicago, IL

NOTE: OTA appreciates and is grateful for the valuable assistance and thoughtful critiques provided by the advisory panel members. The panel does not however, necessarily approve, disapprove, or endorse this report. OTA assumes full responsibility for the report and the accuracy of its contents. 


\section{OTA Project Staff-Genetic Witness: Forensic Uses of DNA Tests}

Roger C. Herdman, Assistant Director, OTA

Health and Life Sciences Division

Gretchen S. Kolsrud, Biological Applications Program Manager'

Robyn Y. Nishimi, Project Director

Kevin W. O'Connor, Legal Analyst

Holly L. Gwin, Legal Analyst

Margaret A. Anderson, Analyst

Support Staff

Cecile Parker, Office Administrator

Linda Rayford-Journiette, Administrative Secretary

Jene Lewis, Secretary

Sharon Kay Oatman, Administrative Assistant ${ }^{2}$

\section{Publishing Staff}

Katie S. Boss, Publishing Officer

Chip Moore, Publishing Assistant

Debra Datcher Cheryl Davis

Dorinda Edmondson Steve Kettler

Christine Onrubia Ted Williams

Susan Zimmerman

\section{Editor}

Linda Starke (Contractor), Washington, DC 


\section{Contents}

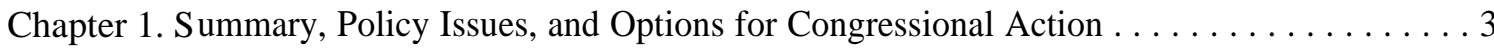

Chapter 2. The Technologies and Their Applications $\ldots \ldots \ldots \ldots \ldots \ldots \ldots \ldots \ldots \ldots \ldots$

Chapter 3. Validity, Reliability, and Quality Assurance .......................... 59

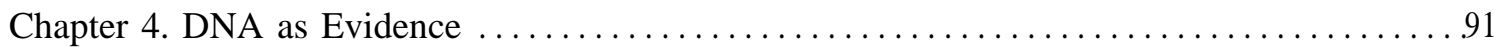

Chapter 5. Computer Technology and Informational Privacy . . . . . . . . . . . . . . 113

Chapter 6. DNA Typing by Federal, State, and Local Crime Laboratories . . . . . . . . . . 141

Appendix A. Reported Uses of DNA Testing in Crimin al Investigations and Proceedings . . 157

Appendix B. Survey Instrument for OTA Survey of State \& Local Crime Laboratories . . . . 173

Appendix C. Acknowledgments . . . . . . . . . . . . . . . . . . . . . . . . . . 179

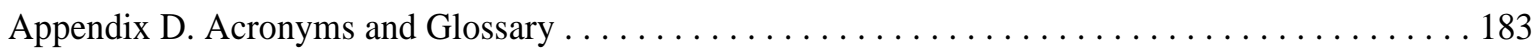

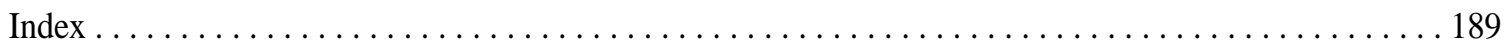




\section{Chapter 1}

\section{Summary, Policy Issues, and Options for Congressional Action}

"Positive identification by DNA profiling is fact. It is not subjective. It is not influenced by the vagaries of human emotion."

William S. Sessions

Director, Federal Bureau of Investigation

Feb. 20,1989

"DNA fingerprinting is all but foolproof, but some fool is going to use it."

anonymous, August 1989 


\section{CONTENTS}

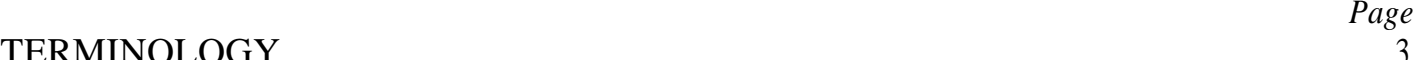

DNA AND HOW IT DIFFERS FROM PERSON TO PERSON

THE ROLE OF DNA TYPING IN FORENSIC IDENTIFICATION $\ldots \ldots \ldots \ldots \ldots \ldots \ldots 6$

ARE DNA TESTS VALID AND RELIABLE? . . . . . . . . . . . . . . . . . . . 7

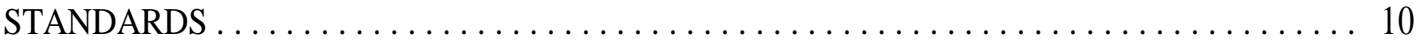

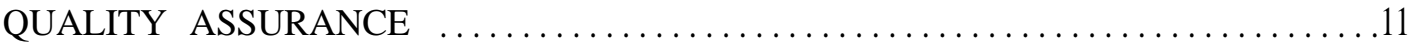

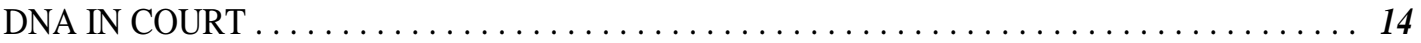

ADVANTAGES AND LIMITATIONS OF DNA TYPING AS EVIDENCE $\ldots \ldots \ldots \ldots 17$

COMPUTER TECHNOLOGY AND DNA IDENTIFICATION . . . . . . . . . . . . 18

PRIVACY AND CIVIL LIBERTIES CONSIDERATIONS $\ldots \ldots \ldots \ldots \ldots \ldots \ldots \ldots \ldots . \ldots \ldots$

DNA TYPING IN THE UNITED STATES: CURRENT PRACTICE

AND FUTURE OUTLOOK . . . . . . . . . . . . . . . . . . . . . . . . . . . 23

THE ROLE OF CONGRESS AND POLICY ISSUES AND OPTIONS $\ldots \ldots \ldots \ldots \ldots 26$

Quality Assurance and Standards . . . . . . . . . . . . . . . . . . . . . . . . 27

Funding for Forensic Sciences . . . . . . . . . . . . . . . . . . . . . . . . . . . . . . . . . . . 30

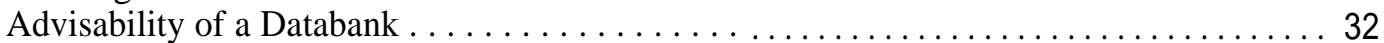

Standardization for Databanking $\ldots \ldots \ldots \ldots \ldots \ldots \ldots \ldots \ldots \ldots \ldots \ldots \ldots \ldots \ldots$

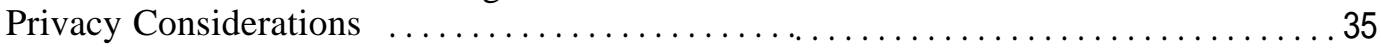

Boxes

1-A. The Leicester Case: DNA's Criminal Debut ......................... 8

I-B. Quality Assurance and Drug Testing Laboratories . . . . . . . . . . . . . . . . . . . . 12

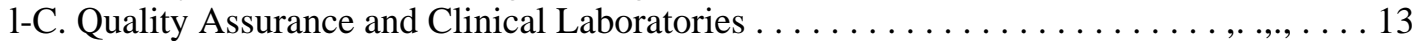

1-D. Uses of Forensic DNA Tests Internationally . . . . $\ldots \ldots \ldots \ldots \ldots \ldots \ldots \ldots \ldots \ldots \ldots$

1-E. What Does DNA Typing Cost? .................................. 25

\section{Figures}

$1-1_{4}$ The DNA Double Helix $\ldots \ldots \ldots \ldots \ldots \ldots \ldots \ldots \ldots \ldots \ldots \ldots \ldots . \ldots \ldots \ldots \ldots . . \ldots \ldots$

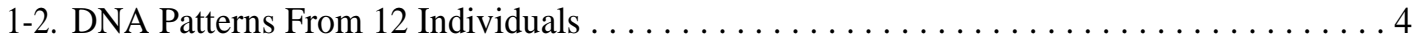

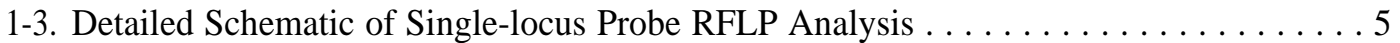

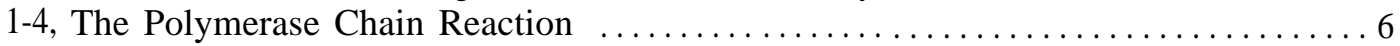

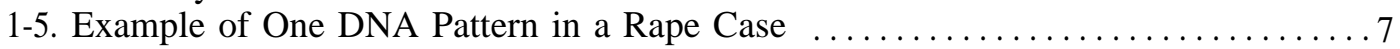

1-6. DNA Typing in Two Paternity Cases .......................... ...., 9

1-7. DNA Typing and Murder: A Less Than Ideal First Analysis and a Solution ..... 11

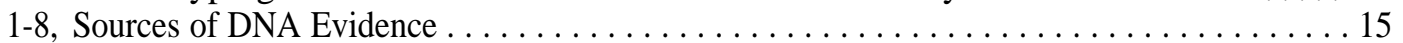

1-9. DNA Typing: Reported Uses and DNA Databank Legislation by State . . . . . . . 16

1-10. How a Database of DNA Information Could Be Created and Used . . . . . . . . . . . 19

1-11. Proposed Data Files: Who Will Maintain Them? . . . . . . . . . . . . . . . . . 20

\section{Tables}

1-1. Number of DNA Cases by State ................................ 15

1-2. State Laws To Establish Computer Files of Known Offender Genetic Patterns . . . 20

1-3. Costs for Forensic DNA Testing by Private Laboratories . . . . . . . . . . . . 25

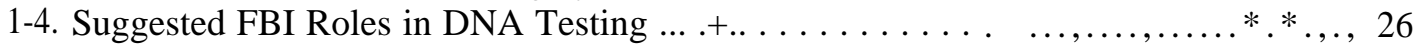




\section{Summary, Policy Issues, and Options for Congressional Action}

Genetic uniqueness is a fact of life. From generation to generation, characteristics are inherited, combined, assorted, and reasserted among individuals through a common denominator: the chemical deoxyribonucleic acid, or DNA. And, except in the case of identical twins, no two humans share the same DNA sequence.

This report is about technologies used to distinguish the DNA among individuals. It is about techniques to identify and prosecute violent criminals, as well as exonerate innocent persons who are suspects in criminal cases. To a lesser extent, it is about applications that use the same techniques to determine parentage or identify and reunite missing children with relatives. Undertaken at the request of the Senate Committee on Labor and Human Resources, this assessment evaluates the scientific, legal, and ethical issues surrounding forensic applications of DNA tests: the validity and reliability of DNA tests for forensic casework, quality assurance and standards for DNA analysis by forensic laboratories, the legal basis for the admissibility of such tests in courts of law, privacy and civil liberties concerns about collecting, using, and storing genetic information and material, and criminal justice interest in employing DNA tests at the Federal, State, and local level.

\section{TERMINOLOGY}

Forensic science involves the application of many scientific expertise (e.g., biology, chemistry, toxicology, medicine) to situations concerned with courts of justice or public debate. This report uses the term forensic applications to refer to potential uses of recombinant DNA technologies to identify individuals.

The increased acceptance and popularization of recombinant DNA techniques for forensic uses, especially criminal investigations, have led to some confusing terminology. In particular, some commentators have adopted the terms "genetic fingerprinting," "DNA fingerprint- i ng, or "DNA prints" as generic phrases to describe all techniques, while others use the terms to describe specific techniques by specific companies. This report uses the terms DNA testing, DNA identification, DNA analysis, DNA typing, and DNA profiling to describe the two current and any future technologies, the practical goal of which is unique association or exclusion determined by DNA-based tests.

\section{DNA AND HOW IT DIFFERS FROM PERSON TO PERSON}

As the chemical dispatcher of genetic information, DNA's structure resembles a twisted ladder, referred to as a double helix (figure 1-1). DNA in all organisms consists, in part, of four chemical subunits commonly called bases. These four bases-guanine $(\mathrm{G})$, adenine $(\mathrm{A})$, thymine $(\mathrm{T})$, and cytosine $(\mathrm{C})$ - are the genetic alphabet. Their unique order, or sequence, in the DNA helix serves as the blueprint for an organism. Of the 3.3 billion base pairs making up a human

\section{Figure I-I-The DNA Double Helix}

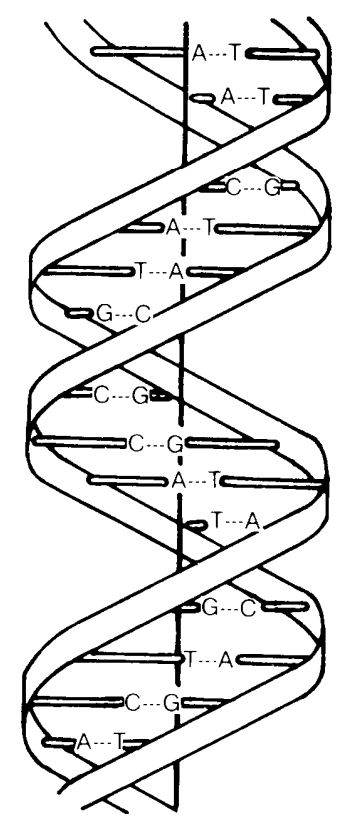

SOURCE: Office of Technology Assessment, 1990. 
Figure 1-2-DNA Patterns From 12 Individuals

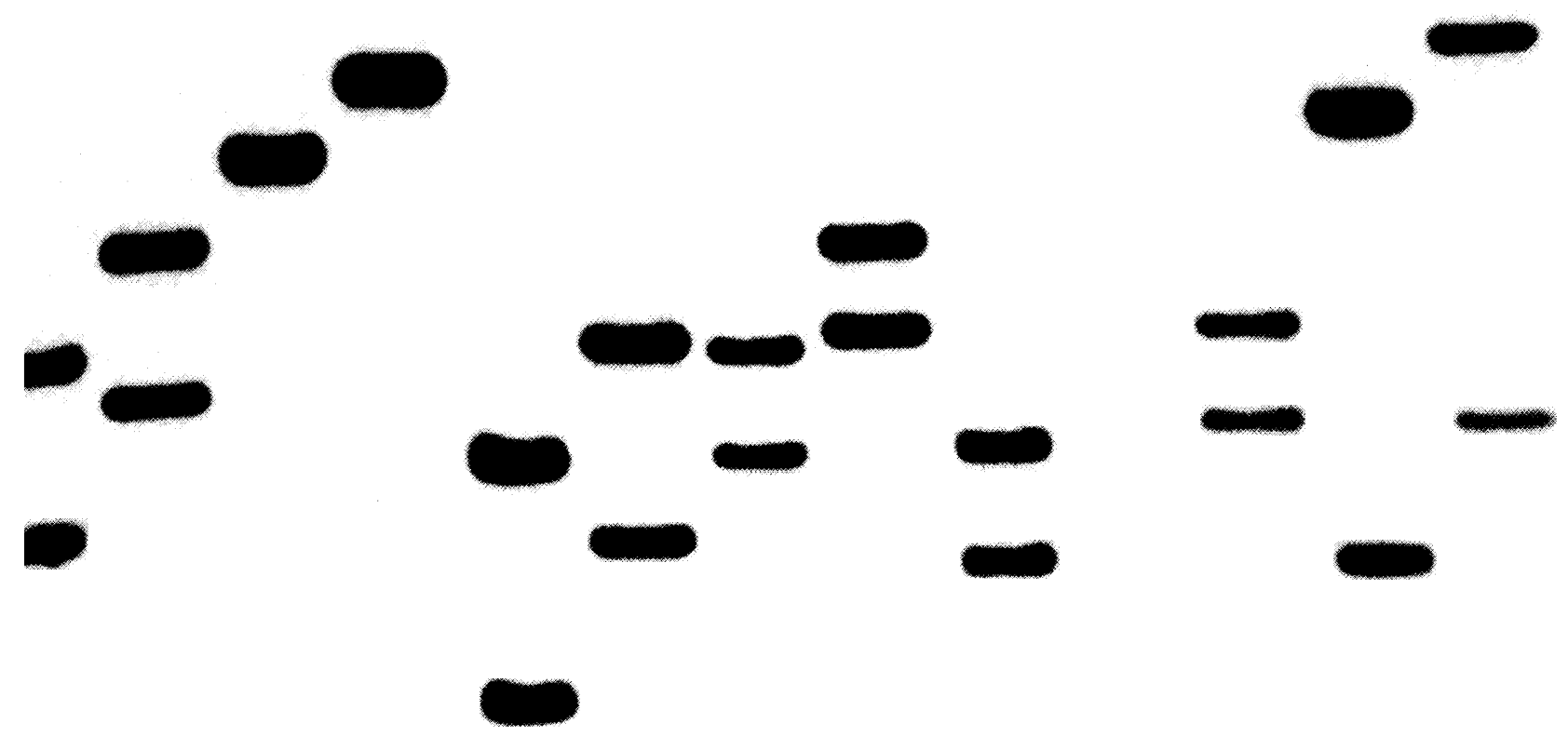

In this mock-up to demonstrate that DNA patterns differ among individuals, blood samples were obtained from 12 different people and RFLP analysis performed using 1 single-locus probe. Although some individuals do share 1 band in common, all 12 exhibit different patterns overall

SOURCE: Federal Bureau of Investigation, 1989.

blueprint, only a fraction-approximately 3 million-differ between any two individuals.

Several methods to detect DNA differences exist; the majority of DNA tests currently used in forensic applications detect some of these differences through DNA probes that reveal size variations. Scientists measure these size distinctions between people through a process called restriction fragment length polymorphism (RFLP) analysis (figures 1-2 and 1-3) ${ }^{1}$. Although the specific protocols used for RFLP analysis vary from laboratory to laboratory, the vast majority of forensic casework carried out today involves this basic approach.

Another technology, polymerase chain reaction (PCR), can be thought of in some respects as molecular photocopying (figure 1-4). PCR itself is not used to directly analyze DNA, rather it makes possible the application of other techniques when only minute biological specimens are available. PCR allows a scientist to take a sample of what ordinarily would be insufficient DNA to assess, and reproduce it until enough DNA copies are available for examination by a number of technologies, including RFLP analysis. Chapter 2 describes details of RFLP analysis and PCR.

DNA is found in all body cells except red blood cells. (Blood contains many cell types in addition to red blood cells, such as white blood cells, and it is from these cells that DNA can be obtained when forensic evidence is a bloodstain.) With few exceptions, the composition of a person's DNA does not vary from cell to cell, except in egg and sperm cells, which have half the complement of DNA present in other body cells. (Although DNA content differs from sperm to sperm, a DNA profile of semen-e. g., from evidence in a rape case-is a composite of thousands of DNA molecules from thousands of

\footnotetext{
${ }^{1}$ The illustration of RFLP analysis involves the use of a type of DNA probe called a single-locus probe. A similarly performed analysis uses a different type of DNA probe, called a multilocus probe, which is only applied in some paternity cases in this country. Chapter 2 describes the differences between the two approaches. For purposes of this report-with the exception of chapter 2-RFLP analysis refers only to the use of single-locus probes.
} 
Figure 1-3-Detailed Schematic of Single-locus Probe RFLP Analysis

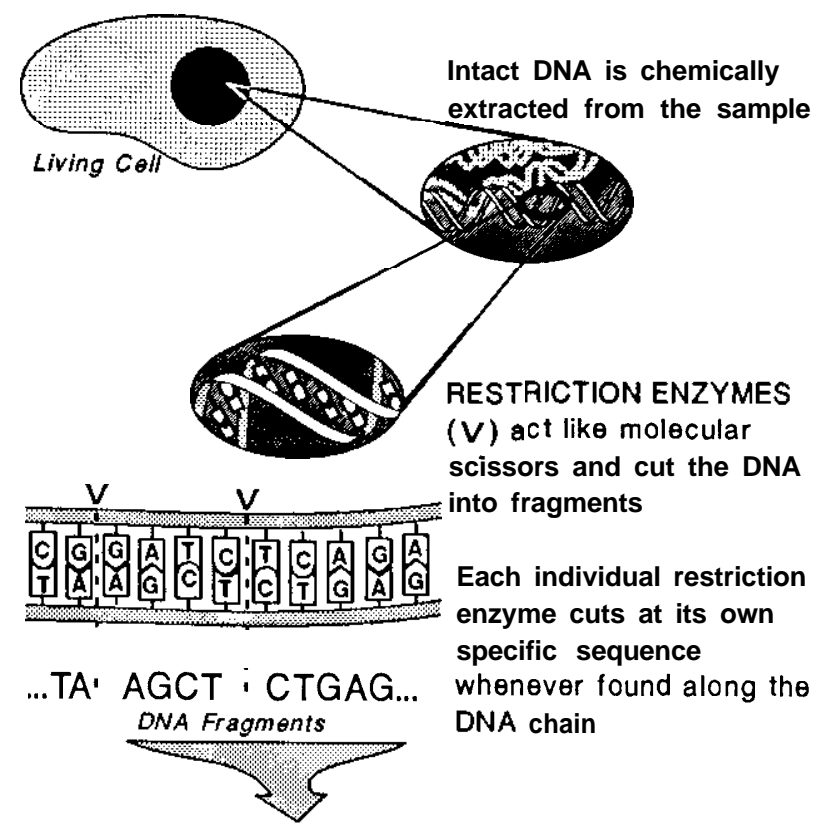

Single-locus probes with varied sequences exist and key with areas of specific DNA.

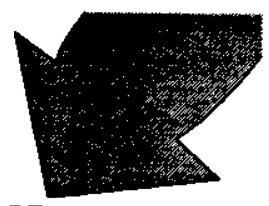

One single-locus probe is made radioactive, Many copies of the probe are used to combine with a specific DNA sequence on the nylon membrane.

\section{PROBE} 亩方南

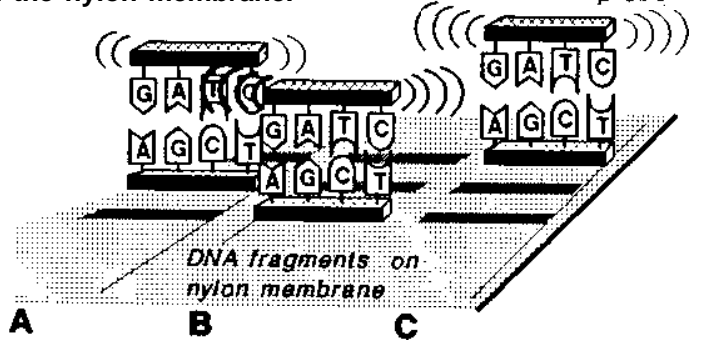

$X$-ray film is placed over the membrane to detect and image the radioactive probe pattern.
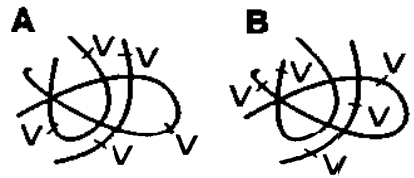

C

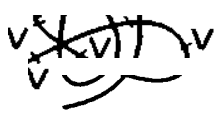

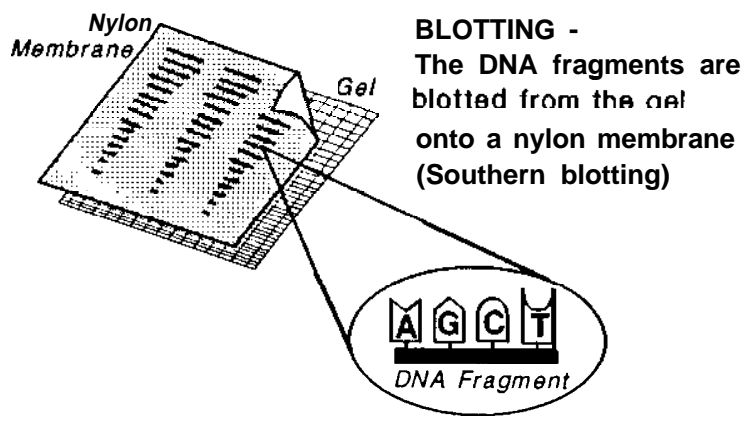

SOURCE: Office of Technology Assessment, 1990,

Using different probes in sequence demonstrates whether the specimen sample matches the suspect type.

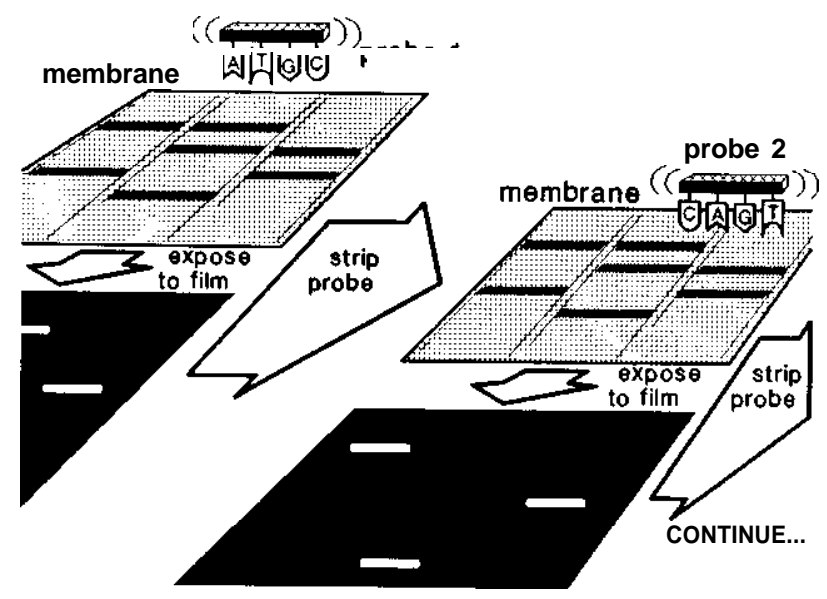

SINGLE-LOCUS PROBE PATTERN

Suspect Victim Evidence

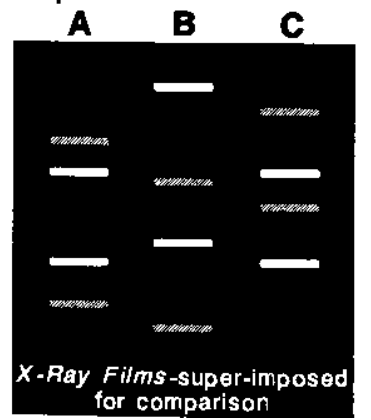

When using single-locus probe analysis one must use different probes to obtain identity. 
Figure 1-4-The Polymerase Chain Reaction
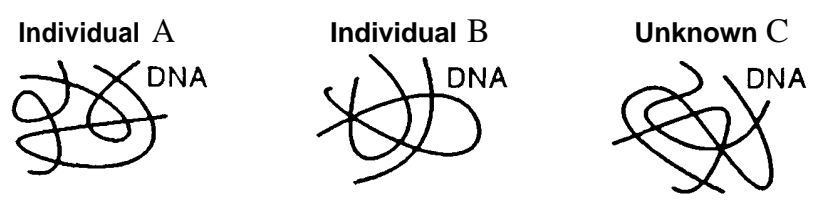

\section{AMPLIFICATION \\ (Molecular Photocopying of DNA)}

Each sample is amplified

nanually or in a machine.
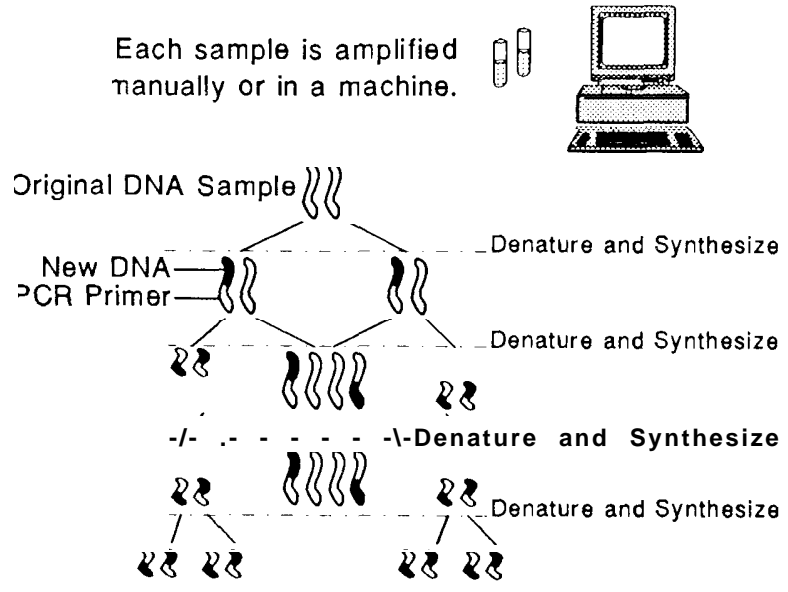

Multiple copies of DNA Sample

20-25 cycles of the PCR yields about

one million-fold reproduction).

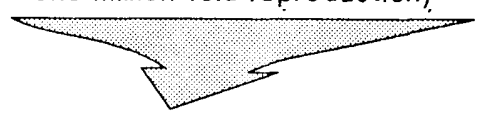

\section{DOT BLOT}

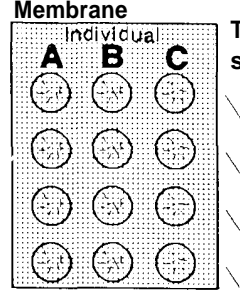

The membrane is challenged with a DNA probe that has a key iequence specific to an HLA DQ-Alpha Allele.

The amplified DNA is spotted onto a membrane
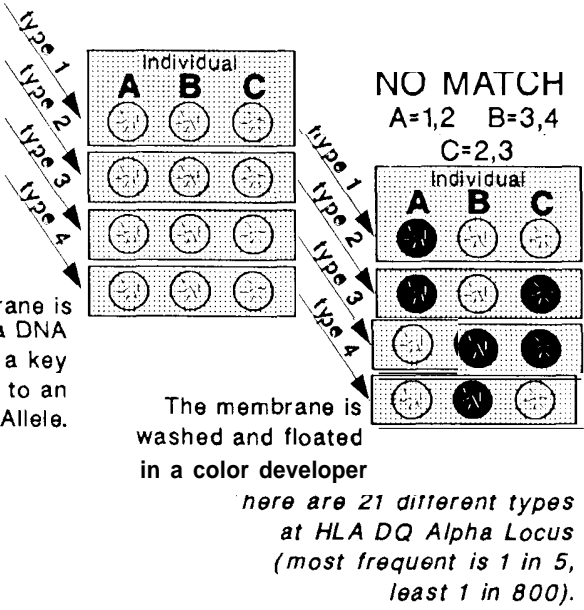

SOURCE: Office of Technology Assessment, 1990. sperm and therefore reflects a man's overall profile (figure 1-5).) Thus a scientist can examine DNA from blood or tissue from a hair root and, if the specimens are from the same person, find the same DNA banding pattern. Similarly, patterns can be matched between DNA isolated from sperm on a vaginal swab or a semen stain and a known blood sample from a suspect.

\section{THE ROLE OF DNA TYPING IN FORENSIC IDENTIFICATION}

Traditional genetic markers, such as $\mathrm{ABO}$ blood groups, have been used in forensic casework since the turn of the century. Conventional markers available to forensic analysts provide the potential for a high degree of discrimination among different individuals, but the upper limit is attained infrequently, in part because of the instability of some of these markers in dried and aged evidence stains. Thus, in practice, the individualization of many evidentiary stains cannot be carried out to any great extent given the present array of conventional serological landmarks. In general, traditional genetic tests used in forensic casework also, at best, can associate an unknown sample with a suspect specimen at a level of 90 to 95 percent inclusion.

Forensic applications of DNA tests involve two components: molecular biology and population genetics. Molecular biological techniques allow analysts to directly examine the material responsible for heritable differences among humans, i.e., DNA. Population genetics, also a part of traditional forensic genetic testing, is used to interpret DNA tests to approximate the degree to which two samples are associated by greater than random chance. Like traditional genetic tests, DNA typing is used in the forensic context to determine whether biological material from a known individual can be linked to a sample from an unidentified specimen (i.e., whether the individual can be included in or excluded from the population of humans who could have deposited the biological material). Yet unlike traditional genetic testing, DNA typing technologies - one of which was first used in a criminal case in the United Kingdom 
Figure 1-5-Example of One DNA Pattern in a Rape Case

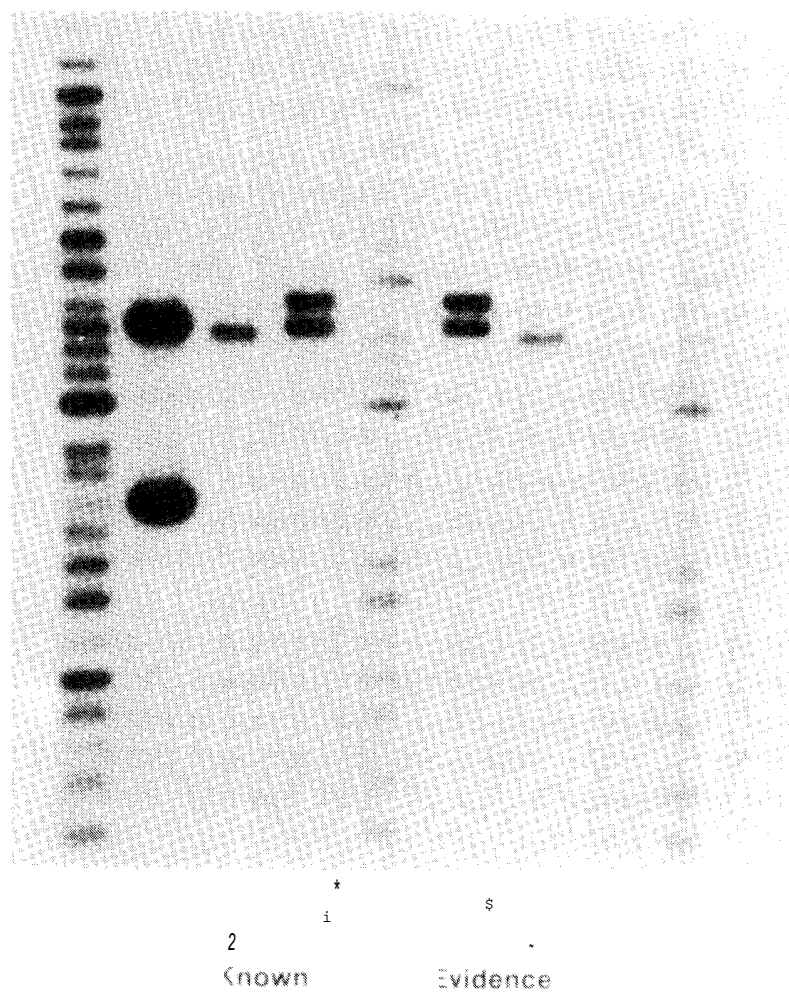

Biological evidence from this rape case was separated by laboratory techniques into separate male and female fractions. After RFLP analysis of these fractions and known samples obtained from the victim and suspect, the results reveal that-for this particular probe-the DNA pattern of the male fraction matches the pattern of the suspect.

SOURCE: Federal Bureau of Investigation, 1989.

(box 1-A)-have been heralded as forensic tools that will change the judicial landscape.

It is the population dynamics of DNA markers that separates it from the use of conventional genetic markers in forensic analysis. With DNA markers, much greater variation exists and can be detected-hence their potential for what amounts to statistical individualization when a combination of markers is examined. That is, because the assortment of genetic markers detected by DNA tests is great, a sufficiently detailed examination of DNA patterns can yield a result that effectively amounts to a positive identification between a questioned sample and a suspect sample. By the same token, because DNA markers do vary so much, exclusion of innocent suspects can be easier to achieve.
Forensic DNA analysis can provide more definitive and objective evidence to ascertain the innocence or guilt of an individualespecially compared to subjective evidence such as eyewitness testimony.

Forensic applications of DNA techniques are not limited to criminal investigations. Their use in parentage testing (figure 1-6), the identification of unknown remains, human rights abuses, and immigration has been successful. And as more information is gained through genetic research, including efforts to map and sequence the human genome, the range of applications, of information gained, and of technologies involved in forensic uses of DNA tests is likely to increase.

\section{ARE DNA TESTS VALID AND RELIABLE?}

An important matter in the use of DNA for forensic casework is whether the detection methods are scientifically valid. Validity is the probability that a test will correctly identify true matches and true nonmatches. For RFLP analysis, validity centers on whether the test yields the correct RFLP pattern. A valid test or set of tests in criminal applications, for example, would not falsely classify or exclude a subject by yielding a profile not true to type.

A second, but equally important aspect of DNA testing of forensic samples is reliability. Reliable tests measure reproducibly that which they are capable of measuring under defined conditions of use. Reliable methods must perform reproducibly within a laboratory, across multiple laboratories, and in the hands of disparate practitioners. Reliability involves several factors, including the procedures used, laboratory performance, laboratory recordkeeping, and quality control and quality assurance.

Genetic and molecular principles underlying DNA identification are solid and can be applied to DNA isolated from forensic evidence. The Office of Technology Assessment (OTA) finds that forensic uses of DNA tests are both reliable and valid when properly performed 


\section{Box I-A-The L.eicester Case: DNA's Criminal Debut}

On November 21,1983, Lynda Mann, 15 years old, was sexually assaulted and killed on an isolated footpath in the small English county of Leicestershire. Semen recovered from an internal labial swab and a deep vaginal swab was tested. The blood tests could not positively identify the killer, and the scientific label 'Group A secretor, PGM $1+$," a blood type shared by just 10 percent of the population, was the only clue police had.

The police went to every residence in three nearby villages filling out a pro forma document on male residents between the ages of 13 and 34 (an arbitrary range). Patient records from the local psychiatric hospital were also carefully examined. The local newspaper published appeals for help, leading to many tips, all of which proved useless. The investigation team started out with 150 officers, dropped to 8 by May, and was disbanded in August 1984. One-hundred-and-fifty blood tests on potential suspects were performed with no positive results.

In a neighboring village, 15-year-old Dawn Ashworth was similarly slain on July 31, 1986. Police assumed this was a serial murder, and semen was recovered from a vaginal swab and a clothing stain.

On August 8, 1986, police arrested 17-year-old Richard Buckland, a kitchen porter from the psychiatric hospital, for Ashworth's murder. Buckland had a history of sexual behavior that would fit the pattern presumed for the murderer and had kmown the victim. After prolonged questioning, he made a graphic confession to killing Ashworth.

At this point, the police officer charged with investigating Mann's murder decided to try to connect Buckland to her death. He delivered the semen samples taken from Mann and Ashworth and blood from Buckland to Dr. Alec Jeffreys at Leicester University. Jeffreys, well known because of a highly publicized immigration case in which he applied his new technique of "DNA fingerprinting, " accepted the request for assistance. He concluded that both girls were raped by the same man, and that Buckland was not the perpetrator. On Nov. 21,1986, Buckland became the first accused murderer in the world to be set free as a result of a DNA test.

A new inquiry to investigate both murders began immediately, and on January 2, 1987, police announced a "revolutionary step" - a campaign of voluntary blood testing for every mate resident in the three villages. Men were requested by form letter to appear at a certain time for sampling. Collected blood and saliva was first tested for PGM 1+, A secretor characteristics; any blood meeting these criteria was forwarded to Jeffreys for the DNA test. The police made "house calls" on those men who failed to appear. English civil liberties experts expressed concerns about coercion and the ultimate disposition of test results.

Colin Pitchfork received his notice to appear that January and told his wife he was afraid to give blood because of his criminal record for flashing. Pitchfork eventually convinced a coworker, Ian Kelly, to give under Pitchfork's name using a falsified identity card, and Pitchfork received notification of a negative test.

By May 1987, the police had taken samples from 3,653 men and boys, a 98 percent response rate, but had not found the killer. In August, Kelly admitted his act of deception to other coworkers, one of whom had also been approached by Pitchfork. Six weeks later the police were informed and Kelly was arrested. Pitchfork confessed to both murders on his subsequent arrest in September 1987.

Pitchfork received a double life sentence for the murders, a 10-year sentence for each of the rapes, 3 years each for two earlier sexual assaults, and 3 years for conspiracy, all to be served concurrently. The concurrent sentences mean he could be released within 10-12 years. At sentencing, the judge noted that without DNA testing, Pitchfork might still beat large.

SOURCE: J. Wambaugh, The Blooding (New York, NY: William Morrow \& Co., Inc., 1989).

and analyzed by skilled personnel. Molecular genetics techniques can accurately disclose DNA patterns that reflect DNA differences among humans. Questions about the validity of DNA typing-either the knowledge base supporting technologies that detect genetic differences or the underlying principles of applying the techniques per se-are red herrings that do the courts and the public a disservice. Critical questions about the reliability of DNA testing, however, have been raised in a few cases. Challenges to the reliability of DNA tests will mount unless the issue of standards is addressed.

The validity of forensic DNA tests does not hinge on population genetics. Interpretation of test results, however, depends on population frequencies of the various DNA markers (for 
Figure 1-6-DNA Typing in Two Paternity Cases

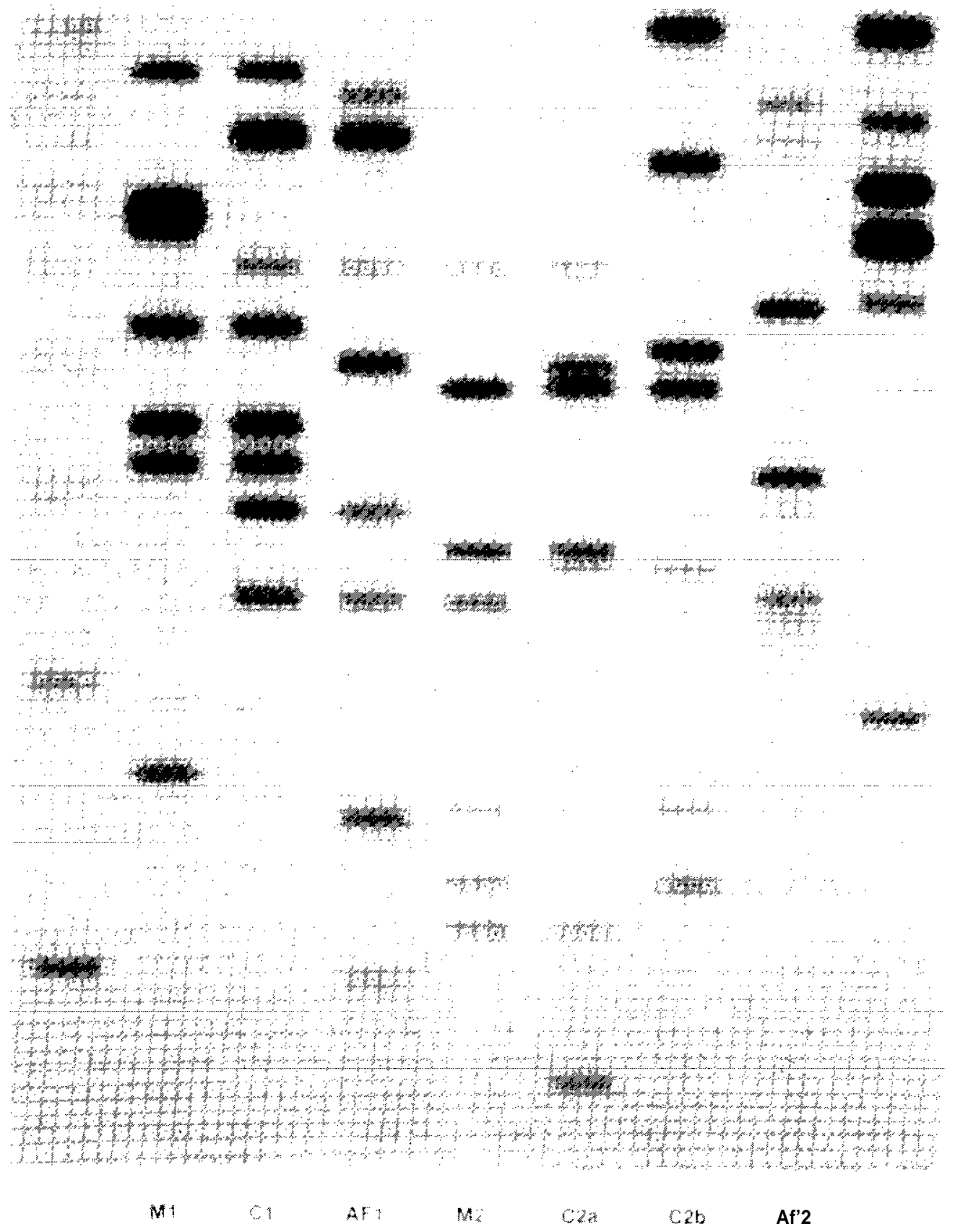

DNA typing in two different paternity disputes revealed that the alleged father (AF) is the biological father in case 1 , but not in case 2 . Note that all bands present in the child in case 1 (C1) can be accounted for in either the mother (M1) or alleged father (AF1). In case 2, however, no bands from the alleged father (AF2) appear in either child (C2a and C2b), nor do bands that the children do not share with their mother (M2) match any present in the alleged father (A2).

SOURCE: Cellmark Diagnostics, 1989. 
RFLP analysis, the size of the band in a particular test). In other words, population genetics provides meaning - numerical weight - to DNA patterns obtained by molecular genetics techniques. Given any set of patterns, or just two patterns, that match, population frequencies are used to report the frequency of such an event arising; they are key to establishing confidence in associating an unknown evidence pattern with that of a suspect - for example, whether 1 in 30 billion, 1 in 2 million, 1 in 50, or 1 in 10 random individuals could be expected to share that test result. That scientific principles of population genetics can be applied to forensic DNA analysis is not in question, but how best to apply which principles to RFLP analysis is under debate. Disagreement exists as to the extent such debate can or should be resolved. General agreement does exist that any potential bias that could result from calculating population frequencies favor a defendant. Some argue, however, that the magnitude of the number is not the issue, just that the analyst assigns it with scientifically valid confidence. Others argue that because of the pivotal role population frequencies can play in reporting results of forensic DNA tests, agreement is necessary.

\section{STANDARDS}

Although consensus exists that the power of DNA typing technologies to theoretically individualize is valid and reliable, a constellation of recommendations are offered on how best to implement forensic uses of DNA tests. These opinions focus on the most effective way of minimizing realistic technical variability, human error, and the vagaries of working with specimens obtained under less than ideal conditions (figure 1-7). Such differences underscore the urgent need to develop both technical and operational standards. Setting standards for forensic applications of DNA testing is the most controversial and unsettled issue. Standards are necessary if high-quality DNA forensic analysis is to be ensured, and the situation demands immediate attention. Leaving the issue of standards unresolved places a burden on all parties involved in forensic DNA analysis. Undoubtedly some queries will still arise on a case-by-case basis, and at such times specific details can and should be evaluated in court. Given time and the implementation of standards, such questions are likely to decrease.

The Federal Bureau of Investigation (FBI), industry, research molecular biologists, population geneticists, and forensic scientists agree that standards are desirable. For many matters, however, little agreement exists on who should decide, what standards are best, and how to achieve and implement them. OTA identified two types of standards: technical and operational. The former include such issues as proper reagents and gel controls; electrophoresis conditions; rules to match DNA banding patterns; the extent that computer-assisted matching should be permitted; and population data to compute the likelihood of matches. Operational standards include elements such as recordkeeping and proficiency testing; they are likely to be more controversial than technical standards, for historically, attempts to regulate laboratory practices in any sector have met with resistance. (Quality assurance most directly addresses many issues in operational standards and is discussed in the following section.)

Technical standards that allow flexibility for laboratory-to-laboratory variations need to be evaluated. Clearly defined rules and proceduresobjective and scientifically based-should be established, set, and, most importantly, followed. One critical area lacking full agreement is that of declaring matching patterns in RFLP analysis. For example, calling a match or nonmatch can be difficult if a pattern in the evidence is similar, but off-set, or shifted, compared to a suspect sample. Agreement is desirable on what the best, and the minimal, mechanisms are to control for potential anomalies so that data interpretation is still possible if situations such as band-shift arise in a particular case. With PCR, minimum standards and controls to avoid contamination that could lead to erroneous interpretation should be determined. 
Figure 1-7-DNA Typing and Murder: A Less Than Ideal First Analysis and a Solution

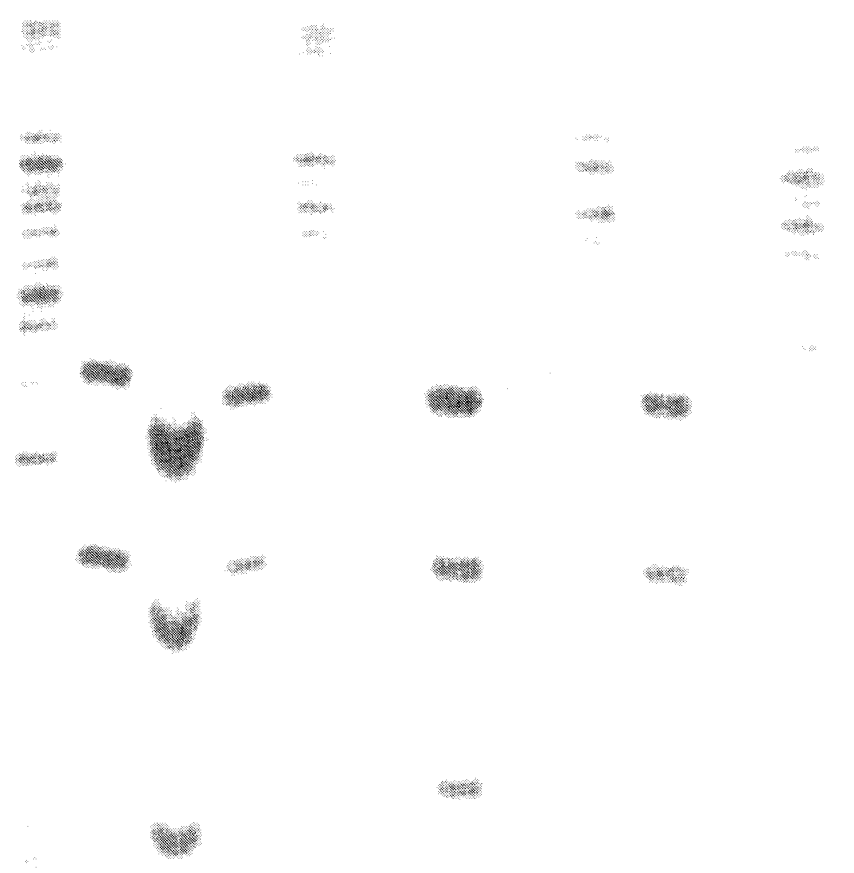

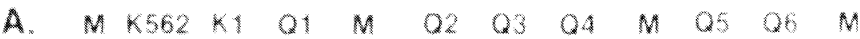

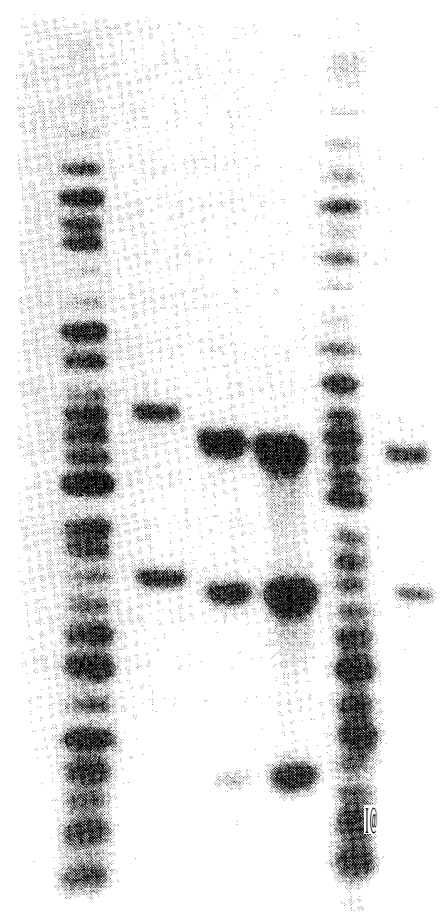

B. $M \quad K 562 \quad K 1 \quad K 1 M$ Q3

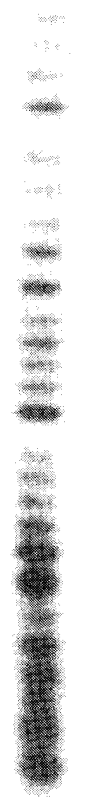

M

$\mathrm{n}$ this murder case, six separate pieces of evidence were obtained from the crime scene and a suspect identified. RFLP analysis was Jerformed (M=markers; $K 1=$ suspect; $Q 1-6=$ evidence; $K 562=$ standard), but the results revealed that too much of the suspect sample (K1) lad been placed on the gel, which led to distortion in the K1 lane, as well as the lanes next to it (K562 and Q1) (panel A).

Even though the suspect's pattern for this probe is an extremely rare and unusual three-band pattern that is similar to the six questioned samples, the forensic analyst cannot call a "match," but must report the test "inconclusive" because the alignment is unacceptable. This, Jespite knowing from experience that if less suspect sample had been used, the patterns likely would have aligned and been called a match.

Fortunately, not all of evidence sample Q3 had been used in the test in panel A (although Q1,2,4-6 had been exhausted). The case was epeated (panel B) with diluted amounts of the suspect sample (K1), which now clearly align with the evidence pattern (Q3). Had no эvidence sample been available for an additional try, however, DNA analysis would have reported "inconclusive," and could not have been used as evidence to prove guilt or innocence.

SOURCE: Federal Bureau of Investigation, 1989.

Decisions about standards in forensic applications of DNA tests need to be made within the constraints of performing DNA analysis on case samples, but achieved without compromising scientific and technical integrity. For example, some feel that mixing tests (used to determine if two apparently identical RFLP samples that are run side-by-side actually run as one when mixed) are critical. Others strongly feel alternative controls provide enough safeguards and that mixing tests are impractical for most forensic casework-particularly when material may be limited.

\section{QUALITY ASSURANCE}

Quality assurance mechanisms in forensic uses of DNA profiling encompass a range of options, including certification, licensing of facilities and personnel, accreditation, recordkeeping, and proficiency testing. Professional societies, State and local Governments, and the Federal Government all have or could have roles in ensuring high-quality forensic DNA typing services. Similarly, numerous methods are available to these entities to implement an assortment of options. 
Professional societies can set informal standards and encourage voluntary compliance, and several organizations have developed or are developing guidelines for quality assurance for forensic applications of DNA tests. Many professional societies have a stake in quality assurance of DNA typing for forensic applications, and cooperation between them could be a powerful mechanism to ensure high-quality analysis. On the other hand, because such efforts are voluntary, some criticize current optional programs as insufficient, and note that professional society membership or claims of adherence to different professional guidelines can sometimes confuse lay observers and should not be viewed as the ultimate imprimatur of quality assurance. For forensic science, only one voluntary accreditation program is offered-by the American Society of Crime Laboratory Directors.

In addition to the role professional societies can play, States have the authority to regulate DNA typing by both public and private laboratories. Presently, no State has enacted general licensing requirements for private laboratories, crime laboratories, or personnel performing DNA analysis on forensic specimens, although a September 1989 report by a special commission appointed in New York made recommendations in each of these areas. (In contrast, all 50 States and the District of Columbia require that public and private hospitals be licensed, although the scope of the laws varies considerably.)

The Federal Government has broad authority to direct that solutions be found for quality assurance issues surrounding forensic uses of DNA tests. Federal leadership can focus on nonregulatory mechanisms, or Congress and the executive branch could move to directly regulate crime laboratories, as it has for drug testing facilities (box 1-B) and clinical laboratories (box 1-C). Some feel, however, that legislation like the Clinical Laboratory Improvement Amendments of 1988 (CLIA) (Public Law 100-578) is more a short-term solution-that, in fact, court conflict, as is presently occurring, sharpens the

\section{Box l-B-Quality Assurance and Drug Testing Laboratories}

Drug testing of employees and job applicants has become increasingly commonplace. The dramatic increase in testing facilities to handle samples has spawned concern about ensuring that sufficient care is taken so that those tested are not harmed by poor-quality tests or inadequate quality assurance policies or quality control procedures. In 1988, the General Accounting Office surveyed all 50 States on the nature of laws, regulations, and other legally enforceable provisions in effect that would govern quality assurance of drug testing laboratories. The survey revealed that no uniform system exists to regulate laboratories doing employee drug testing. Some States do have formal mechanisms specific for quality assurance oversight of drug testing facilities. Others regulate laboratories that perform employee drug analysis through general medical or clinical laboratory statutes. Still others voluntarily adhere to standards prescribed by various professional associations. Some do not control such services at all.

The executive branch has moved to improve results from laboratories providing employee drug testing services (53 FR 11970, Public Law 100-71). Congress also is interested in ensuring quality in laboratories that do employee drug testing, Legislation considered during the 100th Congress would have required proficiency testing and certification by the U.S. Department of Health and Human Services for all facilities engaged in urinalysis and blood analysis for employee drug testing. Similar legislation is pending in the 101st Congress.

SOURCE: OffIce of Technology Assessment 1990.

examination and evaluation of forensic DNA typing and will ultimately ensure quality by defining its boundaries. Moreover, questions are raised whether high-quality necessarily follows from mandatory regulation.

Nonregulatory Federal efforts could focus on authorizing additional efforts for research in forensic sciences, particularly cross-disciplinary projects that apply newly emerging basic research tools to real-world casework. Other nonregulatory Federal initiatives can encourage the use of consensus conferences to develop and recommend protocols for quality assurance. This role in particular, perhaps modeled after the existing National Institutes of Health (NIH) 


\section{Box l-C-Quality Assurance and Clinical Laboratories}

In October 1988, Congress passed sweeping legislation that subjects clinical laboratories to a number of requirements, including qualifications for the laboratory director, standards for the supervision of lab testing, qualifications for technical personnel, management requirements, and an acceptable quality control program. Prior to enacting the Clinical Laboratory Improvement Amendments of 1988 (CLIA) (Public Law 100-578), Federal regulations covered the approximately 13,000 labs that either transported samples between States or performed tests billed to Medicaid and Medicare. Beginning in 1990, however, the Health Care Financing Administration (HCFA) of the U.S. Department of Health and Human Services (DHHS) wilt exercise sweeping regulatory authority over clinical laboratories. HCFA will set standards for staffing and maintaining all medical laboratories, including physician office testing. HCFA will also manage a comprehensive program to police the facilities and can impose sanctions.

CLIA is at once broad, encompassing the estimated 98,000 physician labs, and specific. For example, the Secretary of DHHS is to establish national standards for quality assurance in cytology services, including the maximum number of cytology slides that any individual may screen in a 24-hour period. The Secretary is also required to determine and implement recordkeeping, inspection, and proficiency testing programs, and to study and report to Congress on a range of issues gauging the impact of various quality assurance mechanisms.

CLIA expands DHHS's regulatory authority over clinical laboratories, and grants HCFA the power to suspend or revoke a lab's certificate for violation of the rules. Further, fines up to $\$ 10,000$ for each violation or each day of noncompliance can be levied, and jail sentences of 3 years can be imposed. The law continues to permit, subject to approval by the Secretary, the involvement of State or private nonprofit associations (which at present include the College of American Pathologists, the American Association of Bioanalysts, agencies in 3 States, the Joint Committee on Accreditation of Healthcare Organizations, and the American Osteopathic Association) to substitute for the Federal regulatory process.

Prior to CLIA's enactment, one issue of critical concern to Congress was proficiency testing programs. Until CLIA, such programs varied broadly in testing criteria and in grading of test results. Moreover, uniform or minimally acceptable Federal standards did not exist. Now, except under certain circumstances, proficiency testing shall be conducted on a quarterly basis, with uniform criteria for all examinations and procedures. The Secretary shall also establish a system for grading proficiency testing performance.

SOURCE: Office of Technology Assessment 1990.

consensus conference process, could be effective in addressing outstanding controversies surrounding forensic applications of DNA testing. Another structure, the NIH Recombinant DNA Advisory Committee, could be used as a model structure for Federal oversight or regulation of forensic DNA analysis.

One specific nonregulatory effort in place involves the National Institute of Standards and Technology (NIST) of the U.S. Department of Commerce, a neutral Federal agency and the only Federal laboratory with the explicit goal of performing research in and providing reference standards. As a significant part of quality assurance involves confidence in measurement standards, proposals put forth by NIST to examine state-of-the-art gel electrophoresis, reagent quality, electrophoresis conditions, and evaluation of size markers could be important.
Another nonregulatory Federal initiative presently under way is the FBI's Technical Working Group on DNA Analysis Methods (TWGDAM), which among other issues is examining quality assurance, population statistics, and databanking. Consisting of representatives of crime laboratories at or near implementation of DNA profiling techniques, as well as of commercial laboratories, TWGDAM has been praised by some as the nucleus around which national expertise will develop. Other have criticized it for being generally closed-by invitation only - in its early stages of decisionmaking. Some, both within and outside the forensic science community, are bothered that any largely investigative and enforcement body serve as the lead player in developing standards in which it has a vested interest. For many, TWGDAM represents the first step in a probable 
multistage process that will unfold as efforts to ensure quality of forensic applications of DNA typing develop.

Instituting quality assurance mechanisms should proceed without delay. Accreditation, licensing, and certification are among the mechanisms of quality assurance that could be applied to facilities performing forensic DNA analysis. Such initiatives individually, or as a package, do not guarantee high-quality DNA typing, but some effort appears necessary to assist private laboratories, the Federal Government, courts, and crime laboratories. Further, any program must be flexible for two reasons: to address the inherent variability of forensic casework and to account for the evolution of existing technologies and emergence of new ones. These endeavors also must acknowledge that introducing and maintaining formal quality assurance mechanisms can be costly and timeconsuming, and will place additional staffing and financial burdens on public facilities already overwhelmed with casework and historically underfunded. And, while some argue that standardizing DNA typing is an additional layer of quality assurance, standardization clearly is most important to computer databanking issues (discussed in a following section).

Finally, nothing is routine during the course of a forensic investigation. Thus, no amount of standardization, standard setting, or quality assurance can be substituted for appropriate interpretation and analysis by a forensic scientist during the course of an individual case. Federal leadership in providing adequate and proper education and training, perhaps confirmed through certification or licensing, would enhance forensic DNA analysis across the country, although improved training and education should not be viewed as substitutes for the implementation of standards.

\section{DNA IN COURT}

In courtrooms, DNA testing is a recent and highly touted evidentiary tool (figure 1-8). First introduced into U.S. criminal proceedings in
1986, forensic DNA analysis has since been admitted into evidence in at least 185 cases by 38 States and the U.S. military as of January 1, 1990 (table 1-1; figure 1-9). This number does not reflect its even wider use in investigations that did not go to trial; although impossible to precisely determine, OTA estimates that, to date, DNA tests have been used by law enforcement in over 2,000 investigations. OTA found DNA tests were used for criminal investigations and proceedings in at least 45 States and the District of Columbia as of January 1, 1990. Nor do the numbers reflect the use of DNA tests in thousands of paternity disputes annually. Three private laboratories and the FBI provided expert testimony in 216 criminal cases as of January 1990. Court-appointed and privately retained experts, and State law enforcement personnel also have testified.

Although the admission of DNA testing in courts is a new phenomenon, scientific evidence is not. Both, however, present a special dilemma because they usually involve technical information "beyond the ken" of the average citizen. To address this situation, Congress, States, and many courts have created standards governing the admission of such information into evidence in courts. Generally involving expert scientific testimony, two rules address the admissibility of scientific evidence, including DNA typing, into U.S. courtrooms: The Frye test and the relevancy test. Both are designed to deduce, through analysis and the testimony of expert witnesses, whether the scientific test in question is reliable. In addition, some States have passed specific laws addressing the admissibility of certain scientific techniques, for example, radar or intoxication tests. As of January 1990, four States, Maryland, Minnesota, Louisiana, and Nevada, have passed laws addressing the admissibility of DNA typing.

Under the Frye standard, which is the oldest and most often used test in determining the admissibility of scientific evidence, courts admit evidence based on a scientific technique only when the technique has gained general acceptance in the relevant scientific community. 
Figure 1-8-Sources of DNA Evidence

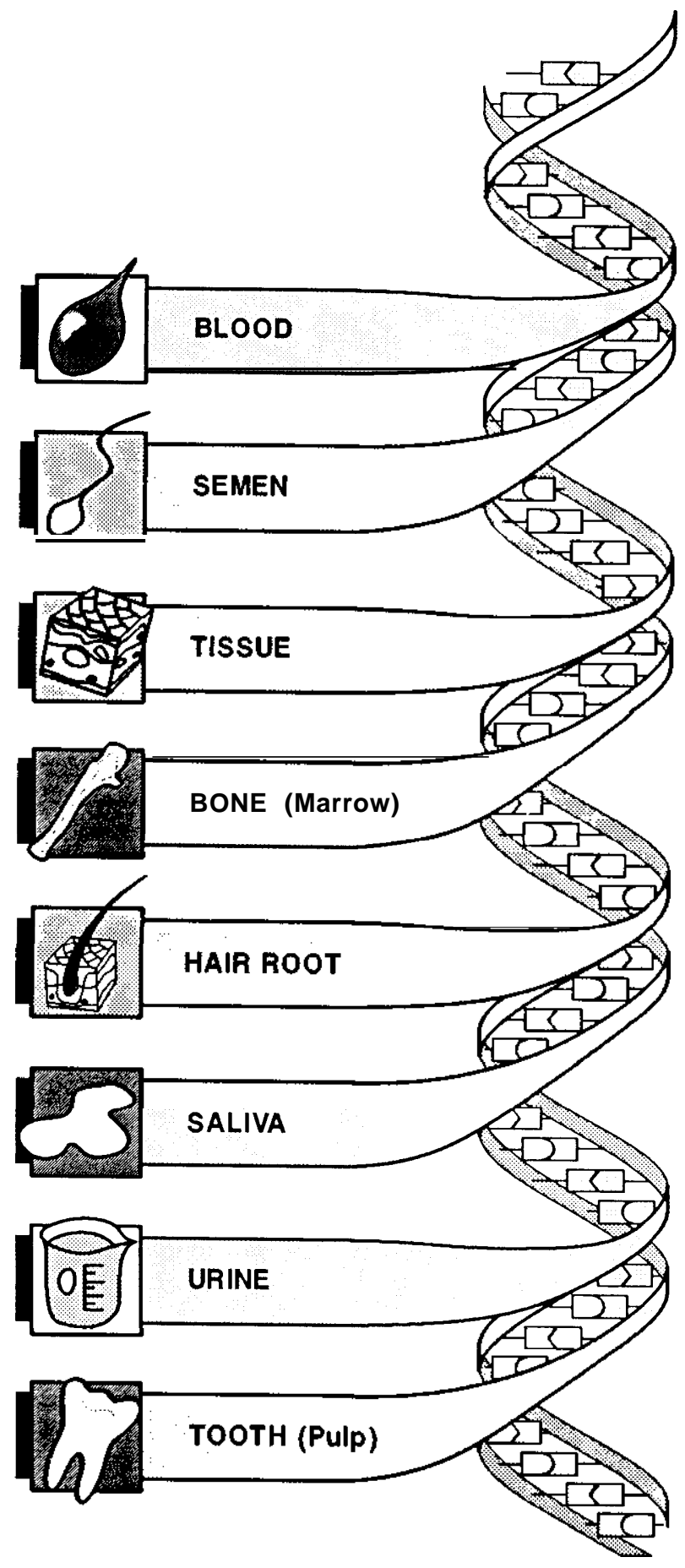

SOURCE: Office of Technology Assessment, 1990
Table I-I-Number of DNA Cases by State

\begin{tabular}{|c|c|}
\hline State & er of cases \\
\hline Alabama & 6 \\
\hline Alaska $\ldots \ldots \ldots \ldots \ldots \ldots \ldots \ldots \ldots \ldots \ldots \ldots \ldots \ldots$ & - \\
\hline Arizona $\ldots \ldots \ldots \ldots \ldots \ldots \ldots \ldots \ldots \ldots \ldots$ & 3 \\
\hline Arkansas $\ldots \ldots \ldots \ldots \ldots \ldots \ldots \ldots \ldots \ldots \ldots$ & 1 \\
\hline California $\ldots \ldots \ldots \ldots \ldots \ldots \ldots \ldots \ldots$ & 8 \\
\hline Colorado $\ldots \ldots \ldots \ldots \ldots \ldots \ldots \ldots \ldots \ldots \ldots \ldots$ & 7 \\
\hline Connecticut $\ldots \ldots \ldots \ldots \ldots \ldots \ldots \ldots \ldots \ldots$ & 1 \\
\hline Delaware $\ldots \ldots \ldots \ldots \ldots \ldots \ldots \ldots \ldots \ldots \ldots \ldots$ & 1 \\
\hline District of Columbia ................. & $\longrightarrow$ \\
\hline Florida $\ldots \ldots \ldots \ldots \ldots \ldots \ldots \ldots \ldots \ldots \ldots \ldots \ldots$ & 25 \\
\hline$\underset{\text { Gawaii }}{\text { Georgia }} \ldots \ldots \ldots \ldots \ldots \ldots \ldots \ldots \ldots \ldots \ldots \ldots \ldots$ & 4 \\
\hline Hawaii $\ldots \ldots \ldots \ldots \ldots \ldots \ldots \ldots \ldots \ldots \ldots \ldots \ldots \ldots$ & 1 \\
\hline Idaho $\ldots \ldots \ldots \ldots \ldots \ldots \ldots \ldots \ldots \ldots \ldots \ldots \ldots \ldots \ldots \ldots$ & 1 \\
\hline 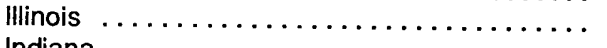 & 1 \\
\hline Indiana $\ldots \ldots \ldots \ldots \ldots \ldots \ldots \ldots \ldots \ldots \ldots \ldots \ldots$ & 3 \\
\hline lowa $\ldots \ldots \ldots \ldots \ldots \ldots \ldots \ldots \ldots \ldots \ldots \ldots \ldots \ldots \ldots \ldots$ & 2 \\
\hline 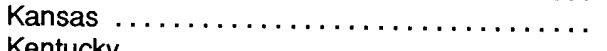 & 5 \\
\hline Kentucky $\ldots \ldots \ldots \ldots \ldots \ldots \ldots \ldots \ldots \ldots \ldots \ldots \ldots \ldots \ldots$ & $\longrightarrow^{c}$ \\
\hline Louisiana $\ldots \ldots \ldots \ldots \ldots \ldots \ldots \ldots \ldots \ldots \ldots \ldots \ldots$ & 1 \\
\hline Maine $\ldots \ldots \ldots \ldots \ldots \ldots \ldots \ldots \ldots \ldots \ldots \ldots \ldots \ldots$ & $\rightarrow$ \\
\hline Maryland $\ldots \ldots \ldots \ldots \ldots \ldots \ldots \ldots \ldots \ldots \ldots \ldots \ldots \ldots \ldots \ldots$ & 11 \\
\hline Massachusetts $\ldots \ldots \ldots \ldots \ldots \ldots \ldots \ldots \ldots$ & 1 \\
\hline Michigan $\ldots \ldots \ldots \ldots \ldots \ldots \ldots \ldots \ldots \ldots \ldots \ldots \ldots \ldots$ & 5 \\
\hline Minnesota $\ldots \ldots \ldots \ldots \ldots \ldots \ldots \ldots \ldots \ldots$ & 2 \\
\hline Mississippi $\ldots \ldots \ldots \ldots \ldots \ldots \ldots \ldots \ldots \ldots$ & 4 \\
\hline Missouri $\ldots \ldots \ldots \ldots \ldots \ldots \ldots \ldots \ldots \ldots \ldots \ldots \ldots \ldots$ & 2 \\
\hline Montana $\ldots \ldots \ldots \ldots \ldots \ldots \ldots \ldots \ldots \ldots \ldots \ldots \ldots$ & 1 \\
\hline 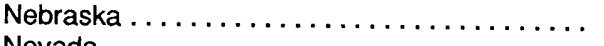 & $一^{\circ}$ \\
\hline Nevada $\ldots \ldots \ldots \ldots \ldots \ldots \ldots \ldots \ldots \ldots \ldots \ldots \ldots \ldots \ldots$ & $\underset{0}{c}$ \\
\hline $\begin{array}{l}\text { New Hampshire } \ldots \ldots \ldots \ldots \ldots \ldots \ldots \ldots \ldots \ldots \\
\text { New Jersev }\end{array}$ & 2 \\
\hline $\begin{array}{l}\text { New Jersey } \ldots \ldots \ldots \ldots \ldots \ldots \ldots \ldots \ldots \ldots \ldots \ldots \ldots \ldots \ldots \\
\text { New Mexico }\end{array}$ & $-b$ \\
\hline New Mexico $\ldots \ldots \ldots \ldots \ldots \ldots \ldots \ldots \ldots \ldots \ldots$ & -6 \\
\hline New York $\ldots \ldots \ldots \ldots \ldots \ldots \ldots \ldots \ldots \ldots \ldots \ldots \ldots$ & 17 \\
\hline North Carolina $\ldots \ldots \ldots \ldots \ldots \ldots \ldots \ldots$ & 4 \\
\hline North Dakota . . . . . . . . . . . . . . . . . & $\square^{c}$ \\
\hline Ohio $\ldots \ldots \ldots \ldots \ldots \ldots \ldots \ldots \ldots \ldots \ldots \ldots \ldots \ldots \ldots \ldots \ldots$ & 10 \\
\hline Oklahoma $\ldots \ldots \ldots \ldots \ldots \ldots \ldots \ldots \ldots \ldots$ & 3 \\
\hline Oregon $\ldots \ldots \ldots \ldots \ldots \ldots \ldots \ldots \ldots \ldots \ldots \ldots \ldots$ & 1 \\
\hline Pennsylvania $\ldots \ldots \ldots \ldots \ldots \ldots \ldots \ldots \ldots$ & 9 \\
\hline Rhode Island $\ldots \ldots \ldots \ldots \ldots \ldots \ldots \ldots \ldots \ldots$ & $\longrightarrow$ \\
\hline South Carolina $\ldots \ldots \ldots \ldots \ldots \ldots \ldots \ldots \ldots$ & 4 \\
\hline South Dakota . . . . . . . . . . . . . . . . & 1 \\
\hline Tennessee $\ldots \ldots \ldots \ldots \ldots \ldots \ldots \ldots \ldots$ & 1 \\
\hline Texas $\ldots \ldots \ldots \ldots \ldots \ldots \ldots \ldots \ldots \ldots \ldots \ldots \ldots$ & 18 \\
\hline Utah $\ldots \ldots \ldots \ldots \ldots \ldots \ldots \ldots \ldots \ldots \ldots \ldots \ldots \ldots \ldots \ldots$ & 1 \\
\hline Vermont $\ldots \ldots \ldots \ldots \ldots \ldots \ldots \ldots \ldots \ldots \ldots$ & $\longrightarrow$ \\
\hline Virginia $\ldots \ldots \ldots \ldots \ldots \ldots \ldots \ldots \ldots \ldots \ldots \ldots \ldots \ldots \ldots$ & 10 \\
\hline Washington $\ldots \ldots \ldots \ldots \ldots \ldots \ldots \ldots \ldots \ldots \ldots$ & 4 \\
\hline West Virginia $\ldots \ldots \ldots \ldots \ldots \ldots \ldots \ldots \ldots \ldots$ & 1 \\
\hline $\begin{array}{l}\text { Wisconsin } \ldots \ldots \ldots \ldots \ldots \ldots \ldots \ldots \ldots \ldots \ldots \\
\text { Wyoming } \ldots \ldots \ldots \ldots \ldots \ldots \\
\end{array}$ & $1_{c}$ \\
\hline Wyoming $\ldots \ldots \ldots \ldots \ldots \ldots \ldots \ldots \ldots$ & $-c$ \\
\hline
\end{tabular}

aWhere such evidence was admitted by a court or used to obtaln a plea prior to an admissibility hearing. Total of 185 cases includes two military cases not reported in this table (see app. A).

Case pending, DNA used for exculpation only, DNA evidence withdrawn, or DNA used in investigation, but no prosecution. None identified.

SOURCE: Office of Technology Assessment, 1990. 
Figure 1-9-DNA Typing: Reported Uses and DNA Databank Legislation by State

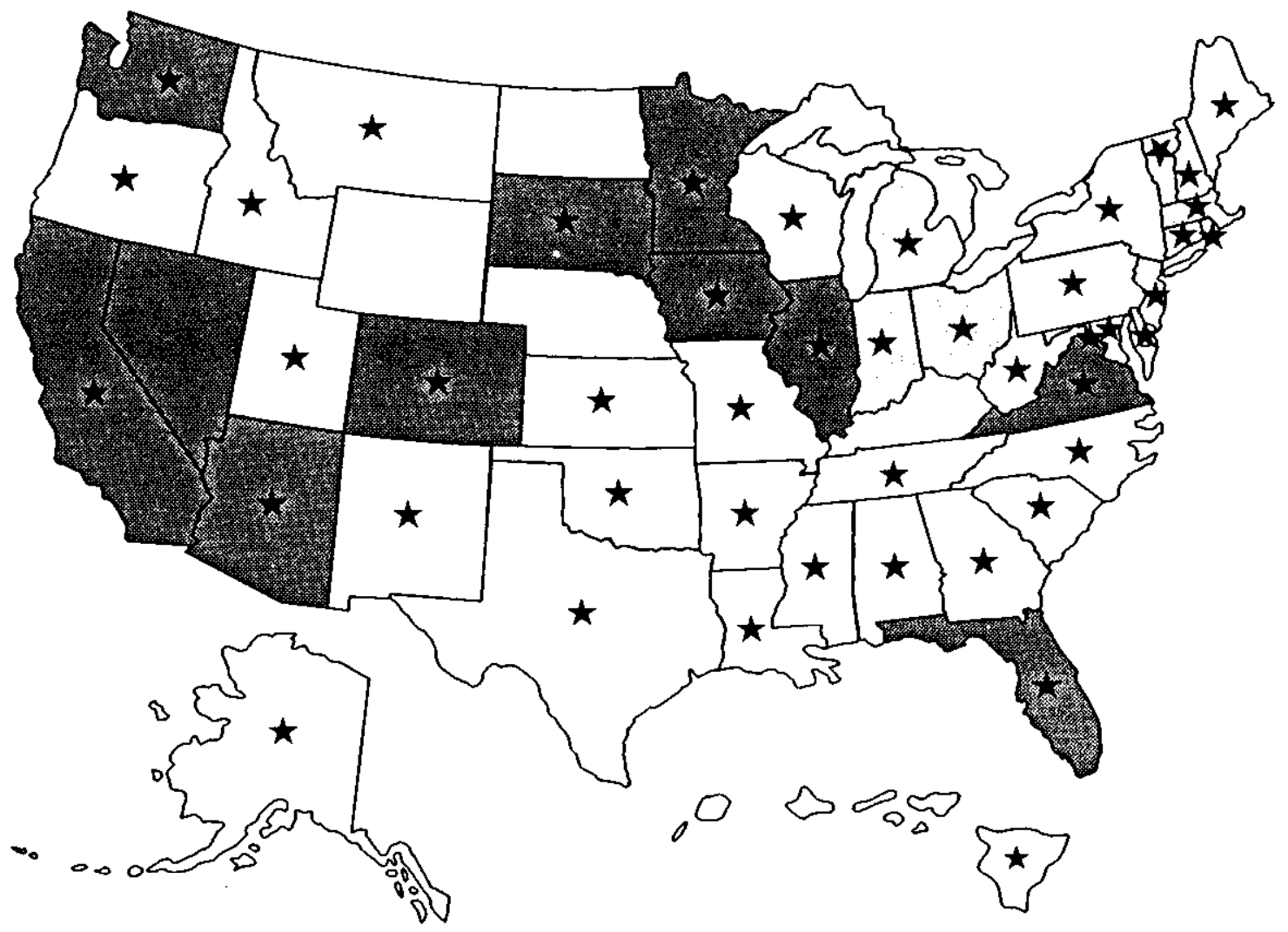

Reported use of DNA typing in that State as of January 1990 (see app. A).

Gray= Legislation proposing databanking of DNA information from certain convicted offenders,

Black= State law requires databanking of DNA information from certain convicted offenders.

First introduced in a United States criminal court case in 1986, DNA typing has since been applied in criminal investigations in at least 45 States and the District of Columbia as of January 1990. Interest in a means to store and exchange DNA test results across jurisdictional boundaries is also increasing, as reflected by State legislation.

SOURCE: Office of Technology Assessment, 1990.

Although criticized because "general acceptance' may not equate with scientific reliability, proponents note that the Frye test guarantees a minimal amount of support by experts for a scientific test or procedure prior to allowing cutting-edge technology into legal deliberations. Under the relevancy test, which is based on the Federal Rules of Evidence originally promulgated by the Supreme Court and affirmed by the Congress in 1975 (Public Law 93-595), scientific evidence is admissible if it is relevant and helpful to the judge or jury hearing the case. Among other conditions, the trier-of-fact must have the technical expertise to assess properly the reliability of the scientific testimony of the expert witness (and the evidence thus be help- ful). Applied in all Federal courts, the relevancy test also serves as the standard for admissibility of scientific evidence in non-Federal courts in 32 States.

The admissibility of DNA testing as evidence under the Frye test v. the relevancy test is of limited significance. The 185 cases identified by OTA indicate that in using either criteria courts find DNA typing technologies per se to be generally accepted by the scientific community, or relevant and helpful to judges and juries. No State court has found that DNA testing per se fails to meet established tests for admissibility, although in some cases the admissibility of DNA evidence has been limited or barred. Although DNA currently intro- 
duced as evidence is evaluated case-by-case, some argue that as more acceptance occurs a carte blanche for the admissibility of DNA typing evidence could soon be seen. Nevertheless, because aspects of forensic DNA analysis are receiving increased scrutiny, future court considerations will hinge on standards and quality assurance in forensic applications of DNA tests.

Even before determining whether biological evidence meets established grounds for admissibility, some argue that constitutional considerations in obtaining such evidence need to be considered; in particular, that Fourth, Fifth, Sixth, and Fourteenth Amendment issues of search and seizure, self-incrimination, right to counsel, and due process (respectively) should be raised. Although a comprehensive examination of constitutional issues is beyond the scope of this report, it appears that DNA testing as evidence for identification is unlikely to be viewed as presenting special constitutional considerations-in particular, as violating Fifth, Sixth, and Fourteenth Amendment rights. In the case of rights against unreasonable search and seizure, OTA identified one appellate-level case involving DNA typing where the issue was raised, but the court did not review the claim that the taking of a blood sample violated the Fourth Amendment since the defendant had consented to the procedure. In any case, search and seizure of evidence for DNA typing is unlikely to center on issues unique to DNA evidence.

\section{ADVANTAGES AND LIMITATIONS OF DNA TYPING AS EVIDENCE}

DNA testing for identification purposes affords several advantages to the law enforcement and the legal system and no disadvantages per se. In the United States, high violent crime rates often yield biological evidence, but traditional serological technologies achieve only modest success in either associating or disassociating suspects with the crime. DNA identification is likely to influence and build on present-day success with such traditional forensic genetic technologies.

As a biological material distinguishing individuals, DNA is more variable and stable, and detection methods more robust, than traditional genetic markers examined by forensic laboratories. As an index of differentiation between two humans, it is also more powerful than conventional markers because it can provide what amounts to a statistically positive link between an individual and biological evidence from a crime scene. And, because it is more discriminating, it is also easier to clear wrongly accused persons. For example, approximately 37 percent of the cases received by the FBI for DNA analysis result in exclusion of the primary suspect.

DNA testing can save law enforcement and courts time and money by exonerating innocent suspects before trial, or through plea bargaining for guilty parties, as increasingly defendants are confronted with DNA typing results. DNA profiles can also be stored in a computer network that could subsequently be used to investigate rapes and serial crimes. In 1988, 92,486 forcible rapes were reported, and studies indicate that this number is an underestimate since fewer than half of rape victims report this crime. In terms of impact on convictions or acquittals, sexual assault cases are most likely to reap the benefits of DNA typing.

No disadvantages of DNA testing technologies themselves were identified by OTA, but limitations and criticisms exist. In 1988,20,675 murders and nonnegligent manslaughter cases were reported in this country, and although forensic analysis using DNA typing in specific homicide cases certainly will be useful, its effect on aggregate homicide solution rates might not be appreciable, except perhaps in serial murders. Critics argue that DNA testing has been rushed into court without agreement being reached in the scientific community regarding either standards that ensure the reliability of the evidence or guidelines for interpreting results. And, because DNA testing itself and the costs associated 
with expert witnesses can be substantial, the ratio of defense to prosecutorial resources, already heavily in favor of the prosecution, could be widened. Finally, many harbor the misconception that DNA typing applied to forensic samples always yields a "yes" or " no answer. Tests are not black and white, and DNA profiling tests are no exception. An important, and often overlooked, result of an analysis could be 'inconclusive, ' 'uninterpretable, or "uninformative,' which should not be misconstrued as either inclusion or exclusion of a suspect. Nor does any matching profile necessarily mean positive identification, since the power of DNA analysis depends on the population characteristics of the tests used.

\section{COMPUTER TECHNOLOGY AND DNA IDENTIFICATION}

Computer technologies are central to forensic applications of DNA typing in two respects. First, computers can be used to more objectively and precisely analyze results of DNA typing, including RFLP analysis. Second, computers can be used to store DNA typing results. Databanking of DNA profiles can be used to either collect population statistics, which leads to more accurate estimates of the frequency that a particular DNA pattern occurs in a population, or to provide criminal investigative support.

In the area of analyzing DNA test results, computers help scientists by both speeding the process and employing computational tools to augment the power of the human eye. Because the actual readability of $x$-ray films, which are the final units depicting an individual's stripelike pattern, varies from case to case, computers are used to reduce human discrepancies. Without computers, analysts ' eyeball' banding patterns on x-ray films-potentially leading to more subjective results from analyst to analyst, or even for the same individual.

A range of computer systems exists for RFLP analysis, and the amount of analyst-computer interaction is tremendously diverse. One system involves the individual marking the location of bands, then allowing the computer to calculate whether known and questioned samples match. In another, more-automated system, the computer automatically marks band positions it detects through a video camera and image analysis. Such systems can also apply mathematical algorithms to normalize band patterns, 'sstraighten' lanes, account for inconsistent gel composition, variation in electric field, or other conditions prior to calculation of fragment size. Computers can, without operator involvement, discriminate banding patterns not detectable with the human eye alone. Yet while they can assist in identifying legitimate bands, computers can also be influenced by background noise and create, even in controlled situations, a result where none was expected. Computer-assisted analysis of RFLP patterns is under way at commercial firms and at FBI, State, and local laboratories.

Computer-assisted image analysis of DNA tests, while useful, raises the question, do computers lie? Depending on the level of computer v. analyst interaction in analyzing DNA testing data, special consideration may be necessary in judicial deliberations. Forensic analysts, not computers, will appear in court for examination as witnesses. The forensic science community may want to ensure that analyst-computer integration can be traced so that edited patterns can be reconstructed, and that the initial image is available for review by another individual. Courts could be required to determine the admissibility of computer-enhanced imagescleaner and, arguably, more persuasive than typical x-ray film-and will need assurances that such images are an accurate representation of a test's results. Thus, both courts and the forensic science community should be prepared for future discussions on whether to subject computer analysis tools to verification and reliability testing analogous to those applied to DNA technologies.

In the second area of utility, databanking, computer technologies enhance the ability of Federal, State, and local law enforcement officials at many levels (figure 1-10). The auto- 
mated fingerprint identification system, for example, has revolutionized the ability of criminal investigators to identify suspects within and across jurisdictional boundaries. Similarly, considerable interest exists in using computer technologies to enhance criminal investigations through datasharing of DNA test results. Centralized or linked databases containing DNA profiles would permit rapid, electronic comparison of results from tests on different samples within a laboratory and among laboratories nationwide. An OTA survey of State and local crime laboratories revealed a large majority of laboratories (95 percent) said that DNA results should be incorporated into a database for exchange among law enforcement agencies.

As mentioned earlier, databanks are being used to store information to generate population genetics data to support RFLP analysis. Databases for population statistics purposes arouse little controversy; computer storage of investigative support data are more controversial. (See following section on privacy.) The FBI is currently developing a theoretical model and working prototype for an investigative DNA profiling database. At least three types of information files would be included: open case, missing persons/unidentified deceased, and convicted offenders. The former two types would be centrally maintained by the FBI. Open case files could be used to help investigators determine if a series of crimes were committed by the same person. Missing persons/unidentified deceased files could include DNA information from parents who report their children missing, so that as children are located, the child's DNA can be compared with parental DNA profiles on file. Convicted offenders files would be maintained by individual States, but the FBI would provide an indexing service, with States capable of gaining access to other States' files after certain approvals were obtained (figure 1-1 1). Sixteen States and one county have authorized or initiated legislation to authorize known offenders files (table 1-2).

Because a cross-jurisdictional network will be required to maintain proposed investigative databases, discussions are being held about the

Figure 1-10-How a Database of DNA Information Could Be Created and Used

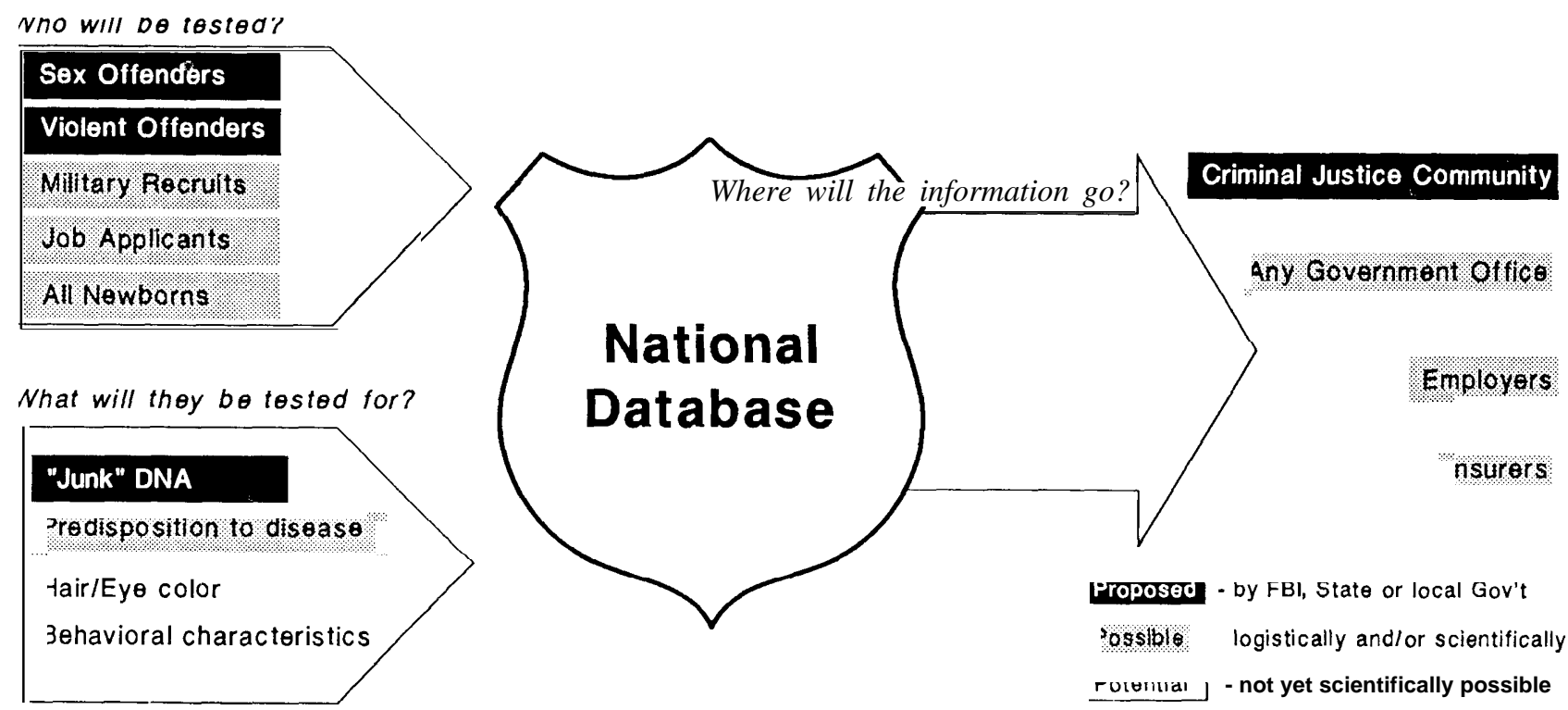

The law enforcement community cites a need for a DNA database to apprehend repeat offenders and solve serial crime; the military for additional identification (e.g., for victims of wars and mass disasters). Civil liberties experts, however, fear that DNA testing could expand beyond legitimate identification needs, and that test results would be widely available through the de facto national database.

SOURCE: Office of Technology Assessment, 1990. 
Figure I-Il-Proposed Data Files: Who Will Maintain Them?

Proposed Data Files: Who will maintain them?

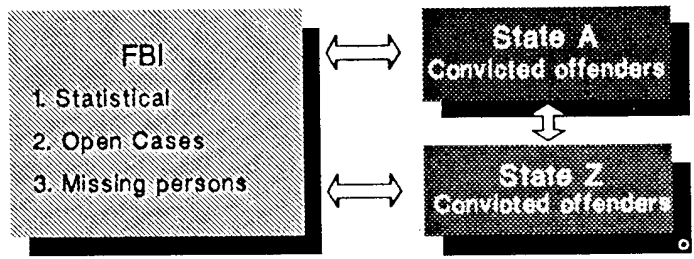

The FBI has proposed separate responsibilities for Federal, State, and local jurisdictions in creating and maintaining DNA databanks. This effort will require significant levels of coordination and cooperation to be effective.

SOURCE: Office of Technology Assessment, 1990.

most appropriate mechanism. DNA data held in Federal, State, or local files could be exchanged through the National Law Enforcement Telecommunications System (NLETS). A computerized message switching network operated by a nonprofit corporation controlled by the States, NLETS does not hold or manage data files, but is a possible vehicle for DNA data transmission. The most likely candidate to handle interjurisdictional inquiries is a system maintained by the FBI, the National Crime information Center (NCIC). NCIC currently contains about 20 million records on persons and property, and answers almost instantly about 75,000 inquiries a day. Although in December 1987 the NCIC Advisory Policy Board voted not to add DNA information to NCIC at that time, DNA testing and acceptance by law enforcement has spread rapidly since then. In June 1989, the Board reconsidered its actions, voting to index and match DNA profiles in NCIC.

Another area related to databank development (as well as to standards of statistical analyses) where many agree attention should be focused results from the dynamic and diverse nature of the U.S. population. Collection, classification, and databanking of genetic differences based on ethnic and racial subgroups affects efforts geared toward both population statistics and investigatory databanks. Stratification based
Table 1-2-State Laws To Establish Computer Files of Known Offender Genetic Patterns ${ }^{2}$

\begin{tabular}{ll}
\hline State & Action \\
\hline Arizona &
\end{tabular}

Governor signed a 1989 law requiring DNA testing of convicted sex offenders.

California

Passed laws in 1985 and 1989 requiring all convicted sex offenders to provide blood and salivia specimens at the time of their release from prison. Samples collected to date and future samples will be submitted for DNA testing, and the Attorney General's Office has begun studies to determine Colorado the best methods for collecting and storing data.

Enacted legislation to require genetic testing of all sexual Florida assault offenders released on parole after May 29, 1988.

Illinois

A law enacted in 1989 calls for a computer bank for genetic information on convicted rapists.

Legislation enacted requiring those convicted of sexual assault or attempted sexual assault, or who have been in an institution as a sexually dangerous person, to submit specimens of blood or saliva to the State police.

Iowa

Governor signed a law in 1989 that permits DNA testing in the criminal law context. The Attorney GeneraJ's Office will issue rules about which crimes are covered and who will be required to donate DNA samples. Genetic profiling Minnesota could become a rendition of parole.

Law enacted in 1989 that requires uniform procedures for collecting DNA information in cases of criminal sexual conduct, requires a court that is sentencing a person for criminal sexual conduct to order a DNA analysis specimen, and provides for admission of DNA test evidence without expert testimony.

Nevada

Requires that convicted sex offenders submit to DNA testing of their blood and saliva, and requires that the test results be maintained in the State's criminal history records.

South Dakota

1990 law allows law enforcement agencies to perform DNA typing of people convicted of sex crimes, calling for blood and saliva samples to be taken from those convicted and arrested.

Virginia

State legislature passed a bill in the 1989 session that Washington requires DNA typing of convicted sex offenders.

State law requires a system to collect genetic descriptions of violent and sexual offenders. In addition, King County (Seattle) passed an ordinance requiring DNA testing of sex offenders.

aAs of January 1990, at least five other States-Connecticut, Massachusetts, Michigan, Indiana, and Ohio-have proposed DNA databanking legislation that had not yet been enacted.

SOURCE: Office of Technology Assessment, 1990.

on self-reporting or surname (e.g., Hispanic) can be misleading. If future investigatory databanks rely on such information to associate a certain DNA banding pattern from an unknown sample 
to a racial or ethnic group, problems will likely arise.

Finally, DNA test results have been successfully computerized, but unless methods are standardized, e.g., restriction enzyme and probes, the potential usefulness of known offenders files or missing persons files will be constrained. Although no insurmountable technical difficulties face databank development, without quality control and quality assurance for DNA typing itself, without computer compatibility, institutional protocols to review results before data entry, and a capability to handle new DNA typing developments, computer technology combined with DNA analysis as a tool will be limited. Some postulate that the push to establish investigatory databanks will, by itself, be the factor that leads to standardization and quality assurance.

\section{PRIVACY AND CIVIL LIBERTIES CONSIDERATIONS}

As long as information refers to an identifiable individual-whether that reference is made by a person's name, a number, or some other distinguishing characteristic-it is personal information. The pervasive use of computer systems to collect personal information raises civil liberties issues and informational privacy concerns. Social security numbers are personal, as are fingerprints. Use or misuse of personal information collected in electronic databases can affect an individual's ability to obtain employment, credit, insurance, security clearances, and other services and benefits. Not surprisingly, then, proposals to store a person's genetic information in a national network evoke several concerns about privacy.

Yet the Government and private sector regularly collect and "bank" personal information. The law enforcement community currently maintains databases that include much personal information, such as a person's name and aliases, fingerprints, criminal record, sex, eye and hair color, and some medical information, such as whether a person has epilepsy. Never- theless, because DNA is specific to an individual and so highly personal, some are reluctant to see any DNA test results become part of a de facto national database. Still others fear that genetic testing will not be limited to identity, but will expand to include disease (e.g., sickle cell or Huntington's disease), proclivity toward disease (e.g., cancer or coronary disease), or behavioral characteristics (e.g., schizophrenia) that could then find their way into the database. Some believe it to be an inappropriate use of government authority to collect and store genetic information tied to a specific individual, because it is sensitive and personal. Related to these concerns are those about data security and the quality and reliability of the information that will be stored, should databanking of DNA results proceed.

One aspect of privacy considerations relevant to forensic applications of DNA tests can be separated into databanking DNA profiles $v$. storing DNA. Current proposals for law enforcement databases anticipate a need only for the test results of convicted offenders and unidentified crime scene evidence in investigatory databanks. Since the vast majority of tests are currently limited strictly to identification, such proposals assuage for many the privacy concerns of these types of databanks. For most people, the information most likely to be put, for now, into criminal history files-RFLP banding patterns for identification only-probably does not escalate privacy concerns because scientists do not currently know of any disease association with these markers. Contributing patterns of nondisease-linked DNA to military recruit files or newborn files might be indistinguishable from health status or a social security number for some.

Many object, however, to proposals for storing DNA profiles that can be associated with genetic disease, even though highly polymorphic areas of DNA correlated to disease exist and can be important in forensic casework. Further, many believe any type of DNA sample storage (as opposed to just coded DNA patterns) is inappropriate, primarily because it increases 
the likelihood that there will be testing for information beyond unique identity. Still others believe actual storage of genetic material and information is included in that category of information-along with religion, votes, special confidences-that civil liberties tradition in this country protects from compelled disclosure.

Yet new means to detect and deter crime are necessary and compel great respect in this country. Violent crimes nationwide increased 5.5 percent from 1987 to 1988 . With high rates of recidivism among convicted offenders, databases could be used to analyze whether evidence found at a crime scene matched a profile in the database, and thus provide police with a lead toward identifying a suspect. According to the Bureau of Justice Statistics, a survey of recidivism among State prisoners released in 1983 revealed that 62.5 percent had been rearrested within 3 years, with 41.4 percent returned to prison. Rearrest among violent offenders was 59.6 percent, and released murderers were about five times more likely than other offenders to be rearrested for homicide. In particular, the FBI believes DNA genetic databases will aid their efforts to solve some forcible rape cases-a woman is raped in the United States approximately every 6 minutes. Released rapists were 10.5 times more likely than other released offenders to be rearrested for rape. DNA genetic databanks could also be of aid to law enforcement in the growing number of serial crimes.

On the other hand, on a percentage basis, 6.6 percent of released murderers were rearrested for homicide and 7.7 percent of released rapists were arrested in new rape cases. Some opposed to DNA databases point out that many accused rapists choose to litigate only the issue of consent, thus the source of the semen-the only issue that can be addressed with DNA testing and databanks-is never in question. Research shows that blood evidence is available to link a suspect to murder in only 15 percent of cases, semen available to link a suspect to rape in 10 percent of cases, and hair available to associate a suspect to murder or rape only 5 percent of the time. These statistics appear less compelling than those presented by database advocates, and suggest a need to weigh potential social benefits of investigatory databases against both economic costs (expenditures to establish a databank) and, perhaps more importantly, potential social costs (including invasion of privacy.)

Finally, privacy considerations about forensic DNA analysis also center on DNA databases themselves-as opposed to whether to store DNA v. encoded DNA profiles. Civil liberties tradition holds that personal information collected under government authority should not be indiscriminately shared. The Privacy Act (U.S.C. 552a) offers some protection regarding data collection and access to information about most individuals included in Federal databases, but specifically provides that criminal justice agencies may exempt their record systems from many of its provisions.

If DNA information were to be incorporated into the NCIC Interstate Identification Index, as suggested by the FBI, access would be limited because noncriminal justice use is prohibited. The FBI has adopted privacy regulations that govern the NCIC. States that violate these standards can be denied NCIC services.

FBI proposals for DNA databases, however, envision maintenance of DNA information in State criminal history files, which vary in their accessibility. State law governs maintenance of non-Federal databases, and State criminal history files range from being completely open records, as in Florida, where private access is permitted, to being sealed from public scrutiny, as in Massachusetts. Concern about some types of criminal behavior, particularly sex offenses, led Congress to require that State criminal history files be opened to certain noncriminal justice agencies and employers. For example, in 1984, Congress required States to establish procedures to provide for nationwide criminal history checks for all operators and employees of child care facilities (Public Law 98-473). In addition, there has been increased 
emphasis on such record checks for current and prospective Federal employees.

Informational privacy safeguards interests in personal freedom. Constitutional principles, particularly the right of privacy and the right to due process, establish a framework for questions about what types of records are kept, on whom, by whom, and the protocols for access to them. Recognition of these rights evinces a belief that individual freedom and liberty prosper when detailed information about a person's life is private. Ensuring that sensitive or stigmatizing information remains private protects an individual from harm.

\section{DNA TYPING IN THE UNITED STATES: CURRENT PRACTICE AND FUTURE OUTLOOK}

Despite the fact that only a few years have passed since DNA evidence was first used in a U.S. criminal proceeding and that several issues, such as technical standards, quality assurance, and civil liberties and privacy concerns, remain to be resolved, interest in implementing DNA typing at the Federal, State, and local levels has skyrocketed. Likewise, forensic applications of DNA analysis have generated excitement in the international law enforcement community (box 1-D).

Commitment to forensic applications of DNA testing at the Federal level is demonstrated by extensive efforts by the FBI in research, training, technology transfer, and casework. With the mandated mission of performing research of value to both the FBI's DNA Analysis Unit and to State and local crime laboratories, the $\mathrm{Bu}$ reau's Forensic Science Research and Training Center (FSRTC) has investigated applications of DNA typing to forensic casework since 1986, and has trained over 100 State and local forensic scientists in DNA techniques. Research at FSRTC encompasses a range of projects, including examining gel electrophoresis techniques that might replace current methods and evaluating environmental effects on reliability and validity of RFLP analysis applied to foren- sic specimens. In fiscal year 1989, FSRTC devoted approximately 20 percent $(\$ 104,200)$ of its research and training budget and 36 percent $(\$ 143,200)$ of its supply budget on DNA technologies. Seminars, symposia, the Visiting Scientist Program, collaborative research, and publications have been and continue to be important mechanisms used by the FBI to disseminate information about DNA techniques to State and local crime laboratories. Related to this role in technology transfer, as mentioned earlier in this chapter, the Bureau has served and continues to serve as a facilitator in discussions about many of the controversies surrounding forensic applications of DNA testing, including quality assurance, databanking, and statistical analysis and reporting of RFLP results.

In addition to these programs, the FBI Headquarters Laboratory established a DNA Analysis Unit to perform DNA tests on forensic samples from the State and local law enforcement communities at no cost to the jurisdiction. Since accepting casework in December 1988, and since reporting its first case in March 1989, the FBI DNA Analysis Unit received 2,619 samples for 536 cases as of July 1989; by mid-February 1990 these numbers had risen to 6,377 and 1,338, respectively. The FBI anticipates being capable of processing 10,000 samples per year.

DNA identification is a forensic tool that has been quickly embraced by the State and local criminal justice communities. Over threequarters of 221 crime laboratories responding to a 1989 OTA survey stated that DNA typing is very important to their mission, and nearly one-half had contracted for this service with an outside facility (overall response rate of 85 percent). Forty-six percent of State and local crime laboratories said they have plans to implement onsite DNA testing in the next 1 to 2 years.

Yet costs associated with establishing and maintaining onsite capability will clearly be beyond reach of some crime laboratories (box l-E). The OTA survey revealed a diversity in 


\section{Box l-D-Uses of Forensic DNA Tests Internationally}

An informal OTA survey in January 1989 of 40 countries found that at least 15 have implemented or are exploring forensic applications of DNA tests, 'with most expecting to perform DNA typing of forensic samples in late 1989 or 1990. Two-the Republic of Korea and Yugoslavia-reported that such use of DNA identification was not planned. South Africa indicated that DNA typing is used only for medical applications at present, but embassy staff did not say whether this might be broadened to forensic uses. Yugoslavia also reported that such tests are used for medical applications.

The extent to which DNA typing technologies have been used abroad varies. In the United Kingdom, where forensic applications of DNA typing originated, single-locus and multilocus approaches have been fully accepted for criminal, paternity, and immigration casework. Over the past 2 years, Norway has gradually begun to use DNA typing in selected penal and civil cases. In other countries, DNA profiling is in an early, exploratory phase, with law enforcement units developing suitable systems and, in particular, collecting population data. In 1988, for example, Finland replaced traditional genetic human leukocyte antigen (HLA) typing for paternity cases with DNA-based profiling, which is now routinely used; DNA identification for criminal offenses has been used on a selective basis.

The Israeli police intend to use DNA typing on a routine basis, and as of February 1989 were beginning trials on case samples. The Main Office of the Polish police and the Polish Academy of Sciences are conducting research on DNA typing for forensic applications and anticipate field applications at the end of 1989 for selected rape and murder cases. Explorations into DNA typing for paternity purposes in Poland has been discontinued due to lack of funding. In the State of South Australia, RFLP analysis is used for paternity testing, and polymerase chain reaction has been used for crime work. Two of New Zealand's three forensic laboratories plan to be performing DNA analysis by early 1990. Several countries, while currently in the development phase, have contracted with commercial laboratories on a limited basis.

Full international cooperation that would result in standardization and a coordinated investigative databank as with some current NCIC files, appears beyond reach at the moment. On the one hand, close coordination between the Royal Canadian Mounted Police and the FBI will likely lead to effective data sharing from the outset-especially since the FBI anticipates its system eventually will become the de facto system in the United States. On the other hand, in anticipation of a unified European Community in 1992, officials of Denmark Italy, the Netherlands, the United Kingdom, and Federal Republic of Germany met and agreed to a series of issues pertinent to standardization, including a designated restriction enzyme (different from the U.S. system) and a common probe. Nevertheless, although current technologies and applications appear to have advanced too far for international standardization for the present, the situation is likely to change as future technical advances are adopted. In the interim, the Federal Government could facilitate dialogue and encourage cooperative efforts leading toward a system amenable to DNA identification among, not just within, international criminal justice entities.

'Australia, Canada, Finland, India, Ireland, Israel, Italy, Japan, New Zealand, Norway, Poland, Sweden, Switzerland, United Kingdom, and West Germany.

SOURCE: Office of Technology Assessment, 1990.

crime laboratory budgets and staff sizes, and further indicated that some might not even be able to cover costs of contracting with commercial laboratories for DNA typing (table 1-3) -13 percent of laboratories responding to the OTA survey have provisions to contract with private firms for DNA services, but may not be able to submit cases due to cost. Of the 110 laboratories contracting for tests, nearly half (49 percent) have not submitted budget provisions to do their own DNA analysis onsite. Thus, because it is not inconceivable that all forensic laboratories will reach a point where access to DNA typing will be essential, services provided at no cost by the FBI DNA Analysis Unit will become increasingly important. For laboratories pursuing onsite DNA typing services (41 have submitted budget provisions), some unique financing mechanisms are being employed, including revenue from a cigarette tax in one State and money derived from the sale of goods and property confiscated from drug-related investigations. At the time of the survey, only one laboratory conducted DNA identification onsite. 


\section{Box l-E-What Does DNA Typing Cost?}

State and local laboratories have three options available to them if they are interested in DNA analysis of forensic specimens: the FBI DNA Analysis Unit, commercial laboratories, and onsite testing. The FBI laboratory provides DNA testing to State and local crime laboratories at no cost, while the fee structure of the three commercial laboratories varies from $\$ 200$ to $\$ 490$ per sample, or $\$ 1,500$ per case, depending on the exact service and company (table 1-3). The FBI estimates that performing DNA typing on one sample, after a laboratory is equipped, will cost $\$ 28.50$ (excluding labor), and $\$ \mathbf{9 8 . 5 0}$ including labor, but not overhead costs such as rent and utilities, which are included in the fee structures of the commercial companies. The Miami-Dade Police Department Crime Laboratory Bureau estimates it will cost their facility $\$ 41.60$ per sample (excluding labor) and with labor costs added, $\$ 97.60$. The cost of establishing a DNA typing unit onsite will vary from laboratory to laboratory, depending on the case load expected and existing equipment, but the FBI estimates that $\$ 60,000$ to $\$ 70,000$ would cover equipment expenses. Upto $\$ 11,000$ more could be necessary to cover the cost of the FBI computer analysis hardware, and, should DNA databanking be implemented through the NCIC, States could expect an additional expense of approximately $\$ 200,000$ for databanking efforts.

In addition to startup costs, a laboratory program would need to expect certain monthly operating costs. Although, again, the expense will depend on the number of samples on which a laboratory does DNA analysis, the FBI estimates monthly costs (excluding labor) based on handling 10,000 samples a year of approximately $\$ 18,100$. The Miami-Dade facility estimates monthly costs (excluding labor) based on handling 3,600 samples a year of approximately $\$ 12,300$. Future techniques are likely to rely increasingly on automation and could require a significant one-time outlay in exchange for greater speed and accuracy. Whether operating costs would increase or decrease with such automation, however, is difficult to predict.

Although the FBI provides DNA testing services at no cost, many laboratories will opt to do at least some DNA typing onsite. Enhanced turnaround time and the ability to keep evidentiary material are frequently cited as the primary benefits State and local facilities believe onsite DNA profiling will provide.

SOURCE: Office of Technology Assessment 1990.

Table 1-3-Costs for Forensic DNA Testing by Private Laboratories ${ }^{a}$

\begin{tabular}{|c|c|c|c|}
\hline Service & Cellmark & $\begin{array}{c}\text { Forensic Science } \\
\text { Associates }\end{array}$ & Lifecodes \\
\hline $\begin{array}{l}\text { DNA testing } \ldots \ldots \ldots \ldots \ldots \ldots \ldots \ldots \\
\text { Processing isolated DNA sample } \ldots \ldots \ldots \ldots \ldots \ldots \ldots \ldots \\
\text { Expert witness (daily rate }+ \text { expenses) } \ldots \ldots \ldots \ldots \ldots \ldots\end{array}$ & $\begin{array}{l}\$ 490 / \text { sample } \\
\$ 350 / \text { sample } \\
\$ 1,000 / \text { day (Ph. D.) } \\
\$ 750 / \text { day (non-Ph.D.) }\end{array}$ & $\begin{array}{l}\$ 1,500 / \text { case } \\
\text { Not available } \\
\$ 100-\$ 125 / \mathrm{hr} \text {. }\end{array}$ & $\begin{array}{l}\$ 325 / \text { sample } \\
\$ 200 / \text { sample } \\
\$ 750 / \text { day }\end{array}$ \\
\hline Processing of insufficient sample $\ldots \ldots \ldots \ldots \ldots \ldots \ldots$ & $\$ 21$ O/sample & $\$ 250 /$ sample & $\$ 125 /$ sample \\
\hline
\end{tabular}

SOURCE: OMce of Technology Assessment, 1990.

Overall, results from the OTA survey indicate that the likelihood of integration of DNA testingvia contracting or onsite-in the next 1 to 2 years appears mixed. Although 46 percent of labs have plans for onsite testing during this period, and 46 percent (not necessarily the same ones) have plans to contract with commercial laboratories, 21 percent stated they were not planning to contract in the next 24 months, and 51 percent have no plans for onsite testing. Fewer than 10 percent said they would neither contract nor had plans to pursue DNA typing onsite. Nevertheless, the demand from State and local crime laboratories for outside DNA profiling will likely continue in the future, since 83 laboratories estimated they will seek outside DNA analysis of from 2 to 3,000 samples.

Finally, the necessity for present and future cooperation between the FBI and State and local laboratories was clearly revealed by the OTA survey. Respondents believe, to varying extents, that an FBI role in many issues is appropriate (table 1-4). 
Table 1-4-Suggested FBI Roles in DNA Testing

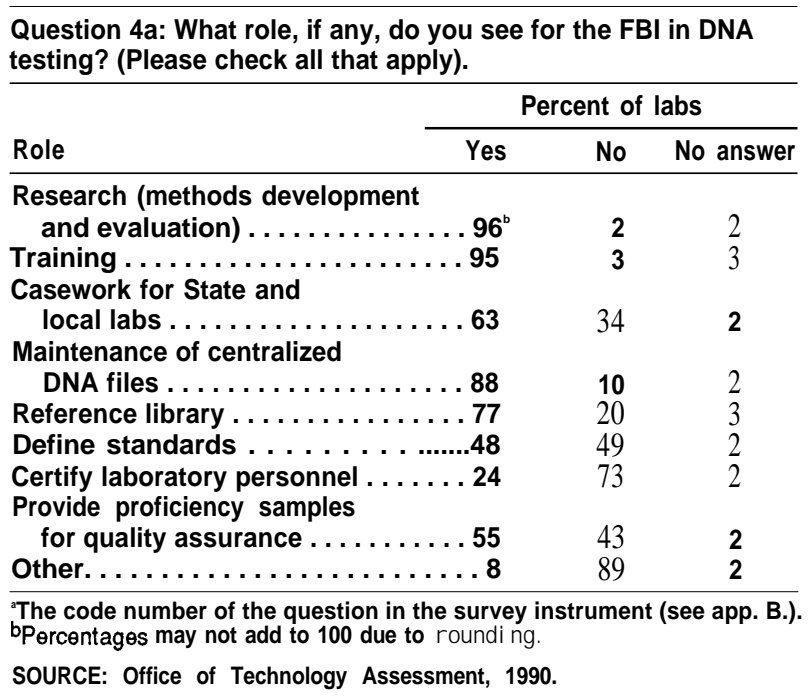

\section{THE ROLE OF CONGRESS AND POLICY ISSUES AND OPTIONS}

With crime rates always a concern in local jurisdictions, the advent of any new method to assist investigators is welcomed. DNA testing has been no exception. Forensic applications of DNA tests have come to the attention of Congress because of the high visibility their use receives in congressional districts throughout the country. In fact, many Federal, State, and local law enforcement authorities have fueled public fascination in forensic uses of DNA tests by touting them as a revolutionary breakthrough in crime work, particularly rape and homicide cases. In some measure, congressional interest in recombinant DNA technologies, biotechnology, and the human genome project has also contributed to congressional interest in forensic DNA analysis.

Five policy issues related to forensic uses of DNA tests were identified during the course of this assessment. They are:

- quality assurance of forensic uses of DNA testing, including technical and operating standards for private and public facilities;

- funding of crime laboratories, forensic personnel training, and forensic research;
- the advisability of establishing computer databanks of DNA tests results;

- standardization of DNA analysis for improved data collection; and

- privacy considerations of collecting, using, and storing DNA data or samples.

Congress could play a role in each of these policy issues through oversight of activities related to forensic uses of DNA tests or through authorization of actions by the executive branch to set up formal coordinating structures or specific mandates-which could be freestanding or tied to appropriations.

Specific options that Congress could consider to address policy issues related to forensic uses of DNA typing build on the discussions presented earlier in this chapter and in chapters 3 through 6 of this report. Associated with each policy issue, discussed in turn in the following sections, are several options for congressional action that range from taking no specific steps to making major changes.

The order in which the options are presented does not imply their priority. Moreover, the options are not generally mutually exclusive: Adopting one does not necessarily disqualify others that pertain to the same or other issues, although changes in one area could have repercussions in others. A careful combination of options within and among the five policy issues could produce the most desirable effects.

Finally, since DNA testing is used in a criminal context, issues regarding the overall adequacy of the U.S. criminal justice system naturally arose during this study. Prominent among these issues was universal access to DNA typing for defendants, who often are less able than the prosecution to fund services. The adequacy of funding for defense-related services, however, is a broad social issue that is beyond the scope of this report. Nevertheless, access to DNA typing services and test results could be a topic tied to a number of the options presented for the five policy issues. 


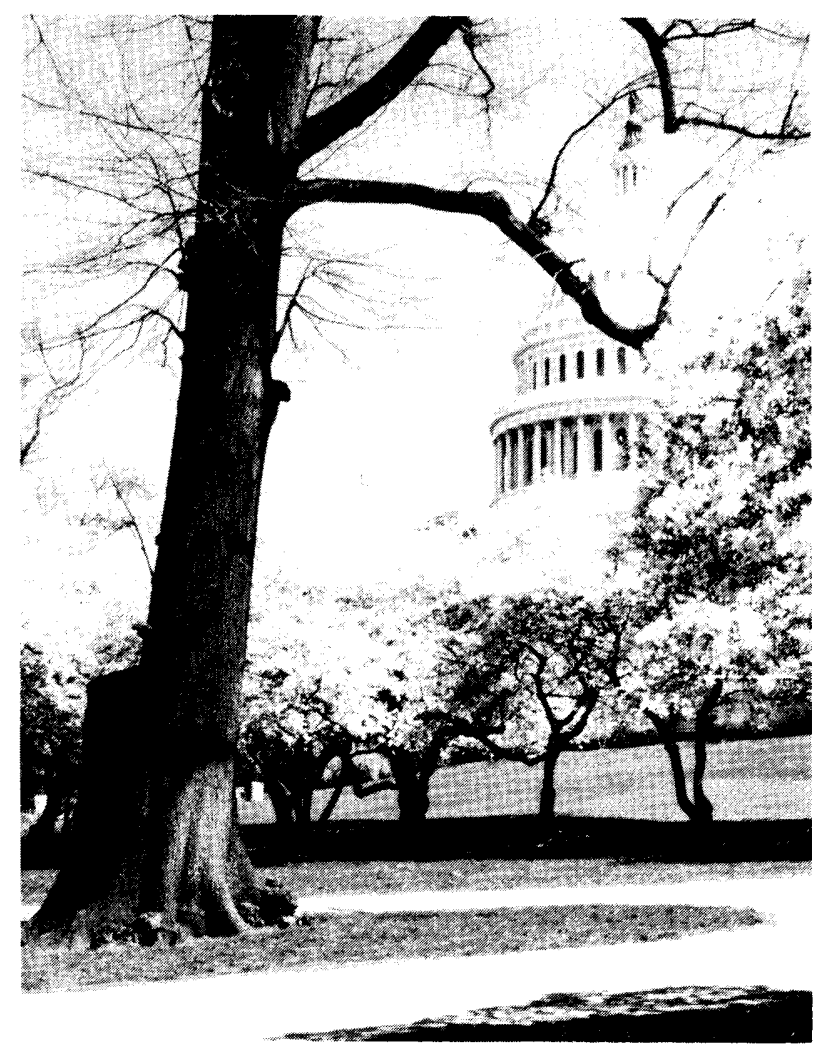

Photo credit: Robyn Nishimi

\section{Quality Assurance and Standards}

The issue of setting standards for forensic applications of DNA testing is the most pressing of the five policy issues identified by OTA. Standards for public and private facilities performing forensic DNA tests are essential to quality assurance of DNA analysis of forensic samples. Establishing standards at the earliest possible date is imperative.

OTA identified two distinct types of standards for forensic applications of DNA testing. Technical standards include matters such as proper scientific controls, choice of probe sequence, and analytic methods. Operational standards refer to areas of laboratory performance, such as recordkeeping, laboratory accreditation, licensing of personnel, and proficiency testing.

At present, neither the Federal Government nor any State regulates DNA testing by companies or crime laboratories. This situation is not unique to DNA analysis. Except in certain restricted areas, such as forensic alcohol analysis, no general licensing requirements for laboratories or personnel exist for crime laboratories. In contrast, Congress and the executive branch have stepped in to regulate drug testing laboratories and clinical laboratories.

\section{Option 1: Take no action.}

In the absence of congressional action to set or encourage adoption of technical standards, voluntary efforts by the FBI and professional organizations and case-by-case examination by the courts will likely move forward. FBI efforts to develop and disseminate recommended technical and operational requirements will continue. Continued case-by-case examination of proper technical and operational standards could slow full implementation of forensic analysis using DNA tests, as courts could become mired in scientific detail. If Congress takes no action, a haphazard array of standards could be developed, and disparate initiatives are likely to prove more expensive overall than a centralized effort. On the other hand, some feel the courts are adequately handling issues raised by the technology. By taking no action, Congress leaves to the courts the decision as to whether adequate technical and operational standards were employed in a particular case by a particular laboratory. In addition, if Congress takes no action, it would avert Federal oversight or regulation of the network of State and local crime laboratories that were established as local entities, which to date have been responsive only to their individual jurisdictions and are funded nearly totally by local monies.

\section{Option 2: Encourage the National Conference} of Commissioners on Uniform State Laws to promote uniform practices in forensic applications of DNA tests.

An organization set up for and by the States to promote uniformity of laws in a variety of areas, the Conference has Commissioners appointed by each State. In response to recommendations and appeals from numerous sources, it identifies areas where uniformity of law would 
be useful, and drafts laws that are then proposed to State legislatures for enactment. For example, the Uniform Anatomical Gift Act was designed to address issues surrounding the area of organ transplant donation.

Congress could encourage the Conferencethrough a letter of request by a Committee or through legislation-to address the issue of standards and quality assurance for forensic DNA analysis. Adopting this option would signal congressional interest in uniform standards for forensic DNA typing, while leaving their development to a body controlled by the States. On the other hand, the Conference is under no obligation to respond to letters or legislation to address an issue, so the consequences could be the same as taking no action.

Option 3: Encourage the use of a formal, open consensus review or conference to address and recommend quality assurance guidelines.

Short of regulating forensic uses of DNA tests, Congress could facilitate voluntary efforts to achieve quality assurance of forensic services, including DNA analysis. Congress could specifically authorize the use of governmental agencies and appropriations to hold consensus conferences that would establish review processes or recommend protocols for technical and operational standards.

In encouraging this approach, Congress could exercise oversight to direct the FBI or NIST to hold consensus conferences and recommend procedures to ensure high-quality services for DNA analysis of forensic samples. A consensus process similar to that employed by the National Institutes of Health (NIH) could be effective and lead to greater quality assurance in forensic practices using DNA tests. An important consideration, however, is that the process should be open and represent the full range of stakeholders to be most effective, since many questions surrounding forensic uses of DNA technologies involve public policy decisions, not purely technical issues. Present efforts by the FBI to facilitate consensus-building fall short of an $\mathrm{NIH}$-like process, because to date they have been meetings gathering a limited number of individuals by invitation.

Finally, Congress also could commission a private research institute or professional society to evaluate, through a consensus review process, quality assurance concerns pertinent to operational standards or technical standards. (In October 1989, a committee of the National Research Council, National Academy of Sciences, began a study of forensic DNA analysisalthough not specifically to set standardsfunded in part by the FBI and the National Institute of Justice (NIJ).)

\section{Option 4: Direct the National Institute of} Standards and Technology of the Department of Commerce to review and report on acceptable technical standards for forensic applications of DNA tests.

Identification of suitable technical standards by a neutral, nonregulatory agency whose mission is to conduct research in measurement standards would provide Federal oversight of setting technical standards and could enhance standardization of analyses, which could have a positive impact on databank initiatives (see following section). Directing NIST to report independently on technical standards might remove the objection of some to FBI-centered involvement in standard setting. On the other hand, because no regulatory authority exists for NIST, recommendations for appropriate standards would still be subject to voluntary compliance unless mandated otherwise by Congress. Voluntary compliance, including FBI participation, is likely to be perceived as less than sufficient by those who seek mandatory standards. A majority of laboratories, including the FBI laboratory, currently do not participate in the criminalistics accreditation program of the American Society for Crime Laboratory Directors. 
Option 5: Establish an independent commission to examine quality assurance issues surrounding forensic uses of DNA analysis.

Congress could pass legislation to establish an independent commission to evaluate quality assurance issues of forensic DNA testing by Federal, State, local, and private laboratories. A commission directed to represent all interested parties could address either technical or operational standards (or both) necessary for quality assurance of forensic applications of DNA tests. As with directing NIST to examine technical standards, establishing an independent commission might remove the objection of some to FBI-centered efforts for both technical and operational standards. By the same token, absent a clear mechanism to implement any commission recommendations, some will view this option as insufficient. Furthermore, if Congress adopts this option, others will object to any effort to remove control of such issues from a laboratory-by-laboratory basis and will be concerned that an examination of general forensic laboratory practices would be imminent.

Option 6: Enact broad-based quality assurance legislation that covers forensic laboratories.

Congress could determine that current voluntary efforts to address quality assurance in forensic applications of DNA analysis, forensic practices in general, or both are insufficient or moving too slowly, and could enact broad-based quality assurance legislation that encompasses public and private facilities doing forensic casework. Legislation could be based, in whole or part, on similar, separate congressional action addressing regulation of clinical and drug testing laboratories. In the case of Public Law 100-578, which regulates clinical laboratories, Congress gave broad authority to an executive agency, but also specified detailed measures, including mandatory accreditation by Federal authorities or a private, nonprofit body meeting certain congressional criteria and approved by the Federal Government, national standards for certain laboratory methods, recordkeeping and reporting requirements, mandatory quarterly proficiency testing, sanctions, and penalties.

If Congress enacts quality assurance legislation, courts might be freed of some of the burden of having to evaluate certain aspects of DNA testing, or other forensic scientific analysesalthough the onus would remain with the laboratory to demonstrate it had adhered to good laboratory practices. Establishing legislatively mandated responsibility would likely satisfy those individuals who believe Federal oversight and regulation of public and private laboratories doing DNA analysis specifically, or forensic casework generally, is necessary. On the other hand, although States do not currently regulate their own laboratories, local crime laboratories, or private laboratories accepting forensic casework, they likely will object to Federal preemption of their authority to regulate their facilitiesregardless of whether such regulation pertains only to DNA tests or includes other technologies.

Congress could enact quality assurance legislation that encompasses only private laboratories, and could require States to implement measures for State and local laboratories. Such legislation could mitigate some objection to Federal intervention, but is likely to be opposed by the few private companies that exist and by those who believe a Federal regulatory role is needed for all forensic laboratories doing forensic casework.

\section{Option 7: Direct the U.S. Attorney General to set and oversee technical and operational requirements for forensic uses of DNA testing.}

Present efforts by the FBI on behalf of the U.S. Department of Justice focus on facilitating the development of laboratory standards. Congress could decide that direct Federal regulation and oversight is necessary, and enact legislation directing the U.S. Attorney General to implement standards for forensic uses of DNA typing and to ensure compliance. Mandatory Federal standards at both the technical and operational levels could be issued, while allowing the U.S. Attorney General flexibility in how such stan- 
dards would be set, evaluated, and refined as DNA typing technologies advance. For example, Congress could direct the Attorney General to adopt a process similar to the NIH Recombinant DNA Advisory Committee, which has demonstrated how a flexible Federal role to oversee recombinant DNA activities can evolve.

Nevertheless, placing the U.S. Attorney General or a designee such as the FBI in the role of regulator is likely to receive strong opposition from both State and local crime laboratories as well as other interested parties. Fewer than half the laboratories (48 percent) surveyed by OTA believed setting standards was an appropriate role for the FBI. Only 24 percent believed providing certification was appropriate. State and local facilities are likely to resent intrusion of Federal authority in what has been, to date, locally funded and operated entities. Others not connected to crime laboratories probably will object to FBI oversight as a situation of the fox guarding the hen house.' Finally, it is likely that the FBI will prefer to retain its role as an investigative agency, rather than a regulatory body. Further, because regulatory duties would require a significant sum of money for development and enforcement of standards, appropriation of new funds or reallocation of existing Department of Justice funds would be necessary if Congress adopts this option.

\section{Funding for Forensic Sciences}

Hand-in-hand with standards for forensic DNA analysis is ensuring that education and training of personnel is adequate, that facilities are properly equipped and funded, and that basic research to evaluate forensic applications of DNA be performed. Most agree that crime laboratories and forensic sciences research that supports technology transfer to crime laboratories are underfunded. Increasingly, indications are that crime laboratories are experiencing difficulties managing the steadily rising influx of casework. Interest in implementing DNA testing onsite, which could be coupled to increased requirements for laboratory accredita- tion, personnel licensing, or proficiency testing, is likely to further stretch fiscal resources and exacerbate the casework backlog.

Crime laboratories are public facilities that receive operating monies from State, city, and county sources, with little direct Federal investment. Present Federal spending is largely indirect, taking the form of research, training, and casework. Is State and local funding of crime laboratories sufficient, or is additional Federal assistance necessary?

\section{Option 1: Take no action.}

Congress could conclude that State and local funding for crime laboratories is adequate. If Congress takes no action, State and local governments will continue to fund crime laboratories through a variety of mechanisms. Laboratories planning to conduct DNA typing onsite will need to make substantial investments of funds and personnel. A push by law enforcement, prosecutors, defense attorneys, and politicians for widespread dissemination of DNA typing in crime laboratories without attendant increases in funds would place additional financial burdens on facilities already strapped for personnel and money. Additionally, if Congress takes action to implement standards such as licensing or proficiency testing, or to standardize DNA analysis of forensic samples to enhance databanking efforts, and takes no action to provide increased Federal assistance, State and local funds to cover costs associated with such actions will need to increase or be diverted from other crime laboratory activities.

For State and local crime laboratories that cannot conduct DNA testing onsite, the FBI will continue to accept their casework. If Congress takes no action and State and local resources prove limited, however, the number of crime laboratories relying on the FBI for DNA testing of forensic samples will likely increase and could strain resources the FBI has devoted to its DNA analysis program. 


\section{Option 2: Increase direct Federal support for} crime laboratories.

Federal funds support crime laboratories indirectly through research and training at the FSRTC and casework performed at the FBI's forensic laboratory, and DNA typing is one of the array of forensic tools supported by these efforts. Only a minute fraction, however, of Federal funds for crime laboratories is direct. The lack of available funding for some crime laboratories to implement DNA testing highlights a much larger issue: that of insufficient funding and personnel for crime laboratories to carry out even routine forensic science procedures, let alone DNA analysis.

Congress could conclude that State and local crime laboratories need additional funding to perform their missions effectively, and could directly appropriate funds for distribution to these facilities; such funds could be linked to quality assurance and standards requirements. Congress could designate that the funds be slated solely to support DNA testing, or could leave the nature of programmatic spending to State or local discretion. Congress also could require that funds be matched by State and local monies. Increased general Federal support, not tied to DNA typing, might provide the best relief for laboratories with casework backlogs. Providing directly for DNA testing could release additional State and local funds for other forensic analyses or personnel training, but it also might result in no net gain in crime laboratory funds if State or local monies designated for forensic serology and DNA analysis were diverted from crime laboratory budgets rather than used to supplement other crime laboratory activities. Such a situation, while allowing State and local laboratories to perform DNA tests on forensic samples, would not alleviate, for example, case loads in firearms or drug analyses. Present budgetary concerns also would need to be balanced against the need for Federal spending in this area.
Option 3: Increase Federal support for the training and education of crime laboratory personnel.

Federal funds, chiefly through the FBI and to a lesser extent through NIJ, support training and education for active and future crime laboratory personnel. For example, FSRTC provides training to crime laboratory analysts in numerous areas, including biochemistry, physics, polygraphs, latent fingerprints, toxicology, immunology, and DNA analysis.

Given the rapid pace of scientific and technical developments in forensic casework, Congress could decide to increase funding for training and continuing education of crime laboratory personnel. Congress could focus on funding courses specific to applications of DNA typing, or could appropriate training and education funds on a broad basis. In increasing Federal support, Congress could appropriate increased funds to the FBI for training at FSRTC, to NIJ for grants to academic institutions to train future forensic analysts or to hold continuing education courses, or directly to State and local laboratories to offset costs of training personnel. For example, Congress could provide increased funding that would allow FSRTC to hold more DNA testing courses, which are currently oversubscribed. Nontargeted training grants through NIJ or directly to crime laboratories could encourage the development of programs tailored to specific needs of State and local facilities.

Option 4: Increase Federal support for basic research in forensic applications of DNA technologies.

Federal funding of research specifically in forensic applications of DNA analysis is limited. Congress could encourage the transfer to crime laboratories of state-of-the-art molecular genetics techniques developed in basic biomedical research laboratories by increasing support for "bridge" research in forensic applications of DNA techniques-i.e., research that explicitly evaluates new molecular techniques applied 
to forensic specimens. Such bridge research strengthens the underlying scientific and technical knowledge base for DNA analysis of forensic casework.

Congress could increase support by directing monies to FSRTC, to NIJ for grants to academic departments, or to both. If Congress increases Federal appropriations for such research, present controversies surrounding technical standards for forensic applications of DNA technologies might be more quickly resolved, or perhaps even avoided, as additional techniques are adopted by crime laboratories. In an era of fiscal constraint, however, increased Federal spending for basic research in forensic applications of DNA technologies would need to be evaluated against the backdrop of Federal budget considerations.

\section{Advisability of a Databank}

The FBI and others in the criminal justice community believe that realization of the full law enforcement potential of DNA testing depends on developing investigative databanks of DNA patterns that are accessible nationwide. Proponents of such databanks often cite high rates of recidivism among violent offenders and the growing incidence of serial crimes as justification for electronic storage of genetic profiles. Many experts who recognize the importance of a nationwide databank oppose investigative DNA databanking for the moment on technical grounds, arguing that such proposals are premature given the great technological flux likely to occur in the near future. And although current databanking proposals recognize the need to incorporate flexibility in their design so that files can be updated as technologies improve, predicting the course of forensic DNA analysis to account for changes even over the next year or two could prove tricky; accurate long-term forecasting of the precise direction is impossible. Finally, others oppose DNA computer databanks on the grounds that the purported benefits fail to outweigh the threats to civil liberties they pose.
The FBI has developed computer hardware and software necessary to convert DNA testing results to data amenable to computerized storage and retrieval. These tools will be provided to all users of their testing system. Along with others, it is discussing a proposal to implement a nationwide investigative DNA databank network. Additionally, the FBI maintains a computer network, the NCIC, that provides for swift exchange of electronic information between criminal justice organizations at the Federal, State, and local levels. The Director of the FBI has committed himself to including DNA testing results in NCIC files.

Commercial laboratories, State and local laboratories, and the FBI have already established databases of population statistics to support their RFLP analysis systems. Collecting population data information for noninvestigative purposes enhances the population genetics knowledge base necessary to refine statistical analyses of forensic applications of DNA typing. Such DNA databanks are not controversial, for the most part, and so limits on such DNA databanks are not discussed.

\section{Option 1: Take no action.}

Computerized DNA information could benefit criminal investigative work via three classes of files: open cases (where a suspect has not yet been identified), known offenders (most likely rapists and murderers), and missing/unidentified deceased persons. Several States have passed or proposed legislation that would support establishment of known offenders' files, by requiring DNA typing results on certain convicted offenders (most often defined as sex offenders or violent offenders). No State has actually begun investigative databanking at this time, but sample collection is under way or imminent in several locales. If Congress takes no action, the FBI will likely proceed with plans to create several investigatory databases containing DNA profiles (most likely in the NCIC) and to integrate these files with State and local efforts that adopt the FBI DNA analysis protocol. 


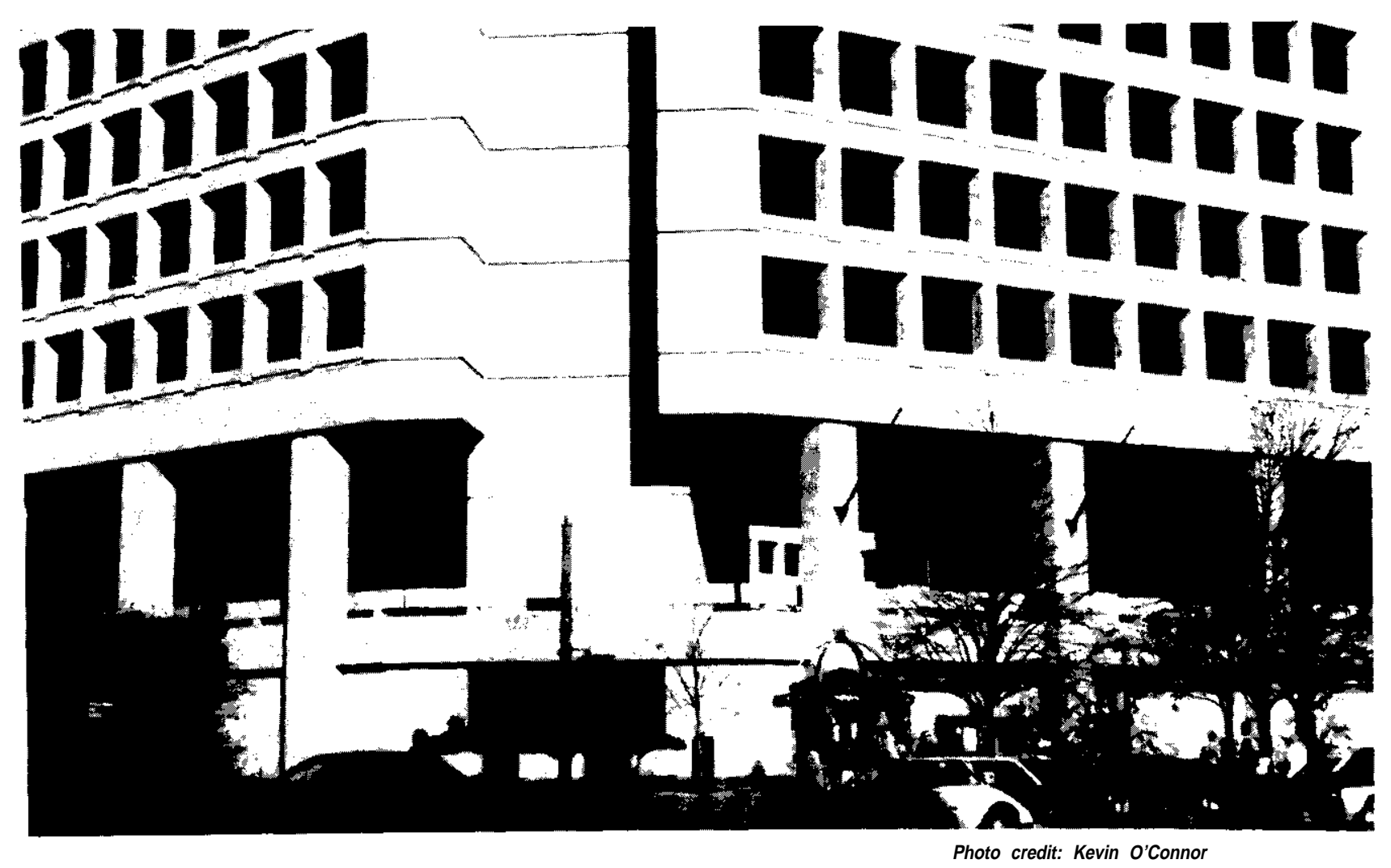

J. Edgar Hoover Building, Washington, DC: Headquarters of the Federal Bureau of Investigation.

Option 2: Place limits on interstate DNA databanking activities.

If technological and social considerations appear to need further exploration, Congress could enact legislation to place limits on all law enforcement activities related to interstate electronic transmission of DNA test results, could prohibit FBI activity in the area of database development or interstate transmission of DNA information, or both. Such legislation could be for a limited or an indefinite period, and could be targeted to investigative databases, population frequency databases, or both.

Adopting a short-term moratorium on any interstate DNA databanking analysis could mollify some concerned about technological considerations and privacy, but it would limit the FBI and local agencies in their mandate to fight crime. Enacting legislation that limits all interstate electronic activities related to DNA typing would be viewed by many as draconian, al- though it would be applauded by some concerned about privacy considerations. Limits or a ban on interstate transmission of DNA test results would not prohibit a State from storing DNA test results for crimes within its border, but cooperation with a neighboring State, for example, via a computer network of DNA results would be precluded.

Because population frequency databanking is largely uncontroversial from both the privacy and technological perspectives, as well as being considered necessary to improve and refine reporting of forensic DNA test results, legislation suspending interstate or FBI databanking activities related to population frequency activities would likely cripple forensic DNA analysis nationwide.

A moratorium directed solely toward the FBI's nationwide investigative DNA databank could allow time for a full public discussion of important issues, not only those pertinent to 
privacy but also technology-related considerations, including those involving standardization (see following section). But it might also be viewed as an unnecessary delay because the FBI plans to store just DNA profiles involving its system, which currently involves only noncoding, nondisease-linked DNA. A prohibition on FBI activities in this area would deny the law enforcement community the opportunity to implement what it sees as the one of the chief utilities of DNA typing and a computerized network of profiles: the ability to link an unknown biological sample from a crime scene to a specific individual.

Although legislation that specifically precludes FBI investigative databanking efforts might not limit State efforts per se, if States had to provide the telecommunication and, especially, the indexing capabilities necessary for interstate transmission of test results, the costs of the system could outweigh the perceived benefits. Further, absent the FBI, there would be no clear coordinator of interstate database activities-for prototype development or implementation. It is unlikely that the States could successfully implement an investigative DNA databank without Federal support. Thus, adopting this option would at some level hinder DNA analysis as an investigative tool of law enforcement and effectively eliminate its utility for cross-jurisdictional purposes.

\section{Option 3: Encourage Federal and State DNA databanking activities.}

Congress could directly encourage DNA databanking by appropriating funds to the Department of Justice, State and local governments, or both. Such funds could be for investigative datafiles or for improved data collection on population frequency information related to DNA typing. The Federal Government, through efforts of the FBI, has an interest in collecting broad-based information to ensure accurate population frequency data for RFLP analysis of forensic samples. Congress could direct funds to State and local laboratories doing DNA typing that would facilitate the collection and transfer of individual laboratories' genetic population frequencies to the FBI or its designee. Improved population genetics data enhances DNA analysis of forensic samples. Further, FBI implementation of a national investigative DNA profile databank would benefit from close coordination with States in gathering this information. Encouraging immediate implementation of electronic storage and transmission of DNA typing results for investigative purposes would be opposed by many - on privacy and technical grounds - and would require concurrent examination of two other policy issues: standardization for databanking and privacy considerations.

\section{Standardization for Databanking}

Whether or not Congress takes action to intervene in database development for forensic uses of DNA analysis, the issue of standardization could warrant attention. Standardization is an issue distinct from setting standards to achieve quality services. It involves developing a uniform, national system of certain techniques to make DNA analyses compatible for exchange through computer data systems across the 50 States. An effective, nationwide database will depend on standardization and quality control of both the test and the computer technologies necessary to extract and transmit DNA information. Without standardization, the potential for databanking will be limited unless each organization conducting DNA tests collects the same type of information. Devising an institutional means to settle on standardized data is generally agreed as critical to a successful national DNA databank, although a few would argue that methods could possibly be developed to apply conversion factors to data not obtained through the standardized protocol. Thus, the issue is whether the Federal Government should promote standardization of DNA testing to improve data collection, which would make DNA databanking further amenable for investigative use.

\section{Option 1: Take no action.}

Several factors currently operate to encourage standardization even in the absence of congres- 
sional action. Because of the high interest in establishing a network of DNA profiles for investigative purposes, the incentive is high to standardize. Still, of the two crime laboratories doing onsite DNA testing as of August 1989, one had adopted the Lifecodes methodology, but the other was switching from Lifecodes' to the FBI system.

If Congress takes no action, it is likely that the current FBI system and future refinements of it will become the de facto system in the United States. Several organizations favor adopting the FBI's testing system so that a national DNA profile databank can be achieved. Furthermore, the FBI also provides two services that encourage standardization using their system: They currently conduct tests on State and local specimens at no charge, and they offer free training in their testing methods for State and local laboratories who choose to establish DNA testing capability onsite.

\section{Option 2: Appropriate funds for States contingent on adoption of standardized technology.}

Congress frequently uses incentives to encourage certain results from States. Congress could allocate funds to speed the penetration of DNA testing and databanking throughout the country, could tie such grants to quality assurance, and could make those funds available only to States or localities that agreed to use them for specific types of testing materials and computer hardware and software. This action would both encourage the quality and standardization necessary for successful databanking and provide Federal funds for forensic uses of DNA typing in jurisdictions perhaps otherwise unable to afford it. It might also have the effect, however, of locking States into a testing technology that could soon become outdated, and could be viewed as micromanagement of State criminal justice affairs. This effect might be mitigated by delegating to the FBI the authority to regulate standardization of the initial technology selection and future alterations, rather than standardizing DNA forensic analysis through legislation.
Option 3: Direct the FBI to deny NCIC access to States that fail to implement a technology according to a standardized protocol.

Since NCIC exists by legislative authority, Congress could enact legislation specifying theterrns by which its services are made available to the States. Depending on the perceived importance of DNA testing to criminal justice, total or partial access to NCIC could be predicated on compliance with standardization. At one extreme, Congress could direct the FBI to deny access to all NCIC files, including fingerprint, vehicles, or other files, to any State that fails to comply with federally directed DNA standardization. Or Congress could direct the FBI to construct NCIC files to hold only standardized information and make no provisions for handling nonstandardized data. Such an action would deny the use of DNA files to States that fail to standardize, while allowing them to have continued access to other NCIC files.

\section{Privacy Considerations}

Civil liberties and privacy considerations are important policy issues often raised separately in the context of genetic information or computer technologies. Forensic applications of DNA typing involve both. Although the question of standards for forensic DNA analysis is the most pressing issue in this field, policy decisions by Congress and the executive branch on privacy considerations loom and are likely to be more controversial.

Citing the inherent intimacy of genetic information, the current and developing ability to test for personal information other than unique identity, and the difficulties of maintaining confidentiality in a computer network, experts raise concerns that genetic information could be used unfairly to deny future benefits to persons with criminal records, and that genetic profiling within the criminal justice sphere could lead to wider testing and broader threats to privacy. And the probability that DNA will be stored in some form, in addition to test results, heightens concern about an increased likelihood that 


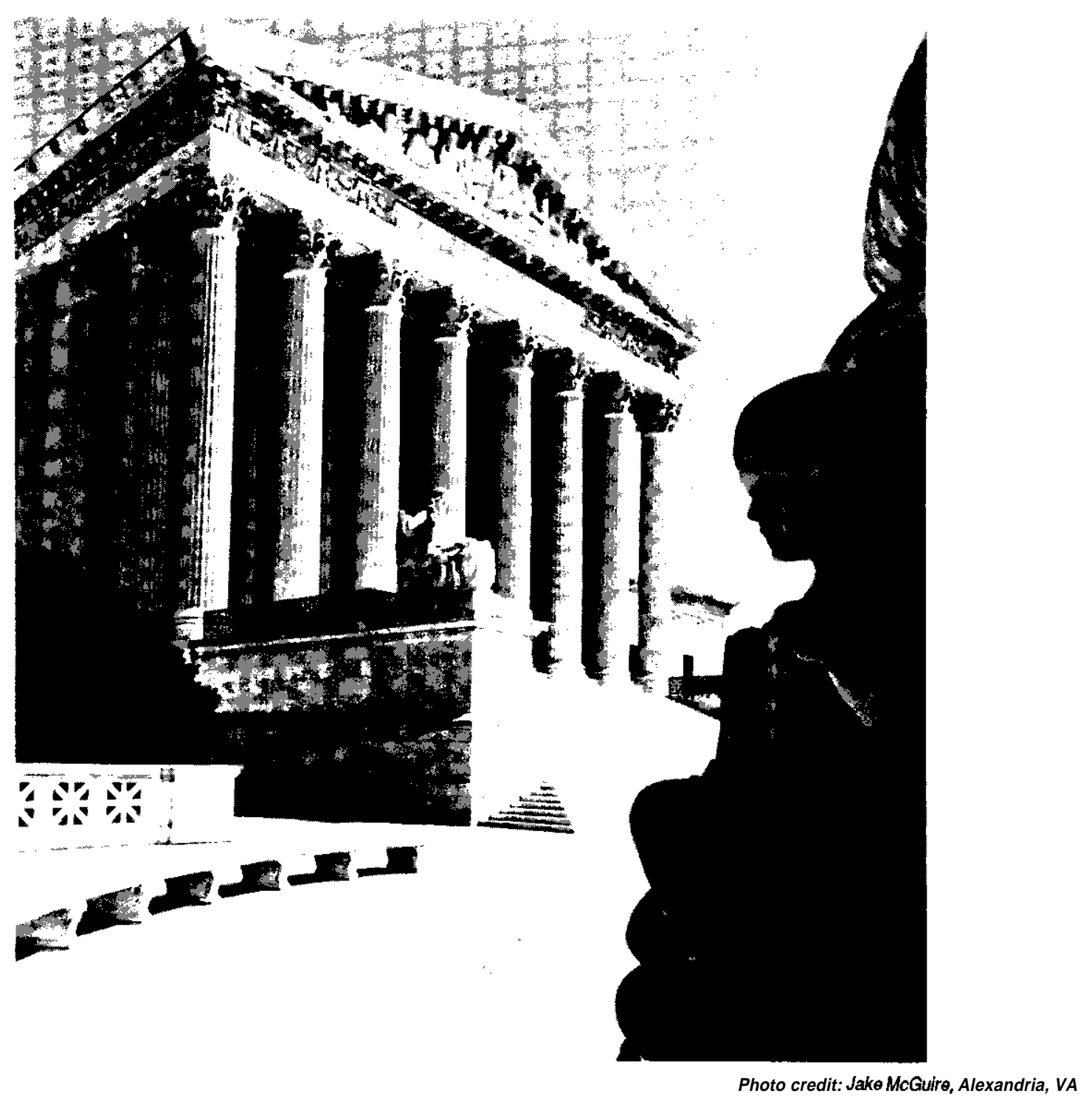

stored DNA will eventually be probed for genetic information beyond identity.

\section{Option 1: Take no action.}

By taking no action, Congress delegates to the FBI and State and local governments several civil liberties decisions: Specifically, the appropriate level of privacy protection to be afforded the collection, use, and storage of DNA data or samples. Since existing privacy laws and regulations among these jurisdictions differ widely, their application to DNA records will span the range of privacy that States currently provide for other types of criminal records-from closely held within the criminal justice community to freely available to the public. State laws passed and proposed to collect material for DNA typing from individuals and to store samples, results, or both also would continue and will vary from jurisdiction to jurisdiction.

Option 2: Establish a commission to study the privacy considerations related to collection, use, and storage of genetic information and material.

The specter of a de facto, widely accessible national database indexed by a genetic identifier and containing personal genetic information 
attends most proposals for genetic databanking, whether the proposal addresses forensic applications of DNA tests, medical diagnostics, or efforts to map the human genome. Concerns raised about genetic databases evolve from a strong tradition of protecting individual liberty and compete with arguments supporting the utility of genetic databanking. Congress could establish a commission to study the broader social implications of DNA databanking. Since only preliminary steps have been taken to establish genetic databanks within the law enforcement community, a study of these competing concerns, which could be designed to merely clarify the issues or to try to reach consensus on them, could be a timely and useful addition to the debate. A commission charged with examining privacy considerations of collecting, using, and storing genetic information could also evaluate privacy issues about DNA testing proposed beyond criminal justice applications, including, for example, typing military personnel or DNA typing as a tool for missing children.

By taking a lead in fostering discussion about these issues, Congress could preempt some criticism that DNA databanking proceeded without adequate consultation of the public. Unless the commission acted in a timely manner, however, Federal and State endeavors would continue unabated. And, depending on the outcome of the commission's work, State efforts and conclusions could be preempted.

Option 3: Allow DNA test results to be databanked, but prohibit storage of DNA.

One particularly acute civil liberties concern is that current and future DNA-based tests for genetic diseases and predispositions will be used on forensic samples and their results stored in Federal or State computer databases. In particular, the probability that DNA samples will be stored in addition to test results heightens concern about the increased likelihood that stored DNA samples will eventually be probed for genetic information beyond identity. Congress could enact legislation that expressly allows only planned FBI efforts to databank RFLP patterns for identification purposes to proceed, but that limits from whom samples can be taken for analysis and prohibits DNA sample storage by the FBI and other forensic facilities.

Such legislation could be perceived by many as a step to ensure that personal genetic information beyond DNA profiles does not find its way into centralized computer data files that could have adverse effects on an individual's future, including employability or insurability. Scientific and technological developments in molecular biology and genetics, including efforts to map and sequence the human genome, are proceeding rapidly, however. Prohibiting law enforcement officials from storing DNA would preclude them from applying new technologies or probes to reprofile individuals with state-of-theart methods. Further, crime scene samples are presently retained by each jurisdiction until their value as evidence no longer exists. Because today's technology allows near-permanent storage of some types of suspect or victim evidence, distinguishing between storing actual DNA and storing evidence containing DNA is impossible. Thus, Congress might need to consider a timeframe beyond which evidence samples could not be stored, which could hamper criminal investigations. Finally, restricting DNA storage could result in a databank of information locked into a dinosaur technology, or one with varying profiles depending on when an analysis was performed.

Option 4: Limit the type of genetic information that can be stored in federally supported systems.

Opponents of DNA databanking frequently cite the ability of DNA tests to reveal more than unique identity-e. g., genetic conditions, predisposition to diseases, or, in the future, behavior characteristics - as a primary reason for their objections. They fear that identity testing could lead to full probing of an individual's DNA samples, with subsequent storage of sensitive, medically informative details in databanks that 
cannot or will not be protected from unauthorized access.

Congress could enact legislation to prohibit the FBI from supporting storage or transmission of the results of DNA tests that probe anything other than portions of the human genome that are both noncoding and not associated with disease genes. (Both criteria, because many noncoding, 'junk' regions of DNA can be medically informative). Racial or ethnic identifiers could remain in the system, if Congress deems such distinctions as important for population statistics or other purposes. Details that could be precluded as DNA probes become available range from health factors to eye color.

Legislation that specifically precluded the FBI or any Federal entity from participating in the interjurisdictional transmission of results of DNA tests for anything other than noncoding, medically uninformative DNA might assuage the fears of some. Currently, the FBI uses only DNA analyses that test nondisease-linked DNA, thus such legislation would have no ill effect on the FBI's intentions to employ DNA databanks as investigatory tools. If Congress adopts this option, it would also limit the utility of storing DNA samples except to the degree that they were saved to accommodate technical advances in identity testing. On the other hand, limiting information only to noncoding DNA patterns could hinder law enforcement efforts as scientists elucidate genetic details such as eye color or hair color. Confining electronic storage to just "junk" DNA also would prevent the use of many well-characterized and highly polymorphic genetic markers that are not noncoding sequences, but that could be of significant use in forensic DNA analysis.

Option 5: Place more stringent restrictions on access to genetic information stored in federally supported databanks.
The Freedom of Information Act does not compel the FBI to release sensitive personal information contained in criminal history files, but neither does the Privacy Act compel the FBI to keep such information confidential. The FBI has adopted regulations to protect the privacy of criminal history information, but compliance with these regulations is largely voluntary. In recent years, Congress has authorized Federal cooperation with criminal history checks on potential employees in several fields. The combined effect of existing law is to make it possible, if not likely, for employers, insurers, and noncriminal-justice government agencies to gain access to genetic information of persons with criminal records if such information is contained in the NCIC.

To ensure that information collected by the law enforcement community is used solely for intended uses, i.e., criminal justice identification or investigations, Congress could prohibit dissemination of genetic information stored in federally supported databanks outside the law enforcement community. Congress also could prohibit private contractors from possessing such data, and, in addition, could enact legislation to require the FBI to place special restrictions on access to genetic information and include sanctions for noncompliance-e. g., denying NCIC access to States that fail to abide by the guidelines for protection of genetic information. Singling out genetic information for specific limitations on dissemination would indicate that Congress believes genetic data to be special, requiring new or extended protection if placed in computer databanks. Adopting this option, however, would likely be viewed by some as unduly burdensome intervention in an area where adequate protection and restriction exists. 


\section{Chapter 2}

\section{The Technologies and Their Applications}

"Scientifically speaking, it's like discovering a new star. It's a breakthrough in our lifetime."

John Williams, Police Chief

Woodlawn, Ohio

Associated Press

Mar. 7, 1988

"Many times, today's science is tomorrow's fiction."

Hal Uhrig, Defense Attorney

Orlando, Florida

Apr. 17, 1989

"You can prove almost anything with the evidence of a small enough segment of time. How often in the search for truth the answer of the minute is positive, the answer of the hour qualified, the answers of the year contradictory. "

Edwin Way Teale $1899-1980$ 


\section{CONTENTS}

WHAT IS DNA?

HOW DOES DNA DIFFER FROM PERSON TO PERSON? . . . . . . . . . . . . ...42

WHAT TECHNOLOGIES ARE USED FOR DNA TESTING? . . . . . . . . . . 43

Restriction Fragment Length Polymorphism Analysis $\ldots \ldots \ldots \ldots \ldots \ldots \ldots \ldots \ldots . \ldots 4$

Polymerase Chain Reaction ........................................ 47

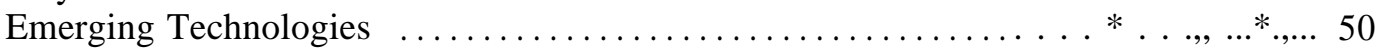

DNA TYPING: PRESENT AND FUTURE USES $\ldots \ldots \ldots \ldots \ldots \ldots \ldots \ldots \ldots \ldots \ldots \ldots \ldots$

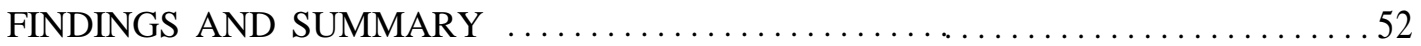

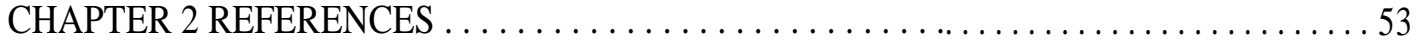

\section{Boxes}

2-A. Terminology ......................................... 41

2-B. DNA Differences in Humans: Variable Number of Tandem Repeats . . . . . . . . . 44

2-C. The Polymerase Chain Reaction: Step-by-Step . . . . . . . . . . . . . . . . . . . 49

2-D. Mitochondrial Genes and Forensic Identification $\ldots \ldots \ldots \ldots \ldots \ldots \ldots \ldots \ldots \ldots$

\section{Figures}

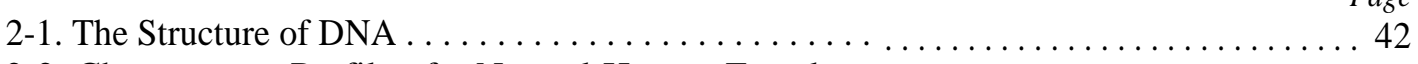

2-2. Chromosome Profile of a Normal Human Female ...................... 43

2-3. Detailed Schematic of Single-locus Probe RFLP Analysis .................... 45

2-4. DNA Patterns Using a Multilocus Probe . . . . . . . . . . . . . . . . . . . 47

2-5. DNA Patterns Using a Single-locus Probe . . . . . . . . . . . . . . . . . . . . . . . . 47

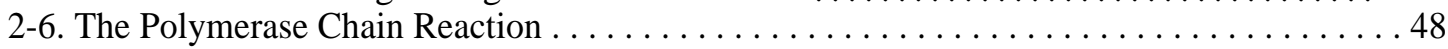

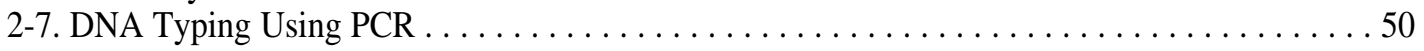

\section{Table}

2-1. Restriction Enzymes Currently Used in Forensic Tests ............................. 46 


\section{The Technologies and Their Applications}

Genetics is the study of factors that influence the inheritance of specific traits. People have recognized since time immemorial that like begat like, that individuals share familial features yet have distinct characteristics. In 1865, Austrian monk Gregor Mendel postulated that discrete biological units-geneswere responsible for both the maintenance and variation of certain characteristics from one generation to the next. Genetic uniqueness is a fact of life.

Historically, the thrust of research and applications in human genetics focused on medical uses, especially determination and diagnosis of genetic diseases. Since the turn of the century, however, forensic scientists have exploited human genetic variability in the analysis of evidence from crime scenes. Blood tests have been used as evidence in paternity disputes since the 1920s (18). Yet while these traditional genetic landmarks (often referred to as markers) have been useful for excluding suspects $(17,19,20,21)$, positive identification using these markers has been elusive because they occur in limited combinations. In contrast, much greater variation exists and can be detected with deoxyribo-

\section{Box 2-A-Terminology}

Forensic science involves the application of many scientific expertise (e.g., biology, chemistry, toxicology, medicine) to situations concerned with courts of justice or public debate. This report uses the term "forensic applications" to refer to potential uses of recombinant DNA technologies to identify individuals.

The increased acceptance and popularization of recombinant DNA techniques for forensic uses, especially criminal investigations, have led to some confusing terminology. In particular, some commentators have adopted the terms "genetic fingerprinting, " "DNA fingerprinting," or "DNA prints" as generic phrases to describe all techniques, while others use the terms to describe specific techniques by specific companies. This report uses the terms "DNA testing," "DNA identification," "DNA analysis, " "DNA typing," and "DNA profiling" to describe the two current and any future technologies-the practical goal of which is unique association or exclusion determined by DNA-based tests. SOURCE: Ofilce of Technology Assessment 1990. nucleic acid (DNA) markers-hence the potential for individualization (box 2-A).

This chapter briefly outlines the biological basis for using DNA to differentiate individuals, summarizes concepts of recombinant DNA technology, and discusses the two principle techniques currently employed in forensic applications. It also explores future recombinant DNA technologies that could be applied to forensic science. Finally, the chapter describes the wide range of nonmedical applications for which the techniques have or could be used. Other Office of Technology Assessment (OTA) reports address issues of related topics in human genetics and biotechnology $(57,58,59,60)$.

\section{WHAT IS DNA?}

Faithful transmission of genes is common to the entire spectrum of living organisms. It is the result of the remarkable capacity of a living cell to reproduce, encode, and translate a chemical into its ultimate biological fate. Except in rare instances, the chemical responsible for the maintenance and expression of inherited characteristics is DNA.

As the chemical dispatcher of genetic information, DNA's structure resembles a twisted ladder, referred to as a double helix (figure 2-1). DNA in all organisms consists, in part, of four chemical subunits commonly called bases. These four basesguanine $(\mathrm{G})$, adenine $(\mathrm{A})$, thymine $(\mathrm{T})$, and cytosine (C)-are the genetic alphabet. The bases normally pair predictably - A with $\mathrm{T}$, and $\mathrm{G}$ with $\mathrm{C}$ - to form the rungs of the double-stranded DNA helix, and these combinations are termed base pairs. Their unique order, or sequence, in the helix determines the structure of proteins and the regulation of cell activities. Regions of DNA not involved in such capacities, as far as can be determined, are called noncoding DNA.

In humans, DNA is associated with protein in organized microscopic bundles called chromosomes. Humans have 46 chromosomes-1 pair of sex chromosomes (two $\mathrm{X}$ chromosomes for females; an $\mathrm{X}$ and a $\mathrm{Y}$ for males) and 22 pairs of autosomes. Individuals receive 22 autosomes plus one $\mathrm{X}$ chromosome from their mothers, and 22 autosomes plus either an $\mathrm{X}$ or a $\mathrm{Y}$ from their fathers. Figure 2-2 
illustrates the chromosome profile of a normal female.

DNA in humans is found in all body cells except red blood cells. (Blood contains many cell types in addition to red blood cells, such as white blood cells, and it is from these cells that DNA can be obtained.) With few exceptions (that can only be detected through specific, sophisticated laboratory methods), the composition of a person's DNA does not vary from cell to cell, except in egg and sperm cells. These cells have half the complement of DNA present in other body cells.

Thus, a forensic scientist can examine DNA from blood (35) or tissue from hair roots and, if the specimens are form the same person, find the same patterns. Similarly, DNA patterns can be matched between DNA isolated from sperm on a vaginal swab or semen stain and DNA from a rape suspect's sample. With semen, the DNA composition differs from sperm-to-sperm, but the DNA profile is a composite of thousands of DNA molecules from thousands of sperm and therefore reveals a man's overall profile (24).

\section{HOW DOES DNA DIFFER FROM PERSON TO PERSON?}

Virtually the entire complement of genetic material resides in an individual's chromosomes. This complement, or genome, consists of about 3.3 billion base pairs. Only a fraction of these 3.3 billion base pairs in each person differ between any two individuals (approximately 3 million on average). The challenge to forensic DNA analysis is to detect some of these differences.

To find these differences, scientists rely on the fact that "addresses" can be assigned for genes or DNA sequences. An address, or physical location, of a gene or sequence on a chromosome is called its locus (from Latin for place). Chromosomes contain many loci occupied by different genes or DNA sequences. For example, the locus for the gene responsible for sickle cell anemia is on chromosome 11 , and the locus for cystic fibrosis is on chromosome 7. Except for the sex chromosomes, normal individuals have two copies of any given gene or sequence at a particular locus because human chromosomes come in pairs-one copy inherited from the mother and one from the father.
Figure 2-I-The Structure of DNA

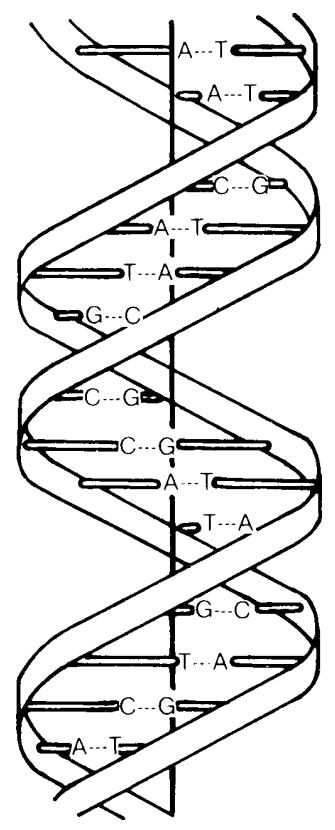

SOURCE: Office of Technology Assessment, 1990.

Genetic variants at a particular locus are called alleles. At each locus along pairs of autosomes, an individual can have two identical, or two different, alleles. If the alleles are the same, the person is said to be homozygous for that particular locus. If the versions differ, the person is said to be heterozygous.

Even though one individual has at most two alleles at a given locus-again, one copy inherited from the mother and one from the father-additional forms can exist in other individuals. That is, many different alleles can exist for that same locus within the population. When multiple alleles exist at a particular locus - as in the case of the common ABO red blood cell typing system - the genetic variant is referred to as a polymorphism. Polymorphisms (i.e., genetic differences among people) are at the heart of forensic applications of DNA typing.

Some addresses (loci) in humans have as many as 50 to 100 different forms (alleles). DNA tests are designed to detect these highly polymorphic loci and to distinguish among the alleles that exist there. DNA analysis does not examine an individual's entire genome, but rather a snapshot of a specific area. And because DNA from any two individuals is more alike than different, relatives or unrelated persons can share the same allele or alleles at any 
Figure 2-2-Chromosome Profile of a Normal Human Female
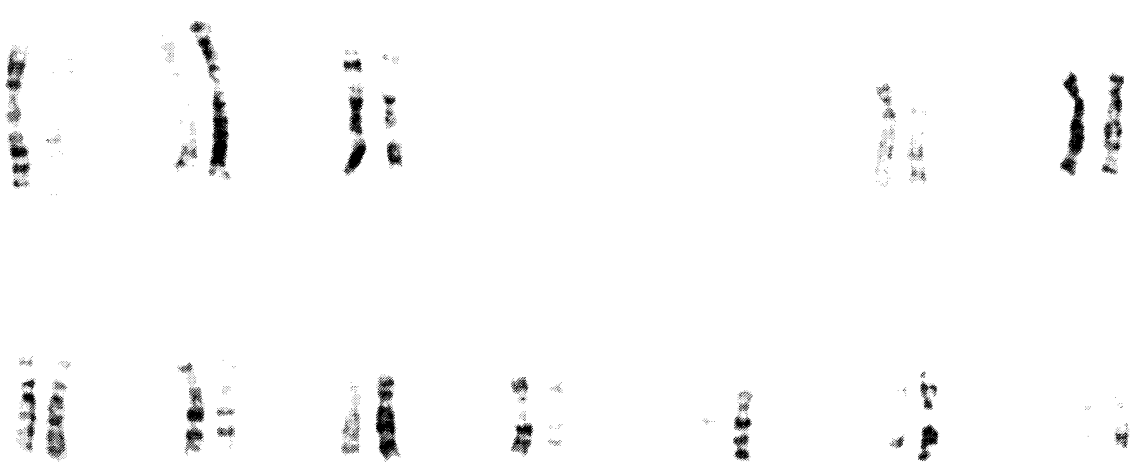

*
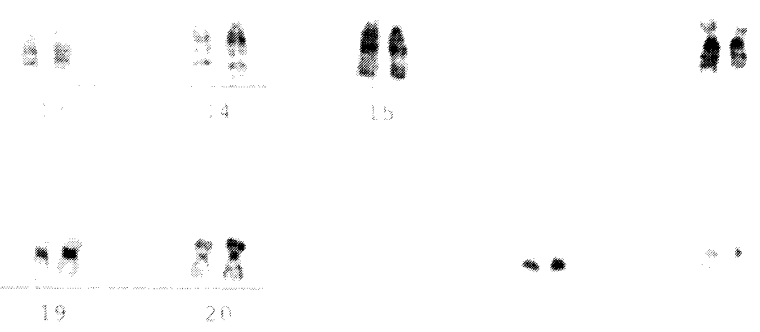

...
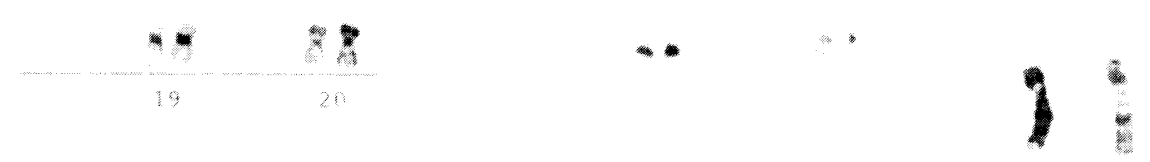

Chromosomes from humans can be matched into 22 pars (the autosomes) plus one pair of sex chromosomes. In this figure, both sex chromosomes are X. A normal male chromosome complement would include the 22 pairs plus an $X$ and a $Y$. One of each type of autosome (1-22) is inherited from an individual's mother, and one from the father. Chromosome profiles such as this one do not reveal which particular chromosome within the pair derived from which parent.

SOURCE: The Genetics \& IVF Institute, Fairfax, VA, 1990.

given locus-even highly polymorphic loci. Thus, forensic uses of DNA tests depend on examining several loci to determine whether DNA types from two different samples match.

\section{WHAT TECHNOLOGIES ARE USED FOR DNA TESTING?}

DNA testing technologies encompass an array of molecular techniques developed since the early 1970s, and designed to examine the detailed structure, function, and inheritance patterns of DNA. Applications of two of these technologiesrestriction liagment length polymorphism (RFLP) analysis and amplification of DNA by polymerase chain reaction (PCR)-have found their way into courtrooms in the United States and abroad. RFLP analysis is most widely used, although PCR, which is combined with other genetic techniques in foren- sic analysis, has been used in some casework (see app. A).

\section{Restriction Fragment Length Polymorphism Analysis}

Examination of DNA from individuals, other than identical twins, reveals that variations in DNA sequence occur, on average, about once every thousand base pairs. These variations exist in both coding and noncoding regions of DNA, and although most do not lead to functional changes in the protein products of genes, a few can cause disease. In 1978, two scientists demonstrated this phenomenon by showing that a DNA sequence was altered in certain individuals, and that this change in the DNA correlated with the inheritance of sickle cell disease (34). 
This important discovery led researchers to propose that these natural differences in DNA sequence @ polymorphisms) could be used as markers to track genetic traits through families $(5,32)$. Further research revealed that a specific DNA pattern could be associated with a specific individual-to the extent of positive association $(23,29,30,31,66)$. Although initial research looked at changes associated with disease genes, the majority of the DNA variations now identified, including the majority of markers used in forensic identification, are not linked to disease.

How were these markers discovered and subsequently exploited? At the core of detecting the types of DNA polymorphisms just mentioned are enzymes called restriction endonucleases, or restriction enzymes. Sometimes characterized as molecular scissors, each type of restriction enzyme recognizes a short DNA sequence specific for that enzyme and cuts DNA only at that site. RFLP analysis uses these enzymes to uncover genetic variants. In forensic applications, RFLP analysis detects size differences of DNA fragments at specific loci (box 2-B) $(29,30,46,64,65,66)$. It does not directly reveal sequence differences.

Scientists call the basic procedure used in RFLP analysis 'Southern blotting' or 'Southern hybridization,' after the person who developed the technology (54). Generally speaking, it includes the following major steps (figure 2-3):

- isolating DNA from the specimen to be examined;

. cutting the DNA into discrete pieces with a restriction enzyme;

- separating the different sized DNA pieces using a process called gel electrophoresis;

- transferring the DNA from a gel to a nylon membrane (producing the "Southern blot' ');

- applying, or hybridizing, a DNA probe to the membrane; and

\section{Box 2-B-DNA Differences in Humans: Variable Number of Tandem Repeats}

Comparison of two randomly chosen individuals' DNA yields many more similarities than differences, but scientists have identified some of the loci where genetic variation exists. Some variants, or polymorphisms, are single-base pair alterations. Other loci involve more base pairs and take on many forms. In forensic uses of DNA tests, this latter type of polymorphism is most important.

In 1980, scientists discovered that short, identical segments of DNA lined head to tail in a repeating fashion are interspersed throughout the genome. Both the number of base pairs and the actual DNA sequence that comprise the repeated unit can vary from locus-to-locus and chromosome-to-chromosome. Some variants are found at multiple loci, others at only one site--a single-locus-in the human genome, Most importantly, the number of repeated units varies between individuals. Such sequences, or regions of repeated units, are called variable number of tandem repeats, or VNTRs. VNTRs account for the size differences that can be measured by RFLP analysis, and the wide variation in the number of repeats within the human population at VNTR loci is the critical element for forensic DNA analysis. (Single-locus v. multilocus RFLP analysis is described in a following section.)

For example, one VNTR in humans consists of a 17-base pair unit repeated from 70 to 450 times at one locus in the genome. Thus, the total number of base pairs would vary from 1,190 (17 x 70) to 7,650 (17 x 450), Because chromosomes come in pairs (one inherited from the mother and one from the father), individual A could have 74 repeated units at one locus and 300 repeats at the other, yielding two measurable bands in a RFLP analysis. Individual B, a sibling, might also have 74 repeats at one locus, but the other chromosome might have 145 repeats, which would yield a RFLP pattern with one similar and one divergent band. An unrelated individual C might have repeats of 83 and 216. A forensic scientist measures size differences at this locus, not direct sequence variation, to identify the distinctions in the DNA patterns of these individuals.

However, the number of forms (alleles) of a VNTR at a particular locus is limited. Siblings D and E, for example, could be expected to have the same pattern at this particular locus 25 percent of the time if both parents are heterozygotes. Similarly, unrelated individual F could, by chance, share either or both fragments in their pattern. Thus, a DNA fragment pattern derived from examining one locus does not enable the individualization of a DNA specimen. Rather, the power of DNA testing results from analyzing several VNTR loci throughout the human genome. A number of people will have the same fragment at one VNTR locus, but the chances of more than one person having the same combination of DNA fragments when 4,5, or 6 different VNTR loci are analyzed becomes vanishingly small. Combining the data from each of these snapshots is one of the keys to statistically positive association. 
Figure 2-3-Detailed Schematic of Single-locus Probe RFLP Analysis

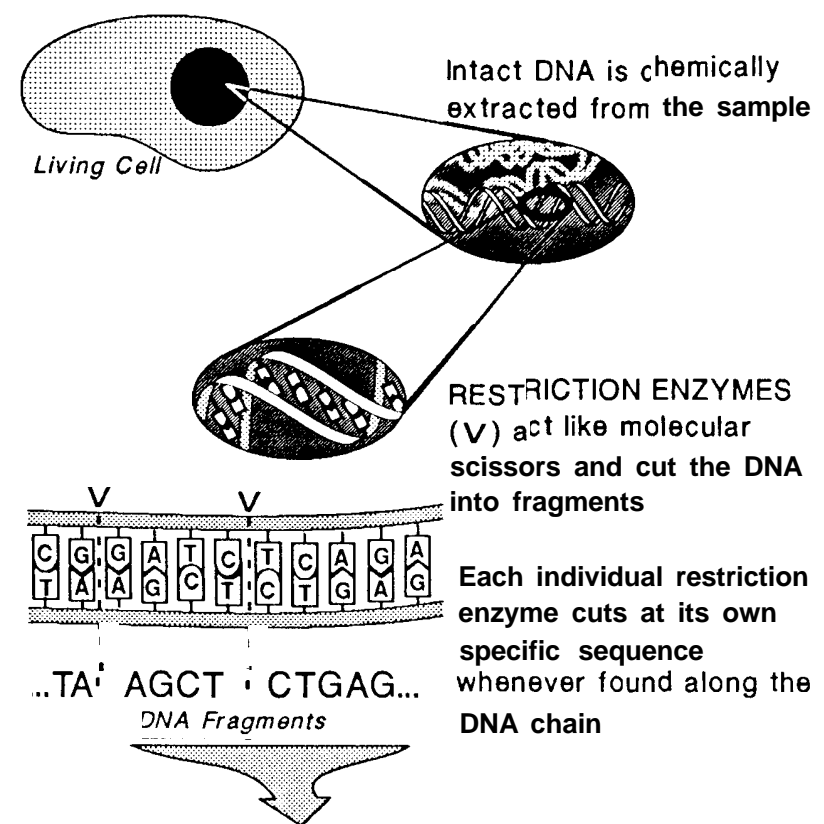

Single-locus probes with varied sequences exist and key with areas of specific DNA.

One single-locus probe PROBE

is made radioactive, Many copies of the probe are used to combine with a specific DNA sequence on the nylon membrane.
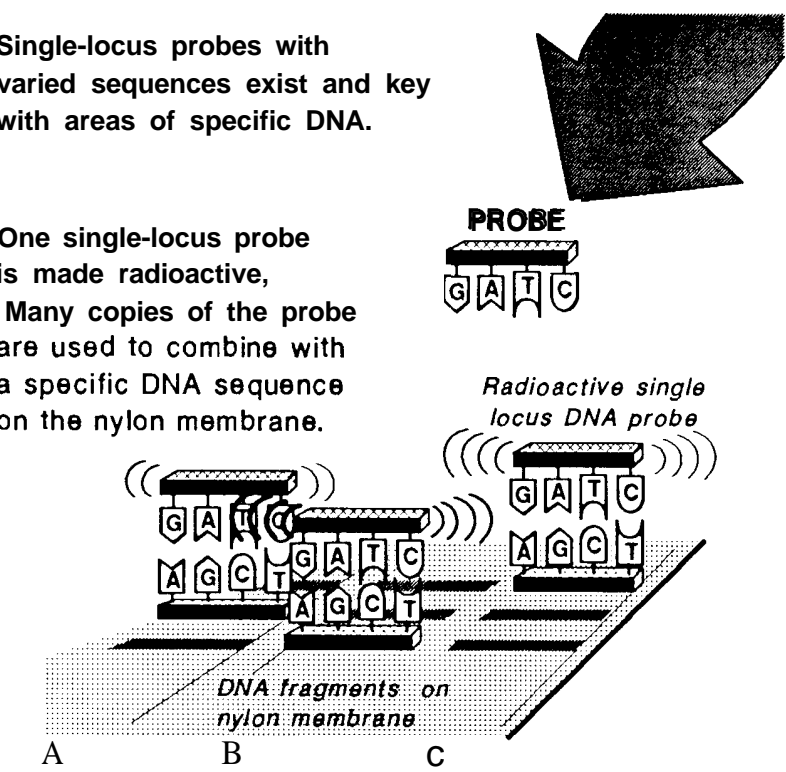

$X$-ray film is placed over the membrane to detect and image the radioactive probe pattern.

A

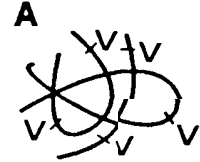

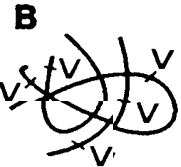

C

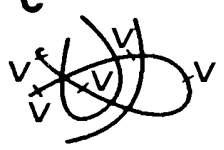

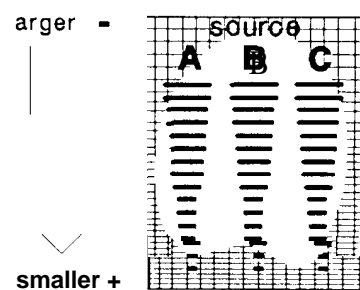

ELECTROPHORISIS The DNA fragments are separated by size into bands in a gel

Gel

(screening by size)

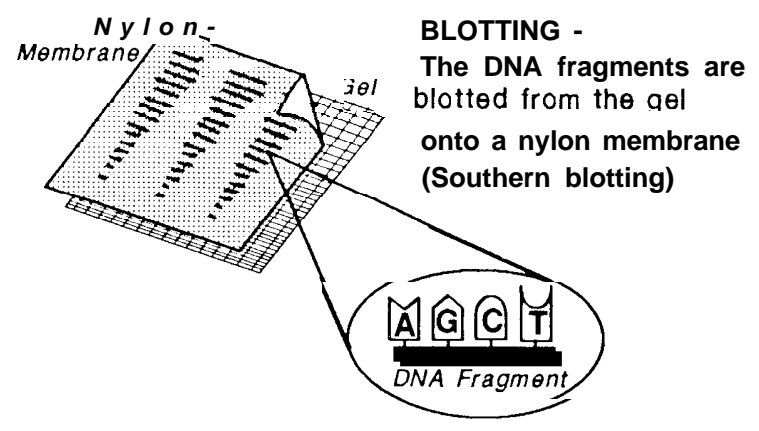

SOURCE: Office of Technology Assessment, 1990.

Using different probes in sequence demonstrates whether the specimen sample matches the suspect type.

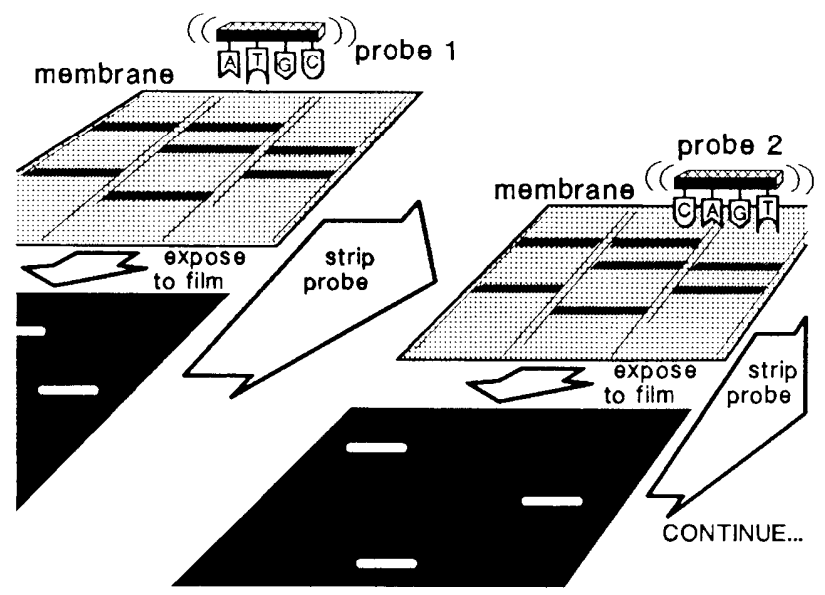

SINGLE-LOCUS PROBE PATTERN Suspect Victim Evidence

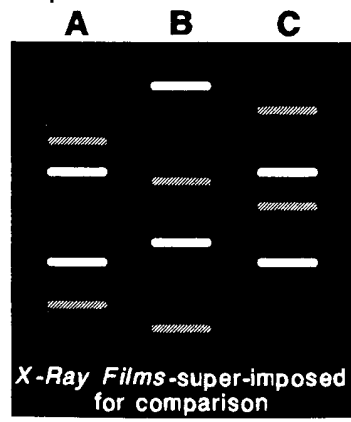

When using single-locus probe analysis one must use different probes to obtain identity. 
- visualizng the location of the probe's hybridization, and hence the DNA pattern-for radioactive probes, usually by exposing the membrane to x-ray film, a process called autoradiography.

DNA Isolation and Restriction Enzyme Digestion

Proper sample collection and storage of evidentiary materials are critical for successful forensic RFLP analysis. Various environmental factors can affect the quantity and quality of DNA isolated from evidentiary stains, sometimes leading to degradation, or breakdown, of the DNA in the sample $(43,44)$. Successful RFLP analysis in forensic casework hinges on obtaining large, intact (high molecular weight) DNA from case specimens.

Once isolated, a small amount of the sample is generally tested to ascertain the general quality and quantity of the DNA. If both are sufficient, a portion of the DNA is then cut, or digested, into discrete flagments with a specific restriction enzyme. This step, digestion with a particular restriction enzyme, is the first element in establishing a DNA profile based on size polymorphisms. Using different enzymes leads to different DNA patterns for the same individual. At this time, RFLP systems used by the two major commercial laboratories and the Federal Bureau of Investigation (FBI) each rely on different restriction enzymes (table 2-1). (See chs. 3 and 5 for discussion of standardization.)

\section{Gel Electrophoresis and Southern Transfer}

Because DNA digested with a restriction enzyme creates thousands of DNA fragments ranging in size from a few to tens of thousands of base pairs, the pieces must be separated by size through a process called gel electrophoresis. In this process, the mixture of DNA fragments is placed in a semisolid

Table 2-I-Restriction Enzymes Currently Used in Forensic Tests

\begin{tabular}{|c|c|c|}
\hline Laboratory & Enzyme & $\begin{array}{l}\text { Basic DNAsequenoe } \\
\text { recognized }\end{array}$ \\
\hline Cellmark ........ & Hinfl & $\begin{array}{l}\text {---GANTC---" } \\
\text {---CTNAG--- }\end{array}$ \\
\hline FBI $\ldots \ldots \ldots \ldots$ & Haelll & $\begin{array}{l}\text {---GGCC-- } \\
\text {---CCGG-- }\end{array}$ \\
\hline Lifecodes . . . . . . & Pst I & $\begin{array}{l}\text {---CTGCAG--- } \\
\text {---GACGTC--- }\end{array}$ \\
\hline
\end{tabular}

${ }^{\mathrm{a}} \mathrm{N} / \mathrm{N}$ represents any base pair.

SOURCE: Office of Technology Assessment, 1990. matrix, called a gel, and exposed to an electric field. Because the chemical makeup of DNA gives it a net negative charge, the DNA fragments travel through the pores in a gel toward a positive electrode. The gel acts as a sieve, with large DNA fragments moving more slowly than small ones. Thus, the mixture is separated, or resolved, according to size. In RFLP analysis of human DNA, the numerous fragments are laddered continuously along the entire length of the gel, and any single DNA fragment cannot be visualized without further effort.

After a period of time, the electrophoresis is stopped and the DNA transferred out of the gel onto a nylon membrane in a process called Southern transfer. The nylon membrane, or Southern blot, retains the DNA in the orientation obtained in the gel after electrophoresis.

Forensic applications with RFLP analysis currently employ a substance called agarose to form the gel foundation. Small DNA fragments can be separated through another substance, acrylamide, and advances in the method could increase use of this material in forensic casework (2).

Probe Hybridization and Fragment Visualization

After the nylon membrane has been prepared, DNA patterns are revealed by using molecular tools called probes. Probes are short, single strands of a known DNA sequence. Scientists adjust conditions so that probes will seek out and bind, or hybridize, to their complementary sequence among the thousands of sequences that exist on a nylon membrane. For example, a probe with the sequence -G-A-T-CC-T-A-C-G-T-C-C-A-A- will find pieces of DNA on the membrane with its complementary sequence -C-T-A-G-G-A-T-G-C-A-G-G-T-T-.

Thus, DNA probes can be thought of as reporter molecules that seek out and bind to their complementary sequence on the Southern blot. DNA probes in forensic RFLP analysis are typically tagged with a radioactive label. This radioactive label facilitates the visualization of the particular fragment of DNA that the probe bound to on the Southern blot. By exposing the nylon membrane, or blot, to apiece of $\mathrm{x}$-ray film (or other detection system) after hybridization of the probe, scientists can determine which specific fragment the probe identified from among the thousands in a sample of human DNA. The fragment detected by the probe is actually visualized 
as a dark band on the transparent x-ray film. Its size can be approximated by comparing it to pieces of DNA of known length that were electrophoresed on the gel along with the sample.

In addition to the restriction enzyme used, probes are the second key element in determining what an individual's DNA profile will look like-i. e., polymorphisms are detected by particular restriction enzyme-probe combinations. For example, if restriction enzyme A and probe A are used on a DNA sample, two restriction fragments might be revealed, one 250 base pairs in length, the other 600 . Restriction enzyme A and probe B might detect a different polymorphism, yielding fragments of 2,300 and 900 base pairs for the same individual. Similarly, a third pattern-fragments of 370 and 450 base pairsmight be revealed by restriction enzyme $\mathrm{B}$ in combination with probe $\mathrm{A}$. Choice of restriction enzyme and probes affects the DNA banding pattern of each individual's DNA sample. Hundreds of probes exist; several are used in forensic casework. Chapter 3 discusses issues surrounding the number and types of probes that are most appropriate for use in DNA profiling, as well as protocols for determining whether two DNA fragments are of equivalent size.

Two classes of probes are used in forensic applications of RFLP analysis. Multilocus probes recognize and bind to several locations throughout the human genome and reveal a complex DNA banding pattern (figure 2-4). In 1985, a case in the United Kingdom used multilocus probe analysis and became the first use of a DNA technology in a forensic case (29). Multilocus probe analysis in the United States is used by one company, which confines it to paternity examinations (although it has great potential for use in veterinary and agricultural applications). The second class of probes used in forensic RFLP analysis identities a unique genetic address, or single locus. Under defined conditions, single-locus probes generally identify one, two, or a few bands out of the thousands bound to the Southern blot (figure 2-5). Single-locus RFLP analysis is currently the most widely applied DNA technology in forensic casework in the United States.

\section{Polymerase Chain Reaction}

The FBI estimates that DNA profiles using single10CUS RFLP analysis can be obtained from a fresh, dried blood stain approximately the size of a dime and a semen stain about the size of a pencil eraser
Figure 2-4-DNA Patterns Using a Multilocus Probe

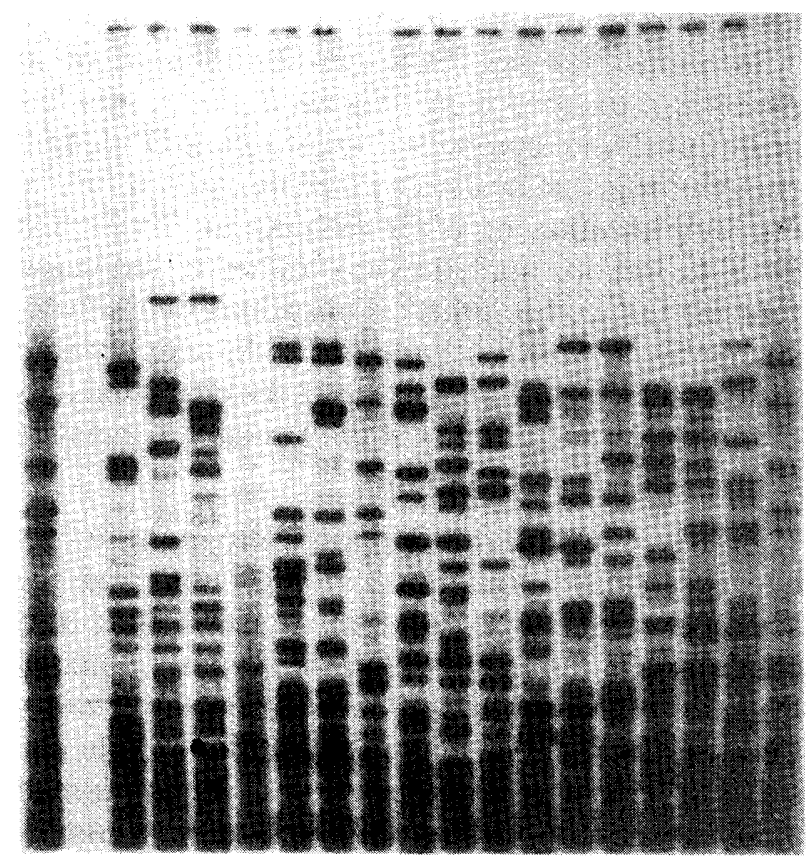

Autoradiogram of restriction fragment length patterns using a multilocus DNA probe (33.15).

SOURCE: Cellmark Diagnostics, Germantown, MD, 1990.

Figure 2-5-DNA Patterns Using a Single-locus Probe

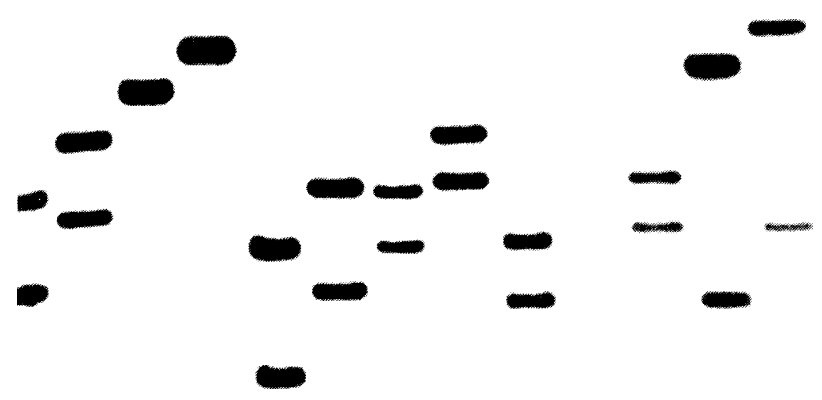

Autoradiogram of restriction fragment length patterns using a single-locus DNA probe (YNH24).

SOURCE: Federal Bureau of Investigation, 1988.

(36); others report success with smaller stains (22). Many forensic specimens, however, are smaller, aged, or have been exposed to extreme environmental conditions that damage DNA and make standard RFLP analysis uninformative. For these types of samples-when the quality and quantity of DNA is unsuitable for RFLP analysis-a different DNA technology, the polymerase chain reaction (PCR), $(45,50,51,52)$ can sometimes surmount these 
difficulties and permit the examination of biological evidence $(12,15,62)$.

In some respects, PCR can be thought of as molecular photocopying (figure 2-6). It uses repeated cycles to reproduce a target area of DNA until enough copies are available for analysis using Southern hybridization or other techniques. Thus PCR itself is not an analytic tool, rather it facilitates forensic (as well as other) applications by allowing a scientist to take a sample of DNA, which would generally be insufficient to detect the characteristics of the DNA, and amplify it until enough copies are available for further analysis.

Briefly, PCR involves using two specific sequences, called primers, that flank the area the scientist wants to copy. The scientist then sets conditions in the reaction that allow new copies of the DNA of interest to be produced from the primers. Because the products generated in one sample can serve as templates in the next cycle, the number of amplified copies doubles with each cycle. Thus, 20 to 25 cycles of PCR potentially yield about a millionfold reproduction (box 2-C).

Currently, one DNA region is being used in PCR applied to forensic specimens, the human leukocyte antigen (HLA) DQxct-1 gene, although several others are being examined for their potential utility in forensic casework $(12,15)$. The HLA DQ $x-1$ locus, like its related genes responsible for tissue transplantation rejection, is polymorphic, with 21 different typing possibilities detectable. Overall, the probability of distinguishing between two people chosen at random using this system is 93 percent (62). In contrast, the probability using the conventional red blood cell typing system is 60 percent $(1,53)$.

The HLA DQ $x$ - 1 system distinguishes people by detecting which genetic bases---G,A,T, arere present at certain sites in the allele, rather than measuring the size of DNA fragments, as in RFLP analysis. Instead of gel electrophoresis, the process in forensic casework employs what is called a" 'reverse dot-blot hybridization" (figure 2-7). Some argue that this method is more straightforward because the tests do not define alleles on the basis of size (i.e., mobility through a gel), but are theoretically designed to give "yes' ' $/$ 'no' answers. In practice, however, the results can require interpretation for some case samples (36). Finally, because PCR generates large amounts of DNA, analysis need not involve radioactive materials.
Figure 2-6-The Polymerase Chain Reaction
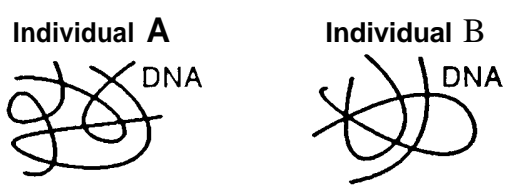

Unknown C

\section{AMPLIFICATION \\ (Molecular Photocopying of DNA)}

Each sample is amplified manually or in a machine.
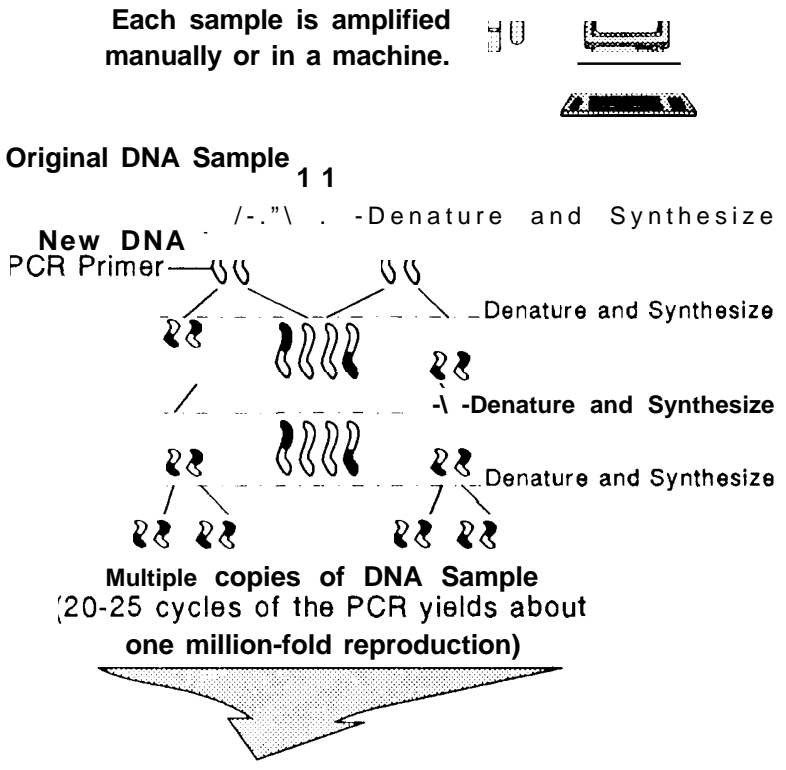

DOT BLOT
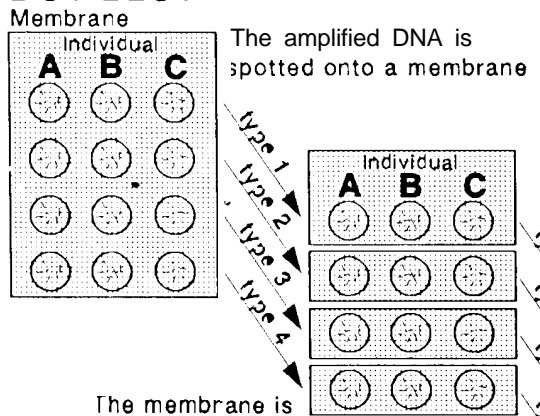

The membrane is challenged with a DNA probe that has a key sequence specific to an HLA DQ-Alpha Allele.

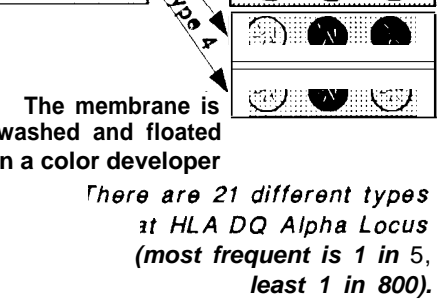

SOURCE: Office of Technology Assessment, 1990. 


\section{Box 2-C-The Polymerase Chain Reaction: Step-by-Step}

As mentioned earlier, for the most part, all body cells contain the same DNA. Thus, DNA molecules in cells must regenerate copies of themselves each time a cell divides. DNA in all living cells continuously reproduces through a process called replication. During this process, the original strands in the DNA double helix unwind and serve as templates for the building of new, complementary strands, resulting in two identical copies of the original DNA molecule.

The polymerase chain reaction (PCR) is an in vitro technology based on the principles of replication. First described in 1985, PCR is now widely performed in research and clinical laboratories, and many see it as a critical DNA technology for forensic identification.

PCR involves the repeated duplication of a specific area of DNA. For example, consider the following sequence of DNA to be amplified using PCR:

$$
\begin{aligned}
& \text {-T-T-C-G-A-T-G-G-A-T-A-A-A-C-C-G-A- } \\
& \text {-A-A-G-C-T-A-C-C-T-A-T-T-T-G-G-C-T- }
\end{aligned}
$$

In order to perform PCR, the sequence of the DNA at both ends of the region of interest must be known, and their complimentary sequences available as short pieces of purified DNA called primers. One primer must be complementary to the end of one strand the second to the opposite end of the other strand. In this case, the primers would be $-A-A-G-C$ for the top strand of DNA and $-C-C-G-A$ for the bottom strand. These two specific sequences flank the area the scientist wants to copy, and serve as the foundation to which bases can be added and the DNA strand copied. In PCR, the temperature of the sample containing the DNA to be amplified is raised to about $95^{\circ} \mathrm{C}$, which results in the separation, or melting, of the double helix to yield single-stranded pieces:

$$
\text { -T-T-C- G-A-T-G-G-A-T-A-A-A-C-C-G-A- }
$$

$$
\text { -A-A-G-C-T-A-C-C-T-A-T-T-T-G-G-C-T- }
$$

Copies of the primers are then allowed to hybridize to the DNA of interest, by lowering the temperature:

$$
\begin{aligned}
& \text {-T-T-C-G-A-T-G-G-A-T-A-A-A-C-C-G-A- } \\
& \text {-A-A-G-C+ }
\end{aligned}
$$$$
\text { -A-A-G-C-T-A-C-C-T-A-T-T-T-G-G-C-T- }
$$$$
+C-C-G-A-
$$

The scientist then sets conditions in the reaction that allow new copies of the DNA of interest to be produced from the primers (referred to as primer elongation). That is, DNA polymerase (a heat-stable version of the enzyme from Thermus acquaticus, a thermophilic micro-organism isolated from a hot spring in Yellowstone National Park) starts at the end of the primers and using bases $(\mathrm{G}, \mathrm{A}, \mathrm{T}, \mathrm{C})$ that are part of the reaction mixture, synthesizes complementary strands of each of the two single strands to yield two strands from the original one:

$$
\begin{aligned}
& \text {-T-T-C-G-A-T-G-G-A-T-A-A-A-C-C-G-A } \\
& \text {-A-A-G-C-T-A-C-C-T-A-T-T-T-G-G-C-T--- } \\
& \text {-A-A-G-C-T-A-C-C-T-A-T-T-T-G-G-C-T- } \\
& \text {---T-T-C-G-A-T-G-G-A-T-A-A-A-C-C-G-A- }
\end{aligned}
$$

Thus, one cycle of PCR has occurred, doubling the number of DNA copies from the original area of interest. After this first round of synthesis, and for each subsequent cycle, the temperature of the reaction is raised to approximately $95^{\circ} \mathrm{C}$ to separate the DNA strands. Primers are again allowed to hybridize to the strands, and DNA synthesis allowed to occur. After a second cycle of PCR, the two strands become four, and after 20 to 25 cycles of PCR, the original DNA sequence theoretically has been amplified about a rnillionfold. Generally, 20 to 30 cycles yield enough DNA to perform forensic analysis with one particular genetic locus, the HLA DQ $x$ - 1 locus. SOURCE: OffIce of Technology Assessment 1990. 
Figure 2-7-DNA Typing Using PCR

Reverse dot-blot. Fuller case
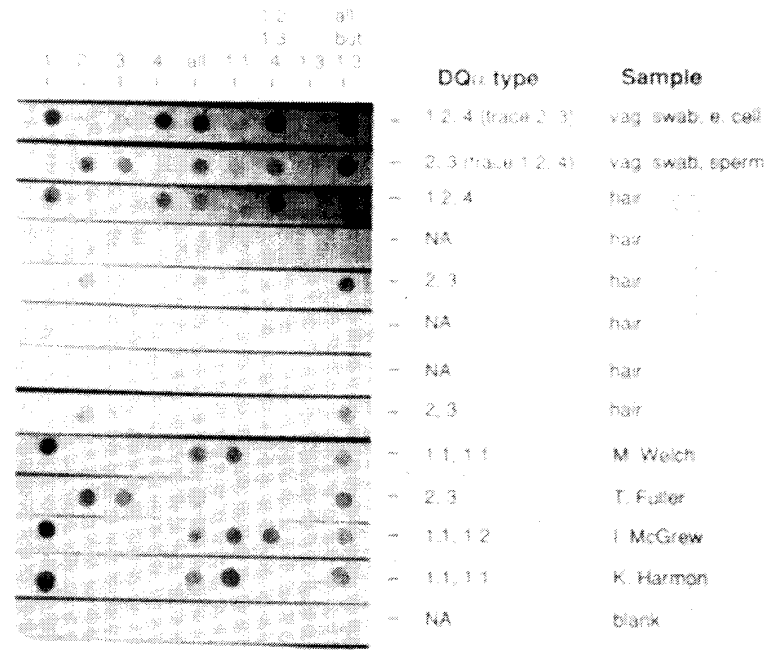

PCR at the HLA DQa-1 locus using a type of dot-blot hybridization performed by Forensic Science Associates in a rape-murder case. SOURCE: Cetus Corp., Emeryville, CA, 1990.

In research laboratories, PCR has been used to examine DNA for a range of novel applications involving minute or ancient samples. DNA from a single hair root, cell, or sperm has been amplified and analyzed $(27,40)$, as have DNA from the remains of a 7,000-year-old body found preserved in a Florida peat bog (48) and a 17 million-year-old magnolia tree fossil (25).

\section{Emerging Technologies}

RFLP analysis and PCR are only two of a battery of DNA-based tests that can be used in forensic identification. For example, DNA typing techniques that combine principles of PCR and RFLP analysis are being developed in several laboratories. These methods apply PCR amplification to regions of DNA where known variants exist, and would allow RFLP-type analysis to be performed on increasingly smaller quantities of forensic samples $(8,9,33,63)$. Another technique that could prove useful in forensic casework is a form of PCR called multiplex amplification, which simultaneously examines at least nine different polymorphic loci (11). Other research efforts are aimed at enhancing standard RFLP analysis for criminal casework, e.g., eliminating the use of radioactive isotopes by refining nonradioactive methods used in other applications $(4,13,14,38,41,56)$.
Although not in the immediate future, one DNA technology widely used in research laboratories could find its way into forensic applications: DNA sequencing. DNA sequencing would be the ultimate genetic identification because it directly elucidates differences in the arrangement of the genetic alphabet (G's, A's, T's, and C's) among individuals' DNA. Success in adopting DNA sequencing as a forensic tool probably depends on geneticists identifying one or more highly polymorphic addresses (loci) for which DNA sequence data would yield positive identification among individuals. Although such loci remain, as yet, unidentified, many believe that with efforts under way to map and sequence the entire human genome (59), identifying such loci is only a matter of time. Existing automation for DNA sequencing could provide a boost for this technology, although the cost of such instrumentation could place sequencing beyond the reach of some public forensic laboratories.

\section{DNA TYPING: PRESENT AND FUTURE USES}

One advantage of DNA typing techniques lies in the array of ways they can be used. Many of the applications provide solutions to practical areas, yielding information previously unattainable. Compared to both subjective evidence like eyewitness testimony and objective evidence like traditional genetic markers, forensic DNA analysis can also provide more definitive and objective evidence to assist in the determination of both the innocence and guilt of persons.

Although traditional genetic tests provide the potential for a high degree of discrimination among different individuals, the upper limit is attained infrequently because of the instability of some of these markers in aged stains. Moreover, of the markers that retain their structure and activity in the dried evidence state, the number of observed or expressed forms is limited. In practice, the individualization of many evidentiary stains cannot be carried out to any great extent given the present array of traditional genetic landmarks (6). In general, conventional genetic tests used in forensic casework at best can associate a suspect to the evidence at about 90 to 95 percent certainty (42). DNA, on the other hand, is more stable, and the range of genetic variability revealed through batteries of DNA-based tests are much broader. Finally, in some cases, an 
advantage of DNA v. conventional testing is that a stain from multiple contributors can be more readily detected and, perhaps, deciphered (22).

Thus today, many argue that DNA technologies stand to change the judicial landscape. With recombinant DNA methods, forensic practitioners isolate and examine DNA from traces of human biological material such as blood, semen, or hair roots. As noted, such analyses potentially provide forensic examiners with the ultimate in discrimination power-the ability to statistically connect samples to the exclusion of all other individuals except identical twins. On the other hand, questions about the reliability of forensic DNA analysis have been raised (see ch. 3) $(37,47,55)$, as have privacy concerns (see ch. 5).

Nevertheless, the advent of DNA typing techniques has provided opportunities to apply DNA analysis to a number of situations, including:

- criminal investigations, particularly violent crimes, such as homicides and sexual assaults, and serial crimes;

-identification of unknown remains;

- paternity determination and child support enforcement;
- human rights abuses, such as people who have disappeared in Argentina (see box 2-D);

- immigration;

- missing children;

- incidents with multiple casualties (e.g., plane accidents, war);

- settlement of contested wills and estates; and

- baby swapping.

Other nonhuman applications include identifying purloined endangered species, wildlife management and protection, tracing illegal export of agricultural products, tracking genetic markers in breeding programs, and documenting pedigree, e.g., in thoroughbred horses. While each of these applications is likely to have significant impact, the current policy debates in the United States center on using DNA typing in criminal and paternity investigations.

Of the thousands of murders and nonnegligent manslaughter cases in this country (20,675 reported in 1988) (26), most remain unsolved. Although it is too early to gauge the impact of DNA typing on homicide investigations, estimates comparing casework where DNA typing is used v. non-DNA analysis indicate the effect will be significant (10). In fact, DNA tests might not appreciably affect solution rates, but could increase conviction rates (39). One analysis, however, suggests that DNA

\section{Box 2-D-Mitochondrial Genes and Forensic Identification}

Mitochondria are microscopic watermelon-shaped organelles found by the hundreds in every cell in the body. Often referred to as the cell's power supply, mitochondria produce the energy necessary for cellular functions. They carry their own genetic material-multiple copies of tiny circular pieces of DNA, about 16,500 base pairs total (compared with the 3.3 billion in a person's chromosomes).

An unusual aspect of rnitochondrial DNA (mtDNA) is its pattern of inheritance. Whereas individuals inherit half their chromosomes from their mother and half from their father, mtDNA is passed through the maternal lineage. That is, an individual inherits mtDNA only from his or her mother.

One particular region of mtDNA, known as the D-loop, has been found to be highly variable between unrelated individuals. It is generally stable across generations, however, so a child's version of this region almost never varies from his or her mother, sisters, brothers, or even grandmother, maternal aunts and uncles, and other genetic relatives on the maternal side.

Recently, scientists have taken advantage of PCR and mtDNA inheritance patterns to identify children kidnapped in Argentina between 1975 and 1983. In all, more than 9,000 people 'disappeared" in Argentina during this 8-year period, including more than 200 infants+ More than 120 pregnant women also were kidnapped, with most forced to bear their children in captivity before being killed. The children, now between 10 and 12 years old, were often sold on the black market. Today, using PCR to amplify the D-loop region of mtDNA, kidnapped children are being matched to surviving biological relatives because the mtDNA pattern of a surviving child is the same as any maternal relative, including any first cousins who are children of a maternal aunt.

SOURCE: OffIce of Technology Assessment, 1990, based on M.-C. King, "Genetics and the Disappeared: The Search for Two Generations," presentation at the 155th Annual Meeting of the American Association for the Advancement of Science, San Francisco, CA, January 1989; and M. Specter, “Microbiology Reunites Families: Long-Lost Children's Genes Match Parents," The Washington Post, p. All, Jan. 17, 1989. 


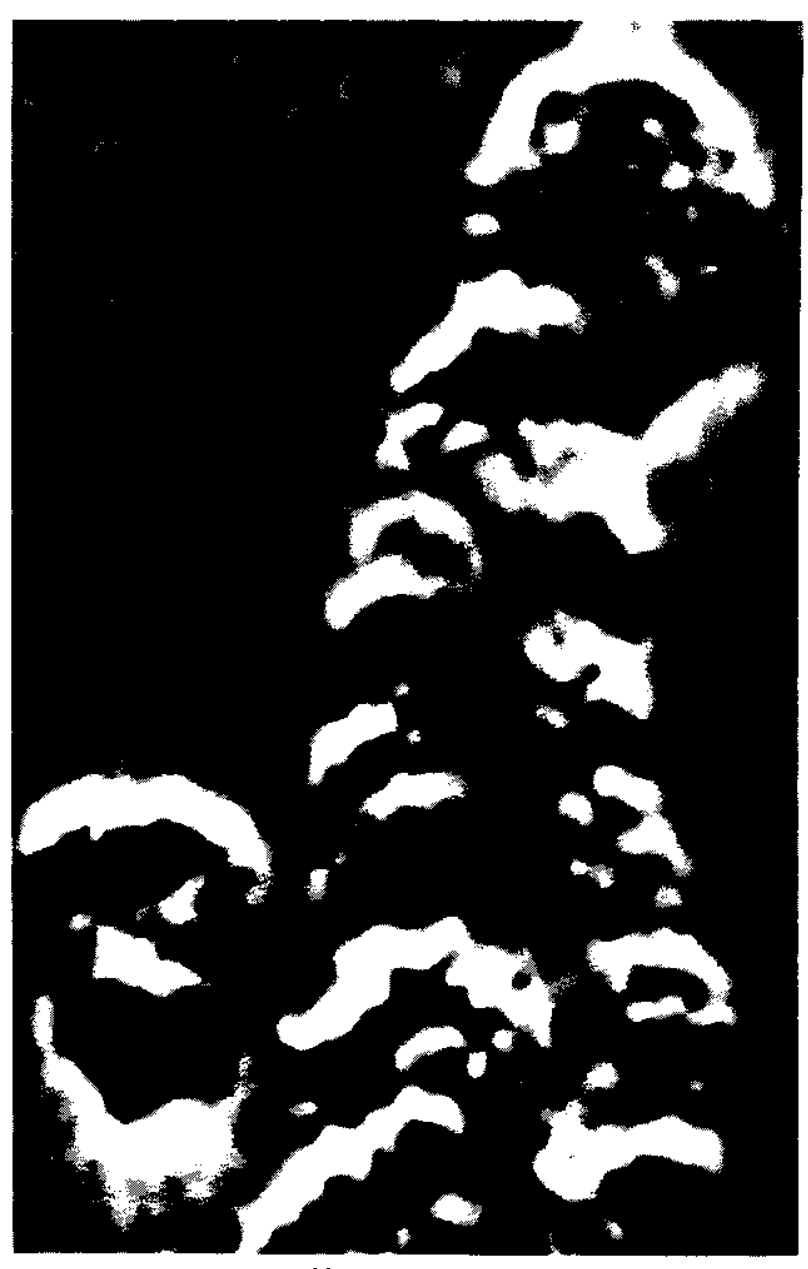

Photo credit: Lawrence Livermore National Laboratory, Livermore, CA

Direct image of a chemically unaltered strand of DNA obtained using a scanning tunneling microscope. (Light microscopes magnify objects up to about 1,000 times; electron microscopes about 300,000 times. Scanning tunneling microscopes can magnify images up to 1 million times.)

typing might not significantly improve conviction rates for murders (49).

On the other hand, DNA typing has had, and will likely continue to have, a marked impact on rape cases (49). A woman is forcibly raped every 6 minutes in the United States. In 1988, 92,486 rapes were reported, but because generally less than half the victims report a rape, the actual number is estimated to be much higher. DNA typing of semen stains stands to significantly enhance positive association, because useful protein genetic markers in semen are limited (6). It can have a dramatic impact by exonerating suspects identified through eyewitness testimony who were not excluded by conven- tional genetic tests. DNA tests are also likely to play an important role in serial crime investigations.

Using blood tests in paternity disputes has been an ongoing practice for over six decades (18). Approximately 150 conventional parentage testing facilities exist in the United States (61). Presently, a limited number of these facilities provide DNA testing services for parentage testing. Indications are, however, that many laboratories performing traditional genetic typing for paternity have begun or plan to include DNA testing, with an eye toward replacing traditional methods.

For paternity disputes, the capability provided by DNA typing appears to be resulting in fewer cases being brought to trial (28), with attendant potential savings to both the clients and the public. Since paternity determination is often a prerequisite to child support actions, DNA typing will have an impact on child support enforcement efforts (61). In the State of Virginia, for example, social service agencies are actively pursuing DNA testing to assist them in efforts to enforce child support laws (16).

The technological advances that allow an individual's genetic blueprint to be examined give rise to concerns that forensic uses of DNA testing will extend beyond the type of tests generally employed today to DNA tests presently confined to clinical and medical uses. Genetic information has been used for political purposes in the past (59). The availability of numerous DNA tests that can reveal medical or diagnostic details about an individual $(3,7,57)$ raises concerns about ensuring the privacy of a person's genetic history, especially when DNA or tissue samples are stored in addition to DNA profile data (see ch. 5).

\section{FINDINGS AND SUMMARY}

At present, forensic uses of technologies grouped under the umbrella terms "DNA testing, DNA typing, DNA profiling, or DNA identification" involve two basic techniques: restriction fragment length polymorphism analysis or polymerase chain reaction. RFLP protocols can be subdivided further into single-locus probe analysis and multilocus probe analysis. RFLP analysis has been used by research and clinical laboratories for over a decade; PCR for a few years. In the forensic setting, both techniques can be used to detect differences among individuals at the DNA level. 
The molecular tools of DNA analysis offer forensic scientists a greater degree of specificity than traditional genetic methods. DNA technologies provide the best avenue for unequivocal exclusion of innocent suspects. DNA tests can also yield a statistical result that is effectively positive identification.

DNA typing technologies have a broad range of practical applications, including criminal investigations, paternity determination, identification of unknown remains, human rights abuses, and immigration. As more information is gained through genetic research, including efforts to map and sequence the human genome, the range of applications, information gained, and technologies involved is likely to expand.

\section{CHAPTER 2 REFERENCES}

1. Acton, R.T., The University of Alabama at Birmingham, Birmingham, AL, personal communication, August 1989.

2. Allen, R. C., Graves, G., and Budowle, B., "Polymerase Chain Reaction Amplification Products Separated on Rehydratable Polyacrylamide Gels and Stained With Silver," BioTechniques 7(7):736-744, 1989.

3. Antonarakis, S.E., "Diagnosis of Genetic Disorders at the DNA Level," The New England Journal of Medicine 320:153-163, 1989.

4. Baum, H. J., Fitz-Charles, H., and McKee, R., "The Use of a Sensitive Chemiluminescent DNA Detection System for Paternity and Forensic Identifications,' abstract presented at The International Symposium on Human Identification 1989: Data Acquisition and Statistical Analysis for DNA Typing Laboratories, Madison, WI, November 1989.

5. Botstein, D., White, R. L., and Skolnick, M., et al., "Construction of a Genetic Linkage Map in Man Using Restriction Fragment Length Polymorphisms," American Journal of Human Genetics 32:314-331, 1980.

6. Budowle, B., Deadman, H.A., Murch, R. S., et al., "An Introduction to the Methods of DNA Analysis Under Investigation in the FBI Laboratory,' Crime Laboratory Digest 15(1):8-21, 1988.

7. Caskey C.T, "Disease Diagnosis by Recombinant DNA Methods," Science 236:1223-1229, 1988.

8. Caskey, C.T,, Edwards, A., and Hammond, H., "DNA: The History and Future Use in Forensic Analysis," manuscript prepared for An International Symposium on the Forensic Aspects of DNA Analysis: Department of Justice, Federal Bureau of Investigation, Quantico, VA, June 1989.
9. Caskey, C.T., and Hammond, H., "DNA-basedIdentification: Disease and Crirninals," DNA Technology and Forensic Science, J. Ballantine, G. Sensabaugh, and J. Witkowski (eds.) (Cold Spring Harbor, NY: Cold Spring Harbor Laboratory Press, 1989).

10. Castonguay, R.T., Federal Bureau of Investigation, Washington, DC, personal communication, April 1989.

11. Chamberlain, J. S., Gibbs, R.A., Ranier, J.E., et al., "Deletion Screening of the Duchenne Muscular Dystrophy Locus Via Multiplex DNA Amplification," Nucleic Acids Research 16:11 141-11156,1988.

12. Comey, C.T., "The Use of DNA Amplification in the Analysis of Forensic Evidence," Crime Laboratory Digest 15(4):99-103, 1988.

13. Dykes, D., Fondell, J., Watkins, P., et al., "The Use of Biotinylated DNA Probes for Detecting Single Copy Human Restriction Fragment Length Polymorphisms Separated by Electrophoresis," Electrophoresis 7(6):278-282, 1986.

$14_{0}$ Dykes, D.D., and Polesky, H.F., "Non-isotopic Detection Methods for Identifying DNA RFLPs in Paternity Cases," abstract, Journal of the Canadian Society of Forensic Sciences 20:29, 1987.

15. Erlich, H.A., Higuchi, R., von Beroldingen, C. H., et al.,-' 'The Use of the Polymerase Chain Reaction for Genetic Typing in Forensic Samples," manuscript prepared for An International Symposium on the Forensic Aspects of DNA Analysis: Department of Justice, Federal Bureau of Investigation, Quantico, VA, June 1989.

16. Ferrara, P. B., Virginia Bureau of Forensic Science, Richmond, VA, personal communication, July 1989.

17. Gaensslen, R.E. (cd.), Sourcebook in Forensic Serology, Immunology, and Biochemistry (Washington, DC: U.S. Government Printing Office, 1983).

18. Gaensslen, R. E., University of New Haven, West Haven, CT, personal communication, July 1989.

19. Gaensslen, R.E., Bell, S. C., and Lee, H. C., "Distributions of Genetic Markers in United States Populations, I. Blood Group and Secretor Systems," Journal of Forensic Sciences 32(4):1016-1058, 1987.

20. Gaensslen, R.E., Bell, S. C., and Lee, H. C., "Distributions of Genetic Markers in United States Populations, II. Isoenzyme Systems," Journal of Forensic Sciences 32(5):1348-1381, 1987.

21. Gaensslen, R.E., Bell, S. C., and Lee, H. C., "Distributions of Genetic Markers in United States Populations, 111. Serum Group Systems and Hemoglobin Variants," Journal of Forensic Sciences 32(6):17541774, 1987.

22. Gaudette, B.D., Central Forensic Laboratory, Royal Canadian Mounted Police, Ottawa, Canada, personal communication, August 1989. 
23. Gill, P., Jeffreys, A.J., and Werrett, D.J., "Forensic Application of DNA 'Fingerprints'," Nature 318: 577-579, 1985.

24. Giusti, A., Baird, M., Shaler, R., et al., "Application of Deoxyribonucleic Acid (DNA) Polymorphisms to the Analysis of DNA Recovered From Sperm," Journal of Forensic Sciences 31:409417, 1986.

25. Golenberg, E.M., Giannasi, D.E., Clegg, M.R., et al., "Chloroplast DNA Sequence From a Miocene Magnolia Species, “ Nature 344:656-658, 1990.

26. Hicks, J. W., Federal Bureau of Investigation, "Conference Summary,' International Symposium on the Forensic Aspects of DNA Analysis, Quantico, VA, June 23, 1989.

27. Higuchi, R., von Beroldingen, C. H., Sensabaugh, G.F., et al., "DNA Typing From Single Hairs," Nature 332:543-546, 1988.

28. Huss, J. W., CellmarkDiagnostics, Germantown, MD, personal communication, January 1989.

29. Jeffreys, A.J., Brookfield, J.F.Y., and Semeonoff, R., "Positive Identification of an Immigration Test Case Using Human DNA Fingerprints," Nature 317:81 8819, 1986.

30. Jeffreys, A.J., Wilson, V., and Thein, S.L., "Hypervariable Minisatellite Regions in Human DNA," Nature 314:67-73, 1985.

31. Jeffreys, A.J., Wilson, V., and Thein, S.L., "Individual Specific 'Fingerprints' of Human DNA,' Nature 316:76-79, 1985.

32. Jeffreys, A.J., Wilson, V., Thein, S.L., et al., "DNA 'Fingerprints' and Segregation Analysis of Multiple Markers in Human Pedigrees,' American Journal of Human Genetics 39:11-24, 1986.

33. Jeffreys, A.J., Wong, Z., Wilson, V., et al., "Applications of Multilocus and Single-locus Minisatellite DNA Probes in Forensic Medicine," DNA Technology and Forensic Science, J. Ballantine, G. Sensabaugh, and J. Witkowski (eds.) (Cold Spring Harbor, NY: Cold Spring Harbor Laboratory Press, 1989).

34. Kan, YW., and Dozy, A. M., "Polymorphism of DNA Sequence Adjacent to Human Beta-Globin Structural Gene: Relationship of Sickle Mutation," Proceedings of the National Academy of Sciences (USA) 75:5631-5635, 1978.

35. Kanter, E., Baird, M., Shaler, R., et al., "Analysis of Restriction Length Polymorphisms in Deoxyribonucleic Acid (DNA) Recovered From Dried Bloodstains," Journal of Forensic Sciences 31:403-408, 1986.

36. Kearney, J., Federal Bureau of Investigation, Quantico, VA, personal communications, July-August 1989.

37. Lander, E. S., "DNA Fingerprinting On Trial," $\mathrm{Na}$ ture 338:501-505, 1989.

38. Leary, J.J., Brigati, D.J., and Ward, D. C., "Rapid and Sensitive Calorimetric Method for Visualizing Biotin- labeled DNA Probes Hybridized to DNA or RNA Immobilized on Nitrocellulose: Bio-blots," Proceedings of the National Academy of Sciences (USA) 80:4045-4049, 1983.

39. Lee, H. C., Forensic Science Laboratory, Connecticut State Police, Meriden, CT, personal communication, July 1989.

40. Li, H., Gyllensten, U. B., Cui, X., et al., “Amplification and Analysis of DNA Sequences in Single Human Sperm and Diploid Cells," Nature 355:414417, 1988.

41. Liss, L. R., and Hudson, G.R., "Comparison of Chemiluminescent and Radioactive Methods of DNA Typing," abstract presented at The International Symposium on Human Identification 1989: Data Acquisition and Statistical Analysis for DNA Typing Laboratories, Madison, WI, November 1989.

42. Marx, J. L., "DNA Fingerprinting Takes the Witness Stand," Science 240:1616-1618, 1988.

43. McNally, L., Shaler, R. C., Giusti, A., et al., "Evaluation of Deoxyribonucleic Acid (DNA) Isolated From Human Bloodstains Exposed to Ultraviolet Light, Heat, Humidity, and Soil Contamination," Journal of Forensic Sciences 34(5):1059-1069, 1989.

44. McNally, L., Shaler, R. C., Giusti, A., et al., "The Effects of Environment and Substrata on Deoxyribonucleic Acid (DNA): The Use of Casework Samples From New York City,' Journal of Forensic Sciences 34(5):1070-1077.

45. Mullis, K. B., and Faloona, F., "Specific Synthesis of DNA In Vitro Via a Polymerase Catalysed Chain Reaction," Methods in Enzymology 155:335-350, 1987.

46. Nakamura, Y, Leppert, M., O’Connell, P., et al., "Variable Number of Tandem Repeat (VNTR) Markers for Human Gene Mapping," Science 237:16161622, 1987.

47. Neufeld, P.J., and Colman, N., "When Science Takes the Witness Stand," Scientific American 262:46-53, 1990.

48. Paabo, S., Gifford, J. A., and Wilson, A. C., "Mitochondrial DNA Sequences From a 7,000-year-old Brain,' Nucleic Acids Research 16(20):775-787, 1988.

49. Peterson, J. L., "Impact of Biological Evidence on the Adjudication of Criminal Cases: Potential for DNA Technology,' DNA Technology and Forensic Science, J. Ballantine, G. Sensabaugh, and J. Witkowski (eds.) (Cold Spring Harbor, NY: Cold Spring Harbor Laboratory Press, 1989).

50. Saiki, R. K., Bugawan, T.L., Horn, G. T., et al., "Analysis of Enzymatically Amplified Betaglobulin and HLA-DQcx DNA With Allele-specific Oligonucleotide Probes, Nature 324:163-165, 1986.

51. Saiki, R.K., Gelfand, D.H., Stoffel, S., et al., "Primerdirected Enzymatic Amplification of DNA With a 
Thermostable DNA Polymerase,' Science 239:487494, 1988.

52. Saiki, R.K., Scharf, S., Faloona, F., et al., "Enzymatic Amplification of Beta-globin Genomic Sequences and Restriction Site Analysis for Diagnosis of Sickle Cell Anemia,'Science 230:1350-1354, 1985.

53. Sensabaugh, G.F., "The Biochemistry of Individual Variation," Handbook of Forensic Sciences, R. Saferstein (cd.) (New York, NY: Prentice Hall, 1988).

54. Southern, E., "Detection of Specific Sequences Among DNA Fragments Separated by Gel Electrophoresis,' Journal of Molecular Biology 98:503-517, 1975.

55. Thompson, W. C., and Ford, S., "Is DNA Fingerprinting Ready for the Courts?' New Scientist 1710: 38-43, 1990.

56. Tilzer, L., Moreno, R., and Booth, F., 'DNA Fingerprinting With M13mp8 RF Bacteriophage Using Nonradioactive Methods,' abstract presented at An International Symposium on the Forensic Aspects of DNA Analysis: Department of Justice, Federal Bureau of Investigation, Quantico, VA, June 1989.

57. U.S. Congress, Office of Technology Assessment, "The Commercial Development of Tests for Human Genetic Disorders," staff paper, Washington, DC, 1988.

58. U.S. Congress, Office of Technology Assessment, Genetic Testing in the Workplace (Washington, DC: U.S. Government Printing Office, forthcoming 1990).

59. U.S. Congress, Office of Technology Assessment, Mapping Our Genes-Genome Projects: How Big,
How Fast? OTA-BA-373 (Washington, DC: U.S. Government Printing Office, 1988).

60. U.S. Congress, Office of Technology Assessment, New Developments in Biotechnology: Ownership of Human Tissues and Cells, OTA-BA-337 (Washington, DC: U.S. Government Printing Office, 1987).

61. U.S. Congress, Office of Technology Assessment, "The Use of Biomedical Tests in Paternity Determination," staff paper, Washington, DC, 1986.

62. von Beroldingen, C. H., Blake, E. T., Higuchi, R., et al., "Applications of PCR to the Analysis of Biological Evidence,' PCR Technology: Principles and Applications for DNA Amplification, H.A. Erlich (cd.) (New York, NY: Stockton Press, 1989).

63. Weber, J.L., and May, P.E., "Abundant Class of Human DNA Polymorphisms Which Can Be Typed Using the Polymerase Chain Reaction," American Journal of Human Genetics 44:388-396, 1989.

64. Wong, Z., Wilson, V., Jeffreys, A. J., et al., "Cloning a Selected Fragment From a Human DNA 'Fingerprint': Isolation of an Extremely Polymorphic Minisatellite,' Nucleic Acids Research 14:4605-4616, 1986.

65. Wong, Z., Wilson, V., Patel, I., et al., "Characterization of a Panel of Highly Variable Minisatellites Cloned From Human DNA," Anna/s of Human Genetics 51:269-288, 1987.

66. Wyman, A. R., and White, R., "A Highly Polymorphic Locus in Human DNA," Proceedings of the National Academy of Sciences (USA) 77:6754-6758, 1980. 


\section{Chapter 3}

\section{Validity, Reliability, and Quality Assurance}

"Science is one of the very few human activities in which errors are systematically criticized and fairly often, in time, corrected."

Sir Karl R. Popper

$1902-$

"In most cases, reasonable prudence is in fact common prudence; but strictly it is never its measure; a whole calling may have unduly lagged in the adoption of new and available devices. It never may set its own tests, however persuasive be its usages. Courts must in the end say what is required; there are precautions so imperative that even their universal disregard will not excuse their omission."

Justice Holmes The T.J. Hooper, 60 F.3d 737 (2d Cir. 1932)

"The right to search for truth implies also a duty; one must not conceal any part of what one has recognized to be true.'

Albert Einstein

1879-1955 


\section{CONTENTS}

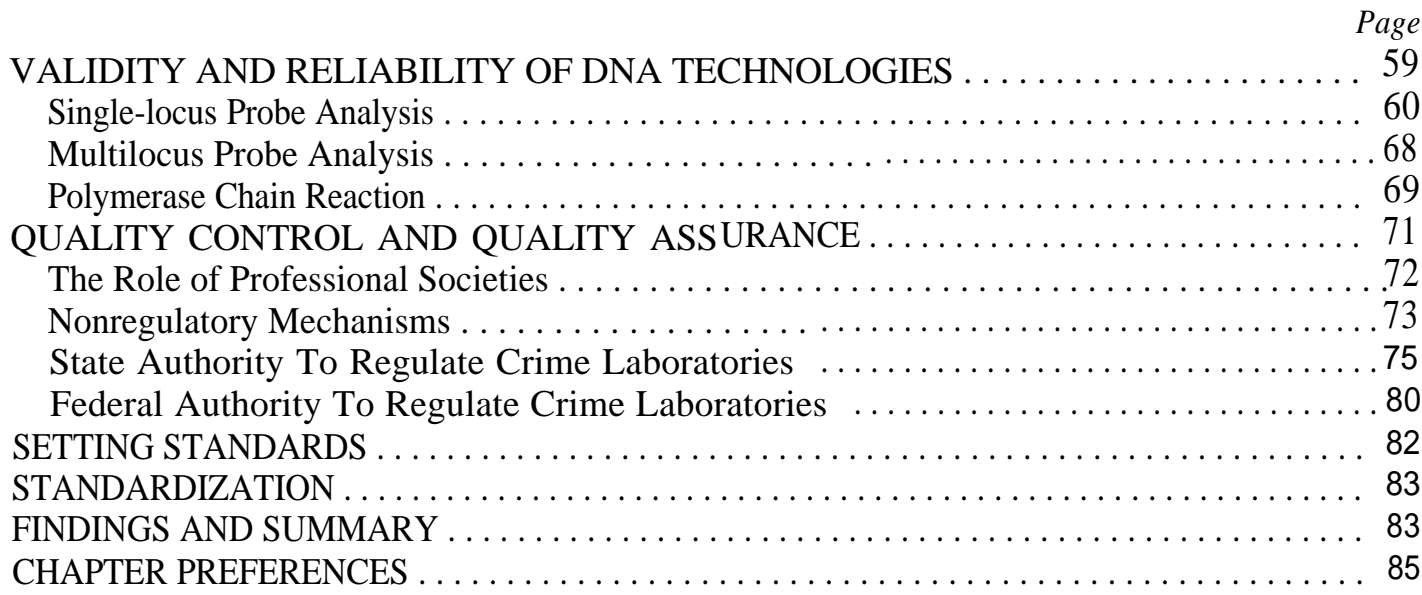

\section{Boxes}

3-B. Scientific Controls for RFLP Analysis. . . . . . . . . . . , .... . . . . . . . . 64

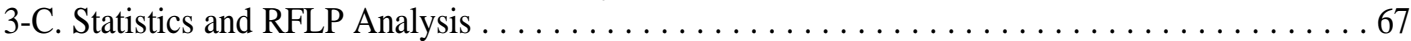

3-D. Quality Assurance and Drug Testing Laboratories . . . . . . . . . . . . . 71

3-E. Quality Assurance and the FBI TechnicalWorking Group on

DNA Analysis Methods . . . . . . . . . . . . . . . . . . . . . . . . . . . . . . . 74

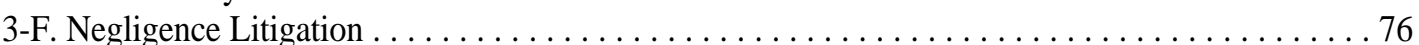

3-G. Quality Assurance and Clinical Laboratories . . . . . . . . . . . . . . . . . 78

\section{Figures}

3-1. Example of One DNA Pattern in a Rape Case . . . . . . . . . . . . . . . . . . . . 60

3-2. DNA Typing in Two Paternity Cases .............................. 61

3-3. DNA Typing and Murder: A Less Than Ideal First Analysis and a Solution.. . . . . 65 
Given the variation in DNA sequence among individuals (see ch. 2), no scientific doubt exists that technologies available today accurately detect genetic differences. Properly performed and interpreted, a sufficiently detailed examination of two samples of DNA can determine if DNA patterns match, and, if they do, the likelihood that a single source is responsible for both samples (except in the case of identical twins).

Nevertheless, it is generally agreed that applying DNA tests to forensic samples, especially criminal evidence, potentially presents more difficulties than analyzing samples in basic research or clinical diagnosis. Samples from crime scenes are frequently small and might be of poor quality because of exposure to a spectrum of environmental onslaughts. And unlike paternity samples, where each sample is from an identified source, the contributor to evidence taken from a crime scene is often unknown. To date, several studies have elucidated ways to overcome some of the demands of using DNA typing on forensic samples. Other efforts are under way to further refine and develop strategies that adhere to generally accepted practices in the scientific community.

What, then, constitutes a sufficient examination of a forensic sample? When does "sufficiently detailed" become unduly burdensome? What criteria are necessary for valid and reliable DNA typing of forensic samples? Does consensus exist for some scientific issues and not others? If so, what can be resolved? Is resolution necessary for all scientific issues? If not, what areas can and should be covered, and what areas are best left to the discretion of the forensic analyst? What are the best mechanisms for settling differences of opinion? And finally, who decides? As the U.S. criminal justice system increasingly turns to DNA tests, these questions, some of them pressing, must be addressed.

This chapter identifies and analyzes several key issues that bear on the validity and reliability of DNA tests for forensic uses, including:

- technical advantages and limitations of the restriction figment length polymorphism (RFLP) technique,

- technical advantages and limitations of the polymerase chain reaction (PCR) technology,
- standards-laboratory and personnel-for ensuring accurate DNA typing in the forensic context, and

- mechanisms for quality assurance.

For some issues, agreement or near agreement has been reached; the chapter describes these areas. It also examines how consensus has been achieved in other applications of DNA techniques or in new medical technologies, and analyzes how such processes could pertain to forensic applications of DNA technologies. Finally, the chapter discusses congressional, Federal, and State interest in quality assurance.

\section{VALIDITY AND RELIABILITY OF DNA TECHNOLOGIES}

An important matter in the use of DNA as evidence (see ch. 4) is whether the detection methods are scientifically valid. Validity centers on whether a test will correctly identify true matches and true nonmatches. For RFLP analysis, a valid test or set of tests would not falsely classify or exclude a subject by yielding a profile not true to type, i.e., a spurious pattern would not randomly arise. The Office of Technology Assessment (OTA) finds that molecular and genetic principles underlying DNA techniques are solid and can be successfully applied to forensic casework. Forensic uses of DNA tests are valid.

Initial concerns about the validity of DNA typing for forensic applications focused on the nature of the samples. Casework samples are obtained from a variety of less-than-sterile materials (e.g., glass, wood, dirt, and fabric) that are often subjected to sunlight, moisture, or desiccation. Samples can also be contaminated with unknown genetic material such as bacteria, plant, or animal secretions. Validation studies, however, have established that general DNA techniques are applicable for the breadth of conditions likely to be encountered in forensic casework, and have dispelled notions that RFLP analysis is invalid because of such conditions. For RFLP analysis, these studies confirmed that forensic samples in and of themselves are not barriers to applying DNA technologies that use single-locus and multilocus probes $(2,19,32,34,35,50,52,66,67)$. 
Similar validation studies for PCR are being performed $(18,25,82)$.

A second aspect of DNA testing of forensic samples is reliability. Any test must be reliable i.e., it must measure reproducibly that which it is capable of measuring under routine conditions of use. Reliable tests must perform reproducibly within a laboratory, across many laboratories, and in the hands of different practitioners. Thus, reliability involves several factors, including the procedures used, laboratory performance, laboratory recordkeeping, quality control, and quality assurance. OTA finds that, properly performed, DNA technologies per se are reliable.

A reliable procedure, used carelessly, does not render the test unreliable-the particular test result would be in question. For forensic DNA analysis, questions exist about the appropriateness of using certain procedures over others, how data are interpreted, or about the extent or type of quality control and quality assurance necessary to minimize human factors and ensure that a particular test result is reliable $(62,70,86)$. As described later in this chapter, some argue that because greater experience exists for RFLP analysis, it is currently more reliable than PCR.

Finally, although forensic uses of DNA tests are valid and reliable when performed properly, many harbor the misconception that DNA typing applied to forensic samples always yields a "yes' or "no" answer. A test that does not give a "yes' or " "no' each time is not incorrect, nor unreliable. An important and often overlooked result of an analysis could be "inconclusive" - a result that should not be misconstrued as either a match or exclusion.

\section{Single-locus Probe Analysis}

Several acceptable protocols exist to determine whether two samples yield similar or different DNA patterns at various loci. In forensic applications, the method most commonly employed in the United States involves using DNA probes that detect size dissimilarities among individuals at certain loci. By using several probes in combination or sequentially, an exam]nier can determine whether DNA patterns from questioned samples are consistent with a suspect's pattern (figure 3-1) or, in paternity cases, whether an alleged father's pattern is consistent with a child's (figure 3-2).
Figure 3-I-Example of One DNA Pattern in a Rape Case

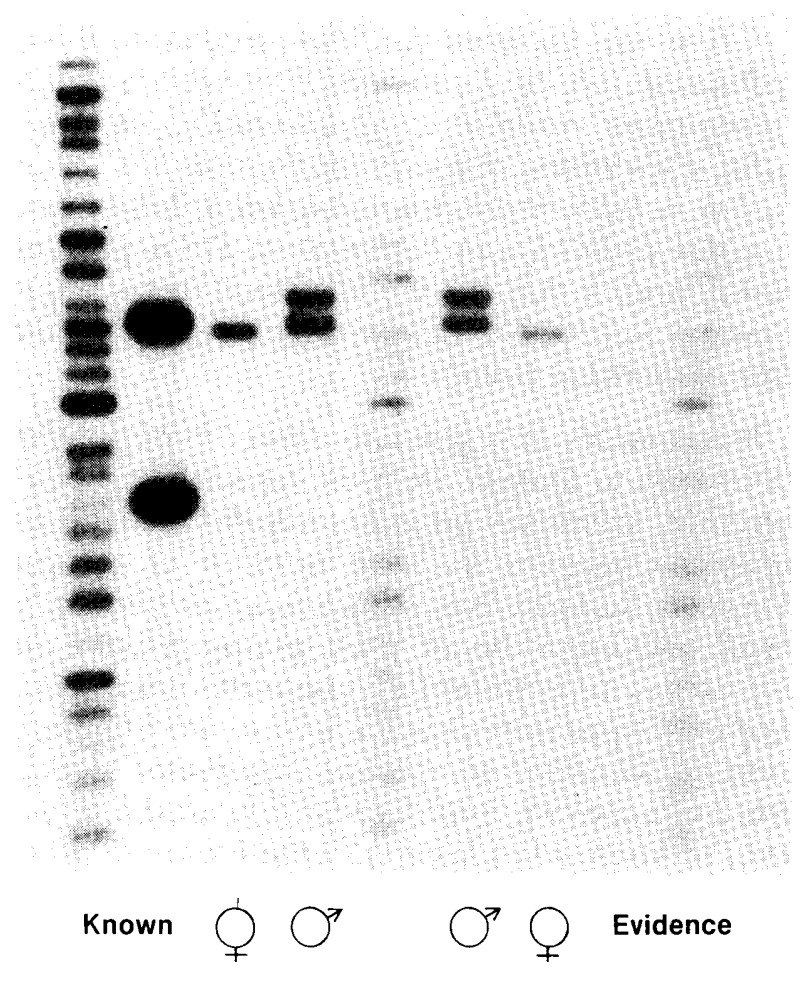

Biological evidence from this rape case was separated by laboratory techniques into separate male and female fractions. After single-locus RFLP analysis of these fractions and known samples obtained from the victim and suspect, the results reveal that-for this particular probe the DNA pattern of the male fraction matches the pattern of the suspect.

SOURCE: Federal Bureau of Investigation, 1989.

The basic tool used in single-locus and multilocus probe analysis is called Southern blotting, or Southern transfer (84) (see ch. 2). One of the workhorses of molecular biology, the process has been in daily use in thousands of laboratories for over a decade. Thus, extensive experience with Southern blotting in research and clinical testing supports the consensus that the technology itself is both a valid and reliable method to examine DNA.

The widespread use of Southern blotting has demonstrated that accurate and reliable single-locus analysis can be obtained across a broad spectrum of conditions. It has also defined the range of artifacts and errors that can occur, and led to solutions to avoid or minimize problems. For example, although partial digestion, differential electrophoresis, crosshybridization, background hybridization, loading errors, probe contamination, incomplete stripping of membrane before rehybridization, and loss of small 
Figure 3-2-DNA Typing in Two Paternity Cases

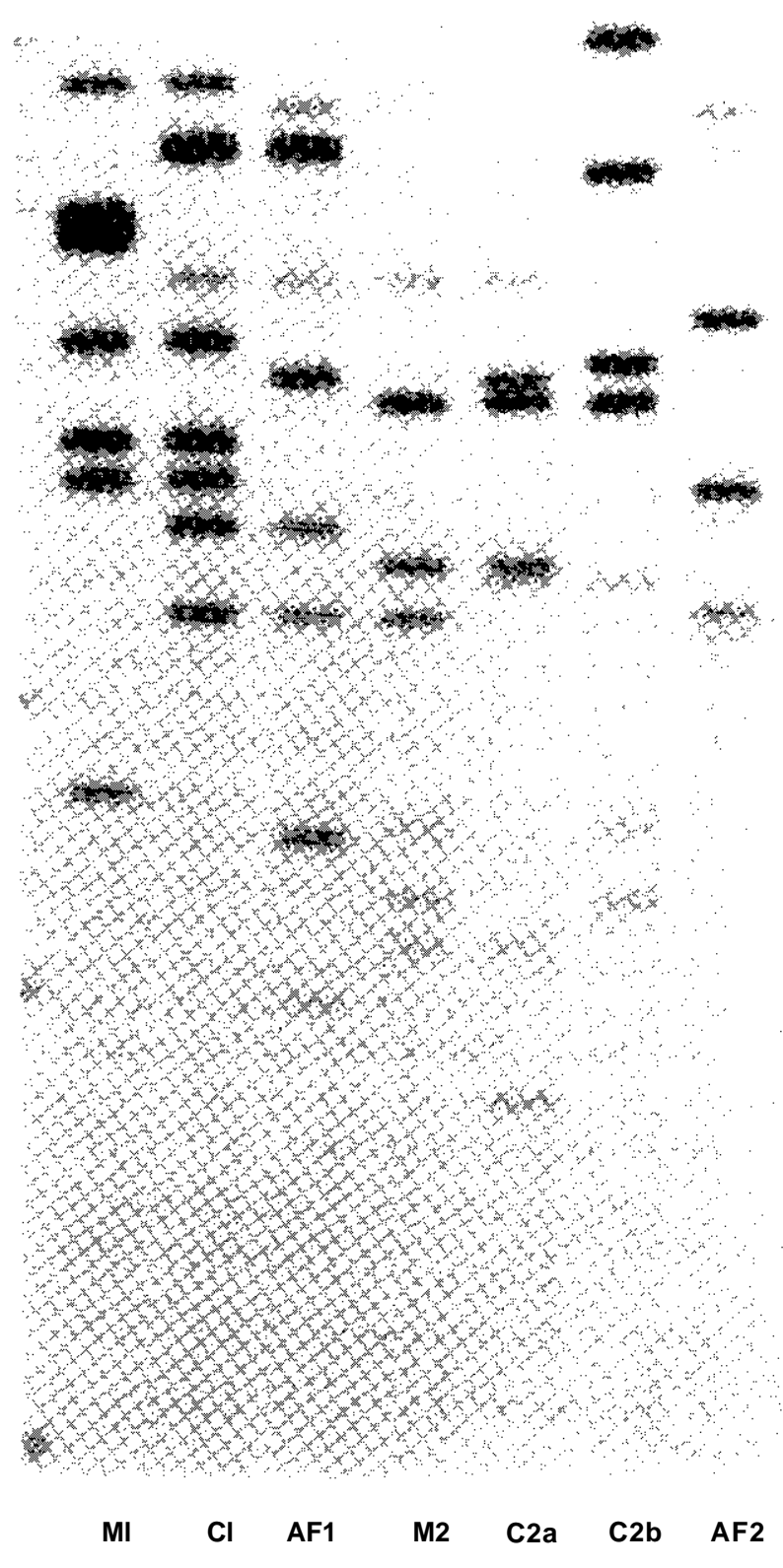

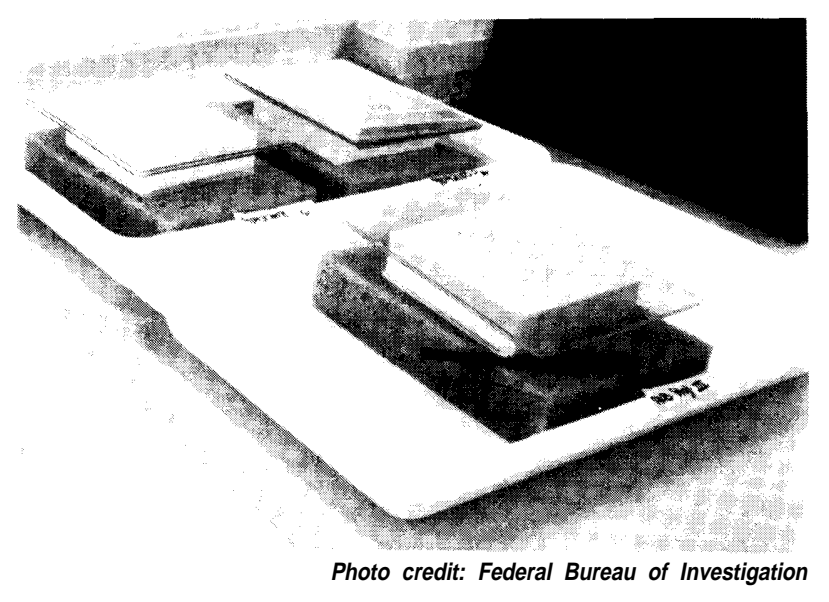

"Southern blotting D.NA is being transferred from gels to nylon membranes. The gel is placed on a sponge, which sits in a salt solution. The nylon membrane is placed on the gel, and a stack of filter papers on top serves as a wick that draws the salt solution up through the sponge, gel, and membrane a process that results in the transfer of DNA from the gel to the membrane. (The glass plate serves as a weight.)

fragments during electrophoresis are all problems that have occurred atone time or another in laboratories, a variety of scientific controls make it possible to recognize, or account for, such situations. Further, most artifacts generally will lead to false nonmatches, or exclusions (although false inclusions could occur, e.g., by incorrectly placing DNA samples on a gel or by loss of bands due to sample degradation) (63).

Nevertheless, forensic applications of single10Cus analysis make somewhat different demands on the method than research and clinical applications. Whereas diagnostic testing usually consumes only a fraction of a typical sample, from which a test can be repeated, forensic case samples can be degraded, contaminated, or in limited supply. DNA diagnostics generally involves determining which RFLP a child has inherited from each parent. Since a total of at most four possibilities exists for the child (two alternatives from the mother multiplied by two alternatives from the father), the system has built-in DNA typing in two different paternity disputes revealed that the
alleged father (AF) is the biological father in case 1, but not in case ${ }^{2}$ onsistency checks that alert scientists to errors, 2. Note that all bands present in the child in case $\mathbf{1}(\mathbf{C l})$ can be such as extra or missing bands; because choices at accounted for in either the mother (MI) or alleged father (AF1), lqiagnostic loci are discrete, the results can typically case 2, however, no bands from the alleged father (AF2) appear share with their mother (M2) match any present in the alleged continuum of possible fragment sizes exists at loci father (A2). This analysis involved a "cocktail" of four single-locu§creened in forensic DNA testing; precise measureprobes.

SOURCE: Cellmark Diagnostics, 1989. ments of the fragment lengths and objective standards for deciding whether DNA patterns match are 
essential. Finally, detailed population genetics analyses are not required in diagnostic DNA testing because conclusions depend only on the samples tested. Forensic analysis, however, requires information about the frequency of DNA patterns in the general population if conclusions are to be drawn about the probability that matched patterns arose from one contributor, or whether many people in a community could have been the source.

Thus, it is important to identify potential sources of errors that could lead to false nonmatches and matches when DNA technologies are used on forensic samples. Most would agree that avoiding false matches in criminal cases is paramount, because decisions regarding liberty, and sometimes life, are at stake. Broadly speaking, three central issues must be considered in evaluating single-locus probe analysis:

- the artifacts that might appear, which might lead to a false interpretation, match or nonmatch, of the samples;

- the accuracy involved in declaring that bands are a match or nonmatch between two RFLP patterns; and

- the population characteristics of RFLP patterns. (Although the validity of forensic DNA tests per se does not involve population genet- ics, when DNA typing results do not exclude an individual, population genetics becomes essential to the interpretation.)

\section{Controls to Avoid Artifacts}

Forensic DNA tests generally involve limited quantities of samples that could have been exposed to centaminants or environmental insults. In some instances, forensic samples might have marginally sufficient DNA to analyze; if too little DNA is obtained, less intense bands might not be detected, misleading the analyst. Some forensic DNA samples might be partially degraded, resulting in the isolation of an insufficient quantity of high molecular weight DNA; depending on the probe used, large fragments might not be detected. Finally, forensic samples can contain chemicals, or DNA from additional sources (a second person or bacteria), that interfere with complete DNA digestion by the restriction enzyme or normal gel electrophoresis.

In different ways, each of these situations could create problems that might interfere with analysis or interpretation of forensic DNA test results. Several factors to minimize potential problems are important, including: quality control of reagents; choice of enzyme and probe (box 3-A); and built-in scientific flags, or controls. Controls are especially critical.

\section{Box 3-A-Considerations for Choosing Forensic Single-locus Probes}

Over 3,000 RFLP loci have been identified to date, including more than 100 highly polymorphic loci at which many alleles exist in the population. With such a wide range available, DNA probes that minimize possible ambiguities can be used. Most agree that, ideally, a DNA probe for forensic use should:

- contain DNA sequences that detect only one chromosomal locus under a reasonable range of hybridization conditions;

- produce well-characterized patterns (such as defined size range, number of bands, and relative band intensities) so that unexpected patterns can be recognized; and

- detect a single polymorphic fragment per allele so that each person's test yields either one or two fragments, depending on whether an individual is homozygous or heterozygous, respectively.

Avoiding probes that detect fragments of varying number or intensity minimizes the problem of identifying the true bands that comprise the RFLP pattern. Otherwise, the potential exists for uncertainty about whether weak-intensity bands are part of the pattern. Furthermore, using a probe that identifies patterns with bands of variable number and intensity could make it difficult to identify bands on a dirty background.

Other considerations related to the use of a DNA probe for forensic casework include:

. using a series of probes from different chromosomes, or reasonably distant on the same chromosome, to ensure that the regions sampled are independently segregating;

. availability of the probe for research purposes, which allows other scientists to confirm its properties; and

- having the chromosomal position of the locus detected by the probe filed with the Human Gene Mapping Workshop.

SOURCE: Office of Technology Assessment 1990. 
To prevent or minimize unexpected or uninterpretable results, often referred to as artifacts or anomalies, scientists have developed several precautions based both on experience in basic research and on validation studies on simulated and actual forensic samples. Controls are steps built into any scientific analysis. They tell the scientist that the assay as a whole proceeded as expected, and that results from unknown specimens are accurate and reliable. For despite vigilant quality control and rigorous adherence to an acceptable protocol, analyses can and do fail. Thus, controls tell a forensic ex aminer whether the overall analysis worked-i.e., whether expected results were obtained from standard samples (box 3-B).

At present, scientists agree on the necessity for some controls, but not others. Different levels of safeguards can be used in a scientific experiment in different laboratories and yield identical, accurate results. Determining the type of controls necessary to ensure confidence in the results of any single DNA typing of a forensic specimen is of the highest priority (see section on setting standards).

Match or Nonmatch?

As mentioned previously, clinical DNA analysis generally benefits from consistency checks provided by family relationships. Additionally, the types of probes usually used detect only a limited number of well-separated alleles, so that visual comparison suffices. In contrast, forensic uses of DNA tests involve determining whether one or more unknown samples match samples collected from known individuals, e.g., a suspect or victim. Probes that detect highly polymorphic loci are used in forensic testing because they provide more information about identity. In particular, because the trend in forensic cases has been to use probes that involve as many as 50 to 100 alleles that often involve fragments of similar lengths, comparing samples requires both visual comparison and precise, quantitative measurements of fragment position. What considerations are necessary in declaring that two or more DNA patterns match?

Controlling for Potential Problems-To demonstrate that two bands appearing to be the same length in a gel are in fact the same length, most molecular biologists would perform a mixing experiment. That is, they would confirm that a 50-50 mixture of the two samples yields precisely the same RFLP pattern as either sample alone. Mixing tests can often reveal even small differences between samples, since coelectrophoresis allows a perfectly controlled comparison.

Mixing assays are generally not performed by crime laboratories in any type of comparative casework (e.g., drug analysis or protein electrophoresis) (59). And, at present, it appears that most laboratories do not routinely perform mixing tests on nonpaternity DNA samples. One important concern is the limited amount of DNA often obtained from evidence. The difficulty of precisely measuring the quantity and quality of human DNA from forensic samples so as to achieve an uniform mixture is also a consideration, as is the perceived difficulty in explaining to a jury why an examiner would deliberately mix two samples. While the latter two issues seem surmountable, most agree that the question of requiring mixing assays as a matter of routine should remain open on a case-by-case basis because, in some instances, not enough DNA will be available. These voices strongly argue that a failure to perform them is not grounds for a priori invalidating results. Nevertheless, many consider mixing tests as the "gold standard" for DNA typing of forensic specimens - a test that should always be performed in accordance with standards linked to DNA quantity, not strictly case-by-case.

When a mixing test is not performed, identity is inferred by comparing the positions of bands, and hence their size, in two separate lanes. Because lane-to-lane differences in electrophoresis can occur within a gel, resulting in "band shifts," the most accurate way to ascertain the size of a fragment is to measure its position relative to a set of internal lane controls, called monomorphic markers. That is, the unknown band should ideally be measured against one or more bands of known size in the lane itself. Although monomorphic markers were not employed initially, their use in forensic DNA analysis now seems to be generally accepted.

In forensic casework, it might be necessary to measure the sizes of bands on different gels. Forensic laboratories performing DNA analysis currently run evidence and suspect samples on the same gel whenever possible. But occasions can arise when, for example, an evidence sample is exhausted on gel A during an analysis that excludes a suspect. Following a period of time, DNA from a new suspect might need to be tested. Again, using proper controlsmonomorphic probes and known size markers- 


\section{Box 3-B-Scientific Controls for RFLP Analysis}

Despite vigilant quality control and rigorous adherence to protocol, analyses can fail. Every valid and reliable scientific test, therefore, includes an appropriate set of scientific controls designed to demonstrate that the procedure worked correctly. When the test works properly, these controls yield certain expected results. If the observed results for the controls deviate from what is expected, then the results for the case samples cannot be considered reliable. A variety of simple and widely accepted scientific procedures are available to detect errors and artifacts that can arise in forensic applications of RFLP tests. Such controls include, but are not limited to the following:

Control human DNA. Together with actual case samples on a gel, one lane should include a known human control DNA that yields a known pattern. If the expected pattern is obtained, it verifies that the hybridization proceeded as expected. Failure to obtain the expected pattern indicates that the hybridization went awry and should be repeated. If a Y-chromosome specific probe is used to recognize male DNA, the blot should contain both control male and control female DNA samples. (The former is a "positive control" to prove that the hybridization would detect male DNA - if present-in the forensic case sample, while the latter is a "negative control" to demonstrate that the hybridization would not yield a spurious positive even if male DNA was not present.)

Molecular size markers. To provide a "molecular ruler" against which fragments sizes can be measured, several lanes should contain discrete DNA fragments of known size. Such ladders of standard molecular size markers provide an initial test of whether the electrophoresis was uniform. By comparing the positions of fragments in the forensic samples to the markers' positions, the approximate molecular size of the unknown fragments can be calculated.

Internal lane controls. Even if the size markers appear to be distributed evenly, the analytical lanes might not have run uniformly; differences in DNA concentration (figure 3-3) or other conditions within a sample (e.g., salt concentration) can contribute to electrophoretic differences between lanes. Therefore, to account for such "band-shifting," monomorphic DNA probe controls-i.e., probes to detect bands that are not polymorphic, but of fixed size in the human population - should be used. If, in fact, lanes ran at different speeds, fragment sizes in each lane can then be more accurately computed by using the internal controls as lane-specific molecular rulers. More than one internal standard, or monomorphic probe, should be used so that there are enough reference points to allow an accurate measurement.

Internal controls can also verify the presence of adequate quantities of high molecular weight DNA. If a DNA sample is partially degraded, the quantity of DNA above a certain size might be insufficient for detection; an important consideration if the probe used detects alleles that are of high molecular weight. In this case, degraded DNA could lead to the conclusion that an individual is an apparent homozygote, rather than a heterozygote whose upper band goes undetected due to DNA degradation. Such situations could give rise either to a false match or nonmatch. A monomorphic probe that detects a high molecular weight band could be used as a control.

Test for incomplete stripping. If a membrane is not stripped completely between sequential applications of probes, radioactively labelled probe can remain attached and produce a signal in a subsequent test. Performing autoradiography on the stripped membrane can demonstrate if a signal results from residual probe. If a pattern is seen, the membrane should be re-stipped. Even if autoradiography is not performed after stripping, extra bands can be accounted for by superimposing consecutive $\mathrm{x}$-ray films,

Control probing with plasmid DNA. Since plasmid vector DNA is a potential contaminant in samples and probes, a band observed on an x-ray film might not be human DNA, but plasmid DNA in the sample that is being recognized by plasmid DNA in the probe. To rule this out, some forensic labs probe the Southern blots with plasrnid DNA to identify the location of any such bands, or use synthesized DNA probes lacking plasrnid sequences.

SOURCE: OffIce of Technology Assessment 1990.

DNA from the new suspect can be tested on gel B and accurately compared with results from gel A.

In any case, unless discrete allele systems are used or mixing tests performed, determining whether two samples in different lanes match (on the same or different gels) can require fine discrimination. In addition to visual comparison, an objective match- ing rule is thus required, reflecting empirical measurement variation observed to occur when known samples are repeatedly analyzed.

Reporting a Match-The systems currently used to report a match vary. While some consensus exists on what broad steps constitute an appropriate method for determining whether two samples match when 


\section{Figure 3-3-DNA Typing and Murder: A Less Than Ideal First Analysis and a Solution}

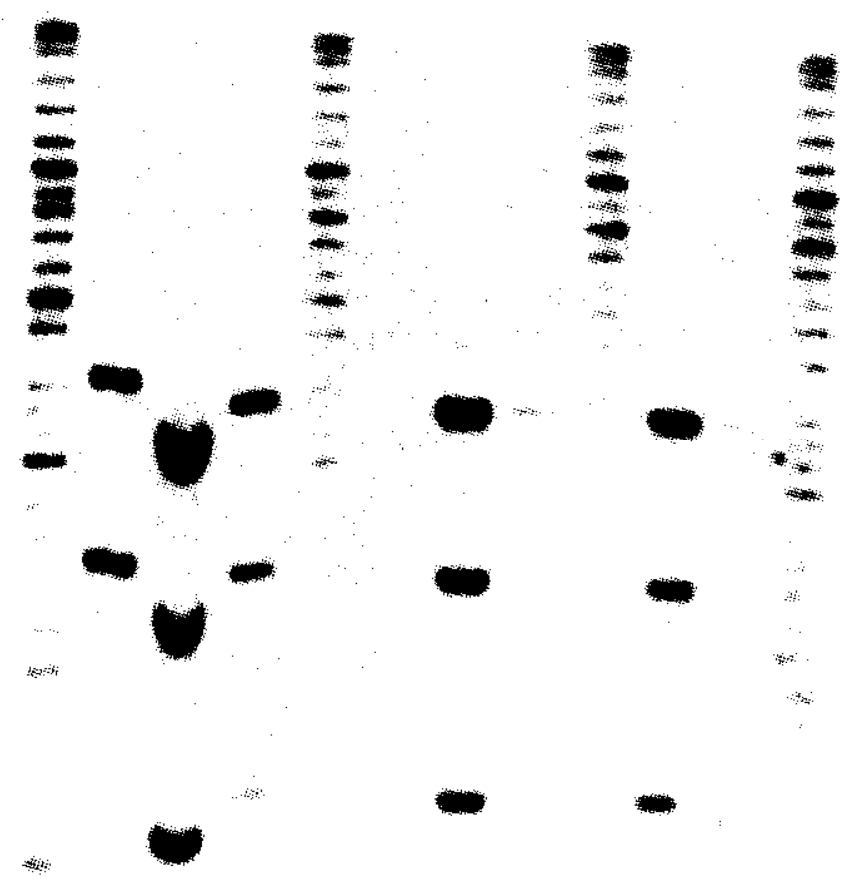

$\begin{array}{llllllllllllll}\text { A. } & \text { M } & \text { K562 } & \text { K1 } & \text { Q1 } & \text { M } & \text { Q2 } & \text { Q3 } & \text { Q4 } & \text { M } & \text { Q5 } & \text { Q6 } & \text { M }\end{array}$

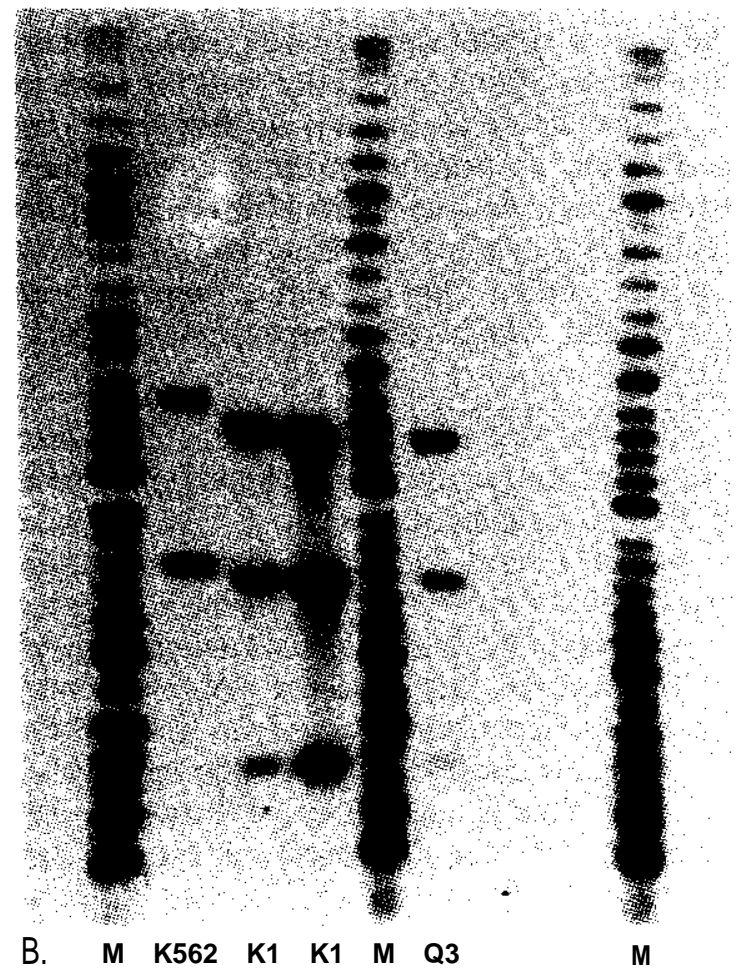

In this murder case, six separate pieces of evidence were obtained from the crime scene and a suspect identified. RFLP analysis was performed (M=markers; K1 =suspect; Q1 $-6=$ =vidence; K562=standard), but the results revealed that too much of the suspect sample (KI) had been placed on the gel, which led to distortion in the K1 lane, as well as the lanes next to it (K562 and QI) (panel A).

Even though the suspect's pattern for this probe is an extremely rare and unusual three-band pattern that is similar to the six questioned samples, the forensic analyst cannot call a "match," but must report the test "inconclusive" because the alignment is unacceptable. This, despite knowing from experience that if less suspect sample had been used, the patterns likely would have aligned and been called a match.

Fortunately, not all of evidence sample Q3 had been used in the test in panel A (although QI ,2,4-6 had been exhausted). The case was repeated (panel B) with diluted amounts of the suspect sample (KI), which now clearly align with the evidence pattern (Q3). Had no evidence sample been available for an additional try, however, DNA analysis would have reported "inconclusive," and could not have been used as evidence to prove guilt or innocence.

SOURCE: Federal Bureau of Investigation, 1989.

highly polymorphic loci are analyzed, scientists disagree to a certain extent on the details. This section describes the general sense of how a match should be reported when radioactive DNA probes are used, which is generally the case for criminal casework.

The initial step in examining the results of hybridizing with a single-locus probe involves identifying the bands in each lane. In all cases, each lane must be evaluated independently-the presence of a band in one lane must not influence whether a questionable signal in another lane should be identified as a band. Ideally, the x-ray film would show only RFLP bands from the test, and would show them distinctly. However, even if there is some degree of background hybridization or the bands are faint, an exami ner can often reliably identify the pattern. For a probe that identifies a single polymorphic band per allele, the task should be relatively easy: the lane should contain one (homozygote) or two (heterozygote) bands that are much more intense than anything else in the lane. On the other hand, evidence samples might be an unequal mixture from two or more contributors, so an additional faint band (or bands) should not just be discounted.

After the bands have been identified, the examiner must then determine whether they are in matching positions. Accurate identification of a band's position depends on a properly exposed piece of x-ray film-one that yields thin, sharp bands. Overexpo- 
sure (or too much DNA on a gel) results in broad bands that cover a significant size range-creating the risk of spuriously suggesting matches between distinct alleles and potentially masking other bands. A consensus exists that visual inspection must be performed, as well as objective measurement of band position with an appropriate measuring device, such as a computer digitizing pad or a computercoupled camera. Opinion varies, however, over the extent and weight of operator involvement (see ch. 5).

Once the size of the fragments is calculated (by comparing the positions of the bands to the positions of the size standards), how close must two bands be to declare a match? Identical measurements are not to be expected, nor are they achievable. Determining an acceptable threshold of measurement imprecision is the key. In fact, because gel electrophoresis conditions vary from laboratory to laboratory, what is acceptable for one might not be appropriate for another. What is agreed on is that an objective matching rule should be used and adhered to (e.g., fragment lengths within " $x$ " percent based on the variability observed empirically when known forensic samples are repeatedly tested).

\section{Population Genetics}

Finding that two samples have the same DNA patterns does not necessarily mean they came from the same individual, just as finding two specimens with the same blood type does not mean they came from the same person. RFLP patterns represent only a snapshot of the unique DNA sequence of each individual. Thus, in the absence of a result that excludes an individual, population genetics is an essential element in forensic uses of all genetic techniques, including DNA technologies.

The validity of forensic DNA tests does not hinge on population genetics. Interpreting test results, however, depends on population frequencies of the various DNA markers $(1,9,10)$ (for RFLP analysis, the size of the band in a particular test). In other words, population genetics provides meaningnumerical weight - to DNA patterns obtained by molecular genetics techniques.

Once a set of patterns (or just two patterns) match, population frequencies are used to report the frequency that such an event could arise randomly; they are key to establishing confidence in associating an unknown evidence pattern with the pattern from a suspect or victim. For example, whether 1 in 30 billion, 1 in 2 million, 1 in 50, or 1 in 10 random individuals could be expected to be contributors to a specific piece of biological evidence. That basic scientific principles of population genetics can be applied to forensic DNA analysis is not in question, but how best to apply which principles to single-locus RFLP analysis is under debate. Disagreement exists as to the extent such a debate can or should be resolved.

Debate over population frequencies and RFLP analysis takes several forms $(16,17,29,57,69)$. General agreement exists that any potential bias that could result from calculating population frequencies be conservative, i.e., favor a defendant. Nevertheless, questions are raised about whether existing population databases are properly applied, and whether they adequately support calculations of inclusion, as currently practiced. Some argue that the magnitude of the number is not the issue, just that the analyst assigns it with confidence that genetics principles have been adhered to. Others argue that because of the pivotal role population frequencies can play in reporting results of forensic DNA tests, agreement is necessary.

Calculating Population Frequencies of RFLP Patterns-After a laboratory has determined that DNA patterns from forensic sample A match forensic sample $B$, an analyst needs to estimate how frequently such a match might arise by chance in the relevant population. Calculating the population frequency of a DNA pattern consists of two steps. The first step involves ascertaining the frequency of individual bands by examining random population samples. The second step requires estimating the population frequency of the overall DNA pattern (box 3-c).

Determining population frequencies of DNA fragments in a pattern, represented by bands on the autoradiograms, is a fundamentally empirical exercise. The size of the band in a pattern is compared to a database containing the distribution of fragment sizes found in a previously studied group of individuals. In contrast, calculating the population frequency of the overall pattern is a fundamentally theoretical exercise. Starting with the frequencies of the individual bands, an assumption must be made that each represents statistically independent events. Using certain basic formulas from populations genetics, the probability that each of these independent 


\section{Box 3-C-Statistics and RFLP Analysis}

Only a small fraction of DNA sequence differs between random individuals, except identical twins. Using DNA probes allows scientists to detect some of those differences. For forensic analysis with the single-locus RFLP technique, using several single-locus probes in combination or serially allows a forensic examiner to conclude whether two different DNA samples came from the same person (or in paternity analysis, whether a man could have fathered a child) and report remarkable statistics that the event is more than a chance occurrence-sometimes more than the number of people living on Earth.

Yet, one RFLP analysis can be thought of as only a snapshot of any given DNA sample. Thus, how many pictures need to be taken before scientists can be sure two unknown samples come from the same individual? How do they arrive at such a conclusion-expressed as a probability of the same event occurring in a random population? What is important: the number of snapshots taken? what information the snapshot reveals? or how often a certain picture can be found in a population? In other words: How many probes? How many bands? How frequently do different bands occur in the population?

Although actual calculations to assign a numerical value to RFLP analyses are far more complicated (and somewhat controversial), the following exercise is designed to provide a sense of statistics and RFLP analysis. The scenario assumes ideal genetic conditions, and eliminates one step in calculating statistics for RFLP tests by arbitrarily assigning frequencies to patterns, rather than bands.

\section{Probe Detects}

A 3 patterns; equally distributed in the population (33.3 percent each)

B 2 patterns; equally distributed in the population (50 percent each)

c 2 patterns; $\mathrm{Cl}$ is found in 90 percent of the population and $\mathrm{C} 2$ in 10 percent of the population

D 10 patterns; equally distributed in the population (10 percent each)

E 20 patterns; equally distributed in the population (5 percent each)

F 50 patterns; equally distributed in the population ( 2 percent each)

Suppose in case 1, probes A, B, C, and D were used, and pattern $\mathrm{Cl}$ was revealed in both a suspect and evidence sample. The frequency of this event-a suspect having the same composite profile as the evidence sample-would be $0.333 \times 0.50 \times 0.90 \times 0.10=0.014985$, or about 1.5 percent, or every 3 in 200 people. On the other hand, if 3 probes were used in case $2-\mathrm{D}, \mathrm{E}$, and $\mathrm{F}$ - the frequency of a suspect matching this overall pattern would be 0.10 x 0.05 x $0.02=0.000100$, or 0.01 percent, or 1 in 10,000 persons. Even though fewer probes were used in case 2, a forensic analyst could declare a greater likelihood of inclusion. In fact, the absolute number of probes used in single-locus RFLP analysis is less important than what information each probe reveals.

Similarly, suppose probes $\mathrm{C}$ and $\mathrm{D}$ were used in case 3, and patterns $\mathrm{Cl}$ and $\mathrm{D}$ revealed. The frequency that the same pattern would occur in a random sample of the population would be $0.90 \times 0.10=0.09$, or 9 in 100 people. Yet, if the same two probes were used in case 4, but patterns C2 and D were revealed, the frequency of this combination would be $0.10 \times 0.10=0.01$, or 1 in 100 people. Even though identical probes were used, a forensic analyst can report a lower chance that a random match had occurred in case 4 because the information provided by the $\mathrm{C}$ probe for case 4 was more revealing-i.e., the analyst can declare that DNA testing in case 4 narrowed the number of individuals who could have contributed the sample more significantly than in case 3 .

SOURCE: OffIce of Technology Assessment 1990.

events would be observed is then computed to yield the frequency with which that particular pattern (genotype) occurs at that locus in the population. Finally, assuming that different single-locus probes have been chosen because they are not correlated, the frequencies of the genotypes can be multiplied to achieve an estimate of how often that particular composite DNA profile could be expected in the population.

One critical factor: These basic calculations are only valid when applied to populations in which the
DNA fragments are statistically independent. Otherwise, the value calculated might greatly underestimate the true occurrence of the pattern in the general population-making a match seem rarer than it actually is. Essentially, the population must be one where individuals randomly marry and reproduce, so that distinct subgroups are absent. In such freely mixed populations, there will be no correlation between the alleles on the maternal and paternal chromosomes (Hardy-Weinberg equilibrium) and no correlation between alleles at different loci (no linkage disequilibrium). 
If the population is not freely mixed, then correlations between alleles at two loci can exist, even if they lie on different chromosomes. In fact, alleles are not randomly distributed among individuals. Certain alleles clearly concentrate within specific ethnic groups, but where do the types of genetic markers used in forensic analysis fall? Consensus exists that genetic departures as extreme as those for rare disease alleles do not exist for alleles detected by forensic DNA probes (63). The best forensic DNA probes would detect loci where the pattern of inheritance most closely resembles that expected in a freely mixed population.

However, no detailed population studies exist yet. Thus, individual population databases used to calculate probabilities of inclusion for DNA forensic analysis should be examined for departures from genetic models. Even if significant departures are found, some estimate of match probabilities is possible. Precisely how statistical tests should be applied to verify that significant deviations from random expectation do not occur is under debate, as is what mathematical compensation can be made to account for any deviation.

Population Substructures-Because the United States is multiracial, with many ethnic subgroups, special care must be taken when determining the likelihood of obtaining a certain pattern within distinct population subgroups. What effect does this population substructuring have on the ability to calculate genotype frequencies within racial subgroups?

For example, several population genetics databases (see ch. 5) collect and classify information as ' 'Hispanic,' based on self-identification or surname. Hispanic as an ethnic subgroup, however, is extraordinarily broad in the United States. In particular, it is possible that frequencies of certain RFLP patterns in Mexican-Americans differ from citizens of Puerto Rican descent, which both could differ from individuals of Cuban or El Salvadoran heritage. The Native American population in the Southwestern United States differs significantly from Native Americans in Alaska or Hawaii. Similarly, race distinction as a division of population genetics could be insufficient. RFLP patterns from persons of Japanese, Chinese, Vietnamese, and Korean ancestry all might differ, yet be classified under the designation Asian or Oriental.
Yet how important are such subdivisions in calculating the probability that a match is real or random? Most observers agree that, while a danger exists in overplaying the "numbers game," population frequencies based on existing databases can be obtainedalthough any reported identification frequency represents an estimate to be used in conjunction with other evidence linking a defendant to a crime. Furthermore, the numerical significance of a match that is expressed needs to take into account the frequently unknown ethnic association of the forensic specimen and details of the ethnic variation for the population database used. On the other hand, many argue that while estimates can be made, a more rigorous and formal system for determining g association probabilities is necessary-both because many aspects of the genetics of RFLPs have yet to be elucidated, and because juries often place great store on statistics (see ch. 4) (30).

Finally, what populations should be studied? Ideally, a random sample of the U.S. population should be tested. Since true random sampling is impractical, as is sampling all ethnic subgroups in the United States, human geneticists must determine standards and criteria that will account for the strengths and weaknesses of population genetics databases. Although it might seem academic to some to know whether the frequency of random match is 1 in 10 million or 1 in 10,000 , others express concern about population frequencies-especially in the context of any single individual on trial. Population studies and analyses of statistical reporting for single-locus RFLP tests are also relevant and critical to the design and potential use of national databases of DNA types (see ch. 5).

\section{Multilocus Probe Analysis}

As described in chapter 2, multilocus probes simultaneously detect a wide range of restriction fragment length polymorphisms, thus yielding a pattern of 30 or more bands per individual $(33,48,49)$. Multilocus probes were the first probes used for DNA identification-an immigration case in the United Kingdom in 1985 (49). Initially, great excitement was generated about the use of multilocus probes in forensic cases, since they could allow unique identification from a single hybridization.

Properly performed, multilocus probe analysis is reliable and valid, using the same basic techniques as single-locus probe analysis. However, many be- 
ing the issue of population genetics are the Genetics Society of America and the Society of Heredity and Evolution.

Lastly, since the technique of electrophoresis is the basis in RFLP analysis for discruminating band sizes among individuals, the expertise of members of the Electrophoresis Society also could be brought to bear on issues surrounding forensic applications of this technique. In particular, efforts of this professional society to evaluate state-of-the-art and quality control considerations for electrophoretic methods could be useful. Joint efforts involving scientists from this society and forensic practitioners would then be able to evaluate whether certain electrophoretic methods were better suited to forensic work, or if new developments in electrophoresis would be adaptable to widespread use in forensic laboratories.

Thus, several scientific professional societies that represent stakeholders in forensic applications of DNA identification exist. In addition, professional organizations devoted to interests of the legal community, including the American Bar Association, the American Association of Trial Lawyers, the National Association of Criminal Defense Lawyers, the National College of District Attorneys and the American Civil Liberties Union, have an interest in resolving issues in DNA typing of forensic samples. Cooperation among professional organizations could be a powerful mechanism to ensure quality; in the area of forensic DNA analysis, no single professional society can claim sole, or even greatest, expertise. Although each group has specific strengths and weaknesses, the collective wisdom and influence of professional groups on quality assurance should not be underestimated or discounted. Nevertheless, professional society membership or claims of adherence to different voluntary professional guidelines can confuse the general public, and should not be viewed as the ultimate imprimatur of quality.

\section{Nonregulatory Mechanisms}

Short of regulating crime laboratories and other facilities that perform DNA typing for nonmedical uses, States and the Federal Government could promote quality assurance through nonregulatory means. Federal efforts, in particular, could facilitate

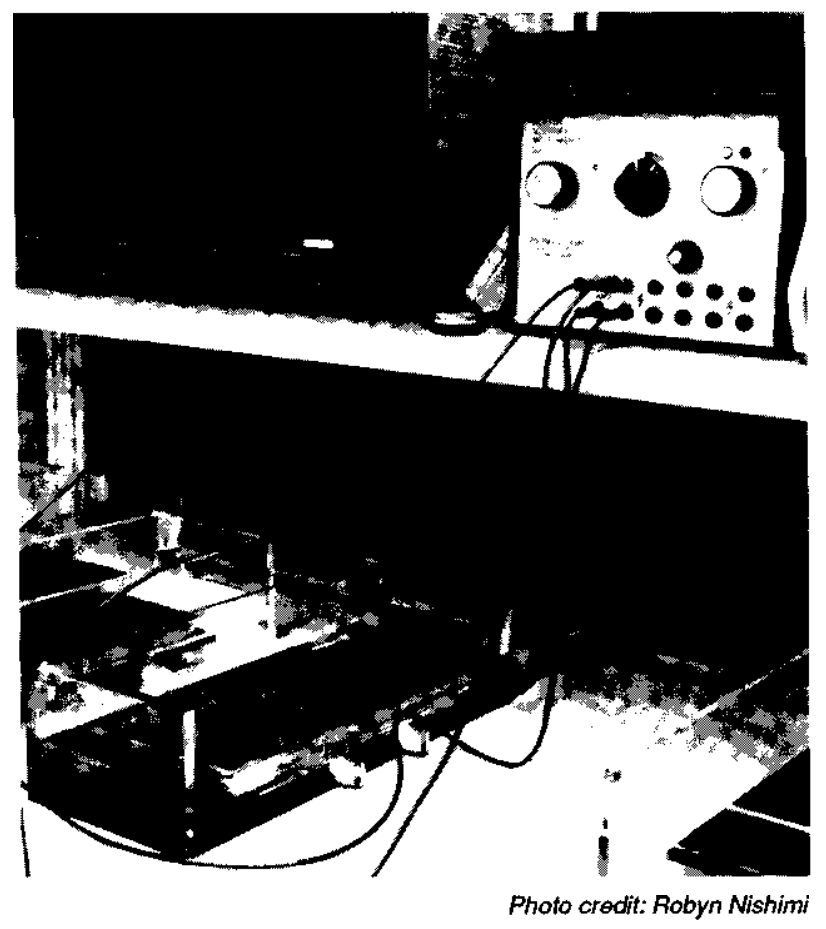

Gel electrophoresis of DNA samples.

self-regulation. Nonregulatory action could also take the form of authorizing additional Federal research in forensic sciences-particularly crossdisciplinary projects that apply emerging basic research tools to real-world casework, or enhanced population data collection for forensic DNA probes. Additional nonregulatory Federal efforts can encourage the use of governmental, professional society, and industry resources to review forensic uses of DNA tests, or to hold consensus conferences that make recommendations for quality assurance of forensic DNA analysis.

A Federal role in a consensus conference process is not novel. For example, concern over costly and possibly premature applications of medical innovations led to the 1977 Consensus Development Program $(71,90,97)$. Part of the U.S. Department of Health and Human Services (DHHS), National Institutes of Health (NIH), its purpose is to develop consensus on the clinical significance of new findings and the financial, ethical, and social impacts of a procedure's development and use. To that end, an Office of Medical Applications of Research coordinates consensus conferences and other activities

In late 1989. at the reauest of several parties. including the FBI and the National Institute of Justice (NU), a committee of the National Research Council, National Academy of Sciences, began a study of forensic DNA analysis. 
In forensic analysis, the problem of crosscontamination could be particularly serious: Should a suspect's sample accidentally contaminate a questioned sample containing degraded (or no) DNA, subsequent PCR amplification of the questioned sample would show that it perfectly matched the suspect. Thus, whereas cross-contamination in RFLP analysis might more likely arise from mislabeling of tubes than physical cross-contamination of samples, forensic uses of PCR must stringently guard against both. Proper controls, including "no DNA controls,' ' are critical to interpretation of PCR-based results.

Proper controls and precautions for forensic uses of PCR have been proposed $(4,61)$. Laboratories must be forewarned, however, that extraordinary care is needed in sample handling-greater than the level required in RFLP analysis. Some even argue that it might be desirable if evidentiary and suspect samples were not stored or amplified in the same room. In any case, even with carefully controlled tests, some argue that results in forensic casework should probably be reconfined by an independent repetition from the original sample. (Fortunately, the minimal sample requirements of PCR and the ease of the procedure make it practical, for the most part, to repeat the test multiple times.)

\section{Misincorporation}

Rarely-about once or twice every 20,000 to 1 million bases - in the molecular copying process of PCR is a nucleotide misincorporated $(28,78)$. Can this amount of misincorporation affect the validity of PCR for forensic uses? Theoretical modeling indicates that although a proportion of PCR products can contain some misincorporation, such events occur at random. Within an amplified sample, the chances of having a group of DNA molecules with the exact same single base substitution would then be minuscule (80), unless the substitution occurs early in the reaction, when the effect could be significant (63).

In fact, misincorporation does not create problems in DNA sequencing analysis or probe typing of PCR-amplified DNA (28), because the entire population of molecules is being ex amined, not a single molecule. Thus, misincorporation of nucleotides might not affect the ability of PCR to distinguish among different DNA profiles in forensic samples. On the other hand, misincorporation of nucleotides could be an issue if the initial amount of DNA is minute, which is often the situation in a forensic case. One component of standards for forensic use of PCR might include the threshold quantity of DNA that would be acceptable for valid and reliable examination (25).

\section{Differential Amplification}

Differential amplification, i.e., preferential copying of one allele over the other, is a concern in PCR testing. During the course of an amplification, differential amplification of one or the other of the two alleles can occur due to variation in length (47), sequence difference, or contamination with nonDNA material in an evidence sample (63). As mentioned previously, individuals are often heterozygous-i.e., have one band larger than the second band in an RFLP pattern. Thus, if one allele is preferentially amplified, one of the bands might not be detected and the person mistakenly typed as a homozygote.

Differential amplification can be addressed, in part, by carefully characterizing the regions to be examined and establishing standards of practice to avoid contamination. Thus, despite concerns about this matter and the previously mentioned issues, few doubt that ongoing research will overcome questions raised about PCR, with full technology transfer of PCR in criminal investigations occurring in the next few years.

\section{Population Genetics}

Population genetics considerations for PCR depend on the genetic locus amplified. At present, the only genetic system generally employed in forensic casework using PCR is the HLA $D Q x-1$ system-a human white blood cell antigen system. Results in this system are scored through the "yes' '/"no" assay described in chapter 2. HLA DQx-1 is a valid and well-defined system (78), but it is not as discriminating as RFLP analysis. It can distinguish between two random individuals 93 percent of the time (98). Such discriminating power has proved useful in excluding or including suspects in criminal cases where conventional serological genetic analysis has failed, or where insufficient DNA was available for single-locus analysis. And, although few population studies involving PCR-based detection systems have been defined to date, such information can be expected to accumulate rapidly as experience in research laboratories increases. One population genetics issue that might need address- 
ing: accounting for differential amplification of alleles in a PCR-based analysis that reveals an apparent homozygote (63).

\section{QUALITY CONTROL AND QUALITY ASSURANCE}

Laboratories use quality control to ensure that an assay's quality achieves specified criteria. Quality control includes the steps taken by a laboratory to produce consistent, interpretable results each time the test is performed. A quality assurance program provides evidence that quality control is being satisfactorily performed. Such documentation can include proficiency testing and external inspections $(5,54-56,85)$. Quality control and quality assurance are essential components of good laboratory practice.

Congress has long had an interest in quality assurance issues. Through its charge to protect the public welfare, Congress and the Federal Government have implemented an array of quality assurance programs-ranging from specific legislative action to encouraging voluntary mechanisms - in a variety of fields. In particular, quality assurance for both drug testing (box 3-D) and clinical diagnostic laboratories has been the focus of recent congressional and executive attention (53 FR 11970; Public Law 100-71; Public Law 100-578; 88,89,96).

The issue of quality assurance for the Nation's crime laboratories is not novel. Scrutiny of crime laboratories has been an issue since their proliferation in the 1970s (68,73). Publicity surrounding DNA typing in criminal casework, coupled with the fact that DNA technologies often capture government and public interest (91,93-95), has simply renewed interest in the performance of forensic facilities. Thus, while DNA testing served as the catalyst for today's debate about quality assurance for crime laboratories, other tests previously sparked attention about this subject $(38,39,68)$.

In one respect, however, concern about forensic DNA analysis differs from previous attention to quality assurance of forensic services: Both public and commercial private providers are involved. While some mechanisms to attain uniform, highquality service can be the same for both sectors, other approaches might apply to only one.

This section concentrates on the role that can be played by professional societies, State and local

\section{Box 3-D-Quality Assurance and Drug Testing Laboratories}

Drug testing of employees and job applicants has become increasingly commonplace. The dramatic increase in testing facilities to handle samples has spawned concern about ensuring that sufficient care is taken so that those tested are not harmed by poor-quality tests or inadequate quality assurance policies or quality control procedures. In 1988, the General Accounting Office surveyed all 50 States on the nature of laws, regulations, and other legally enforceable provisions in effect that would govern quality assurance of drug testing laboratories. The survey revealed that no uniform system exists to regulate laboratories doing employee drug testing. Some States do have formal mechanisms specific for quality assurance oversight of drug testing facilities. Others regulate laboratories that perform employee drug analysis through general medical or clinical laboratory statutes. Still others voluntarily adhere to standards prescribed by various professional associations. Some do not control such services at all.

The Federal Government has moved to improve results from laboratories providing employee drug testing services (53 FR 11970; Public Law 100-71). Congress also is interested in ensuring quality in laboratories that do employee drug testing. Legislation considered during the 100th Congress would have required proficiency testing and certification by the U.S. Department of Health and Human Services for all facilities engaged in urinalysis and blood analysis for employee drug testing. Similar legislation is pending in the 101st Congress.

SOURCE: Office of Technology Assessment 1990.

governments, and the Federal Government to ensure that both private and public laboratories provide high-quality forensic DNA typing. It discusses the structure of professional societies and their potential for providing practitioner education, setting standards, assuring adequate staffing and laboratory facilities, and developing a consensus among all parties who have an interest in high-quality forensic DNA analysis.

Further, Congress has declared that crime is essentially a local problem that must be dealt with by State and local governments (with Federal financial and technical support) if it is to be effectively controlled (42 U.S.C. 3701). Crime laboratories are, in fact, public agencies, and State and local governments play a key role in determining quality of 
forensic services. Thus, this section examines the role of State and local governments in quality assurance of DNA profiling.

In addition, the Federal role in quality assurance can operate at both nonregulatory and regulatory levels. The Federal Government can facilitate nonregulatory efforts to guarantee high quality. It can also actively regulate standards of practice, protocols, and commerce in forensic services (especially those paid for by government programs). In particular, this section describes quality assurance protocols implemented by the Federal Government in other laboratory testing areas, such as clinical diagnostics laboratories and drug testing facilities. Finally, the Federal Government has, over the last 15 years, formed commissions that have recommended action on topics related to applications of the new DNA technologies. Federal powers to implement the suggestions of these advisory groups also are explored.

\section{The Role of Professional Societies}

Membership in professional societies is purely voluntary, as is members' adherence to an organization's code of conduct and standards. Professional organizations can set informal standards, make members undergo continuing professional education to maintain active membership status, and require periodic examination. A professional organization can also survey its members and gather data on new techniques. Again, taking part in such studies is voluntary on the part of the membership.

In the forensic sciences, one of the many influential societies is the American Academy of Forensic Sciences (AAFS). A nonprofit professional society organized in 1948, AAFS is devoted to the improvement, administration, and achievement of justice through the application of science to the processes of law. The organization draws members from the 50 States, all U.S. territories, and over 30 countries, and is the largest professional society devoted to forensic practices. An ad hoc committee has been established to ex amine forensic applications of DNA tests and, as quality assurance mechanisms develop, AAFS members will play a key role in developing standards and disseminating information.

Another group of forensic professionals is the American Society of Crime Laboratory Directors (ASCLD). ASCLD guidelines do not bind a society's members to a particular practice, but do serve to develop some consensus among practitioners. For example, a DNA implementation committee has been established (see ch. 6). ASCLD also encourages proficiency testing before an analyst is assigned casework (6). In particular, ASCLD provides professional advice to a proficiency testing program, and offers a voluntary accreditation program (described in following sections).

In addition to national organizations, forensic practitioners in regional jurisdictions have pioneered efforts to establish guidelines for quality assurance. For example, in 1987, the California Association of Criminalists (CAC) and the California Department of Justice held a statewide symposium of serologists to examine standards in quality assurance, training, record collection and evidence preservation, method validation, and data interpretation. As a result of the symposium, a document articulating the professional consensus of serology practices within California was published (22). In addition, the California Association of Crime Laboratory Directors (CACLD) endorsed a series of guidelines to evaluate DNA testing by commercial services (21), which could provide criteria for measuring performance of public crime laboratories.

Other professional organizations, such as the Council on Forensic Science Education, the American Association of Blood Banks (AABB), the American Society for Histocompatibility and Immunogenetics (ASHI), and the International Society for Forensic Haemogenetics (ISFH), are likely to play an important role in debates surrounding quality assurance for DNA analysis by crime laboratories. For example, AABB and ASHI have standards for using DNA polymorphisms in parentage testing $(3,4)$. ASHI standards address both RFLP analysis and PCR/ HLA typing (4). ISFH recommendations encompass RFLP analysis for parentage and criminal samples (45).

Another important professional society, although not directly involved in forensic sciences per se, is the American Society of Human Genetics (ASHG). A society principally composed of scientific experts in human genetics, ASHG could be useful in evaluating the utility, validity, and reliability of newly emerging DNA technologies, as well as analyzing population genetics data. A recent statement raises several points that ASHG believes should be considered in forensic DNA testing (7). Other professional societies that could contribute to debates surround- 
ing the issue of population genetics are the Genetics Society of America and the Society of Heredity and Evolution.

Lastly, since the technique of electrophoresis is the basis in RFLP analysis for discruminating band sizes among individuals, the expertise of members of the Electrophoresis Society also could be brought to bear on issues surrounding forensic applications of this technique. In particular, efforts of this professional society to evaluate state-of-the-art and quality control considerations for electrophoretic methods could be useful. Joint efforts involving scientists from this society and forensic practitioners would then be able to evaluate whether certain electrophoretic methods were better suited to forensic work, or if new developments in electrophoresis would be adaptable to widespread use in forensic laboratories.

Thus, several scientific professional societies that represent stakeholders in forensic applications of DNA identification exist. In addition, professional organizations devoted to interests of the legal community, including the American Bar Association, the American Association of Trial Lawyers, the National Association of Criminal Defense Lawyers, the National College of District Attorneys and the American Civil Liberties Union, have an interest in resolving issues in DNA typing of forensic samples. Cooperation among professional organizations could be a powerful mechanism to ensure quality; in the area of forensic DNA analysis, no single professional society can claim sole, or even greatest, expertise. Although each group has specific strengths and weaknesses, the collective wisdom and influence of professional groups on quality assurance should not be underestimated or discounted. Nevertheless, professional society membership or claims of adherence to different voluntary professional guidelines can confuse the general public, and should not be viewed as the ultimate imprimatur of quality.

\section{Nonregulatory Mechanisms}

Short of regulating crime laboratories and other facilities that perform DNA typing for nonmedical uses, States and the Federal Government could promote quality assurance through nonregulatory means. Federal efforts, in particular, could facilitate

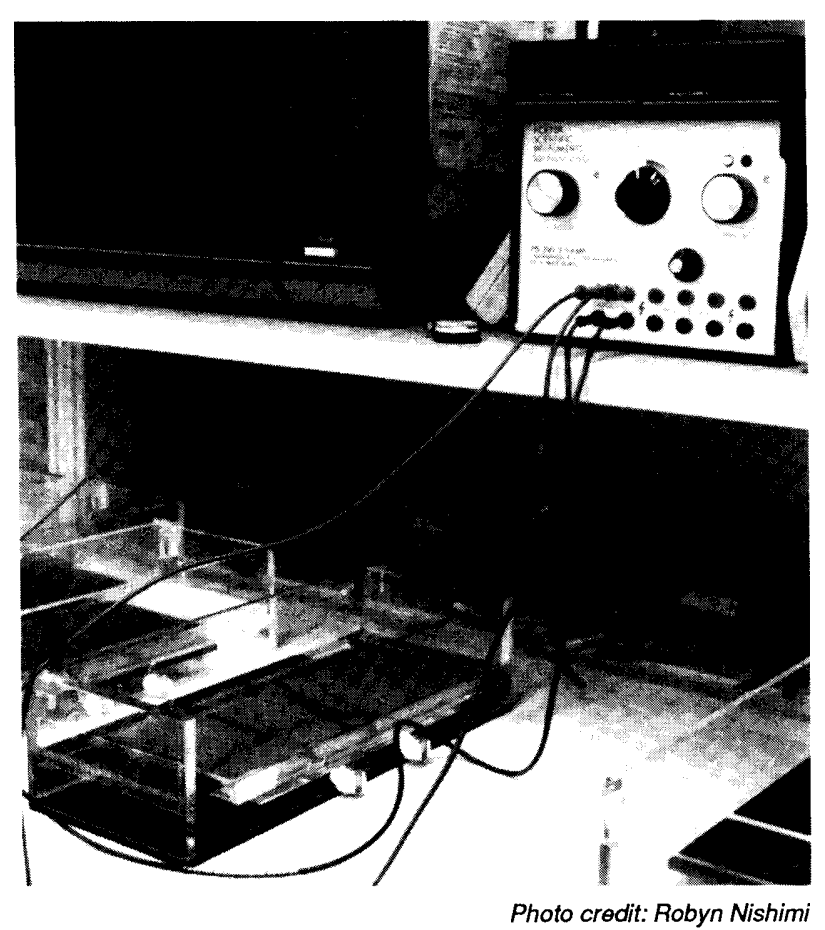

Gel electrophoresis of DNA samples.

self-regulation. Nonregulatory action could also take the form of authorizing additional Federal research in forensic sciences-particularly crossdisciplinary projects that apply emerging basic research tools to real-world casework, or enhanced population data collection for forensic DNA probes. Additional nonregulatory Federal efforts can encourage the use of governmental, professional society, and industry resources to review forensic uses of DNA tests, 'or to hold consensus conferences that make recommendations for quality assurance of forensic DNA analysis.

A Federal role in a consensus conference process is not novel. For example, concern over costly and possibly premature applications of medical innovations led to the 1977 Consensus Development Program $(71,90,97)$. Part of the U.S. Department of Health and Human Services (DHHS), National Institutes of Health (NIH), its purpose is to develop consensus on the clinical significance of new findings and the financial, ethical, and social impacts of a procedure's development and use. To that end, an Office of Medical Applications of Research coordinates consensus conferences and other activities

\footnotetext{
1In late 1989. at the request of several parties. including the FBI and the National Institute of Justice (NIJ), a committee of the National Research Council, National Academy of Sciences, began a study of forensic DNA analysis.
} 
with the NIH Bureaus, Institutes, and Divisions, and guides the appointment of expert advisory panels to review and make recommendations on medical innovations and their applications.

NIH consensus conferences are open to the public and generally involve interdisciplinary panels drawn from a range of interests. Over 60 consensus conferences have been convened in the last decade, with noticeable effects on the practice of medicine in some areas $(44,71)$. The NIH process has served as a general model for consensus development and group judgment programs in the United States and abroad $(8,44)$.

Consensus conferences on forensic DNA analysis, for example, could evaluate data on DNA probes, including studies of the population genetics of probes, and recommend protocols that list the best methods. Conferences and reports could also help define a "successful" program, or distinguish experimental from standard investigative techniques.

One important consideration in whether an NIHlike consensus process would be appropriate to forensic DNA testing is whether the questions are primarily scientific, or primarily ethical or economic. The conferences are more effective when they are the former $(58,92)$, although a recent external review of the program made recommendations that could strengthen its economic, social, and ethical evaluations (44). Thus, the consensus confer- ence process might be most amenable to resolving debates about appropriate probes, electrophoresis conditions, criteria for declaring a match, or calculating population frequencies, but be less successful in addressing a topic such as privacy of DNA databases. Nevertheless, an NIH-like consensus conference process could be effective and lead to greater quality assurance in forensic practices using DNA tests.

One nonregulatory Federal initiative to examine quality control and quality assurance issues is being spearheaded by the Federal Bureau of Investigation's (FBI) Technical Working Group on DNA Analysis Methods (TWGDAM) (see ch. 6). Consisting of individuals representing forensic facilities at or near implementation of DNA profiling techniques, one TWGDAM document outlines a multifaceted program to ensure quality RFLP analysis (box 3-E) (85).

Although some predict the TWGDAM guidelines are likely to be the nucleus around which national consensus on standards for quality assurance will evolve, others are less sanguine. Some critics object to the closed nature of the initial decisionmaking or lack of representation in the group of certain interested parties. A few argue that the FBI-largely an investigative and enforcement body-is an inappropriate lead player, and thus they oppose any role for the FBI in quality assurance mechanisms and standards. On the other hand, the TWGDAM guidelines

\section{Box 3-E--Quality Assurance and the FBI Technical Working Group on DNA Analysis Methods}

From the outset, one goal of the FBI's TWGDAM (see ch. 6) was to suggest guidelines that would assist a crime laboratory in developing a quality assurance program for forensic RFLP analysis. Following review and revision of proposed guidelines, the policies were published in 1989.

The TWGDAM guidelines are designed to encompass 'all significant aspects of the laboratory process." The program includes considerations for personnel education and training, proper documentation of pertinent records, evidence handling, validation of analytical procedures, technical controls and standards, data analysis and reporting, proficiency testing, and independent auditing.

For proficiency testing, the TWGDAM guidelines state that open and blind proficiency tests must be performed, and recommend that an analyst be subject to both types of proficiency testing annually. Yearly independent audits should also be conducted, and it is "highly desirable" that the inspection include at least one person from outside the agency.

Policies detailed in the TWGDAM program "represent the minimum quality assurance requirements for DNA RFLP analysis." Although the guidelines are strictly voluntary, they could become the de facto standard for quality assurance. For example, the Minnesota Supreme Court cited the TWGDAM guidelines in ruling on the admissibility of DNA tests (see ch. 4).

SOURCE: Office of Techmology Assessment 1990, based on Technical Working Group on DNA Analysis Methods (TWGDAM), "Guidelines for a Quality Assurance Program for DNA Restriction Fragment Length Polymorphism Analysis," Crime Laboratory Digest 16(2):40-59, 1989. 


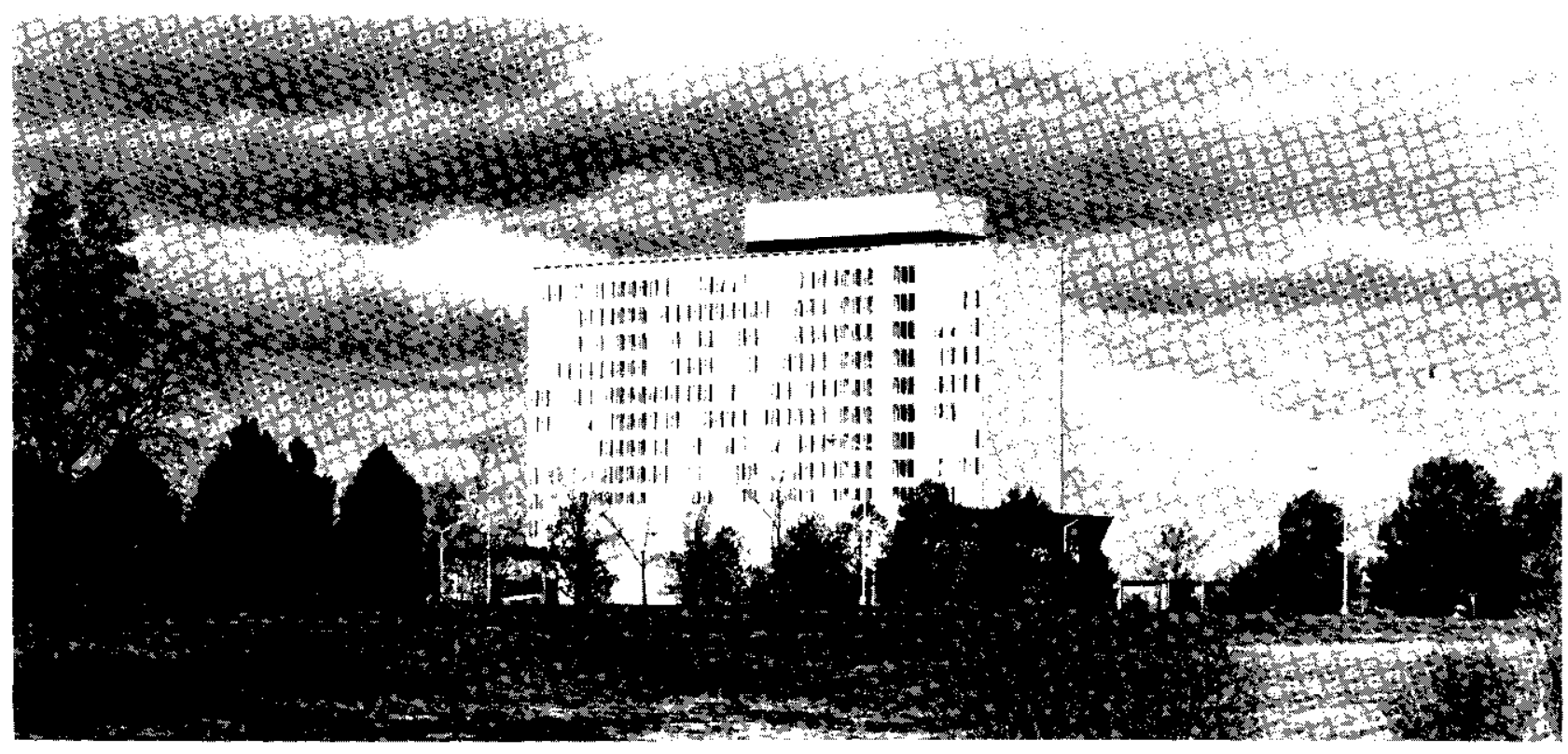

Photo credit: National Institute of Stanckrds and Technology

U.S. Department of Commerce, National Institute of Standards and Technology, Gaithersburg, MD.

represent a first-step in a probable multistage process to achieve consensus on quality assurance programs. In particular, because its members are forensic practitioners, TWGDAM proposals are likely to address the concerns and solutions of this stakeholder.

Finally, a significant part of quality assurance involves confidence in measurement standards. The U.S. Department of Commerce, National Institute of Standards and Technology (NIST) (formerly known as the National Bureau of Standards), established in 1901 (15 U.S.C. 271), is a neutral, nonregulatory agency that conducts research providing groundwork for the Nation's measurement systems. At present, NIST activities include evaluating size markers, reagent quality, and electrophoresis conditions, so that DNA fragment sizes can be more accurately determined (76). Additionally, NIJ, through its Law Enforcement Standards Laboratory at NIST, has initiated a program to examine standards for DNA processing (75). As the only Federal laboratory with the explicit goal of researching and providing reference standards, NIST proposals, as they become available, will likely play an important role in quality assurance of forensic uses of DNA identification.

\section{State Authority To Regulate Crime Laboratories}

States individually make and enforce most criminal laws. Inherent in this authority is the ability to marshal the evidence required for conviction. Thus, each State controls how DNA evidence is analyzedincluding setting standards for performance-and presented in court (see ch. 4). Accordingly, States have the authority to regulate forensic DNA typing by both private laboratories and public crime laboratories. All State jurisdiction is limited by the provisions of the U.S. Constitution regarding the rights of individual citizens, but a State's inherent powers to protect victims and suspects are broad and provide many potential avenues for regulation, even if parallel areas of Federal authority have developed.

Regulation of medical facilities might provide guidance to the States. All licensing of medical personnel and facilities is based on State law, and almost all tort law is State-based, despite Federal activity in all these areas (92). State authorities most relevant to forensic uses of DNA tests are licensing of laboratory personnel and monitoring facilities. At least one State, Maryland, maintains regulatory authority over one private forensic labo- 
ratory through the issuance of a clinical laboratory license in the area of molecular biology (31).

To date, no State has enacted general licensing requirements for crime laboratories. Several have requirements in restricted areas such as forensic alcohol analysis, but no State has licensing requirements for DNA typing in forensic casework. Nor does any State have forensic licensing requirements regulating DNA typing by private companies. One nonregulatory means to regulate forensic uses of DNA tests could be negligence litigation (box 3-F).

\section{Crime Laboratory Personnel}

Two general mechanisms to assure quality of laboratory personnel exist: certification and licensure. Certification is a voluntary process, while licensing is government mandated. Licensing of personnel is generally the domain of State governments. It is a formal mechanism intended to protect both the public and the profession, as well as provide guidance to the judicial system. For forensic DNA testing, a State could specify particular qualifications necessary for either public or private facilities. States could require their licensees to follow certain nationally recognized standards.

As well as requiring minimum standards, licensing provides States with the right to review an individual's practice, and to discipline the person with sanctions ranging from simple censure to license revocation for failure to follow proper standards in delivering services. On the other hand, without licensing, enforcement of honest practice might be stronger, not weaker, because general antifraud provisions might apply (36). In some instances, possession of a license can provide a practitioner with a misleading imprimatur of expertise (36).

At present, no State requires licensing of crime laboratory personnel or private practitioners performing DNA analysis on forensic samples. In contrast, a majority of States regulate the qualifications of clinical laboratory personnel (79). Although no State licenses criminalists or serologists, voluntary certification programs are in place for some forensic fields, but not in criminalistics. As early as 1979, proposals surfaced for certifying criminalists (26). At the time, a majority of professionals in criminalistics withheld support, and no national certification program yet exists. In 1988, certification efforts for criminalistics were revived, and an American Board of Criminalistics was incorporated in August 1989 (27). At the State level, CAC began a certification test in May 1989 (11).

To set and implement licensing or certification guidelines, however, the forensic science professional community must define the body of special-

\section{Box 3-F-Negligence Litigation}

Tort law is a nonregulatory means for social control of risks to health and safety. Permitting individuals to sue those who have wronged them through negligence serves as a mechanism for financial and emotional compensation, and for quality control. Theoretically, by making people responsible for their actions, individuals have an incentive to act responsibly. In practice, negligence litigation involving DNA typing would probably suffer from the same shortcoming found in medical malpractice litigation-a focus on past errors rather than future improvements. Nevertheless, as with medical malpractice, negligence litigation could have an effect on private entities that provide DNA typing for forensic purposes, particularly parentage testing.

To prove negligence, an individual would need to prove the commercial forensic practitioner breached a duty through neglect or lack of due care. Most likely, the plaintiff would have to show that the defendant did not adhere to "good accepted practice," or that the industry-wide definition of such practice is so flawed that failure to go beyond it constitutes negligence.

In the absence of a good-practice standard for forensic DNA testing, each party in a suit must look to other fields to judge the defendant's conduct. This problem complicates the presentation and evaluation of evidence. If one judge tries more than one case involving DNA testing, a de facto standard could develop for that courtroom, but would have little value as precedent outside that jurisdiction. Most courts also are not in a position to promulgate such standards outside the confines of a trial. Thus, while tort suits may remedy individual grievances, they do little to force development of a nationwide, good-practice standard. Tort suits do a better job of enforcing standards after they have been developed. Without standards, the importance of negligence litigation on quality assurance for forensic DNA typing would appear to be minimal at present, and its future impact uncertain.

SOURCE: Office of Technology Assessment 1990, 
ized knowledge required, establish a system to identify qualified persons who meet minimum standards of practice, and agree to guidelines against which courts can measure scientific evidence and performance (12). In particular, minimum curricular requirements, training, and continuing education need delineation. At present, professional training is largely through on-the-job apprenticeships, seminars, and workshops, including training by the FBI's Forensic Science Research and Training Center (FSRTC) in an array of forensic specialties for about 300 State and local crime laboratory personnel annually (51). Formal academic coursework in forensic science at the undergraduate and graduate levels is available in only a few institutions, with internships not widely available.

Recently, however, progress in defining training and educational requirements has been made. For example, the TWGDAM quality assurance guidelines address education and training of forensic personnel (85). The Council of Forensic Science Educators has been formed with the goal of developing standards for forensic science education (12) In the field of serology, that area where DNA typing expertise is likely to fall, the Southern Association of Forensic Scientists has drawn up a training outline (83). Serologists in California have proposed basic educational requirements and training needs for professionals in their State (22).

While some predict national consensus for training and education requirements will be achieved, implementation of such a program does not seem imminent. Clearly, one of the best mechanisms to guarantee quality is providing adequate resources for educating and training forensic laboratory personnel. At present, such resources are woefully inadequate, and most agree that increased State and Federal attention in this area is necessary.

In addition to adequate education and training of forensic laboratory personnel, quality control and quality assurance before evidence samples reach the laboratory door has been underemphasized to date. Providing education for field personnel on how best to gather and preserve evidence so that DNA identification can be performed will aid and enhance the efforts of the forensic examiner.

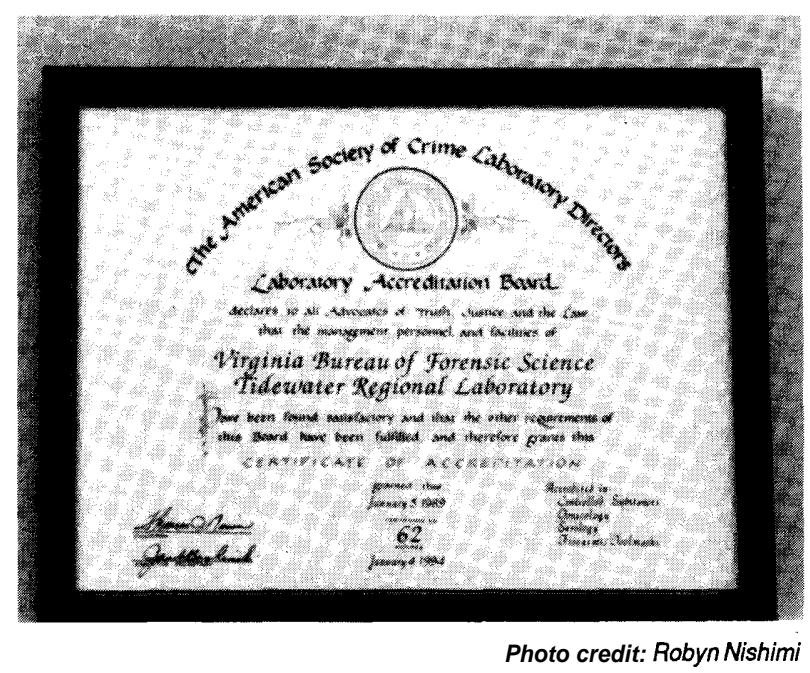

Certificate of accreditation for voluntary program offered to forensic laboratories by the American Society of Crime Laboratory Directors.

\section{Crime Laboratory Facilities}

As well as requiring licensing of personnel, States can mandate licensing of facilities or specific services within facilities. States could, for example, adopt laboratory licensing regulations aimed specifically at DNA typing programs, and not other forensic technologies, in private and public laboratories. Supplemental to or in place of licensing can be an accreditation process offered by a neutral, external body, such as the College of American Pathologists for medical genetics or the Joint Commission on Accreditation of Healthcare Organizations for various medical facilities. Accreditation can be strictly voluntary, and traditionally has been. But increasingly, as a condition of receipt of certain privileges or in exchange for funding, State or Federal officials require accreditation by a specific group or groups.

Licensing-As mentioned, no State currently regulates forensic service facilities in general, although States do have clear authority to oversee such services. In contrast, all 50 States and the District of Columbia require that public and private hospitals be licensed, although the scope of the laws varies considerably (101). In 1988, in an effort to ensure quality services, Congress passed sweeping legislation that subjects all clinical testing laboratories to a uniform standard of regulations (Public Law 100578) (box 3-G).

Accreditation-Although not subject to mandatory oversight, one voluntary accreditation program 


\section{Box 3-G-Quality Assurance and Clinical Laboratories}

In October 1988, Congress passed sweeping legislation that subjects clinical laboratories to a number of requirements, including qualifications for the laboratory director, standards for the supervision of lab testing, qualifications for technical personnel, management requirements, and an acceptable quality control program. Prior to enacting the Clinical Laboratory Improvement Amendments of 1988 (CLIA) (Public Law 100-578), Federal regulations covered the approximately 13,000 labs that either transported samples between States or performed tests billed to Medicaid and Medicare. Beginning in 1990, however, the Health Care Financing Administration (HCFA) of the U.S. Department of Health and Human Services (DHHS) will exercise sweeping regulatory authority over clinical laboratories. HCFA will set standards for staffing and maintaining all medical laboratories, including physician office testing. HCFA will also manage a comprehensive program to police the facilities and can impose sanctions.

CLIA is at once broad, encompassing the estimated 98,000 physician labs, and specific. For example, the Secretary of DHHS is to establish national standards for quality assurance in cytology services, including the maximum number of cytology slides that any individual may screen in a 24-hour period. The Secretary is also required to determine and implement recordkeeping, inspection, and proficiency testing programs, and to study and report to Congress on a range of issues gauging the impact of various quality assurance mechanisms.

CLIA expands DHKS's regulatory authority over clinical laboratories, and grants HCFA the power to suspend or revoke a lab's certificate for violation of the rules. Further, fines up to $\$ 10,000$ for each violation or each day of noncompliance can be levied, and jail sentences of 3 years can be imposed. The law continues to permit, subject to approval by the Secretary, the involvement of State or private nonprofit associations (which at present include the College of American Pathologists, the American Association of Bioanalysts, agencies in 3 States, the Joint Committee on Accreditation of Healthcare Organizations, and the American Osteopathic Association) to substitute for the Federal regulatory process.

Prior to CLIA's enactment, one issue of critical concern to Congress was proficiency testing programs. Until CLIA, such programs varied broadly in testing criteria and in grading of test results. Moreover, uniform or minimally acceptable Federal standards did not exist. Now, except under certain circumstances, proficiency testing shall be conducted on a quarterly basis, with uniform criteria for all examinations and procedures. The Secretary shall also establish a system for grading proficiency testing performance.

SOURCE: Office of Technology Assessment 1990.

for crime laboratories does exist. Established in 1981 by ASCLD, the program includes a selfevaluation, an inspection process, and required proficiency testing. As of December 1988, 58 laboratories representing 15 Federal, State, and local agencies-about 20 percent of the Nation's crime laboratories-have been accredited during the program's 7 years of operation. (An additional seven laboratories were accredited as of May 1989.) In comparison, a 5-year-old AABB program to evaluate parentage testing laboratories had accredited 48 labs representing about 39 percent of potential facilities as of December 1988 (1 1,12).

Many criticize current optional accreditation efforts as inadequate, and assert that mandatory accreditation by an external, neutral body is essential. ${ }^{2}$
Others strongly argue that current voluntary programs improve quality and are sufficient. Many feel that action should focus on increasing participation in voluntary programs, rather than mandating accreditation.

Nevertheless, while simultaneously contributing to quality assurance, mandatory accreditation of laboratories by independent, impartial organizations -in consultation with forensic practitioners and academic forensic scientists-could be effective in dispelling the notion of some that crime laboratories are not neutral bodies. Such programs could remove the perception of many defense attorneys and their clients that crime laboratories are biased-working principally toward conviction for prosecutors and police departments, and secondarily in defendants'

${ }^{2}$ Arguments have been made that mandatory accreditation (and licensing), in general, needs to be evaluated for anticompetitiveness considerations (36,37). It is unlikely, however, that the Antitrust Division of the U.S. Department of Justice (or private individuals or corporations) will find any occasion to attack concerted action in forensic services per se, since these are largely public facilities, or generally run as small business. Additionally, it is difficult to imagine Federal Trade Commission scrutiny for potential "unfair practices" related to information disclosure: Individuals involved in commercial services have routinely communicated their findings and procedures, in part to satisfy legal requirements of introducing DNA tests in court. 
interest. On the other hand, accredi. tation, licensing, and certification are costly and time-cons uming endeavors that would likely place an additional personnel and financial burden on public facilities already overwhelmed with criminal casework and generally underfunded (74).

Proficiency Testing-Proficiency testing in crime laboratories is currently offered through a program administered by Collaborative Testing Services (CTS) in association with the Forensic Science Foundation (FSF) (the research arm of the AAFS). Participation is voluntary and anonymous, and more than half the crime laboratories subscribed to the physiological fluids program in 1985 (65), which now includes samples for DNA testing. In place since the mid1970s, the CTS-FSF program has supporters and critics. Proponents point out that although not compulsory, the program provides a crime laboratory an opportunity to monitor the technical performance of its employees and compare results with other laboratories. Critics argue that results from the program merely underscore the need for tighter control, even mandatory regulation through legislation.

A 1978 study (73) found that an 'appalling' (68) number of participating laboratories reported erroneous results in testing blind samples, with as many as 94 out of 132 laboratories participating obtained ' 'unacceptable' blood typing results. Another critic reports that from 1978 through June 1988, the number of errors for bloodstain or physiological stain proficiency tests varied from 7 percent for one test to 77.7 percent for another, and that overall, an average of 25 percent of crime laboratories returning results made errors (38). In one human blood test to evaluate genetic markers, 15 of 69 participating laboratories (21.7 percent) made at least 1 error (38). None of these tests involved DNA typing.

In contrast, another review of the CTS-FSF serology testing program reported strikingly different findings for 7,827 tests performed during 1978 to mid-1986 (81): an error rate of 2.4 percent (189 errors). Further analysis revealed that 88 of these errors arose in laboratories that made three or more errors in the particular trial; which was acknowledged as an amount signifying serious problems. Subtracting the errors made by these laboratories reduced the rate to 1.3 percent. The study, which included all but one proficiency trial during that period, concluded that, on average, 79.1 percent of reporting laboratories were error-free; 4.2 percent of

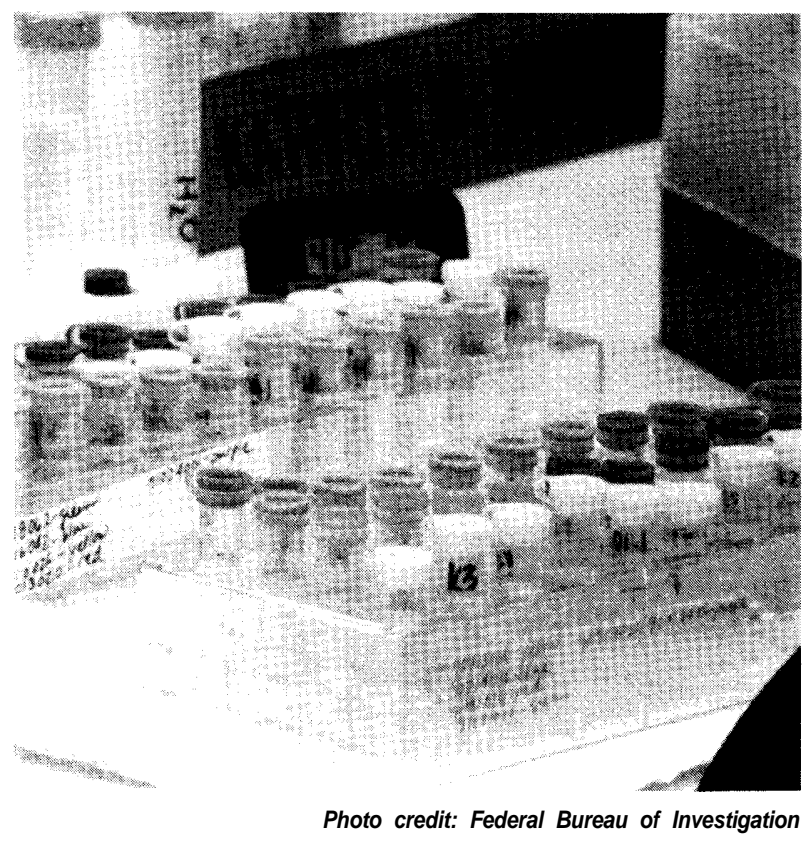

DNA samples for RFLP analysis.

laboratories reported three or more errors (81). The author of this report, as well as many others, attribute the different findings to how 'error' was defined in each study. The analysis reporting the greater error rate counted 'inconclusive' results as errors, a practice with which the vast majority of scientists disagree. Similarly, "unacceptable" in the 1978 study is attributed to laboratories lagging behind in employing certain state-of-the-art tests, not to actual performance (82).

In addition to the CTS-FSF program, some crime laboratories subscribe to the voluntary proficiency program sponsored by the AABB parentage testing committee, which also includes DNA typing. Both the CTS-FSF and AABB voluntary programs, however, are less rigorous than the comparable program in the United Kingdom. Not only is DNA proficiency testing already in place in the United Kingdom, but the program includes blind tests slipped into the flow of actual casework (100). Interspersing blind tests with case samples clearly yields the most accurate measure of a laboratory's performance on a test.

With respect to blind trials of forensic DNA testing in the United States, CACLD organized trials using case-simulated samples in 1987 and 1988. The three major commercial facilities then performing forensic DNA analysis participated in each trial. In 
the first trial, out of 50 samples, 2 firms each declared 1 false match (60) that could have resulted in the conviction of an innocent person. The errors apparently arose from sample handling problems (11). The third company declared no false matches (60). In the second trial, one company again reported an incorrect match (13).

To date, the FBI has not provided blind trials to commercial laboratories, nor does it have plans to do so in the future. However, the FBI's FSRTC will provide initial open proficiency tests to those State and local laboratories that participate in the FBI's training program. FSRTC also prepares proficiency samples to monitor the performance of the FBI DNA Analysis Unit. In addition, the FBI plans to administer a program that offers seed money to encourage commercial ventures to develop proficiency samples and testing $(14,41)$. The FBI will not analyze DNA work performed by State and local laboratories, however, having a longstanding policy not to reexamine evidentiary materials previously examined by another crime laboratory.

Some observers, generally not forensic analysts, suggest that a mandatory, independent process of proficiency testing for public and private forensic laboratories engaged in DNA testing should be established. Others, usually from crime laboratories, support open and blind proficiency tests per se, but categorically oppose an independent, mandated program. What is clear is that proficiency testing has long been recognized to be a key component of quality assurance. Clinical laboratories, for example, are required by Federal law to meet acceptable performance criteria under a proficiency testing program on a quarterly basis (Public Law 100-578). One administrator of a clinical laboratory proficiency testing program argues that such a program is the best, economically feasible, external source for determining lab quality (53). In fact, the TWGDAM quality assurance guidelines-whose authors include crime laboratory personnel-include requirements for proficiency testing (85).

Although consensus exists that some sort of DNA proficiency testing program is desirable, disagreement arises over who shall administer it, who shall judge what constitutes acceptable performance, and the role of proficiency test results in court proceedings. Some argue that forensic practitioners alone are best able to make such decisions, while others maintain that involvement of molecular biologists and human geneticists is necessary. And, while many feel the present CTS-FSF program is wellplaced to administer DNA proficiency testing, others believe a new system is necessary.

Finally, disagreement exists about the general availability of proficiency testing results for trial examination. Some maintain that such testing is designed for internal quality assessment and feedback, and should not be applied punitively against all work performed by a particular examiner or laboratory. Others strongly disagree, arguing that proficiency testing data-especially in the absence of standards-is the only way to determine whether reliable findings were obtained for any case. And, as demonstrated by the studies of the CTS-FSF program, how 'inconclusive' results are classified is important when error rates are reported.

\section{Federal Authority To Regulate Crime Laboratories}

In theory, the Federal Government can only exercise those powers specifically granted to it in the Constitution. None of those powers relate directly to forensic practices in general, or to DNA typing by crime laboratories in specific, Yet the Federal Government is not powerless in this area. With respect to setting standards of practice for other types of laboratories-most notably clinical diagnostics and drug testing-Congress and the executive branch have separately and together imposed requirements designed to ensure consistently high quality. The following sections examine congressional authority to regulate forensic uses of DNA technologies, and analyze present Federal regulation of clinical and drug testing laboratories.

\section{Taxing and Spending Authority}

Article I, Section 8 of the Constitution states that Congress may spend money "for the common Defense and general Welfare of the United States.' It is through the use of conditional appropriations-i.e., attaching strings to grants of moneythat Congress derives its power to regulate through spending (87). The Supreme Court has upheld congressional authority to impose conditions on the use of funds directly distributed to States by the Federal Government. States, to the extent they wish to avail themselves of such monies, must comply with those conditions (40). 
Direct finding of crime laboratories would give the Federal Government the authority to determine a wide variety of requirements for the delivery of high-quality service. For example, the government could attach certain conditions to funds earmarked for crime laboratories for DNA analysis, or attach conditions for general quality assurance to appropriations such as recent finding for drug analysis. Several models of this type exist, for example reimbursement criteria under Medicare for an array of circumstances. One section of DHHS's 1987 "Medicare Program Criteria for Medicare Coverage of Heart Transplants" (52 FR 10935) requires that eligibility for Medicare reimbursement for heart transplants depends on a facility's demonstrated experience and survival rate. For DNA analysis of forensic samples, tying funding to actual performance on proficiency tests could have a powerful influence on the quality of services.

In addition to stipulations for direct funding to crime laboratories, the Federal Government also has the power to condition the receipt of Federal monies by a State (instead of by a single laboratory) on the State's taking a specific regulatory action. Examples of these types of stipulations include recent policies that tie State highway improvement grants to maximum speed limits or the minimum drinking age. Thus, the Federal Government could link funds provided to State commissions or agencies to the adoption of certain quality assurance procedures or regulations that effect both State and local crime laboratories. The power to apply such conditions is likely true even when the connection between the State program and DNA analysis is quite attenuated (92). Congress could mandate, for example, certain quality monitoring protocols for States accepting funds for prison construction or other non-DNArelated criminal justice uses.

\section{Authority Over Interstate Commerce}

The second major area over which Congress has wide authority to regulate forensic uses of DNA techniques is through the commerce clause of Article I, Section 8, which provides the authority "To regulate Commerce .. . among the several States. ..." Congressional authority to pass laws relating in any reasonable manner to interstate commerce is such a broad power that judicial review affirming the right is largely a formality (87). Most judicial review focuses instead on the intent of

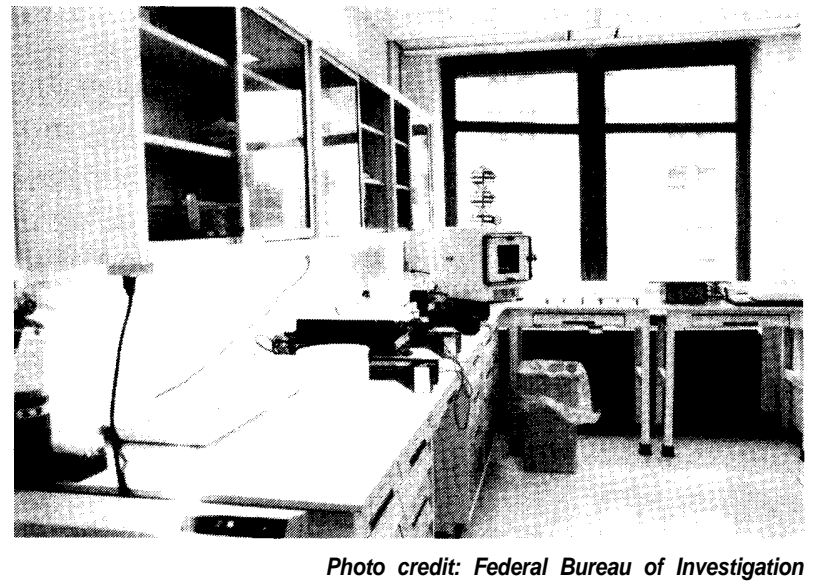

A laboratory of the FBI DNA Analysis Unit, Washington, DC.

Congress to interpret the reach and scope of the legislation.

Regulation of Products-The commerce power provides Congress the specific authority to regulate articles of commerce that pass between two or more States. The Federal Government clearly could use the commerce authority to require licensing of forensic facilities that solicit or provide forensic DNA typing services to out-of-State clients, as it has for medical laboratories engaged in interstate commerce (42 U.S.C. 263). At the moment, only a handful of facilities would be subject to regulation by Congress under this authority. Extremely broad, this authority also could be used to establish a mechanism to regulate products used in DNA typing for forensic applications.

Monitoring the Use of DNA Technologies-Congressional and executive interest and oversight of DNA technologies is not unprecedented. Recombinant DNA technologies have been subject to Federal scrutiny since the early 1970s. The NIH Recombinant DNA Advisory Committee, its Working Group on Human Gene Therapy, and more recently the Biotechnology Science Coordinating Committee have all been established to monitor or regulate various uses arising from the new genetic technologies. Thus, the Federal Government could establish a committee or commission to monitor or regulate forensic applications of DNA tests.

As mentioned, the FBI is the principal investigative arm of the Department of Justice, with no direct authority to regulate individual crime laboratories. The FBI is under the authority of the Attorney General and acts under the Attorney General's 
general statutory authority. Some suggest that the FBI should use its authority to issue official standards for DNA analysis of forensic casework. On the other hand, others oppose an official role for the FBI, believing its laboratories and research facilities should be subject to an independent commission or authority established to provide guidance and oversight of all private and public entities that do forensic DNA identification.

\section{SETTING STANDARDS}

Setting standards for forensic applications of DNA testing is the most controversial and unsettled issue, yet standards are the cornerstone of quality assurance. Technical and operational standards for DNA typing in forensic casework are needed, and needed soon. The FBI (23), industry, molecular biologists, biochemists, population geneticists, and forensic scientists all agree that standards are desirable. Agreement on what standards are appropriate, who should decide, how implementation of standards is best achieved, and whether they should be mandatory has not yet been reached.

Technical standards are needed to specify proper gel controls, electrophoresis conditions, the extent that computer-assisted matching should be permitted, population data to compute probabilities of matches, and many other parameters. It appears that setting technical standards-allowing flexibility for the vagaries of forensic casework and emerging scientific developments-is within reach. A majority agree that such efforts should include balanced input from all relevant scientific disciplines.

In contrast, operational standards, such as recordkeeping and proficiency testing, are likely to be more controversial, for attempts to regulate any sector have historically been met with resistance. Nevertheless, such standards are necessary if full quality assurance is to be achieved. Forensic scientistspractitioners and educators-argue that they are most knowledgeable about how best to set operational standards that achieve quality and meet the needs of crime laboratories without being unduly burdensome. Some in the forensic community are prepared to meet this challenge.

Yet while many forensic scientists acknowledge the need for standards in DNA typing, they resent the imposition of such standards by another scientific community unfamiliar with the vagaries of forensic casework-i.e., molecular geneticists. Some molecular geneticists, on the other hand, believe their experience over the past two decades with recombinant DNA technologies places them in a position to define how DNA tests should be applied to forensic casework. In fact, both communities can and should contribute to standard setting. Forensic practitioners are most familiar with the practical problems and unique situations that can arise in the course of an investigation, which are situations not encountered by molecular geneticists in laboratories. Likewise, research molecular biologists have knowledge about DNA tests on which forensic examiners can draw. Forensic academicians, who often are involved in early stages of evaluating basic research tools before a technology transfers into crime laboratories, are perhaps well placed to bridge the gap between crime laboratory personnel and genetics researchers.

Many have expressed the opinion that an independent commission is the best mechanism to handle both technical and operational standards. Others call for a lead role for the FBI, which some reject as a conflict of interest. Still others seek Federal or State legislative solutions. In any case, crime laboratories and forensic research have generally been underfunded, and new requirements will only increase financial difficulties. In addition, various Federal grant assistance mechanisms have been severely reduced or eliminated in the past decade. Thus, while development of standards for recordkeeping and proficiency testing should be encouraged to move forward, their costs should be recognized. Nevertheless, formalizing quality assurance mechanisms, including standards, should proceed without delay. Such efforts will assist crime laboratories making decisions about using DNA profiling onsite (see ch. 6), private laboratories, the Federal Government, and the courts.

Some commentators contend that ultimately the judicial process can provide a stringent test of scientific evidence and the quality of work in a particular case. Others strongly disagree, maintaining that it seldom does. The vast majority of scientific evidence introduced in criminal cases goes unchallenged by the opposition, usually the defense (72), which generally lacks sufficient resources to dispute such evidence. Many argue that reliance on judicial review for quality assurance has been an unfulfilled promise. 


\section{STANDARDIZATION}

Setting standards to ensure quality is distinct from developing a uniform, national system-i.e., standardization-of DNA typing within the forensic science community. Some contend that standardizing the process is institutional insurance-an additional layer of quality assurance. Others maintain that while this step is a necessary component of usable investigative DNA databanks, its role in ensuring quality is minimal. Still others believe standardization could stifle rapid integration of future innovations.

No amount of standardization, especially of procedures, however, can be substituted for appropriate scientific analysis during the progress of an individual case. By nature, nothing is routine in forensic casework. The discretion of a qualified investigator to evaluate a situation and implement appropriate measures-within standards that need to be established-is a fundamental component of quality assurance.

Is standardization desirable, or even possible? Chapter 5 discusses standardization in greater detail. Nevertheless, achieving some modicum of standardization (e.g., for restriction enzyme-probe combinations used and data interpretation), appears necessary for an effective, national database.

\section{FINDINGS AND SUMMARY}

Prior to the DNA era, the genetic analysis of forensic samples was based strictly on a paradigm of exclusion. Each genetic marker provided limited information that eliminated a fraction of the general population as the originator of a sample (e.g., excluding 30 percent, 67 percent, or 1.2 percent of persons as potential contributors), depending on the marker detected and the test result. Combining results for several different markers reduced the pool of persons who could have contributed to the biological sample. The objective, of course, was to exclude as many individuals as possible-i.e., to reduce the number of potential sources to the smallest possible value.

DNA tests operate no differently. Yet their potential power to discriminate has altered the perception that genetics can be used only for positive exclusion, not positive identification. Among all humans except identical twins, no two share the same DNA sequence. Using single-locus probe analysis, foren- sic examiners can accurately detect some of these differences to the extent that examination of several DNA markers can lead to a report that is, in effect, perceived to be a statistically positive association between an individual and a piece of biological evidence. This change in perception, however, does not alter the fact that forensic uses of DNA testslike traditional genetic marker analysisare valid.

Are DNA tests reliable? Under routine conditions of use, do they perform reproducibly within a laboratory, across many laboratories, and in the hands of different practitioners? OTA finds that, properly performed, DNA tests per se are reliable. Serious questions are raised, however, about how best to ensure that any particular test result is reliable. These questions focus on data interpretation, how to minimize realistic human error, and the appropriate level of monitoring to ensure quality. Such questions, which stem from actual court cases, underscore the need to develop both technical and operational standards now.

Standards alone should not be construed as making evidence analysis absolutely reliable. Standards would, however, provide a benchmark against which all interested parties can judge a particular analysis. Undoubtedly some queries will still arise on a case-by-case basis. At such times, specific details can and should be evaluated in court. But, with time and implementation of standards, such questions should decrease.

What standards are needed for private and public facilities doing forensic DNA testing, and who decides? At present, only a vague consensus exists for the first question, and none for the second. Nor does consensus exist on how standards should be administered. Professional societies are making efforts toward regularization of forensic uses of DNA tests, as is the Federal Government, especially the FBI and NIST. Some contend that such efforts are insufficient because compliance is, or will be, entirely voluntary. These voices argue that quality assurance lapses in both private and public facilities will persist with voluntary guidelines. Balanced against this is the belief of many that voluntary standards are sufficient. Implicit in this point of view is the conviction that consensus and implementation of technical guidelines and standards is imminent.

Yet while consensus has been achieved for some issues, other areas remain contentious. One area 


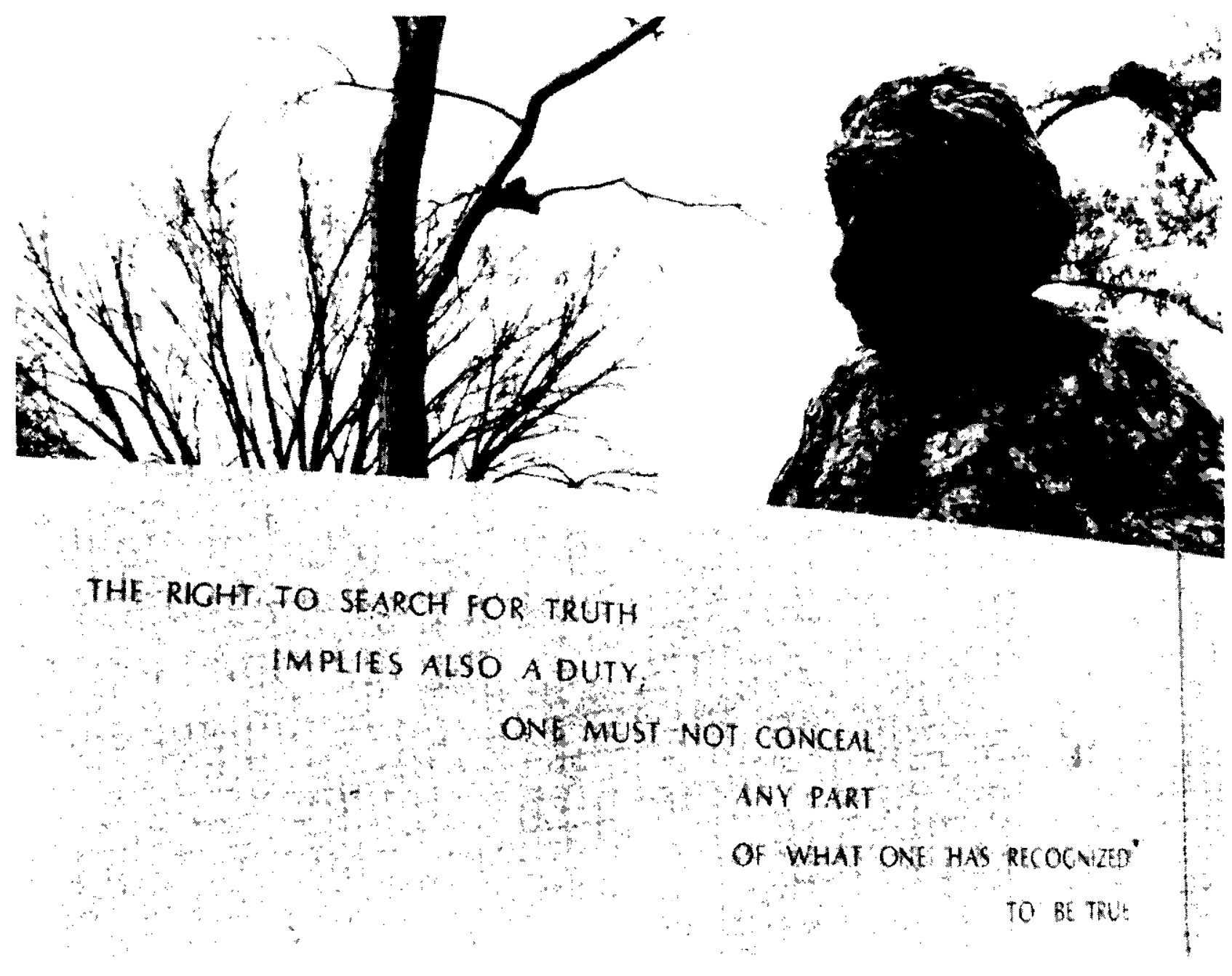

needing particular attention is the population genetics of RFLP analysis. Controversy centers on the size of the databases used and the precise approach that should be used to calculate population frequencies. Some argue that the magnitude of the number is not the issue, just that the analyst assigns it with confidence that genetics principles have been adhered to. Others argue that because of the pivotal role population frequencies can play in reporting results of forensic DNA tests, agreement is necessary. Nevertheless, using certain conservative assumptions probably allows an analyst to assert a likelihood that matched samples came from the same person. General agreement does exist that any potential bias that could result from calculating population frequencies favor a defendant.

One area of population genetics of forensic DNA typing might have an impact on both data analysis and privacy considerations (see ch. 5). The dynamic and diverse nature of the U.S. population calls for special attention to collection and classification of genetic differences based on ethnic and racial subgroups. For example, genetic data classified as 'Hispanic' on the basis of self-identification or surname could skew reported population frequencies, since DNA profiles for Mexican-Americans v. other Hispanic individuals, including those of Puerto Rican, Cuban, or El Salvadoran descent, could differ. Increased population data for RFLP analysis would benefit both questions of population substructuring, as well as calculating population frequencies in general.

Quality assurance mechanisms in forensic DNA profiling encompass a range of options, including certification, licensure, accreditation, and proficiency testing. Methods to implement these options exist, 
such as efforts by professional societies, and formal, nonregulatory methods such as consensus building among all interested stakeholders. States have authority to regulate DNA typing for forensic purposes by both private and public facilities, but to date no State has enacted general licensing requirements for private laboratories, crime laboratories, or personnel. Likewise, the Federal Government has the authority to direct that solutions be found for quality assurance of forensic services.

Federal efforts toward quality assurance for laboratories doing forensic DNA profiling need not develop in a vacuum. Congress and the executive branch have a longstanding interest in quality assurance for other laboratory services, most notably clinical diagnostics and employee drug testing. As such, solutions for these sectors could prove useful in evaluating quality assurance for laboratories performing DNA analysis in forensic casework.

Setting standards for quality assurance should proceed without delay. Such efforts will assist private laboratories, the Federal Government, the courts, and public crime laboratories making decisions about implementing DNA profiling onsite. Such endeavors must also acknowledge that introducing and maintaining formal quality assurance mechanisms can be costly and time-consuming, and will place additional personnel and financial burdens on public facilities already overwhelmed with casework and traditionally underfunded.

Finally, many questions surrounding forensic uses of DNA technologies are really questions of public policy, as much as technical and operational issues of forensic practice. As such, the influence and input of attorneys, businesses, government officials, and others in settling quality assurance issues is appropriate and important.

\section{CHAPTER 3 REFERENCES}

1. Acton, R. T., "Comparison of VNTR Allele Frequencies in White and Black Populations," proceedings, The International Symposium on Human Identification 1989: Data Acquisition and Statistical Analysis for DNA Typing Laboratories, Madison, WI, 1990.

2. Adams, D.E., Baechtel, F. S., and Budowle, B., "DNA Analysis of Body Fluid Stains Subjected to Environmental, Chemical and Biological Insults," abstract, American Academy of Forensic Sciences, 41st Annual Meeting, Las Vegas, NV, February 1989.
3. American Association of Blood Banks, AABB Standards Committee, "P.7000 DNA Polymorphism Testing," Standards for Parentage Testing Laboratories, 1989.

4. American Society for Histocompatibility and Immunogenetics, ASHI Quarterly 14(1), 1990.

5. American Society for Quality Control, "Quality Systems Terminology," American National Standard ANSI/ASQC A3-1978, 1978.

6. American Society of Crime Laboratory DirectorsLaboratory Accreditation Board, Accreditation Manual (Lansing, MI: T.J. Nasser, Michigan State Police, 1985).

7. American Society of Human Genetics, Ad Hoc Committee on Individual Identification by DNA Analysis, "Individual Identification by DNA Analysis: Points to Consider," American Journal of Human Genetics 46:631-634, 1990.

8. Andreasen, P. B., "Consensus Conferences in Different Countries: Aims and Perspectives,' International Journal of Technology Assessment in Health Care 4:305-308, 1988.

9. Baird, M., Balazs, I., Giusti, A., et al., "Allele Frequency Distribution of Two Highly Polymorphic DNA Sequences in Three Ethnic Groups and Its Application to the Determination of Paternity, American Journal of Human Genetics 39:489-501, 1986.

10. Balazs, I., Baird, M., Clyne, M., et al., "Human Population Genetic Studies of Five Hypervariable DNA Loci,' American Journal of Human Genetics 44:182-190, 1989.

11, Bashinski, J. S., California DNA Lab, California Department of Justice, Berkeley, CA, personal communication, August 1989.

12. Bashinski, J. S., "Laboratory Standards: Accreditation, Training and Certification of Staff in the Forensic Context," DNA Technology and Forensic Science, J. Ballantine, G. Sensabaugh, J. Witkowski (eds.) (Cold Spring Harbor, NY: Cold Spring Harbor Laboratory Press, 1989).

13, Bashinski, J.S. (chair), "California Association of Crime Laboratory Directors: DNA Committee Report of CACLD Blind Trial \#2," California DNA Lab, California Department of Justice, Berkeley, CA, March 1990.

14. Biotechnology Newswatch, "FBI To Offer Seed Money for Probing Forensic DNA Proficiency," Biotechnology Newswatch 9(18):5, 1989.

15. Blake, E. T., "DNA Amplification and Typing From Aged Biological Evidence," abstract, An International Symposium on the Forensic Aspects of DNA Analysis: U.S. Department of Justice, Federal Bureau of Investigation, Quantico, VA, June 1989.

16. Brenner, C., and Morns, J., "Paternity Index Calculations in Single Locus Hypervariable DNA Probes: 
Validation and Other Studies," proceedings, The International Symposium on Human Identification 1989: Data Acquisition and Statistical Analysis for DNA Typing Laboratories, Madison, WI, 1990.

17. Budowle, B., "Data for Forensic Matching Criteria for VNTR Profiles,' proceedings, The International Symposium on Human Identification 1989: Data Acquisition and Statistical Analysis for DNA Typing Laboratories, Madison, WI, 1990.

18. Budowle, B., Federal Bureau of Investigation, Quantico, VA, personal communication, April 1989.

19. Budowle, B., Shutler, G., Waye, J., et al., "Selection of Restriction Endonuclease and Interprobe Comparison for RFLP Technology,' abstract, American Academy of Forensic Sciences, 41 st Annual Meeting, Las Vegas, NV, February 1989.

20. Buoncristiani, M., von Beroldingen, C., and Sensabaugh, G. F., "Effects of $W$ Damage on DNA Amplification by the Polymerase Chain Reaction, ' abstract, An International Symposium on the Forensic Aspects of DNA Analysis: U.S. Department of Justice, Federal Bureau of Investigation, Quantico, VA, June 1989.

21. California Association of Crime Laboratory Directors, "Position on DNA Typing of Forensic Samples" (Oakland, CA: J. Bashinski, Oakland Crime Laboratory, November 1987).

22. California Association of Crirninalists, Bureau of Forensic Science and Unysis Corp., Report of a Symposium on the Practice of Forensic Serology, 1987 (Sacramento, CA: F. Springer, Bureau of Forensic Services, 1987).

23. Castonguay, R. T., Federal Bureau of Investigation, Washington, DC, personal communication, April 1989.

24. Cohen, J. E., "DNA Fingerprinting for Forensic Identification: Potential Effects on Data Interpretation of Subpopulation Heterogeneity and Band Number Variability, 'American Journal of Human Genetics 46:358-368, 1990.

25. Comey, C. T., Federal Bureau of Investigation, Quantico, VA, personal communication, April 1989.

26. Criminalistics Certification Study Committee, Certification in Criminalistics: A Find Report to the Profession (Los Angeles, CA: W.J. Cadman, California State University, Los Angeles, 1979).

27. Criminalistics Certification Study Committee, Certification of Criminalists: A Report to the Criminalistics Profession (Los Angeles, CA: W.J. Cadman, California State University, Los Angeles, 1988).

28. Erlich, H. A., Cetus Corp., Emeryville, CA, personal communications, May, August 1989.

29. Evett, I. W., and Werrett, D. J., "Bayesian Analysis of Single Locus DNA Profiles, ' proceedings, The International Symposium on Human Identification
1989: Data Acquisition and Statistical Analysis for DNA Typing Laboratories, Madison, WI, 1990.

30. Fienberg, S.E. (cd.), Panel on Statistical Assessments as Evidence in the Courts, National Research Council, The Evolving Role of Statistical Assessments as Evidence in the Courts (New York, NY: Springer-Verlag, 1989).

31. Garner, D. D., Cellmark Diagnostics, Germantown, MD, personal communication, July 1989.

32. Garner, D. D., Green, D. J., Herrin, G. L., et al., "Validation Studies Utilizing the Jeffreys DNA Probes,' abstract, American Academy of Forensic Sciences, 40th Annual Meeting, Philadelphia, PA, February 1988.

33. Gill, P., Jeffreys, A.J., and Werrett, D.J., "Forensic Application of DNA 'Fingerprints', 'Nature 318:577579, 1985.

34. Gill, P., Lygo, J.E., Fowler, S.J., et al., "An Evaluation of DNA Fingerprinting for Forensic Purposes,' Electrophoresis 8:38-44, 1986.

35. Giusti, A., Baird, M., Shaler, R., et al., 'Application of Deoxyribonucleic Acid (DNA) Polymorphisms to the Analysis of DNA Recovered From Sperm," Journal of Forensic Sciences 31;409-417, 1986.

36. Givens, R. A., Botein, Hays \& Sklar, New York, NY, personal communication, July 1989.

37. Goldenberg, M., "Standards, Public Welfare Defenses, and the Antitrust Laws,' Business Lawyer 42(3):629-674, 1987.

38. Grunbaum, B. W., Moraga, CA, personal communication, June 1989.

39. Grunbaum, B. W., "Physiological State Evidence: Guidelines to Assure Quality Analysis," The California Defender 1:20-26, 1984.

40. Harrisburg Hospital v. Thornburgh, 616 F. Supp. 699 (D.C. Pa. 1985).

41. Hicks, J. W., Federal Bureau of Investigation, Washington, DC, personal communication, February 1990.

42. Higuchi, R., and Blake, E, T., "Applications of the Polymerase Chain Reaction in Forensic Science," DNA Technology and Forensic Science, J. Ballantine, G. Sensabaugh, J. Witkowski (eds.) (Cold Spring Harbor, NY: Cold Spring Harbor Laboratory Press, 1989).

43. Higuchi, R., von Beroldingen, C. H., Sensabaugh, G. F., et al., "DNA Typing From Single Hairs," Nature 332:543-546, 1988.

44. Institute of Medicine, Council on Health Care Technology, Committee to Improve the National Institutes of Health Consensus Development Program, Consensus Development at the NIH: Improving the Program (Washington, DC: National Academy Press, 1990).

45. International Society for Forensic Haemogenetics, "DNA Recommendation," Vox Sang 57:276-277, 1989. 
46. Jeffreys, A. J., University of Leicester, Leicester, England, remarks at An International Symposium on the Forensic Aspects of DNA Analysis: U.S. Department of Justice, Federal Bureau of Investigation, Quantico, VA, June 1989.

47. Jeffreys, A. J., Wilson, V., Neumann, R., et al., "Amplification of Human Minisatellites by the Polymerase Chain Reaction: Towards DNA Fingerprinting of Single Cells," Nucleic Acids Research 16:10953-10971, 1988.

48. Jeffreys, A. J., Wilson, V., and Thein, S.L., "Hypervariable Minisatellite Regions in Human DNA," Nature 314:67-73, 1985.

49. Jeffreys, A. J., Wilson, V., and Thein, S. L., "Individual Specific 'Fingerprints' of Human DNA, " Nature 316:76-79, 1985.

50. Kanter, E., Baird, M., Shaler, R., et al., 'Analysis of Restriction Length Polymorphisms in Deoxyribonucleic Acid (DNA) Recovered From Dried Bloodstains," Journal of Forensic Sciences 31:403408, 1986.

51. Kearney, J. J., Federal Bureau of Investigation, Quantico, VA, personal communication, August 1989.

52. Kearney, J. J., Federal Bureau of Investigation, Quantico, VA, presentation before the U.S. Congress, Office of Technology Assessment, Advisory Panel on Forensic Uses of DNA Tests, April 1989.

53. Kiely, T., "Making Medical Labs Measure Up," Technology Review, pp. 14-15, July 1989.

54. Kilshaw, D., "Quality Assurance. 1. Philosophy and Basic Principles, Medical Laboratory Sciences 43:377-381, 1986.

55. Kilshaw, D., "Quality Assurance. 2. Internal Quality Control," Medical Laboratory Sciences 44:7383, 1987.

56. Kilshaw, D., "Quality Assurance. 3. External Quality Assessment" Medical Laboratory Sciences 44: 178186, 1987.

57. Kirby, L. T., DNA Fingerprinting: An Introduction (New York NY: Stockton Press, 1990).

58. Kosecoff, J., Kanouse, D.E., Rogers, W.H., et al., "Effects of the National Institutes of Health Consensus Development Program on Physician Practice,' Journal of the American Medical Association 258:2708-2713, 1987.

59. Kuo, M., Orange County Sheriff-Coroner's Crime Laboratory, Santa Ana, CA, personal communication, July 1989.

60. Kuo, M. (chair), "California Association of Crime Laboratory Directors: DNA Committee Report to the Board of Directors, Report \#6,' Orange County Sheriff-Coroner's Crime Laboratory, Santa Ana, CA, 1988.

61. Kwok S., and Higuchi, R., "Avoiding False Positives With PCR,” Nature 339:237-238, 1989.
62. Lander, E. S., "DNA Fingerprinting On Trial," Nature 339:501-505, 1989.

63. Lander, E. S., "Reliability and Validity of DNA Typing for Forensics," contract paper prepared for the Office of Technology Assessment, U.S. Congress, October 1989.

64. Li, H., Gyllensten, U. B., Cui, X., et al., ' 'Amplification and Analysis of DNA Sequences in Single Human Sperm and Diploid Cells,' Nature 355:414417, 1988

65. Lucas, D., Leete, C., and Field, K., "An American Proficiency Testing Program," Forensic Sciences International 27:71, 1985.

66. McNally, L., Shaler, R. C., Giusti, A., et al., "Evaluation of Deoxyribonucleic Acid (DNA) Isolated From Human Bloodstains Exposed to Ultraviolet Light, Heat, Humidity, and Soil Contamination," Journal of Forensic Sciences 34(5):1059. 1069, 1989.

67. McNally, L., Shaler, R. C., Giusti, A., et al., "The Effects of Environment and Substrata on Deoxyribonucleic Acid (DNA): The Use of Casework Samples From New York City," Journal of Forensic Sciences 34(5):1070-1077.

68. Moenssens, A.A., Inbau, F.E., and Starrs, J.E., Scientific Evidence in Criminal Cases, 3rd ed. (Mineola, NY: The Foundation Press, Inc., 1986).

69. Mueller, L. D., University of California, Irvine, Irvine, CA, personal communication, August 1989.

70. Neufeld, P. J., and Colman, N., "When Science Takes the Witness Stand," Scientific American 262:46-53, 1990.

71. Perry, S., "The NIH Consensus Development Program: A Decade Later," New England Journal of Medicine 317:485-488, 1987.

72. Peterson, J.L., Department of Criminal Justice, The University of Illinois at Chicago, Chicago, IL, personal communication, August 1989.

73. Peterson, J. L., Field, K., Fabricant, E., et al., Crime Laboratory Proficiency Testing Research Program (Washington, DC: U.S. Government Printing Office, 1978).

74. Peterson, J. L., Mihajlovic, S., and Bedrosian, J. L., "The Capabilities, Uses and Effects of the Nation's Criminalistics Laboratories," Journal of Forensic Sciences 30(1):10-23, 1985.

75. Rau, R. M., National Institute of Justice, Washington, DC, personal communication, July 1989.

76. Reeder, D. J., National Institute of Standards and Technology, Gaithersburg, MD, personal communication, April 1989.

77. Reynolds, R., von Beroldingen, C., and Sensabaugh, G. F., "Effects of DNA Degradation on Amplification by the Polymerase Chain Reaction,' abstract, An International Symposium on the Forensic Aspects of DNA Analysis: U.S. Department of 
Justice, Federal Bureau of Investigation, Quantico, VA, June 1989.

78. Saiki, R.K., Gelfand, D.H., Stoffel, S., et al., "Primerdirected Enzymatic Amplification of DNA With a Thermostable DNA Polymerase,' Science 239:487494, 1988.

79. Schaeffer, M. (cd.), Federal Legislation and the Clinical Laboratory (Boston, MA: G.K. Hall Medical Publishers, 1981).

80. Sensabaugh, G.F., "Consequences of Nucleotide Misincorporation During the Polymerase Chain Reaction, abstract, An International Symposium on the Forensic Aspects of DNA Analysis: U.S. Department of Justice, Federal Bureau of Investigation, Quantico, VA, June 1989.

81. Sensabaugh, G. F., "Genetic Typing of Biological Evidence: Comments for the Cooper Amicus Brief," California Association of Criminalists Newsletter, pp. 11-19, July 1987.

82. Sensabaugh, G. F., University of California, Berkeley, CA, personal communication, August 1989.

83. Southern Association of Forensic Scientists, Forensic Serology Training Program, E. Quarles (cd.) (Decatur, GA: Bureau of Forensic Science, 1988).

84. Southern, E., "Detection of Specific Sequences Among DNA Fragments Separated by Gel Electrophoresis," Journal of Molecular Biology 98:503517, 1975.

85. Technical Working Group on DNA Analysis Methods (TWGDAM), "Guidelines for a Quality Assurance Program for DNA Restriction Fragment Length Polymorphism Analysis," Crime Laboratory Digest 16(2):40-59, April-July 1989.

86. Thompson, W. C., and Ford, S., "DNA Typing Acceptance and Weight of the New Genetic Identification Tests," Virginia Law Review 75:45-108, 1989.

87. Tribe, L., American Constitutional Law (Mineola, NY: Foundation Press, 1978).

88. U.S. Congress, General Accounting Office, Employee Drug Testing: Regulation of Drug Testing Laboratories, GAO/GGD-88-127FS, Washington, DC, 1988.

89. U.S. Congress, House of Representatives, Committee on Energy and Commerce, Clinical Laboratory Improvement Amendments of 1988, Rpt. 100-899 to accompany H.R. 5150 (Washington, DC: U.S. Government Printing Office, 1988),

90. U.S. Congress, Office of Technology Assessment, Development of Medical Technology: Opportuni- ties for Assessment, OTA-H-34 (Springfield, VA: National Technical Information Service, 1976).

91. U.S. Congress, Office of Technology Assessment, Genetic Testing in the Workplace (Washington, DC: U.S. Government Printing Office, forthcoming, 1990).

92. U.S. Congress, Office of Technology Assessment, Infertility: Medical and Social Choices, OTA-BA358 (Washington, DC: U.S. Government Printing Office, 1988).

93. U.S. Congress, Office of Technology Assessment, Mapping Our Genes-Genome Projects: How Big, How Fast?, OTA-BA-373 (Washington, DC: U.S. Government Printing Office, 1988).

94. U.S. Congress, Office of Technology Assessment, New Developments in Biotechnology: Public Perceptions of Biotechnology, OTA-BP-BA-45 (Washington, DC: U.S. Government Printing Office, 1987).

95. U.S. Congress, Office of Technology Assessment, Technologies for Detecting Heritable Mutations in Human Beings, OTA-H-298 (Washington, DC: U.S. Government Printing Office, 1986).

96. U.S. Congress, Senate, Committee on Governmental Affairs, Subcommittee on Oversight of Government Management, Health Care Financing Administration's Management of Medical Laboratories, hearings Mar. 23-24, 1988, S. Hrg. 100-765 (Washington, DC: U.S. Government Printing Office, 1988).

97. U.S. Department of Health, Education, and Welfare, Ethics Advisory Board, Report and Conclusions: HEW Support of Research Involving Human In Vitro Fertilization and Embryo Transfer (Washington, DC: U.S. Government Printing Office, 1979).

98. von Beroldingen, C. H., Blake, E. T., Higuchi, R., et al., "Applications of PCR to the Analysis of Biological Evidence," PCR Technology: Principles and Applications for DNA Amplification, H.A. Erlich (cd.) (New York NY: Stockton Press, 1989).

99. Walsh, S., Blake, E., and Higuchi, R., "PCR Inhibition and Bloodstains," abstract, An International Symposium on the Forensic Aspects of DNA Analysis: U.S. Department of Justice, Federal Bureau of Investigation, Quantico, VA, June 1989.

100. Werrett, D. J., remarks at Banbury Conference on "DNA Technology and Forensic Science," Cold Spring Harbor, NY, November 1988.

101. Wing, K. R., The Law and the Public's Health, $2 \mathrm{~d}$ ed. (Ann Arbor, MI: Health Administration Press, 1985). 


\section{Chapter 4}

\section{DNA as Evidence}

"Lawyers as a group evidence an appalling degree of scientific illiteracy, which ill equips them to educate and guide the bench in its decisions on admissibility of evidence proffered through expert witnesses,

Andre A. Moenssens

Professor of Law

University of Richmond

"In testing for admissibility of a particular type of scientific evidence, whatever the scientific 'voting' power may be, the courts cannot in any event surrender to scientists responsibility for determining the reliability of that evidence."

United States $v$. Williams 583 F.2d 1194 (2d Cir. 1978)

"It (DNA) convinced me. They really never had an eyewitness to the rape. In my opinion, you could hang somebody with DNA fingerprinting.'

Murrel Casselman

Jury Foreman, State of South Carolina v. Ford 


\section{CONTENTS}

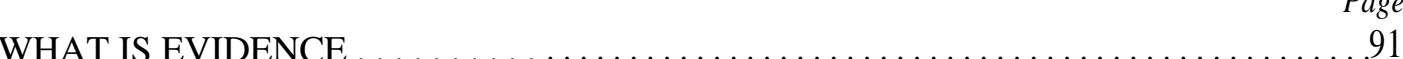

STANDARDS FOR ADMITTING SCIENTIFIC EVIDENCE $\ldots \ldots \ldots \ldots \ldots \ldots \ldots \ldots 91$

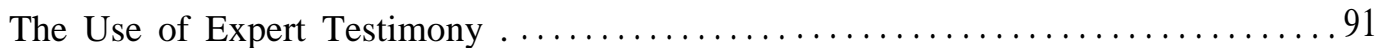

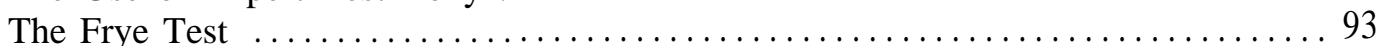

The Relevancy Test . . . . . . . . . . . . . . . . . . . . . . . . . . . . . . . . . . . . . . . . 969

THE DEVELOPMENT OF BIOLOGICAL EVIDENCE $\ldots \ldots \ldots \ldots \ldots \ldots \ldots \ldots \ldots \ldots$

CONSTITUTIONAL CONSIDERATIONS IN OBTAINING

BIOLOGICAL EVIDENCE . . . . . . . . . . . . . . . . . . . . . . . . . . . . . . . . . . 97

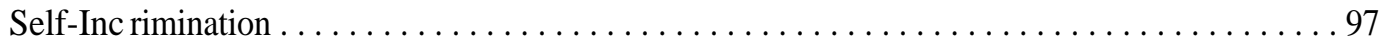

Right to Counsel ........................................... 98

Search and Seizure . . . . . . . . . . . . . . . . . . . . . . . . . . . . . . . . . 98

Due Process . . . . . . . . . . . . . . . . . . . . . . . . . . . . . . . 98

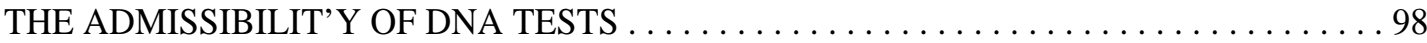

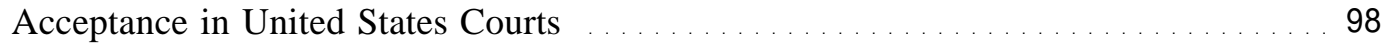

Advantages of DNA Evidence . . . . . . . . . . . . . . . . . . . . . . . . 100

Criticisms and Limitations of DNA Evidence ............................. 101

Pretrial Hearings: Offering and Rebutting DNA Evidence . . . . . . . . . . . . . . . . . 101

DNA Evidence at Trial . . . . . . . . . . . . . . . . . . . . . . . . . . . . . . . . . . . . . 107

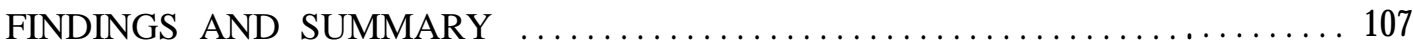

CHAPTER 4 REFERENCES . . . . . . . . . . . . . . . . . . . . . . . . . . . . . . . . 109

\section{Boxes}

4-A. Case Study: State of Florida v. Andrews ............................ 99

4-B. Defense-Initiated Testing ................................... 100

4-C. Case Study: Commonwealth of Virginia v. Spencer . . . . . . . . . . . . . . . . . . . 101

4-D. Case Study: People of New York v. Castro . . . . . . . . . . .................. 103

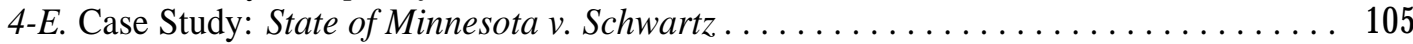

4-F. State Statutes: Admissibility of DNA Evidence $\ldots \ldots \ldots \ldots \ldots \ldots \ldots \ldots \ldots \ldots \ldots$

4-G. Appellate Court Reviews of DNA Testing . . . . . . . . . . . . . . . . . . . . . 108

Figures

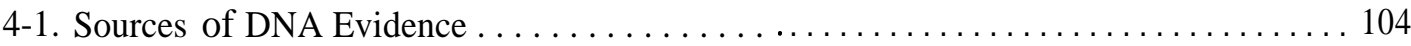

\section{Tables}

4-1. Standards for Admitting Scientific Evidence $\ldots \ldots \ldots \ldots \ldots \ldots \ldots \ldots \ldots \ldots \ldots \ldots$

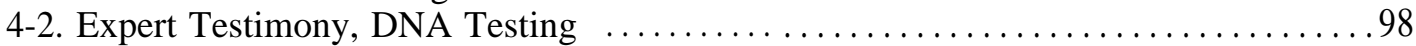


Scientific evidence is an important component of many criminal and civil trials. Because it involves technical information that is usually not well understood by laypersons, Congress, the States, and many courts have created standards governing the admission of such evidence. Scientific evidence covers a wide range of theories, procedures, and tests. Expert testimony, the primary method for introducing scientific evidence, has increased dramatically as technology has evolved.

DNA evidence is a new and dramatic forensic tool that is now at the courtroom door. How does it compare with other types of scientific evidence in terms of relevance, reliability, and impact? What are the primary evidentiary considerations faced by prosecutors in deciding whether to submit DNA evidence? What are the main obstacles for defense counsel in presenting or rebutting such evidence? What points must judges consider in deciding admissibility? Will DNA testing someday become so common that its admission will become routine, or even expected?

This chapter briefly explains what evidence is, the role of the expert witness in introducing scientific evidence, the standards for the admission of scientific evidence, and the use of genetic markers and DNA as evidence in U.S. courts.

\section{WHAT IS EVIDENCE?}

Evidence is data or information on which judgments are made. The law of evidence is the system of rules and standards by which the admission of proof in a court of law is regulated (29). Evidence takes many forms, including testimony of witnesses, records, documents, exhibits, facts stipulated by both sides, and anything perceptible to the five senses (20). The rules and standards that make up the law of evidence address the admissibility, relevancy, and sufficiency of various types of proof. The ultimate objective of evidence in a criminal case is to convince the judge or jury of the prosecution's or defense's contention.

Rules concerning the admission of evidence exist at both the Federal and State levels. The Federal Rules of Evidence (codified in volume 28 of the United States Code Annotated) govern proceedings in Federal courts and before U.S. magistrates (Rule 101). State rules of evidence govern proceedings in the tribunals of various State, county, and local jurisdictions. Although the Federal Rules of Evidence do not govern the proceedings in the courts of the 50 States, they serve as the model for the evidence codes of 32 States (19).

Enacted by Congress in 1975 (Public Law 93595), the Federal Rules of Evidence address relevancy, privileges, witnesses, opinion and expert testimony, hearsay, authentication and identification, and the contents of certain types of tangible items.

\section{STANDARDS FOR ADMITTING SCIENTIFIC EVIDENCE}

The use of scientific evidence, although not new, presents a unique problem because it involves information that is "beyond the ken" of the average layperson (29). Such information normally cannot be presented without touching on data that are beyond firsthand observation of the facts of a particular case, and indeed requires the inclusion and examination of opinions not permitted under normal rules of evidence. This dilemma has resulted in the formation of rules-at the Federal and State level, both by statute and court action-for the admission of scientific testimony.

\section{The Use of Expert Testimony}

A general rule of evidence is that a witness may testify only to facts known to the witness through firsthand observation and inferences based on direct observations (e.g., the identity of a person, the color of a car, the rate of speed of an automobile). The testimony of a lay witness, therefore, does not usually extend to facts beyond direct observation. This requirement has its roots in English common law, which demanded that witnesses test@ only about "what they see and hear' (29). Such a standard created the need for a special rule to permit the introduction-through an expert witness-of scientific evidence that is beyond the normal observation of a layperson.

Over the course of history, the courts have encountered issues that require analysis and explanation by persons with scientific or specialized knowledge or experience. This situation, associated with the development of various fields of science, led to the evidentiary use of expert testimony at trial (30). The 


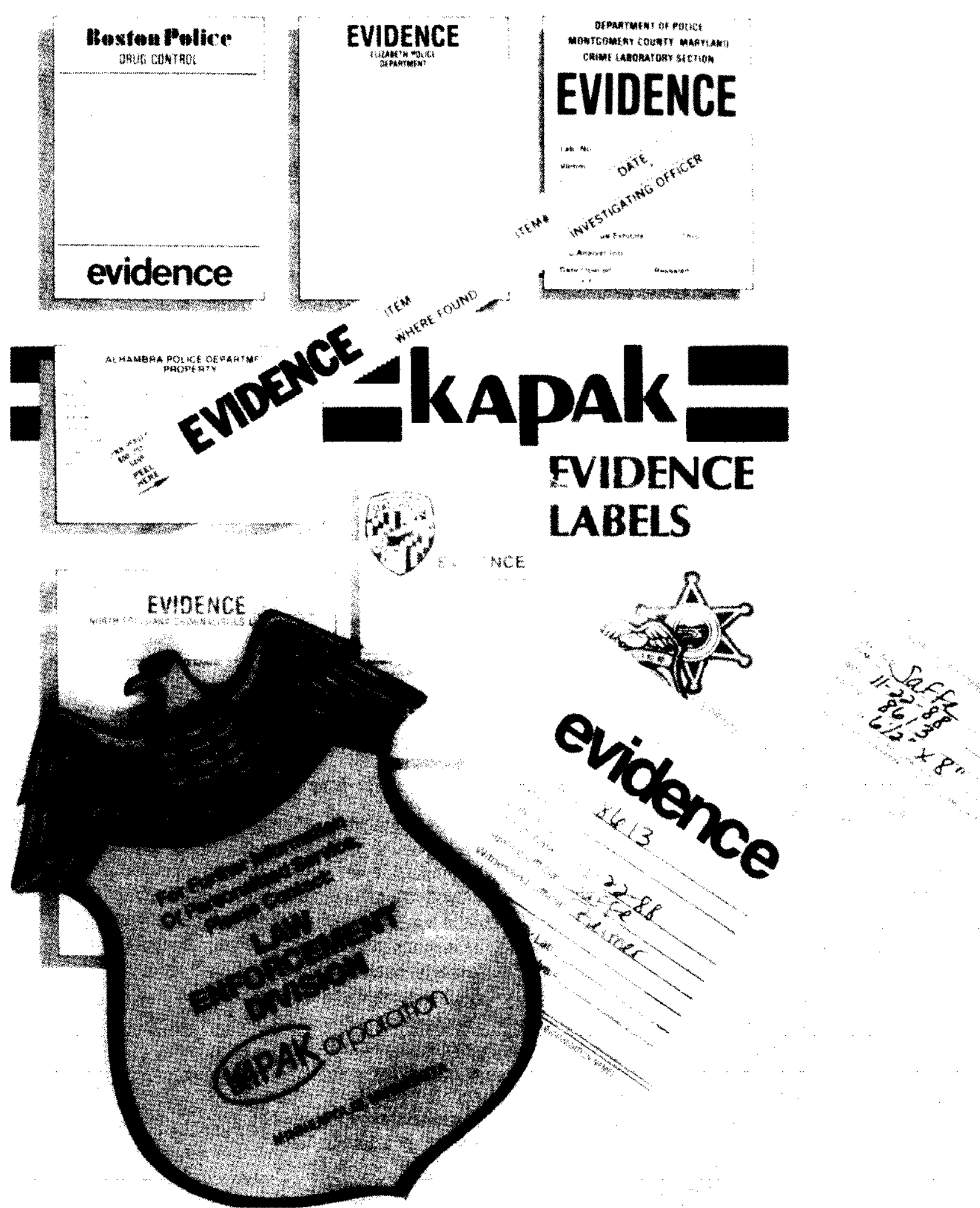


use of expert witness testimony in U.S. criminal trials has expanded over time to include many relevant subjects.

Unlike an observer witness, the expert witness has the power to draw inferences from facts that a jury would not be competent to draw. To warrant the use of expert testimony, two elements are required:

- The subject of the inference must be so distinctively related to some science, profession, business, or occupation as to be beyond the ken of the average layperson.

- The expert must have sufficient skill, knowledge, or experience in that field or calling so that the opinion or inference will probably aid the judge or jury in the search for the truth.

The principal consideration, as stated by one treatise on evidence, is whether on this subject a jury can receive from this person appreciable help (44). It is through the use of expert testimony that scientific tests and data are introduced, explained, and rebutted.

A problem arises when an attempt is made to deduce expert opinion from a procedure that has not yet received widespread scientific recognition (30). A key element is whether the scientific test in question is trustworthy, which has two componentsaccuracy (validity) and consistency (reliability). The trustworthiness of scientific evidence is usually evaluated under one of two standards: the Frye test (or 'general acceptance' test), or the relevancy test (based on the Federal Rules of Evidence) (table 4-1).

\section{The Frye Test}

The so-called Frye test, named after the defendant in a 1923 murder case (11), is the oldest and most often used test in determining the admissibility of scientific evidence. Under the Frye standard, courts admit evidence based on novel scientific techniques only when the technique has gained general acceptance in the scientific community to which it belongs.

Prior to his trial, James Alfonso Frye was subjected to a systolic blood pressure deception test (i.e., a lie detector test). As explained by the court:

... the theory seems to be that the truth is spontaneous, and comes without conscious effort, while the utterance of a falsehood requires a conscious effort, which is reflected in the blood pressure. The rise thus produced is easily detected and distinguished from the rise produced by mere fear of the examination itself.

Frye's lawyer offered the scientist who conducted the test as an expert witness. The government's counsel objected to the use of such expert testimony, and the trial court sustained the government's objection. The appellate court's two-page decision cited no previous case law and ended with the following two paragraphs, which have evolved into the leading test for all types of novel expert testimony:

Just when a scientific principle or discovery crosses the line between experimental and demonstrable stages is difficult to define. Somewhere in this twilight zone the evidential force of the principle must be recognized, and while courts will go a long way in admitting expert testimony deduced from well-recognized scientific principle or discovery, the thing from which the deduction is made must be sufficiently established to have gained general acceptance in the particular field in which it belongs.

We think the systolic blood pressure deception test has not yet gained such standing and scientific recognition among physiological and psychological authorities as would justify the courts in admitting the expert testimony deduced from the discovery, development, and experiments thus far made (11).

The general acceptance test under the Frye standard appears to require a two-step analysis:

- identifying the field in which the underlying theory falls (i.e., in determining whether the technique meets the test of acceptance in the scientific community, defining what community is relevant); and

- determining whether the principle has been accepted by most members of the identified field.

Fulfilling the first element can be difficult, especially if several fields of scientific endeavor are involved. Expert testimony for voice prints, for example, has been held by one court to include the

Table 4-I-Standards for Admitting Scientific Evidence

\begin{tabular}{llc}
\hline Standard & \multicolumn{1}{c}{ Test } & Source \\
\hline Frye $\ldots \ldots \ldots$ & General acceptance by the \\
scientific community & 1923 case \\
Relevancy $\ldots .$. & Relevant to the trier-of-fact & $\begin{array}{c}\text { Public Law } \\
\text { 93-595 }\end{array}$ \\
\hline
\end{tabular}

SOURCE: Office of Technology Assessment, 1990. 
WHEN ONLY AN EXPERT WILL DO..." Nearly 15,000 experts in more than four thousand categories. Here is a partial listing.

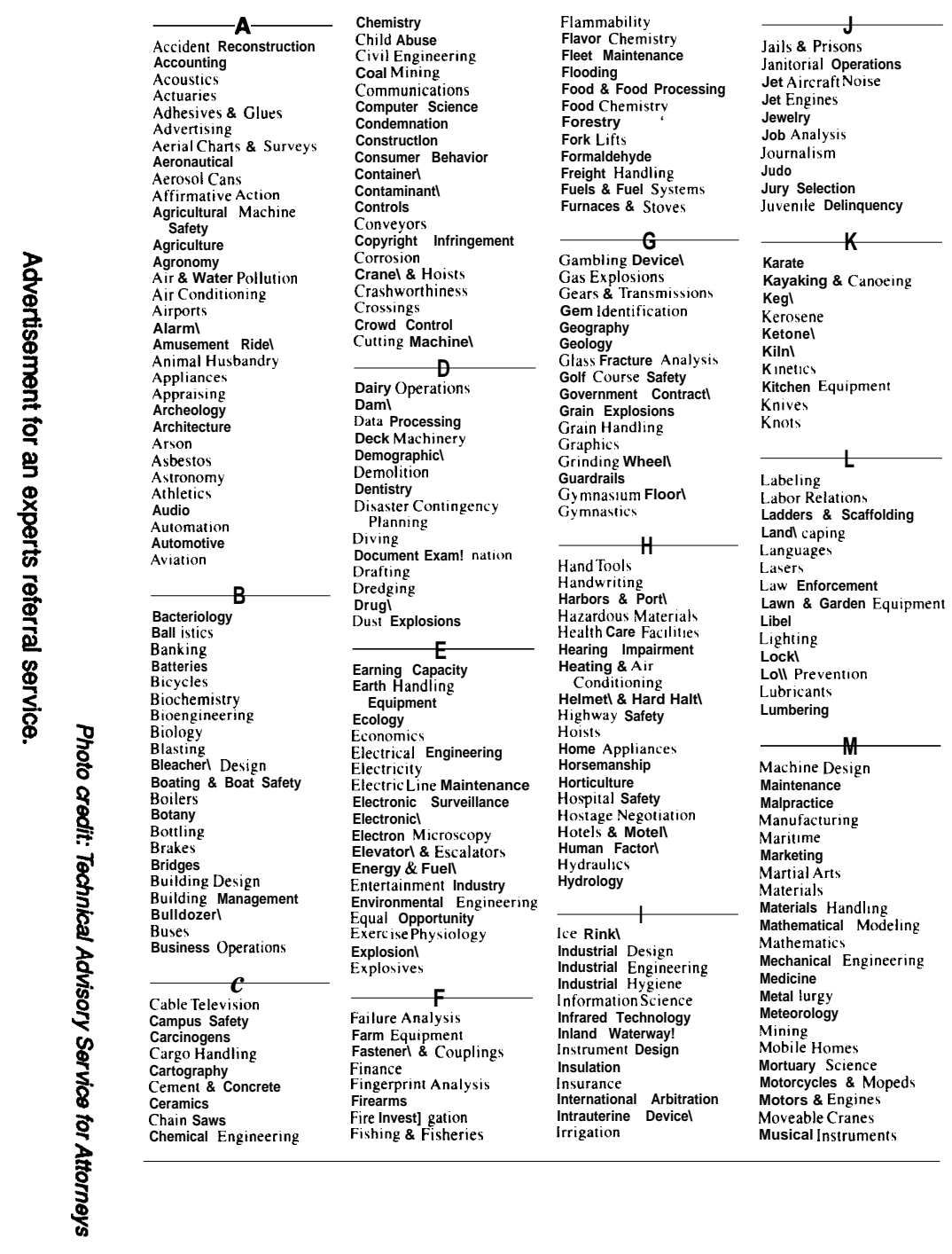

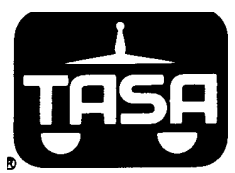

TECHNICAL ADVISORY SERVICE FOR ATTORNEYS Headquarters:

1166 DeKALB PIKE

BLUE BELL, PA 19422-1844

(215)275-8272 FAX:(215) 275-5577 1 (800) 523-2319

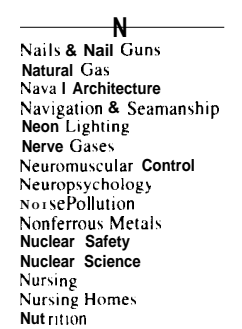

Psychology
Publ IcLtilities

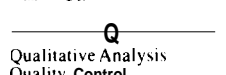

Qualitative Analysi
Ouality Control

Quantitative Analyss:

Quantum Chemistry
Quantum Mechanics

Quantum Physics

Quarrying

Quartz

Quick Release Fasteners

Racing

\begin{tabular}{l}
\hline \multicolumn{1}{c}{$\boldsymbol{O}$} \\
Obscenity \\
oceanography \\
Occupant Safety. Aero \\
Occupant Safety. Auto \\
Occupational Therapy
\end{tabular}

Of fice Equipment
Of fshore OilOperations
$011 \&$ Gas Reserves

011 \& Gas Reserve

OilDrilling\& Exploration
Oil Spills

Operation Research

optic

Ornithologs

OSHA

O) erhead Cranes

P
Packaging \& Centi.jner|
Pain \& Suffering
Paints \& Cuatings

Parachutes

Pesticides
Petroleum

Phatrmaceuticals
Pharmacology

Pharmacology
Physical Training

Phy $\$$ WT:
PI lols

Pr lols
Pit Bulls
Pl astiss

Plastics
Plumbing

Poumbing
Pol lution Procedure

Pol lution
Pornography

Property Taxes
Prosthetic Devices
Protective Equipen

Racing
Radiation Hazard

Radio \& Televisson

Railroading

Range Manage

Real Estate
Recreation

Refrigeration
Regul atory Agenci

Rehabil tation
Riggng
Rioicontrol

Riotic
Rivers
Robot
Roots

Roots
Rugs \& Carpet
Running Shoel

$s$

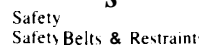

Safety Belts \& Restrain

Satellite Communical

Sawmi I I Operation

Scaftolding

Security \& Alarm

Shoe Design

Shorel \& Coast I iner

Signal System!

Skiing
Snowmobile।
Sociology

Soil 11 En Engineering

Solar Engineerning
Space Operations
Sportl \& Spott Fact

Sportl \& Sport Facilities

Statistics

Structural Engineering

Suicidology

Surveying

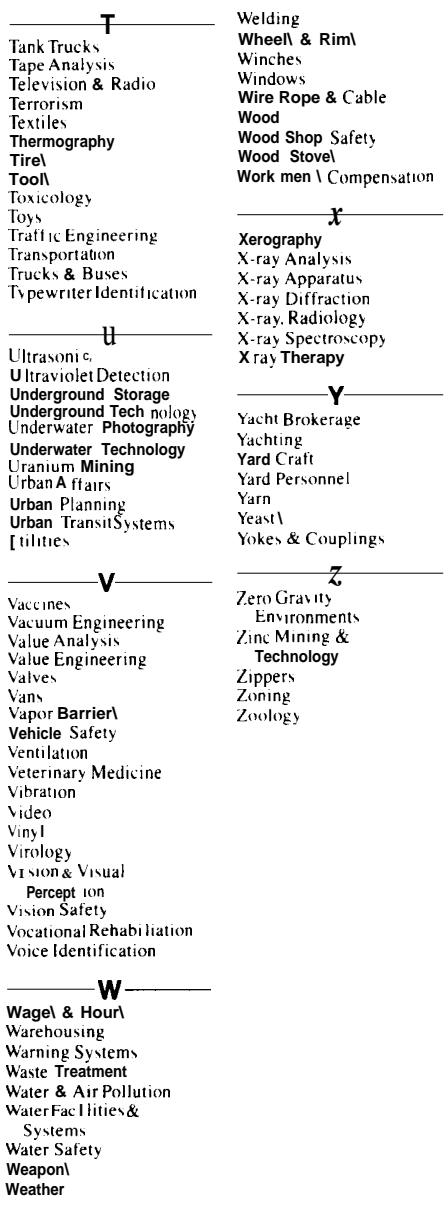

Wheell \& Ri

Wire Rope \& Cable

Xay pectroscopy

$\mathbf{Y}$

yachting

USED WITH PERMISSION OF THE COPYRIGHT AND SERVICEMARK OWNER TECHNICAL ADVISORY SERVICE, INC 


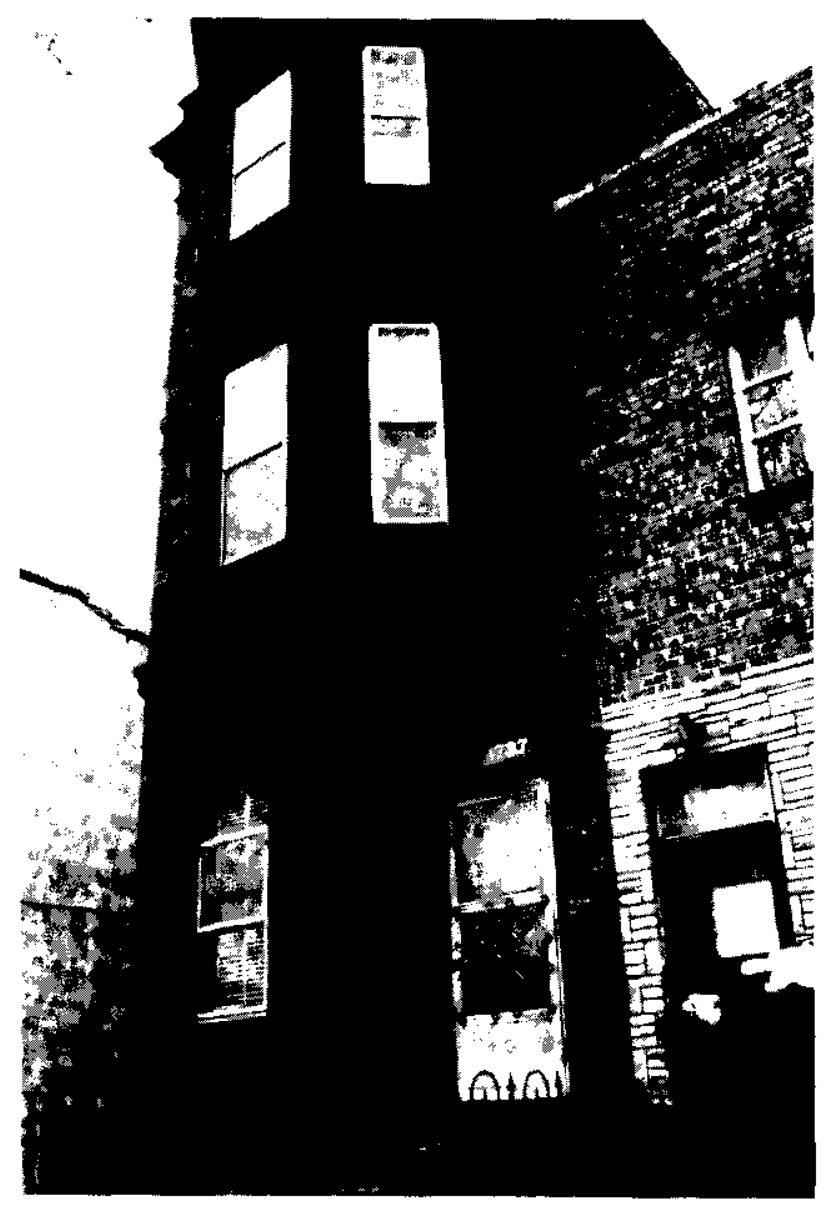

Photo credit: Margaret Anderson

James Alphonso Frye was convicted of the 1920 murder of a physician, Dr. Robert W. Brown, who was slain in his office, located in this building in Washington, DC.

fields of anatomy, physiology, physics, psychology, and linguistics (32).

Once the relevant field has been identified, inquiry can be made as to whether the technique in question has been "generally accepted" by members of that field. The Frye decision itself provides no specific threshold for what constitutes general acceptance, other than to note that at some point a principle crosses the line between "experimental and demonstrable stages" (11). Courts have developed varying definitions of what constitutes " 'general acceptance" by members of the field (13).

The Frye test has several perceived advantages and drawbacks. Its proponents note that the test guarantees a minimal amount of support by experts for a scientific test or procedure prior to its intro-

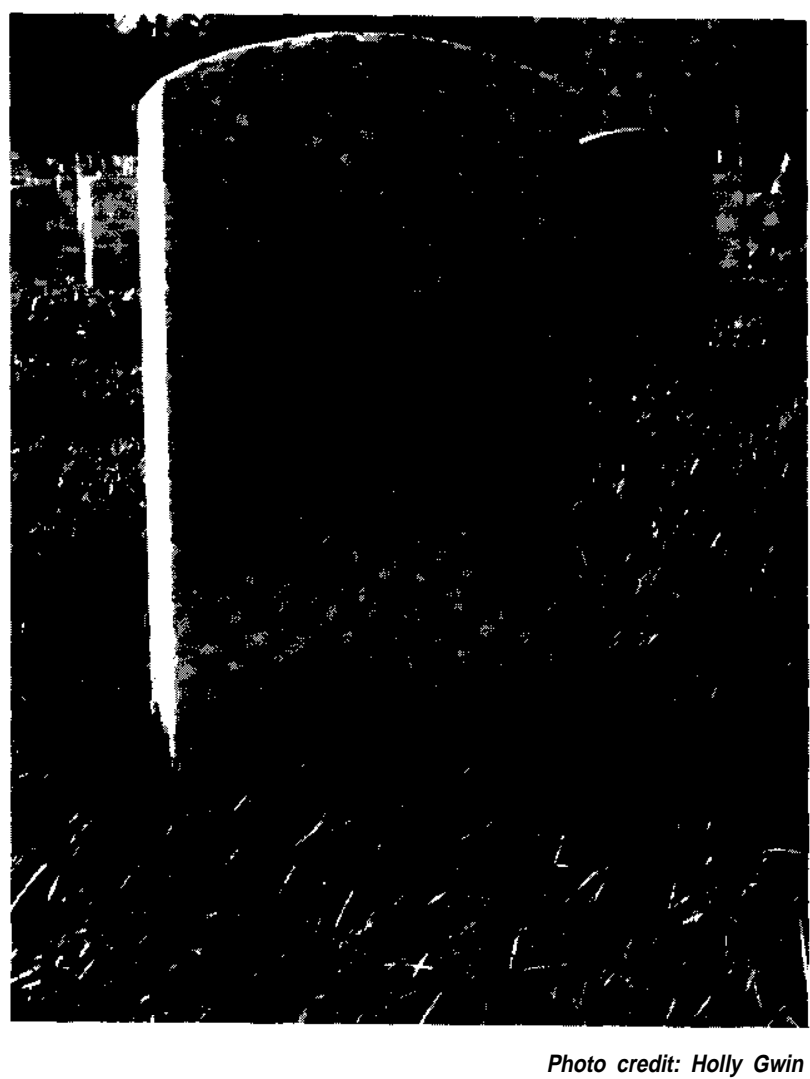

Burial site of James Alphonso Frye, Arlington National Cemetary, Arlington, VA.

duction in a court of law. As noted by one court, the experts "form a kind of technical jury, which must first pass on the scientific status of a procedure before the lay jury utilizes it in making its findings of fact" (31).

On the other hand, the Frye test has been criticized for being difficult to apply and for relying on a theory of 'general acceptance' that may not equate with scientific reliability and validity. Some commentators note that workers in a novel area sharing a common goal can develop a technique that furthers their professional aims and they can "generally accept' it regardless of its scientific reliability (30). Others point out that a literal reading of the Frye standard would always result in a "cultural lag." During this time, the new method can diffuse through the scientific discipline and create the requisite body of scientific opinion needed for general acceptance, but in that interim such evidence would be precluded (14). 


\section{The Relevancy Test}

The alternative to the Frye standard is based on the Federal Rules of Evidence, which address the use of expert testimony and favors the admission of all relevant evidence.

Originally promulgated by the Supreme Court under its authority to prescribe the general rules for Federal civil and criminal proceedings, the Rules were subject to intense scrutiny by Congress prior to enactment in 1975. The Federal Rules of Evidence were designed to secure fairness, eliminate unjustifiable expense and delay, and develop the law of evidence so that the truth may be ascertained and a just verdict rendered (Rule 102). They codify a case-by-case common law approach to evidentiary matters in the Federal courts. The Rules have been amended in 1975, 1978, 1982, and 1984.

Relevant evidence is defined as that having any tendency to make the existence of any fact that is of consequence to the determination of the action more probable or less probable than it would be without the evidence (Rule 401). If a person is not testifying as an expert, such testimony in the form of opinions or inferences is limited to those opinions or inferences that are rationally based on the perception of the witness and helpful to a clear understanding of the testimony or the determination of a fact (Rule 701).

\section{Rule 702 defines expert testimony:}

If scientific, technical, or other specialized knowledge will assist the trier-of-fact to understand the evidence or to determine a fact in issue, a witness qualified as an expert by knowledge, skill, experience, training, or education, may testify thereto in the form of an opinion or otherwise.

Rule 702 embraces a liberal interpretation concerning who is an expert and when a witness may testify in an expert capacity. The subject of the testimony need not be beyond lay comprehension, it can just be an area where expert help would be of assistance (34). This rule regulates the expert's major premise the types of theories, techniques, and principles that the expert may rely on (19).

Rule 703 describes the bases of opinion testimony by experts:

The facts or data in the particular case upon which an expert bases an opinion or inference maybe those perceived by or made known to the expert at or before the hearing. If of a type reasonably relied upon by experts in the particular field in forming opinions or inferences upon the subject, the facts or data need not be admissible in evidence.

This rule addresses the expert's minor premise, i.e., the case-specific information to which the expert will apply 'the major premise (19). The Advisory Committee that drafted the Federal Rules of Evidence noted that Rule 703 permits expert witnesses to draw facts or data from three possible sources:

- firsthand observation of the witness (e.g., a treating physician);

- hypothetical questions posed to the expert or testimony heard by the expert at trial; and

- presentation of data outside of the court (e.g., numerous publications, diagnoses, public opinion polls) (35).

Although an expert can rely on underlying data and need not disclose such data to the trier-of-fact (either a judge or a jury), the court retains the power to require the disclosure of underlying data. Underlying facts or data can also be investigated on cross-ex amination of the expert witness (Rule 705). The court can appoint its own expert witness in addition to experts supplied by the parties (Rule 706), which can help in situations in which the practice of shopping for experts, the venality of some experts, or the reluctance of reputable experts is viewed as a problem (35).

Some argue that the relevancy standard is more liberal than the Frye standard in permitting the admission of novel scientific evidence in that it generally permits the admission of evidence that is relevant (14). Others, however, note that both standards require levels of scrutiny that would force the proponent of DNA typing evidence to address precisely the same technical issues (15).

\section{THE DEVELOPMENT OF BIOLOGICAL EVIDENCE}

Forensic evidence has been admitted into Federal and State courts for decades. Such evidence spans a wide range of scientific and professional disciplines, and encompasses many arts and final products. Scientific evidence can be designed to identify a person or an object (e.g., through fingerprint analysis; bite mark analysis; microanalysis of fibers, hair, 
paint, and trace evidence; photographs; or handwriting and document analysis); to describe a phenomenon or action (e.g., through radar speed detection); or to determine individualization (i.e., finding enough properties of comparison that can render it unique or show that two compared items shared a common origin).

Serology, the forensic field dealing with body fluids and their reactions and properties, plays a key role in the introduction of biological evidence. No area of forensic science progressed as rapidly during the 1970 s as serological analysis (14). A variety of biological matter has been investigated for use in criminal and civil cases:

- Blood typing is most commonly used as evidence in crimes of violence, and has become widespread in paternity cases. Through analysis, conclusions can be reached as to the source (human or animal), type, and sex of source.

- Micro-serological analysis of a semen specimen can answer the following questions: Did the victim engage in sexual intercourse within the recent past? Is the semen of human origin? If so, can a defendant be excluded as the source?

- Identifying the genetic origin of saliva stains can be important if such evidence comes from a "secretor" (i.e., is part of the approximately 80 to 85 percent of the population having blood group substances in their body fluids, such as saliva, tears, and perspiration) or identifies the source as a "nonsecretor" (30).

- Hair retains its structural characteristics for extremely long periods, which makes it of potential importance in identifying corpses (e.g., disaster victims). The ascertainment of color, structure, and pigmentation can be probative in certain circumstances.

Forensic toxicology, which involvte study and identification of toxins, poisorand other added substances, can yield importbinølogical evidence in cases where the presence ofalcohol or drugs is a relevant consideration.

\section{CONSTITUTIONAL CONSIDERATIONS IN OBTAINING BIOLOGICAL EVIDENCE}

By examining various types of biological evidenceblood, semen, hair, and now DNA-authorities can determine whether certain suspects are linked to yvarious crimes. Before deciding whether such evi${ }_{0}$ dence meets established standards for admissibility, it must be determined whether procurement of the samples violates constitutional guarantees regarding self-incrimiration, right to counsel, search and seizure, and due process. This discussion highlights several constitutional issues that can arise; a comprehensive examination of such issues is beyond the scope of this report. Constitutional issues relating to computer technology and informational privacy are discussed in chapter 5 .

\section{Self-Incrimination}

Since the Fifth Amendment to the U.S. Constitution holds that "No person. . . shall be compelled in any criminal case to be a witness against himself," one constitutional issue raised is whether the information obtained from physical evidence constitutes self-incrimination. The leading case addressing this is Schmerber v. California (37), which involved a defendant who was arrested at a hospital while undergoing treatment for injuries suffered in an automobile accident. At the direction of police, a blood sample was obtained from the defendant, who claimed that the extraction violated the privilege against self-incrirnination. In rejecting this argument, the Supreme Court drew a distinction between communicative or testimonial evidence (which is subject to the privilege against self-incrimination) and physical or real evidence (which is not protected). The court noted that the privilege 'offers no protection against compulsion to submit to fingerprinting, photographing, or measurements, to write or speak for identification, to appear in court, to stand, to assume a stance, to walk, or to make a particular gesture.

Under Schmerber, obtaining evidence for most forensic techniques is free from Fifth Amendment concerns because these techniques involve physical, not testimonial, evidence (14). DNA testing is likely to fall into this standard as long as the technology is 
limited to identification purposes akin to fingerprints, voice exemplars, urine samples, and sobriety tests. Complications could arise, however, if DNA testing reveals information that is seen as being testimonial in nature (more akin to, e.g., compelled disclosures during a psychiatric ex amination) (10).

\section{Right to Counsel}

The Sixth Amendment guarantees an accused the right to have the assistance of counsel. Does the collection of biological trace evidence trigger the right to counsel? Generally, the answer is no, since the right to counsel attaches only after the initiation of adversary judicial criminal proceedingswhether by way of formal charge, preliminary hearing, indictment, information, or arraignment (23). The collection of biological samples most often occurs during the investigatory stage, prior to charges being filed or an arrest being made. Further, samples taken later in adversarial proceedings (e.g., prior to release, as mandated by several State laws) occurs after counsel has been obtained, and are subject to protections in the adversarial process such as discovery, cross-examination, and rebuttal evidence.

\section{Search and Seizure}

The Fourth Amendment guarantees the right to be secure against unreasonable searches and seizures. Since the Amendment extends to persons, houses, papers, and effects, issues relating to this area can extend to search and seizure of the person (e.g., arrest) as well as to obtaining samples from homes and other locations.

An arrest is a "seizure" of the person for Fourth Amendment purposes. For an arrest to occur, authorities must have probable cause that a crime has been committed and that the suspect is the person who committed the crime. Generally, if the arrest is valid, the seizure of physical evidence from the person arrested is also valid (14).

Case law and literature on the search and seizure of physical evidence is too comprehensive for discussion here. Fourth Amendment issues span a variety of legal questions involving a multitude of fact patterns. To date, OTA is aware of one appellatelevel case involving DNA testing where Fourth Amendment issues were raised. In that one case, the court did not review the claim that the taking of a blood sample violated the Fourth Amendment, since defendant had consented to the procedure (8).
Because of the complexity of issues that can be raised on Fourth Amendment grounds, cases involving the search and seizure of evidence for DNA typing will undoubtedly arise; they are unlikely, however, to focus on issues unique to DNA evidence per se.

\section{Due Process}

The 14th Amendment of the Constitution forbids States from depriving any person of life, liberty, or property without due process of law. The 14th Amendment due process clause, as interpreted by the Supreme Court, protects individuals against State-sanctioned violations of the Bill of Rights (27). Since cases involving scientific evidence would probably be argued in terms of Fourth, Fifth, or Sixth Amendment grounds, one writer has suggested that the validity of an independent due process analysis in these cases is questionable (14).

\section{THE ADMISSIBILITY OF DNA TESTS}

DNA typing is the latest in a number of scientific techniques designed to link individuals to a crime scene, and has so far been widely accepted in U.S. courts. Three commercial laboratories-Lifecodes Corp. of Valhalla, NY; Cellmark Diagnostics of Germantown, MD; and Forensic Science Associates of Richmond, CA-and the Federal Bureau of Investigation (FBI) have provided expert testimony in 216 criminal cases (table 4-2). The FBI began testing samples for court use in December 1988 (18).

\section{Acceptance in United States Courts}

First introduced in a United States criminal court case in 1986, DNA testing gained national attention following its introduction in a Florida sexual assault case in 1987 (38) (box 4-A). As of January 1990,

Table 4-2-Expert Testimony, DNA Testinga

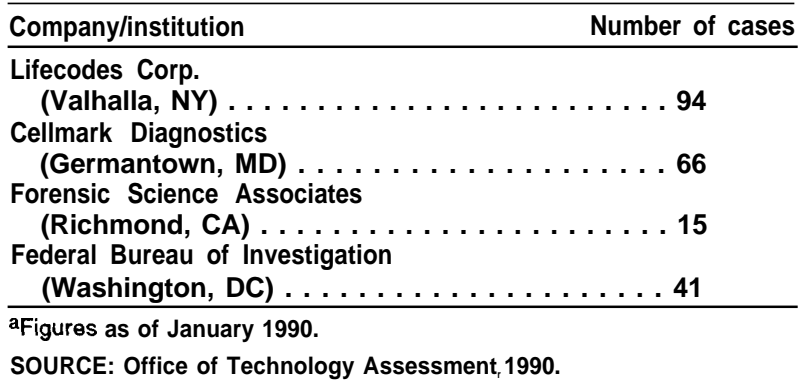




\section{Box 4-A-Case Study: State of Florida v. Andrews}

Throughout 1986, police in Orlando, FL suspected that one man was involved in over 20 cases of prowling, breaking and entering, and attempted sexual assault. In each case, the modus operandi was similar: the man would stalk his victim for weeks, prowling around her house and peeping through windows. When attacked, the victim had little or no opportunity to make a visual identification.

Until Tommie be Andrews was arrested, all police had to go on were composite drawings and several calls about a prowler. After his arrest, one rape victim (who had seen her assailant for only 6 seconds) picked Andrews out of a photo lineup.

When attorney Hal Uhrig was appointed to be the defense attorney for Tommie Ike Andrews, his concern was not about DNA evidence. Instead, he was worried about the amount of time and effort that would be required for him and his small law firm to defend Andrews against multiple rape charges. It was not until later, after prosecutor Jeffrey Ashton read an advertisement in a legal publication about DNA testing and employed the services of Lifecodes Corp., that Uhrig discovered he was involved in the first known DNA criminal case in the United States.

At Andrews' first trial, prosecutors successfully introduced results from the test by Lifecodes. The defense, however, successfully challenged the inproduction of any testimony regarding the statistical probabilities resulting from the test. The trial ended in

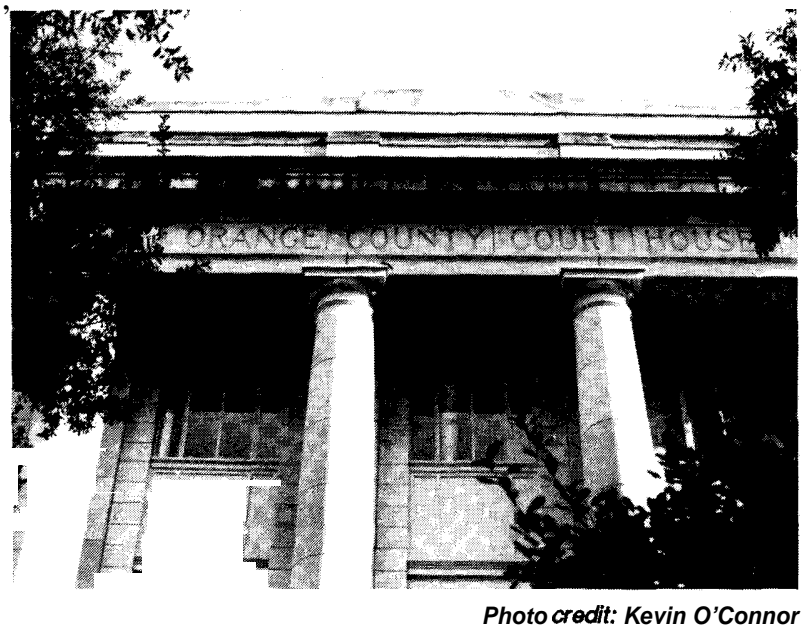

Site of criminal trial for State of Florida v. Tommie Lee Andrews, Orlando FL. a hung jury.

At the retrial, DNA evidence was again admitted. This time, however, the prosecution was prepared to argue that statistical probabilities relating to the test should be introduced. The court, using a relevancy standard similar to that in the Federal Rules of Evidence, admitted the statistical data. Andrews was subsequently convicted.

Prosecutor Ashton said that he was unaware at the outset that this was the first case to use DNA testing in the United States. He feels that it will be a powerful tool in future investigations and cases, especially when the suspect is a serial rapist who is careful not to leave much evidence.

Defense attorney Uhrig said he came away from his experience in defending against DNA evidence most concerned about the use of statistical data, which he feels carries inordinate weight in the minds of the jury. As more population data are collected, the numbers could become much smaller and 'lose real-world meaning' to juries. Hypothetically, says Uhrig, odds of 10 billion to 1 could be introduced into court. But, if the defendant in such a case had an identical twin (and hence identical DNA patterns), the odds would then be 5 billion to 1 of a random match, but still a 50 percent probability that the DNA in question did not belong to the defendant. DNA typing, Uhrig said, may well result in more rape defenses that center on consent as opposed to alibi or denial defenses.

SOURCE: Office of Technology Assessment 1990.

DNA testing had been used in criminal investigatory work in at least 45 States and the District of Columbia and had been admitted by criminal courts in 38 States (see app. A). The numbers do not include civil cases of paternity (Lifecodes Corp. alone estimates that it processes 1,000 paternity tests annually) (4).

Sexual assaults and other crimes of violence (primarily homicides) are the types of criminal cases to which DNA testing has been and will be most often applied. It is a powerful investigative tool in such cases, since reliable eyewitness identification is often not obtained.

DNA testing has been initiated and admitted for both the prosecution and at the request of defendants (box 4-B). It has been admitted in several cases resulting in a death penalty sentence (box 4-C). Only recently has this technology been challenged in court cases on scientific grounds, although in one noteworthy case the challenge was to the application 


\section{Box 4-B -Defense-Inititied Testing}

\section{State of Kansas v. Mosley}

A Topeka man who spent 5 months in jail after being accused of sexually assaulting two women was set free April 13, 1989, when officials announced that laboratory tests determined he was innocent.

When he was released from the Shawnee County Jail, Johnny D. Mosley reported he was frustrated, but relieved. "I felt I was being treated unfairly. I hadn't done these crimes, and I was sick of being accused of doing them.'

Mosley had been accused in the attempted rape of a female gasoline station attendant, and of the rape of a woman who was abducted from a bus stop in Topeka. The victims both identified Mosley as their assailant.

In dismissing charges against Mosley, prosecutor Melanie Jack acknowledged that "the scientific evidence excluded him. It's the most sophisticated type of scientific evidence you can get."

\section{State of Texas v. Trirnboli}

A DNA test that triple-murder defendant Ronald Stephen Trimboli had hoped would clear his name has instead given prosecutors additional evidence against him.

Trimboli, charged in the June 1985 stabbing deaths of three Arlington, TX youths, requested the test by Lifecodes Corp., which concluded that semen found on the bedspread where one of the three victims was raped matched a sample Trimboli had given for the test.

A Johnson County jury convicted Trimboli of all three murders in April 1989, and he was sentenced to three life terms in prison.

SOURCES: Associated Press news wire articles, 1989.

of one laboratory's test in one specific case, and not to the underlying concept of DNA testing itself (box 4-D).

\section{Advantages of DNA Evidence}

DNA evidence offers several unique advantages:

. DNA typing can be used to test any DNAcontaining biological trace evidence. The composition of the DNA molecule essentially does not vary from cell to cell; therefore, the DNA in blood is identical to that in other biological material such as hair, semen, skin, and bone marrow (figure 4-1)(12).
- Except for identical twins, no two individuals are genetically exactly alike. Because of its uniqueness, DNA allows law enforcement officials greater precision than blood typing or other standard genetic techniques in identifying the source of a sample of semen, blood, hair, or tissue.

- Because DNA testing is so sensitive, only a trace amount of biological material is needed for identification purposes.

- DNA evidence can identify probative physical evidence in some cases. For example, semen left at the scene of a rape is more closely related to the commission of the crime of rape than is the presence of a fingerprint (2).

- DNA is more stable and robust than enzymes and proteins, the traditional genetic markers examined in forensic serology laboratories. The chances of obtaining results on older, mixed, and degraded specimens are better than with conventional techniques.

- DNA testing is especially useful in crimes of violence that often yield little useful evidence. Testing is potentially very helpful in identifying perpetrators of sexual assaults where a biological sample is likely to be found, witnesses are often lacking, and identification of the assailant by the victim is unreliable or nonexistent.

- DNA testing can save courts time and money by excluding innocent suspects, eliminating trials where a confession is obtained based on DNA evidence, and focusing defense issues in those cases that do go to trial (e.g., consent or alibi defenses) (9).

- Using DNA test results, the crime laboratory can establish databanks that could identify serial criminals. For example, law enforcement agencies could determine that the same rapist is responsible for a series of assaults in several different jurisdictions. As suspects are identified by investigators through DNA databanks, investigators can redirect and narrow their search for the perpetrator $(16,17)$.

- DNA testing provides crime labs and forensic scientists a new tool that can be used for investigatory purposes (e.g., identifying remains) that, in coordination with other types of evidence, could lead to more arrests and convictions. 


\section{Box 4-C-Case Study: Commonwealth of Virginia v. Spencer}

The multiple murder trials in Virginia of Timothy W. Spencer were the first cases in the United States where the admission of DNA evidence led to guilty verdicts resulting in a death penalty. Spencer was charged with the rapes and murders by strangulation of four women from Richmond, Arlington County, and Chesterfield County.

A test performed by Lifecodes was introduced in the first trial, in Arlington, over the objection of defense counsel. Defense attorney Jeffrey L. Everhart attacked the reliability of the test, arguing that the procedure was so new that only a few States had allowed the results to be used in criminal trials. One expert witness from Lifecodes said that only 1 in 705 million people could be expected to have a pattern that would match Spencer's DNA pattern and the same pattern in the evidence. In July 1988, an Arlington jury convicted Spencer of capital murder and recommended the death penalty.

At the opening arguments of Spencer's second trial, in Richmond, Commonwealth's Attorney Aubrey J. Davis said the DNA left at the scene of the crime was Spencer's: "He left his calling card at the residence of the victim." In November 1988, Spencer was found guilty and sentenced to death.

Spencer was subsequently convicted and sentenced to death a third and fourth time, in February and May 1989, respectively.

In Virginia, death sentence convictions are automatically reviewed by the State Supreme Court. In June 1989, the Virginia Supreme Court heard challenges to the DNA evidence. The arguments revealed that the defense had found no expert witnesses to challenge the DNA evidence submitted by the prosecution. In September 1989, the Court upheld the conviction of Spencer, declaring that the tests linking him to the crimes were scientifically reliable. The U.S. Supreme Court refused to hear Spencer's appeal, letting stand the Virginia high court decision.

SOURCES: Office of Technology Assessment, 1990, based on A. Cooper, "DNA Case is First Before a State High Court," National Law Journal, July 3, 1989:14; Spencer v. Virginia, 384 S.E.2d (Va., 1989).

\section{Criticisms and Limitations of DNA Evidence}

There are no disadvantages to the use of DNA typing for identification purposes per se. However, several criticisms and limitations of this technology have been expressed:

- The development of DNA databanking poses an invasion of civil liberties, particularly due process (the taking of a sample without laying a foundation of probable cause) and privacy (since DNA can reveal more information than identity alone) (6). Such considerations are heard most frequently in regards to storing and databanking DNA (see ch. 5).

- Testing may involve the use of expert witnesses from private companies whose primary goal is to get into court first in order to achieve a judicial imprimatur of acceptability (36).

- DNA testing has been rushed into court without agreement being reached in the scientific community regarding standards that ensure the reliability of the evidence and guidelines for the interpretation of the results (24).

- The probability of a sample having come from any person other than the defendant can be so infinitesimal, according to statistical data, as to hold inordinate weight with a jury, thus obscuring other evidence (43).

. DNA evidence will not solve all crimes. Crime labs rely on a variety of methods in their investigations. DNA evidence, although increasing in popularity, is often not as probative as other types of physical evidence (25). As its use becomes commonplace, however, its admission could be expected by jurors even in cases where such evidence is not available for a variety of reasons.

. Many defendants will not be able to afford the cost of rebutting State-introduced DNA testing. Additional costs incurred in cases involving DNA evidence include testing, expert witness, and legal fees. If defendants cannot afford these costs, the differences between defense and prosecutorial resources, already large, could increase further (21).

\section{Pretrial Hearings: Offering and Rebutting DNA Evidence}

In order for evidence to be accepted into court, it must be offered by one of the parties and be admitted by the court. In most cases, questions regarding the admissibility of evidence are handled at a pretrial hearing. Pretrial hearings involving the admission of 
ICI

CELLMARK

DIAGNOSTICS

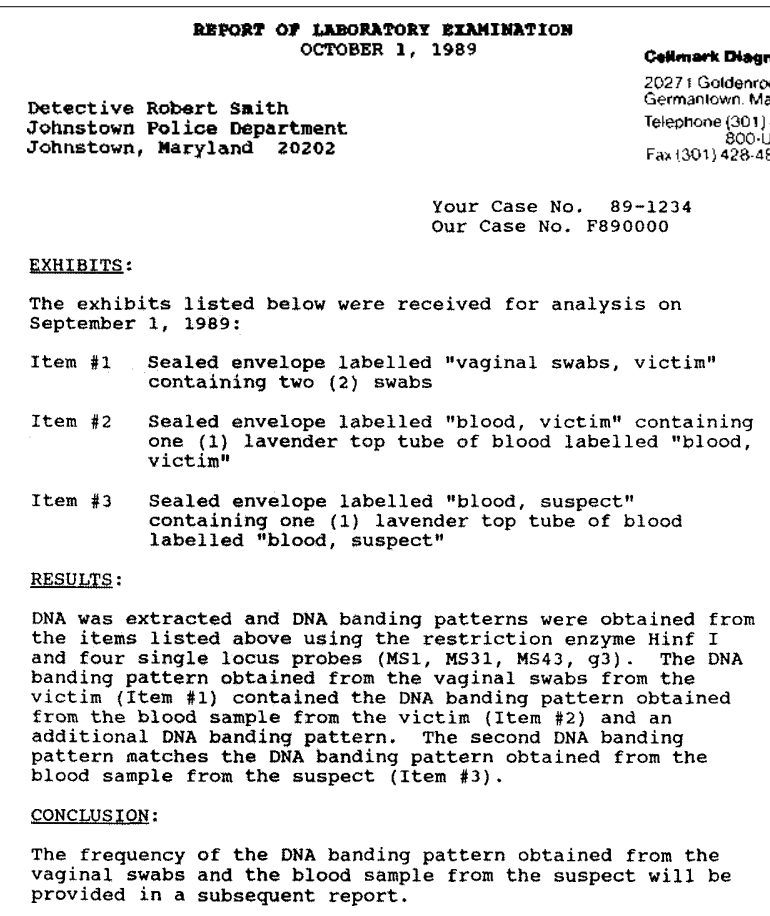

(1C)

CELLMARK

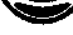

1) I A 20 os I I S

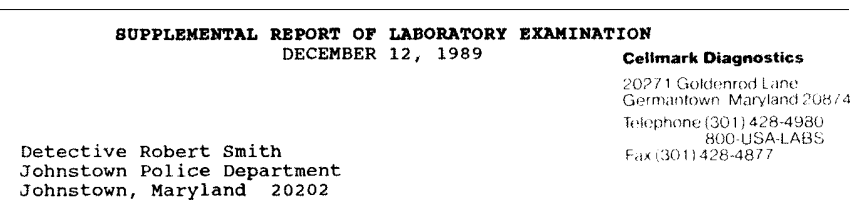

Your Case No. 89-1234

Staff Molecular Biologist

Ph.D.

Our Case No. F890000

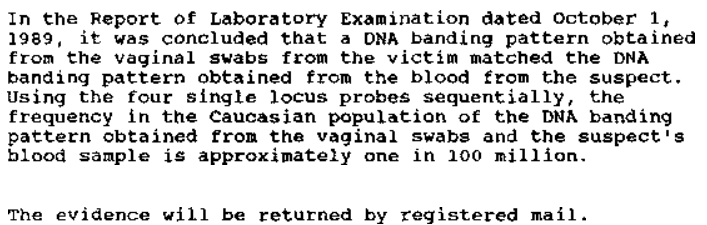

The evidence will be returned by registered mail.

$\overline{\text { Staff Molecular Biologist }}$
Ph.D. 
scientific evidence are often known as Frye hearings (after the standard described earlier in this chapter). By holding a pretrial evidentiary hearing, the court can settle issues relating to whether to admit the evidence into court, thus sparing the jury from the time-consuming issues that can be raised regarding admissibility. Courts are likely to look at several factors: soundness of the underlying scientific principle, reliability of DNA tests, statistical evidence, relevant statutes, and case law.

\section{Soundness of the Underlying Scientific Principle}

The scientfic community agrees that each individual's DNA is unique, except for identical twins, and that it is theoretically possible to identy individuals from their unique DNA patterns. Because the underlying scientific theory is generally accepted (see ch. 3 ), the next level of inquiry relates to reliability of the tests (5).

\section{Box 4-D--Case Study: People of New York v. Castro}

The most heralded challenge against DNA typing to date is the New York case of People v, Castro. Jose Castro a 38-year-old Hispanic, stood accused of murdering his neighbor Vilma Ponce and her 2-year-old daughter. Both victims were stabbed to death in their Bronx apartment building. A small bloodstain on Castro's watch was analyzed by Lifecodes Corp., which in its July 1987 forensic report determined with three DNA probes that the DNA pattern from the blood of Ponce matched that on the watch. The frequency, with the three probes, of these patterns in the Hispanic population was determined to be approximately 1 in 100 million.

A pretrial evidentiary hearing lasted 12 weeks and amassed 5,000 pages of testimony, much of it in the form of expert testimony. In an unusual move, four of the expert witnesses-representing both the prosecution and defense-met to review the scientific evidence after they had already testified. The result of this meeting was a two-page consensus statement that addressed the inadequacy of the scientific evidence and the legal procedures for assessing scientific evidence. Although the statement itself was not accepted as evidence in the pretrial hearing, the substance of the consensus document was introduced by the defense's recall of two prosecution expert witnesses to testify on its substance.

In August 1989, Judge Gerald Sheindlin issued a 41-page decision on the admissibility of the DNA identification tests. Noting that New York followed the Frye standard for admitting novel scientific evidence, a three-pronged test was advanced to determine whether the evidence should be admitted:

. Is there a theory, which is generally accepted by the scientific community, that supports the conclusion that

DNA forensic testing can produce reliable results?

- Do techniques or experiments currently exist that are capable of producing reliable results in DNA identification and that are generally accepted in the scientific community?

. Did the testing laboratory perform the accepted scientific techniques in analyzing the forensic samples in this particular case?

Answering the first point, the court found that "the evidence in this case clearly establishes unanimity amongst all the scientists that DNA identification is capable of producing reliable results." On the second point, the court noted that the techniques and experiments performed are not themselves novel or recently discovered, and are indeed reliable. Hence, the court concluded "that DNA forensic identification evidence meets the Frye standard."

The court relied on the third question-the application of the scientific techniques to the particular case-in order to include certain DNA evidence and to exclude other DNA evidence. The DNA identification evidence of exclusion was deemed admissible, since the testing laboratory did substantially perform the scientifically accepted tests and thereby obtain sufficiently reliable results. However, the DNA identification evidence of inclusion was deemed inadmissible, since the testing laboratory failed in several major respects to use generally accepted scientific techniques and experiments for obtaining reliable results within a reasonable degree of certainty.

As a result, the DNA tests could be used to show that the blood found on Castro's wristwatch was not his, but tests purporting to show the blood was that of the victim could not be used. Judge Sheindlin also enunciated a set of guidelines for DNA pretrial hearings in the future.

Castro's case was never tried He pleaded guilty to the murders in late 1989.

SOURCES: "'Decision on the Admissibility of DNA Identification Tests,' Supreme Court of the State of New York, County of Bronx: Criminal Term Part 28, People v. Castro, Indictment No. 1508/87; R. Lewin, "DNA Typing on the Witness Stand," Science, 244:1033. 
Figure 4-I-Sources of DNA Evidence

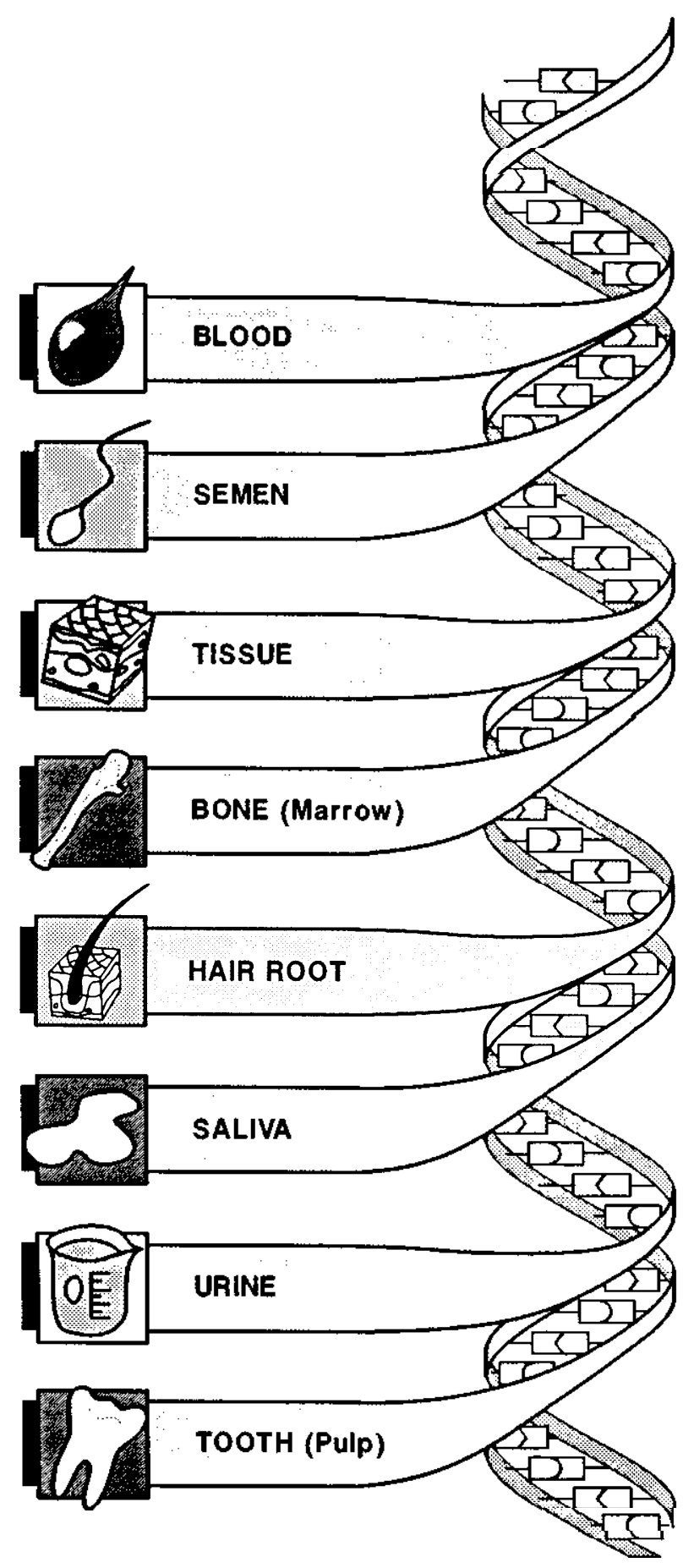

SOURCE: Office of Technology Assessment, 1990.

\section{Reliability of DNA Tests}

Although there is consensus regarding the uniqueness of each individual's DNA and the ability to type an individual's DNA for identification purposes, debate still exists regarding experimental verificationcation (i.e., the presence of adequate population data), the reliability of different laboratories' testing and analytical protocols, the error ratio of tests that are performed, and the quality control of laboratories performing the tests (see ch. 3). Where serious doubts are raised about the reliability of a specific test result, inadmissibility can occur. To date, one State Supreme Court has overturned the use of DNA testing in one instance on the grounds of reliability (bOx 4-E).

DNA testing is complex, requiring a complicated series of procedures that must be carefully performed and analyzed by skilled personnel (see ch. 3). In evaluating scientific reliability, courts generally look to expert testimony from relevant scientific communities, scientific writings, and judicial opinions from other jurisdictions. Expert testimony is generally required because most judges and juries cannot independently assess the reliability of DNA tests. Expert testimony is likely to come from two sources:

- the laboratory that performed the DNA test; and - scientists from the academic community who are familiar with the test but not financially involved with the lab conducting the test, and who can provide expert assistance on particular problems such as statistical frequencies.

If the court employs the Frye standard, individuals specializing in molecular biology and genetics will typically be called on to testify Scientists with relevant experience in certain specialized areas may also be appropriate if the issue focuses on dirty or degraded samples (which might require testimony on, e.g., environmental biology or physical anthropology), or on statistical probabilities (which involves, e.g., population genetics, evolutionary biology, and statistics) (42). It is at this stage-the pretrial hearingthat many aspects regarding reliability can be investigated and challenged, such as procedures and the credentials of personnel.

\section{Statistical Evidence}

According to the judge in the first DNA rape case in the United States (38), the most troublesome problem of admissibility involved how to express to 


\section{Box 4-E-Case Study: State of Minnesota v. Schwartz}

In November 1989, the Minnesota Supreme Court was faced with the issue of whether to admit DNA testing in the case of Thomas Schwartz, who was charged with first-degree murder arising nom the stabbing death of a Minneapolis woman.

The Court ruled the test results inadmissible, even though it found DNA testing to be admissible under Minnesota's Frye standard if performed in accordance with appropriate standards and controls. In rejecting the test results, the Court focused on several issues, including reliability of the test results: crucial.

While we agree that DNA typing is generally acceptable, we nevertheless believe reliability of the test results is

Reliability is particularly important in criminal proceedings because a suspect may face the loss of liberty due to DNA identification. The experts acknowledged that DNA testing could produce a "false negative," where a match between DNA prints is not declaredwhen one in fact exists. Contradictory expert testimony was offered on whether a "false positive," where the wrong individual is identified as the contributor of the DNA sample, could result. We are troubled by the fact that Cellmark admitted having "falsely identified two samples as coming from the same subject" during a proficiency test performed by the California Association of Crime Laboratory Directors (CACLD).

Out of 44 total samples, Cellmark made one incorrect match, which was considered too high an error rate by some experts. The possibility of ambiguous match conclusions is also disturbing. For example, the Cellmark report opined that the DNA from the [victim's stained blue jeans and blood] "are from the same individual," even though the banding patterns did not fit their match criteria. As a direct corollary, specific DNA test results are only as reliable and accurate as testing procedures used by the particular laboratory....

Although Cellmark has implemented protocols and certain quality control standards, deficiencies in several aspects exist ... The director of Cellmark's Development Laboratory ... admitted that because Cellmark did not meet all the minimum guidelines, such as formal methodology validation and published reports of experimental studies in peer review journals, the FBI likely would not consider the test ready for use in court. The experts also reviewed similar standards for DNA typing developed by CACLD. Again.. . Cellmark has not comported with all these standards.

SOURCE: State of Minnesota v. Schwartz, majority opinion of Chief Justice Popovich, Supreme Court of Minnesota, 447 N.W.2d 422 (Minn., 1989).

the jury the statistical probability of the results from the DNA test (33). 'Experts introduce statistical evidence to show that only a tiny fraction of a population possesses the suspect's characteristics. Such statistical evidence is not unique to DNA typing but has, in fact, been used with standard body fluid genetic typing for decades. However, because statistical probabilities introduced in DNA cases are extremely small (sometimes one in billions) and are generally presented-or at least perceived-as an absolute identification, courts must decide if numbers that are introduced can be understood by juries.

Courts generally admit probability calculations based on the empirical sampling of population frequencies of a particular biological characteristic (5), but courts in Minnesota had barred such testimony since it could suggest, by quantification, guilt beyond a reasonable doubt $(39,40,41)$. In such cases, the evidence could be admitted to draw an inference (e.g., scientific evidence that the defendant was the father of a baby that was subsequently born to the victim can be admissible to prove that sexual intercourse occurred), but it could not take the form of a statistical probability. These cases were overturned by action of the Minnesota legislature in 1989 (see box 4-F).

Prior to the action taken by the Minnesota legislature, the defense attorney in the Nation's first DNA rape case (38) cited the Minnesota cases as support for excluding statistical data, an argument that was rejected by the trial court and addressed only briefly on appeal $(1,43)$. In the first trial of Tommie Lee Andrews, statistical evidence was not admitted following defense objection. The case ended in a mistrial. On retrial, the statistical data were offered and ruled admissible, and the jury convicted Andrews. Both the prosecutor and defense attorney agreed that the statistical evidence was key to the second jury's finding of guilt $(3,43)$.

The reliability of statistical evidence is a primary concern to one observer, who notes that:

Despite ... fundamental uncertainties, forensic laboratories blithely cite breathtaking frequencies: a recent report based on the study of only four RFLPs [restriction fragment length polymorphisms] announced that the chance of an alleged match occurring at random was 1 in 738,000,000,000,000. 


\section{THIS DOCUMENI MUST ACCOMPANY A SPECMMN AT ALL MUES}

SECIIONA - SAMPLE REGISTRATION

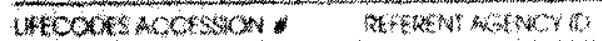

LIFECODES CASE

\section{SECIONB-CASE NFORMAIION}

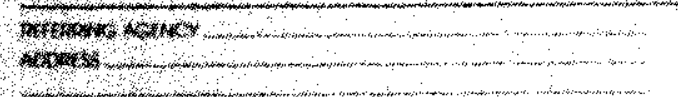

\section{SECTONC - N CASE OF SPUT}

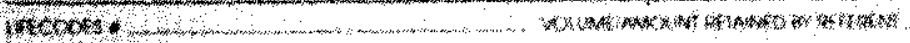

*6)

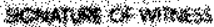

\section{SECIIOND - CHAIN OF CUSTODY RECORD}

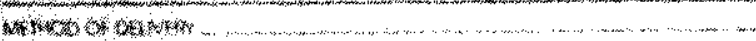

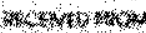

Now

tors

wom

(4)

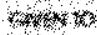

Sks:

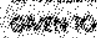

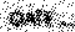

\% 616

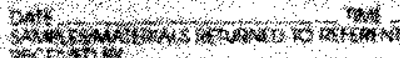

(1)

\section{SECIONE - FOR EVDENCE RECENED BY MAL}

(3)

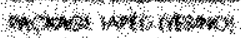

sow

sing

3ato

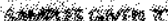

Cos

(n)

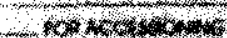




\section{Box4-F-State Statutes: Admissibility of DNA Evidence}

Several States have passed laws regarding the collection of DNA samples (see ch. 5). As of January 1990, four States have laws specifically addressing the admissibility of DNA test results:

. Maryland in 1989 enacted legislation (House Bill No. 711) making DNA profile evidence automatically admissible to prove or disprove the identity of any person.

- Mjnnesota in 1989 enacted a crime bill (Ch. 290, H.F. No. 59) permitting the admissibility of DNA analysis in criminal and civil cases without antecedent expert testimony that DNA analysis provides a trustworthy and reliable method of identifying characteristics in an individual's genetic material. The party offering the evidence must show that it meets the general standards of admissibility under the State's rules of evidence. The same bill also allows the admission of statistical population frequency evidence, based on genetic or blood test results, to demonstrate the fraction of the population that would have the same combination of genetic markers (various blood types or DNA types) as was found in a specific human biological specimen.

- Louisiana has adopteda statute(1989 LaRev.Stat., sec. 15.441.1) holding that "evidence of deoxyribonucleic acid profiles, genetic markers of the blood, and secretor status of the saliva offered to establish the identity of the offender of any crime is relevant as proof in conformity with the Louisana Code of Evidence."

- Nevada law states that "whenever it it relevant in a civil or criminal action to determine the parentage or identity of any person or corpse, the court, by order, may direct. . . one or more blood or saliva tests ... [ [that] may include analysis of a person's blood to determine its genetic markers and of a person's saliva to determine its secretor status. Whenever a test is ordered and made, the results of the test may be received in evidence" (1989 Nev.Rev.Stat.Ann., sec. 56.020 (1)(2)).

SOURCE: Offlce of Technology Assessment 1990.

It is my belief that we, the scientific community, have failed to set rigorous standards to which courts, attorneys and forensic testing laboratories can look for guidance-with the result that some of the conclusions presented to courts are quite unreliable (24).
Some argue that the admission of statistical information to the nth degree is pivotal to the success of DNA testing in forensic applications. Others strongly disagree, maintaining that even low statistical evidence in combination with other facts is sufficient for an attorney to persuade a jury.

\section{Relevant Statutes}

Some States have passed laws specifically governing the admissibility of certain scientific techniques (generally radar detection, blood tests, and intoxication tests). Several States have statutes regarding the taking of DNA samples from certain classes of defendants (see ch. 5) and four States have laws regarding the admissibility of DNA evidence itself as of January 1990 (box 4-F).

Case Law

Although many trial courts have ruled DNA evidence admissible, as of January 1990, only five appellate-level courts have addressed the relevant issues on review (box 4-G). As more appellate courts review and rule on DNA evidence, a foundation of law on the subject will emerge and can be cited.

\section{DNA Evidence at Trial}

Following the pretrial Frye or evidentiary hearing, a court rules whether DNA testing will be admitted into evidence and, if so, under what conditions. Once at trial, any party may offer expert testimony. It is the obligation of the party calling expert witnesses to lay the foundation for such testimony. Such a foundation will normally include the qualifications and experience of the witness, details as to how DNA testing works, what procedures were followed, the results of the test, and the facts and opinions that can be drawn from the test results. During crossexamination, the opposing party can seek to limit the weight of the expert testimony. Such tactics include limiting the credibility of the opponent's expert.

Effective trial strategy can increase or limit the weight of expert testimony. Several recent articles on the admissibility and weight of DNA testing indicate that this area will be the subject of scholarly attention in the near future $(5,7,26,42)$.

\section{FINDINGS AND SUMMARY}

DNA testing is the latest in a number of scientific techniques designed to identify individuals. Compared with other genetic techniques, DNA testing is 


\section{Box 4-G-Appelate Court Reviews of DNA Testing}

\section{Andrews v. State of Florida 533 So.2d 841, District Court of Appeal of Florida, Fifth District}

The Andrew case (see also box 4-A) was the first appellate-level decision of a case challenging the admissibility of DNA testing. The District Court of Appeal upheId the admissibility of the DNA test, ruling that when a form of scientific expertise has no established track record in litigation, courts may look to a variety of factors that may bear on the reliability of the evidence, such as its relationship to more established modes of scientific analysis, the existence of specialized literature dealing with the technique, the qualifications and profossional stature of expert witnesses, and any nonjudicial uses of the scientific technique.

T\&opinion noted:

Admittedly, the scientific evidence here, unlike that presented with fingerprint, footprint or bite mark evidence, is highly technical, incapable of observation and requires the jury to either acceptor reject the scientist's conclusion that it can be done. While this factor requires courts to proceed with special caution . . . it does not of itself render the evidence unreliable.

\section{Cobey v. State of Maryland: 559 A.2d 391, Maryland Court of Special Appeals}

Kenneth Cobey was convicted of rape, sexual offense, robbery, and theft. He appealed, arguing that the single-locus probe technique employed by Cellmark Diagnostics had not been aocepted by the scientific community, the database used by Cellmark was insufficient to support the conclusions drawn by it, and the State violated the Fourth Amendment to the U.S. Constitution when it failed to obtain a search warrant prior to drawing a blood sample from him.

In the opinion of the Court of Special Appeals, the trial court did not err in admitting the evidence, which was supported by expert testimony by the State, while the defendant produced no expert testimony challenging the probe or database. In finding that the State's Frye test requirements were met, the court held that "we are not, at this juncture, holding that DNA fingerprinting is now admissible willy-nilly in all criminal trials . . . We are merely holding that, based on this record, [the trial judge] did not err in finding that DNA fingerprinting was generally acceptable in the scientific community and in permitting its introduction into evidence, since there was no evidence to the contrary."

\section{Woodall v. State of West Virginia: 385 S.E.2d 253, Supreme Court of Appeals of West Virginia}

Woodall, serving two life terms and 335 years in prison on 19 criminal counts stemming from the kidnap and rape of two women, had been rebuffed in his attempts to use DNA testing to prove his innocence. The West Virginia Supreme Court in December 1988 approved Woodall's motion to use DNA testing. The tests, conducted by Cellmark, proved inconclusive due to insufficient amounts of high molecular weight DNA in semen recovered from the crime scenes. As a result, no conclusion could be reached concerning the origin of the DNA in the samples.

The West Virginia Supreme Court, holding that such testing did meet West Virginia's Frye standard, refused Woodall's petition for anew trial, saying that the test's inconclusive (and thus irrelevant) results rendered harmless any decision not to admit the test at trial.

\section{Spencer v. Commonwealth of Virginia: 384 S.E.2d 775,384 S.13.2d 785, Supreme Court of Virginia}

In three unanimous rulings, the Virginia Supreme Court upheld the capital conviction of Timothy Spencer, ruling that submitted DNA test results submitted as evidence at two of Spenser's trials were shown to be 'a reliable scientific technique" (see also box 4-B).

\section{State of Minnesota v. Schwartz: 447 N.W.2d 422, Supreme Court of Minnesota}

In November 1989, the Minnesota Supreme Court barred the use of DNA evidence in a Minneapolis murder trial scheduled to commence in early 1990. The court ruled that forensic DNA typing had gained general acceptance in the scientific community and thus was admissible under the Frye standard. Admissibility in the present case, however, was denied on grounds that Cellmark tests failed to conform to certain reliability standards (see also box 4-E). The court also ruled that such test data must be made available for independent review by the opposing party.

SOURCE: (Mice of Technology Assessment 1990. 
capable of statistically absolute identification (except with identical twins). As with any type of scientific evidence, it must meet certain requirements before it can be introduced into court as evidence.

Two standards-the Frye test and the relevancy test-govern the admission of scientific evidence. The Frye test permits the admission of scientific evidence based on novel scientific techniques only when the technique has gained general acceptance in the scientific community, The relevancy test, based on the Federal Rules of Evidence, permits the admission of relevant evidence that is helpful to the trier-of-fact.

As of January 1990, DNA testing had been used in criminal investigatory work in at least 45 States and the District of Columbia, and had been admitted by criminal courts in 38 States. All reported investigations and cases involved suspected crimes of violence (i.e., homicides or sexual assaults). As of January 1990, the three major companies using DNA testing and the FBI had provided expert testimony in 216 cases. Court cases-all of which have been filed since 1986-indicate that DNA evidence is generally accepted by the scientific community (in cases employing the Frye standard for admissibility) and relevant and helpful to judges and juries (in those cases employing the Federal Rules of Evidence model for admissibility). Appellate-level courts in five States have addressed the admissibility of DNA typing, with four of the courts approving the admissibility of such evidence. Four States have laws permitting the admission of DNA tests in judicial proceedings as of January 1990.

Because each person's genetic material is unique (except between identical twins), DNA testing offers the criminal justice system a more precise and powerful means of identification from a trace amount of biological material. Such evidence could be most useful in cases where eyewitness identification is faulty or nonexistent (e.g., rape) and could save courts time, as suspects are exonerated or confronted with such evidence. Such evidence can be obtained from any DNA-containing source and, because of its stable and robust nature, is more likely to provide usable data than enzymes and proteins used in traditional serological examinations.

Several concerns have been expressed regarding DNA as evidence, including the weight of statistical data, the lack of standards to ensure the reliability of the evidence, the potential bias of expert witnesses whose livelihood depends on the success of the technology, civil liberties considerations related to databanking of DNA information, and the financial costs defendants face in rebutting such evidence.

\section{CHAPTER 4 REFERENCES}

1. Andrews v. State of Florida, 533 So.2d 841 (D.C.A. F1. 1989).

2. Ashton, J.L., Assistant State's Attorney, Orange County, Orlando, FL, testimony before U.S. House of Representatives, Subcommittee on Civil and Constitutional Rights, Committee on the Judiciary, Mar. 22, 1989.

3. Ashton, J.L., Assistant State's Attorney, Orange County, Orlando, FL, personal communication, May 1989.

4. Balazs, L, Lifecodes Corp., Vilhalla, NY, personal communication, April 1989.

5. Beeler, L., and Wiebe, W.R., "DNA Identification Tests and the Courts," Washington Law Review 63:903-955, 1988.

6. Bereano, P.L., Professor, Engineering and Social Policy, University of Washington, testimony before U.S. House of Representatives, Subcommittee on Civil and Constitutional Rights, Committee on the Judiciary, Mar. 22, 1989.

7. Burk, D.L., "DNA Fingerprinting: Possibilities and Pitfalls of a New Technique," Jurimetrics, Summer 1988, p. 455.

8. Cobey v. State of Maryland, 559 A.2d 391 (Md.Ct. Sp.App. 1989).

9. Dean, R.L., Assistant State's Attorney, Montgomery County, MD, personal communication, May 1989.

10. Estelle v. Smith, 451 U.S. 454 (1981).

11. Frye v. United States, 293 F. 1013 (D.C. Cir. 1923).

12. Gaudette, B.D., Central Forensic Laboratory, Royal Canadian Mounted Police, Ottawa, Ontario, Canada, personal communication, August 1989.

13. Giannelli, P. C., "The Admissibility of Novel Scientific Evidence: Frye v. United States, a HalfCentury Later," Columbia Law Review 80:1198, 1980.

14. Giannelli, P. C., and Imwinkelried, E.J., Scientific Evidence (Charlottesville, VA: The Michie Co., 1986).

15. Harmon, R.P., Alameda County District Attorney's Office, Oakland, CA, personal communication, August 1989.

16. Hicks, J. W., Federal Bureau of Investigation, testimony before U.S. House of Representatives, Subcommittee on Civil and Constitutional Rights, Committee on the Judiciary, Mar. 22, 1989.

17. Hicks, J. W., Federal Bureau of Investigation, "Conference Summary," International Symposium on the 
Forensic Aspects of DNA Analysis, Quantico, VA, June 23, 1989.

18, Hicks, J.W., Federal Bureau of Investigation, Washington, DC, personal communication, August 1989.

19, Imwinkelried, E.J., School of Law, University of California, Davis, Davis, CA, personal communication, July 1989.

20. In re Fisher's Estate, 279P. 291,293 (Id. 1929).

21, Jonakait, R.N., New York Law School, New York NY, personal communication, August 1989.

22. Kearney, J., Federal Bureau of Investigation, Quantico, VA, personal communication, April 1989.

23. Kirby v. Illinois, 406 U.S. 682 (1972).

24. Lander, E. S., "DNA Fingerprinting on Trial," $N a$ ture 339:501-505, 1989.

25, Lee, H. C., Connecticut State Police, Forensic Science Laboratory, Meriden, CT, personal communication, April, 1989.

26. Long, R. R., “The DNA 'Fingerprint': A Guide to Admissibility," The Army Lawyer 36, October 1988.

27. Mapp v. Ohio, 367 U.S. 643 (1961).

28, Mauet, T. A., Fundamentals of Trial Techniques (Boston, MA: Little, Brown \& Co., 1980).

29, McCormick on Evidence, 2nd ed. (St. Paul, MN: West Publishing Co., 1978).

30. Moenssens, A. A., Inbau, F.E., and Starrs, J.E., Scientific Evidence in Criminal Cases, 3rd ed. (Mineola, NY: The Foundation Press, Inc., 1986).

31. People v. Barbara, 400 Mich. 352,255 N.W.2d 171, 1977.

32. People v. King, 72 Cal. Rptr. 478, 1968.
33. Powell, R.W., Circuit Court Judge, Orange County, Orlando, FL, personal communication, May 1989.

34. Rothstein, P.F., Federal Rules of Evidence, 2nd ed. (New York, NY: Clark Boardman Co., 1979).

35. Rules of Evidence Advisory Committee, Judicial Conference of the United States, "Rules as Approved by the U.S. Supreme Court," 1972.

36. Scheck B., Professor of Law, Benjamin Cardozo School of Law, testimony before U.S. House of Representatives, Subcommittee on Civil and Constitutional Rights, Committee on the Judiciary, Mar. 22, 1989.

37. Schmerber v. California, 338 U.S. 757 (1966).

38. State of Florida v. Andrews, CR87-1400, Circuit Court, 9th Judicial Circuit, Criminal Justice Division, Orange County Florida, 1987; appeal at 533 So.2d 841 (D. C.A.F1. 1989).

39. State of Minnesota v. Boyd, 331 N.W.2d 480 (Minn. 1983).

40. State of Minnesota v. Carlson, 267 N.W.2d 170 (Minn. 1978).

41. State of Minnesota v. Kim, 398 N.W.2d 544 Minn. 1987).

42. Thompson, W. C., and Ford, S., "DNA Typing: Acceptance and Weight of the New Genetic Identification Tests," Virginia Law Review 75:45-108, 1989.

43. Uhrig, H. G., Winter Park, FL, personal communication, May 1989.

44. Wigmore on Evidence (Chadbourne rev. 1978). 


\section{Chapter 5}

\section{Computer Technology and Informational Privacy}

"Just the mention of one name can clarify the need for the nationwide exchange of crimin al history data including DNA information: Ted Bundy, recently executed killer whose heinous crimes spanned the nation.'

William S. Sessions, Director Federal Bureau of Investigation

Feb. 20,1989

"Experience should teach us to be most on our guard when the govermnent's purposes are beneficent. Men born to freedom are naturally alert to repel invasion of their liberty by evil-minded rulers. The greatest dangers to liberty lurk in insidious encroachment by men of zeal, well-meaning, but without understanding.'

Justice Brandeis Dissenting Opinion

Olmstead V. U.S. 277 U.S. 438,479 (1928) 


\section{CONTENTS}

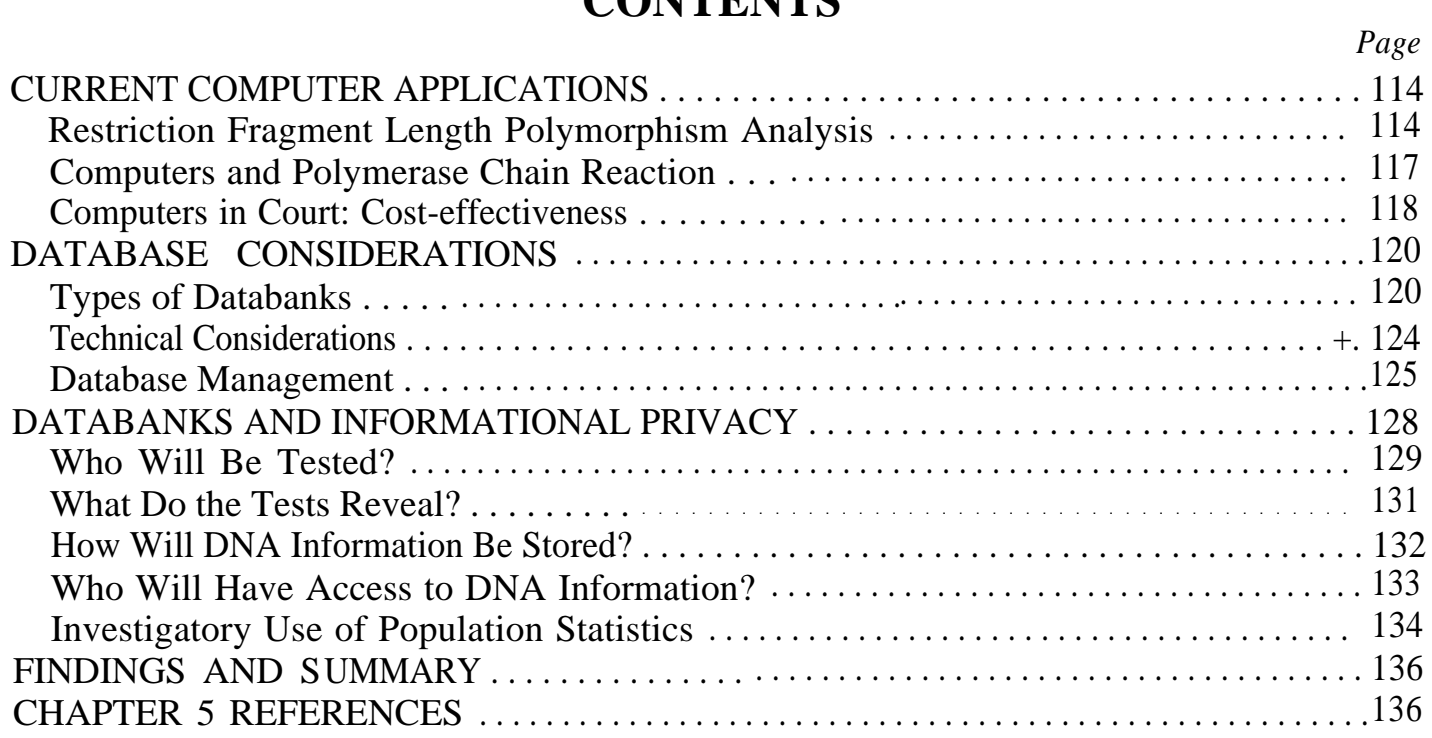

\section{Boxes}

5-A. Automated Fingerprint Identification Systems. .

5-B. The Social Security Number a sa National

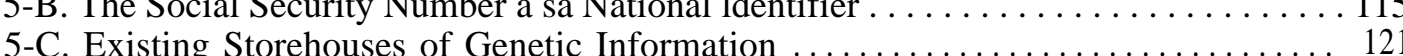

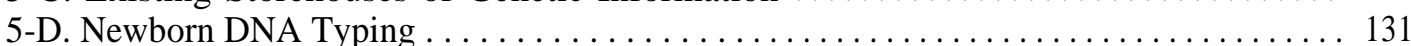

5-E. The Leicester Case: DNA's Criminal Debut . . . . . . . . . . . . . . . . . . . . 135

\section{Figures}

5-1. DNA Sizing Portrayed Through Autoradiography .............................. 116

5-2. Autoradiography :The Importance of X-ray Film Exposure . . . . . . . . . . . . 117

5-3. Semiautomated Analysis of DNA Autoradiogram ....................... 118

5-4. Description of the FBI's Computerized DNA Analysis System . . . . . . . . . . . . 119

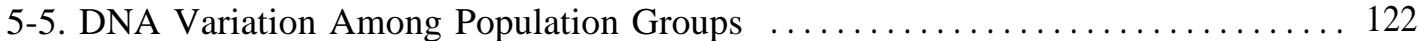

5-6. DNA Typing: Reported Uses and DNA Databank Legislation by State . . . . . . . . . 123

5-7. Proposed Data Files: Who Will Maintain Them? ......................... 127

5-8. How a Database of DNA Information Could Be Created and Used . . . . . . . . . 130 


\section{Computer Technology and Informational Privacy}

Computer technologies enhance the ability ofDNA samples. Computers help derive and maintain Federal, State, and local agencies to uncover wrong-these statistics.

doing at many levels: Entitlement program administrators use computer matching to catch people who abuse welfare, the Internal Revenue Service compares individual returns with information provided by banks to discover where taxes on interest have been underpaid, and the automated fingerprint identification system (box 5-A) has revolutionized the ability ofcriminal investigators to identify suspects within and across jurisdictional boundaries

Computers also help scientists analyze DNA test results by both speeding the process and employing computational tools to augment the power of the human eye. Computer-assisted analysis of restriction fragment length polymorphism (RFLP) tests is possible using existing technology and is underway at laboratories currently involved in testing. Computerization may become more common in certain analyses of DNA amplified by polymerase chain

Applications of these computer systems raisereaction (PCR) (see chs. 2 and 3). issues of informational privacy. Linkage of information in a variety of public and private sources is creating a de facto national database containing information on most Americans (53). (The term de facto is used to distinguish the database from one created by law, i.ea de jure national database.) Social security numbers (SSN) often link these databases, and the SSN has become a national electronic identifier (box 5-B) even though some attempts have been made to control its use. Use or misuse of personal information collected in elec- The possible formation of a national DNA datatronic databases can affect an individual's ability tobase evokes several concerns about privacy. Beobtain employment, credit, insurance, and other cause DNA is unique and so highly personal, some services and benefits (e.g., housing or Aid to are reluctant to see it become part of the de facto Families With Dependent Children).

The law enforcement community maintains fingerprint files and books of mug shots to assist the identification of repeat offenders. If DNA tests were standardized and results computerized, they might be used in a similar fashion. Databases that would permit rapid, electronic comparison of DNA results from tests on different samples have been proposed, but they remain in the preliminary stages of development.

Federal, State, and local criminal justice agencies limited to identity but will expand to include now express considerable interest in using computeproclivity toward disease or behavioral characteristechnologies to improve their abilities to analyze andics, which could then be incorporated in the share the results of DNA tests. Advanced image database. Some believe it to be an inappropriate use analysis technologies, which combine the attributes government authority to collect and store such of video and computational machines, coupled withsensitive, personal information. In addition, there databases compiled from test results, can meet the are concerns about data security and about the needs of forensic scientists using DNA typing to: quality and reliability of the information stored $(8,18)$.

- generate population statistics, aid the technician in the identification of band position, and

- compare the results of different tests.

This chapter sumamizes existing and developing applications of computer technology to forensic uses of DNA tests. Tools used by commercial laboratories and the Federal Bureau of Investigation (FBI)

When experts use DNA tests to confirm the are examined, as are spinoff technologies from the identity of a child's parent or to confirm that a Human Genome Mapping Project. The chapter also suspect is the source of crime scene evidence, theylooks at technical considerations regarding widedeclare a match or nonmatch between DNA speci-spread application of a new technology (e.g., costmens. In the case of a match, they also express theeffectiveness and standardization requirements). The probability of such a match occurring at random. ability to create and secure databanks is addressed These probability calculations are based on popula-(though these issues are covered more thoroughly in tion statistics derived from multiple tests on multiplprevious OTA documents, see refs. 51-54), and 


\section{Box 5-A-Automated Fingerprint Identification Systems}

Automated fingerprint identification systems (AFIS) have revolutionized fingerprint identification technology. A 3-minute scan of millions of prints in a master file helped police identify the man recently convicted in the California "Night Stalker" case, involving 14 homicides and at least 21 assaults. A 6-minute AFIS search, after 8 years of manual searching, led to identification of a suspect in a San Francisco murder case who pled guilty to first-degree murder after being confronted with the fingerprint evidence.

AFIS technology uses a computer to scan and digitize fingerprints, translating the unique ridge patterns and minutiae of the prints into a binary code for the computer's searching algorithm. In a matter of minutes, an AFIS computer can compare a new fingerprint with vast files of prints and make identifications that previously were possible only through a time-consuming and error-prone process of manual comparison.

This technology has greatly increased the speed and accuracy of fingerprint processing and has made it possible to conduct "cold searches" (i.e., a search where there are no suspects or other identifying information other than the crime scene prints) against very large fingerprint files. The search time in a file of about 500,000 prints ranges from a half-hour to a matter of minutes.

AFIS technology also permits the digitized fingerprint images to be stored on an optical disk and retrieved later. The current crime scene prints can be visually compared on the computer screen with retrieved images of the candidate file prints.

One AFIS computer cannot search the files of a different manufacturer's AFIS computer, but this presents only a minor problem. All one AFIS computer needs from another computer is digitized fingerprint image data to make its own search. Facsimile transmission is used to send fingerprint images from remote sites to the AFIS computer. The facsimile prints must be of high quality to substitute for the inked impressions in the AFIS, but this quality is increasingly available.

Linked photographic and telecommunications technologies are also being used to lift and transmit prints to an AFIS. The use of a remote television camera linked to telecommunications lines is under trial. A device attached to the camera converts the photographic image into digital data and sends the information via modem directly from the crime scene to an AFIS computer at the State central repository, allowing virtually instantaneous processing.

As fingerprint matching becomes a more powerful tool of criminal identification and as matching from large files becomes faster and easier, there will be increasing pressure to expand the search capability of law enforcement agencies. For instance, government employees, military personnel, and juveniles are routinely fingerprinted for reasons having nothing to do with crime. Controversy is likely to develop over whether fingerprints that were collected for noncriminal justice purposes should be included in files that can be searched by law enforcement agencies. Congress or the courts are likely to be asked to decide whether this new use violates the constitutional right to privacy.

SOURCES: Office of Technology Assessmen 41990, based on Office of Technology Assessment, Criminal Justice, New Technologies, and the constitution, OTA-CIT-366 (Washington DC: U.S. Government Printing Office, May 1988); Bureau of Justice Assistance, Planning for Automated Fingerprint Identification Systems (AFIS) Implementation (Washington, DC: U.S. Department of Justice, 1988).

arguments concerning the potential usefulness and possible misuse of DNA databanks are explored.

\section{CURRENT COMPUTER APPLICATIONS}

Many crime laboratories currently use sophisticated electronic equipment to perform laboratory tasks, particularly analysis of blood for alcohol or drug content. Private and Federal laboratories engaged in DNA testing have begun to introduce computers into this new area of forensic science as well. Thus computer analysis will likely enter State and local laboratories in tandem with DNA testing procedures.

\section{Restriction Fragment Length Polymorphism Analysis}

Forensic science laboratories performing DNA tests predominantly use the RFLP methodology. Computer technology in use and under development provides tools for interpreting test results. The ultimate information to be analyzed is usually a piece of x-ray film that depicts a part of an individual's genetic code as a banding or stripe-like pattern. 


\section{Box 5-B-The Social Security Number as a National Identifier}

Originally intended for use as an accounting device for contributions to the social security system, the social security number (SSN) has since been appropriated for use in maintaining the records of numerous government and private programs. Prevalent use of the SSN for non-social-security purposes raises concerns regarding its potential for misuse and abuse. It is argued, for example, that the increased use of the SSN as an identifier, coupled with rapidly advancing computer technology, has created a de facto national databank of information on each individual.

The Social Security Act (49 Stat. 620, Aug. 14, 1935) did not expressly mention the use of the SSN, but it authorized a recordkeeping scheme. Use of the SSN as a Federal Government identifier is based on Executive Order 9397 (8 FR 16095-16097; 3 CFR 1943-1943 Comp. 283-284 (1943)), issued by Franklin Roosevelt. In 1962, the Internal Revenue Service adopted the SSN as its official taxpayer identification number, and only then did its use become widespread

Citing possible harm to individual privacy through misuse of information systems, Congress established a Federal policy limiting compulsory divulgence of the SSN in the Privacy Act of 1974 (Public Law 93-579,88 Stat. $18 \%$, codified at 5 U.S.C. 552a). This act prohibits a local, State, or Federal agency from requiring an individual's SSN as a condition of receiving services or benefits, unless the use is authorized by law. The efficacy of that prohibition is subject to question, however, Congress has subsequently not only authorized the use of the SSN, but mandated it. For instance, the 1986 Tax Reform Act requires that all children over the age of 2 claimed as dependents on tax returns have an SSN. including:

Currently, several public and private activities or organizations require an SSN as an identifer or authenticator,

. the National Crime Information Center;

. the U.S. Department of Transportation's National Driver's Register;

- driver's licensing in most States;

- educational recordkeeping, including student admissions;

. hunting or fishing licensing;

- credit checking;

- employee recordkeeping;

. obtaining a library card;

. giving blood;

.joining the Chanber of Commerce;

- enrolling in a health plan; and

- getting a telephone.

All these uses are within the law, though certainly not anticipated when the social security system was devised.

Since the SSN has become a de facto national identifier, concerns about making it tamper-proof (e.g., controlling theft or forgery of numbers) have grown. Those who seek an immutable, unique identifier may look to a numerical reduction of an individual's genetic code, such as would be contained in the FBI's proposed investigatory databases, as a replacement for the SSN.

SOURCES: Office of Technology Assessment, 1990, based on Congressional Research Service, The Social Security Number: Its Historical Development and Legal Restrictions on Its Use (Washington, DC: Library of Congress, 1985); 3. Berman and I. Goldman, A Federal Right of Information Privacy: The Need for Reform, Project on Communication and Information Policy Options, No. 4 (Washington, DC: Benton Foundation, 1989).

Readability of $\mathrm{x}$-ray films varies from case to case. Electrophoresis as currently practiced is an imperfect process (see chs. 2 and 3). Inconsistencies in gel composition or variations in the electric field can cause a gel to "smile, " i.e., create contortions in the lanes of DNA. Foreign matter in the DNA sample (from the restriction enzymes or the original forensic material, for instance) or impurities in the gel can diminish the distinctness of banding patterns and produce artifacts that can be misleading or misinterpreted. Over- or under-exposure of the x-ray film can decrease its legibility (figures 5-1 and 5-2). In the absence of a computer, scientists reading an $\mathrm{x}$-ray film must visually estimate band location or use a ruler-two methods that are subject to fairly large discrepancies from analyst to analyst. 


\section{Figure 5-I-DNA Sizing Portrayed Through Autoradiography}

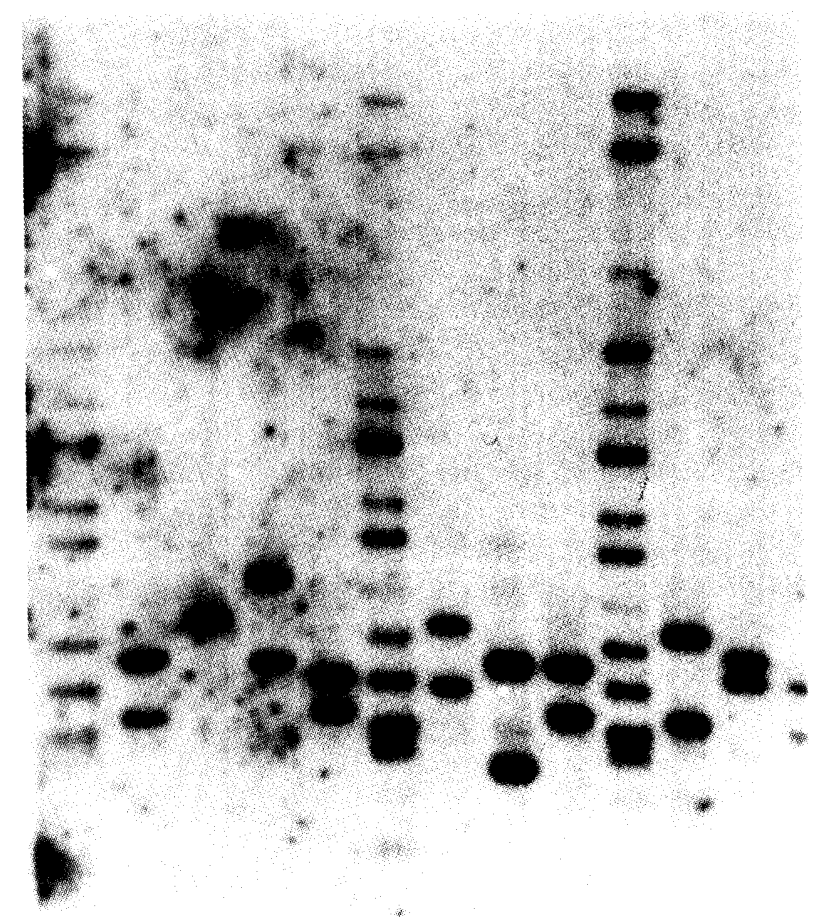

An artifact from the process, the likely source of the splotches on this particular autoradiogram of one RFLP analysis, can decrease an analyst's ability to interpret test results.

SOURCE: Federal Bureau of Investigation, 1989.

Some laboratories involved with RFLP analysis use the bit pad (a digitizing tablet) to assist the scientist's eye. This computerized device requires the analyst to:

- affix the x-ray film to a back-lit tray marked with a computer-readable matrix,

- determine the position of sizing standards by locating them visually and marking their presence with a "see-through" computer mouse, and

- use the mouse to mark the location of bands in the sample and evidence specimens of DNA.

The computer calculates whether samples match, based on the analyst's use of the mouse and on quantitative matching criteria in the computer program (see ch. 3). It also derives the frequency with which that match is likely to appear in a given population, based on statistical data already present in the system. This process is repeated for each probe used on a particular specimen (5).
An alternative, somewhat more automated, aid to RFLP analysis involves application of image analysis technology. Image analysis employs a video camera to create a computer image of the x-ray film. The computer digitizes the image, i.e., divides it into small sectors, called pixels, that can be measured individually for information not easily gathered by the human eye, such as the relative density or precise relative location of bands in widely separated lanes.

Once the image is digitized, the computer can automatically mark band positions and apply a matching rule (see ch. 3) to calculate a match/ nonmatch and the probability of a random match. Use of a digital image also permits application of a mathematical algorithm to straighten' the lanes, in other words, correct for migration differences across the gel. Successful application of the algorithm depends on use of DNA standards-strands of DNA that appear at known size intervals-in the testing process. If inconsistent gel composition or variations in the electric field, for instance, have caused nonuniform migration of the size markers or the specimen DNA, the computer-drawn grid linking the size markers helps the analyst estimate where a band of DNA would have appeared had the test run properly (33). In addition, software can be applied to normalize band patterns from gels run under widely varying circumstances (27). Calculation of fragment length is then based on the computer-assisted estimate (figure 5-3).

Some commercial systems can perform these functions, and the FBI has developed its own system of semiautomated analysis of the x-ray films, known as DNA autoradiograms. A description of the FBI's hardware system is available for emulation (figure 5-4), and their software system will be made available to forensic laboratories that have demonstrated proficiency in the FBI testing method. The FBI's design specifications include speed, ease of use, minimum cost, and the capacity to digitize an $\mathrm{x}$-ray film, establish lane boundaries, give an integrated intensity profile, locate peaks (band position), make geometric corrections, and calculate molecular weights. Each function of the computer can be manually overridden by the operator. If the automatic features are used, it takes about 3 minutes to process an individual $\mathrm{x}$-ray film, and a printout of fragment lengths or direct transfer to disk for incorporation in a database is possible (34). 
Figure 5-2-Autoradiography: The Importance of X-ray Film Exposure

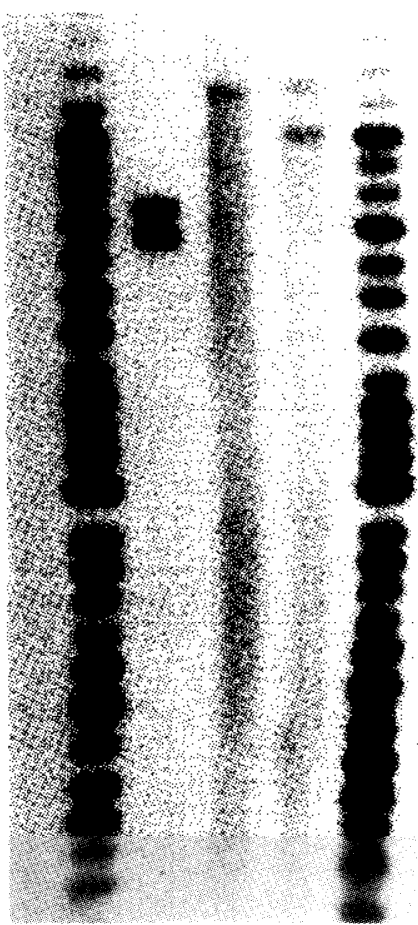

A.

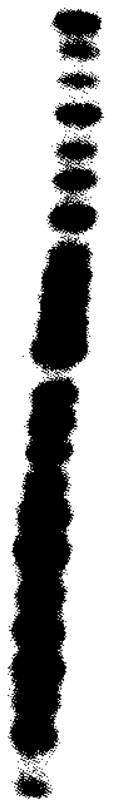

Q1

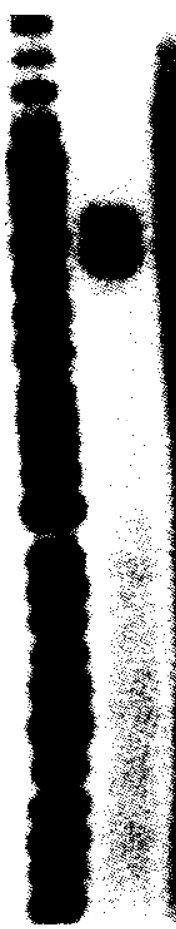

B.

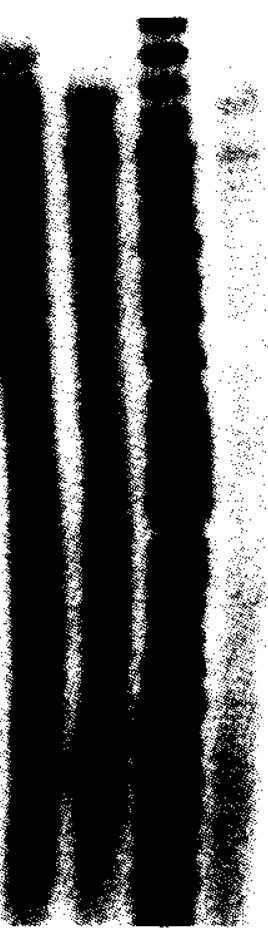

K1 K2

Q1

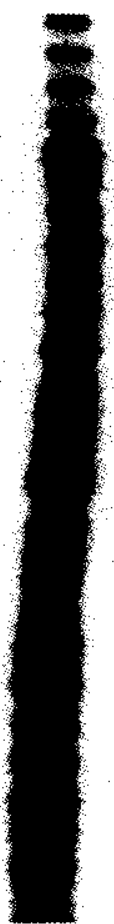

Over- or under-exposure of the x-ray film can also render an autoradiogram unreadable. This case involves a rape committed in the rural Northeastern United States. A semen stain (Q1) was identified on a bed sheet and was submitted to the FBI Laboratory along with blood samples from both the victim (K1) and suspect(K2). Panels A and B are autoradiograms of the same Southern blot (using one probe): Panel $A$ is a4-day exposure; panel B a 10-day exposure. As the photographs demonstrate, results for Q1 in panel A were too weak to interpret. However, the longer exposure (panel B) provided results for Q1 that were interpretable. Once a pattern emerged, analysts determined that the suspect sample pattern matched the semen sample pattern for this particular probe.

SOURCE: Federal Bureau of Investigation, 1990.

Routines for automatic location of lane boundaries, production of density profiles in lanes, and detection of band positions were originally developed at the National Institutes of Health (NIH) (43). Computers used by the Human Genome Project, financed in part by NIH, provide additional functions to improve readability. For instance, nonadjacent lanes can be juxtaposed for closer visual comparison; the computer permits only horizontal movement across the screen since vertical movement would distort band position. These computers can also produce an enhanced visual image-a printout of the digitized $\mathrm{x}$-ray film-after mathematical correction (30).

\section{Computers and Polymerase Chain Reaction}

Laboratories using PCR to amplify DNA currently can test for the presence of specific alleles using a type of enzymatic ' dot-blot' method. This method involves application of a specific enzyme to a DNA sample, which will turn a specified color if the target allele is present. At least one company has considered marketing a colorimetric imaging computer to detect directly the results of enzymatic dot-blot hybridization, but such equipment is not currently in use in any commercial or government forensic science laboratories (27). In the future, DNA amplified by PCR could also be tested using RFLP methodology, and computer technology discussed in the previous section would be applicable.

Dot-blot hybridization analysis of amplified DNA yields results that readily lend themselves to databanking. Use of allele-specific probes results in "yes/no" answers-for instance, alleles 1-6 either are or are not present-that can be computerized with less interpretation (although there is some degree of subjectivity in reading the color change) than is needed in RFLP analysis, which requires 
Figure 5-3-Semiautomated Analysis of DNA Autoradiogram

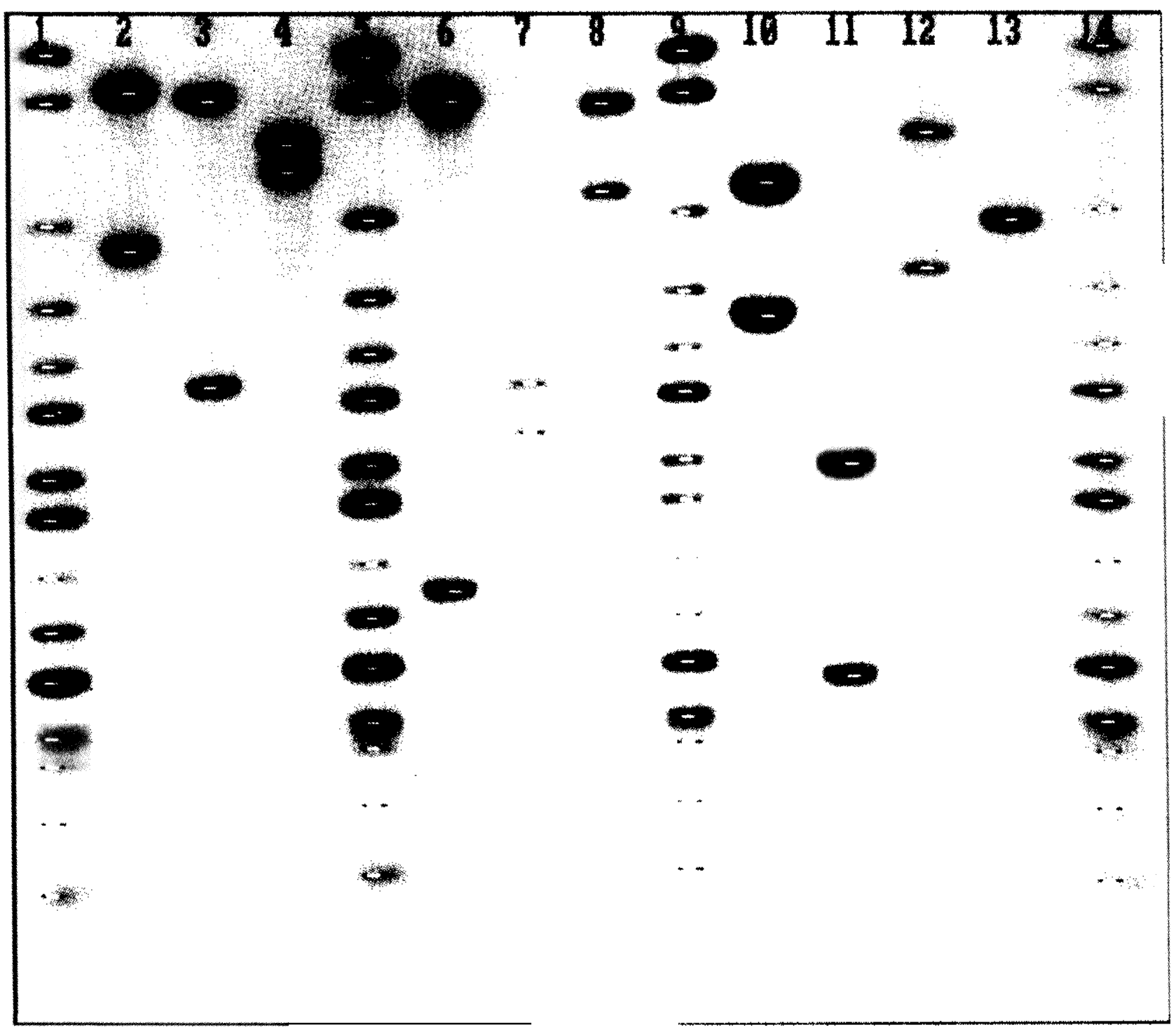

The lighter points within the bands of DNA on this image represent a oomputer's estimate of band positions based on its measurements of the-digitized autoradiogram. The analyst can delete-points believed to be specious or add points ignored by the computer.

SOURCE:L os Alamos National Laboratory, 1989.

calculation of fragment lengths that are distributed continuously. According to the FBI, dot-blot hybridization of PCR-amplified DNA does not yet yield certain enough identifications to warrant creation of data files (22), but the FBI plans to make provisions for recording PCR test results in its proposed investigatory databases.

\section{Computers in Court: Cost-effectiveness}

Computers make attractive analytical tools but are not yet essential or standard to interpretation of DNA tests. The amount of analyst-computer interaction varies tremendously among systems, and while the analyst may be present in court for examination 
Figure 5-4-Description of the FBl's Computerized DNA Analysis System

System functions

1. Digitize autoradiograph

2. Locate lane boundaries

3. Produce integrated intensity profiles

4. Locate bands from intensity peaks

5. Do geometric correction

6. Calculate molecular weights

DNA image analysis equipment requirements

Item

Estimated unit cost

IBM PC/AT (or equivalent) . . . . . . . \$4,000

Camera stand ..................... $\quad 700$

Video camera .................. $\quad \mathbf{2 , 0 0 0}$

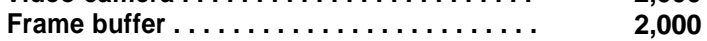

19" RGB monitor. . . . . . . . . . . . . . . $\quad 1,500$

Total ..................... $\$ 10,200$

SOURCE: K.L.Monson, "Semiautomated Analysis of DNA Autoradiograms," Crime Laboratory Digest 15:4, 1988.

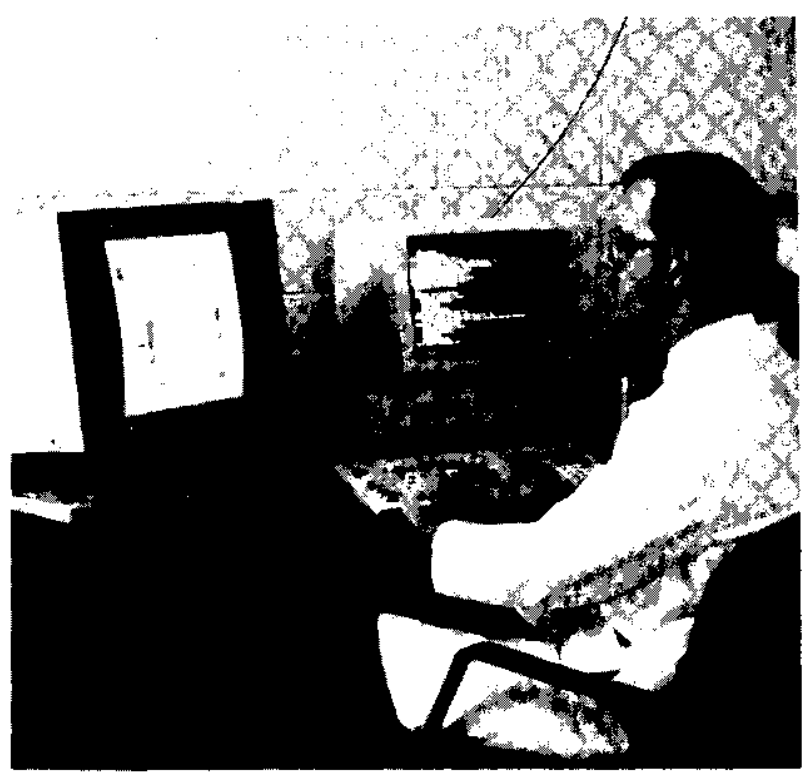

Photo credit Federal Bureau of Investigation, Quantico, VA

The FBI DNA image analysis system and its developer, Dr. Keith L. Monson of the Forensic Science Research and Training Center, Quantico, VA.

as a witness, the computer will not be. This raises the question, do computers lie? When an expert attests to the presence or absence of a match between evidence and suspect DNA, the court will certainly want to know if the opinion is based on computerassisted analysis. Computers arguably locate bands and apply the matching rule (see ch. 3) more objectively and precisely than is possible with the human eye alone. Yet these capabilities also enable the computer to create a result where none was apparent before by, for instance, locating very light

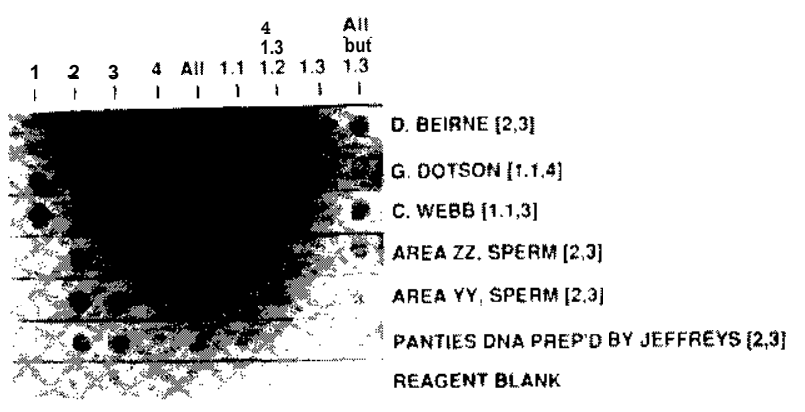

Photo credit: Cetus Corp., Emeryville, CA

A type of dot-blot hybridization analysis of PCR-amplified DNA was used to vacate the 1979 rape conviction in Chicago, Illinois of Gary Dotson. Dotson had been convicted of raping Cathleen Crowell Webb in 1977. Although freed on parole in $\mathbf{1 9 8 5}$ after Webb recanted her court testimony, the rape conviction remained on Dotson's record. PCR amplification of forensic samples (area $\mathrm{zz}$, area yy, and panties) and dot-blot hybridization at the HLA $D Q \alpha-1$ locus revealed that the genetic pattern of the evidence samples (type 2,3), found in approximately 5 percent of men, did not match the pattern of either Dotson (type $1.1,4)$ or Webb $(1.1,3)$. Forensic analysis further revealed that a former boyfriend of Webb, D. Beirne (type 2,3 ), could have been the source of the semen in the evidence stains because his genetic pattern matched that of the samples. (When Mrs. Webb recanted in 1985, she said she accused Dotson to cover up sexual relations with another man.)

bands. The forensic science community may want to ensure the ability to trace analyst-computer interaction so that editing patterns can be reconstructed, and to keep the initial image available for fresh viewing by another analyst. Courts could be required to determine the admissibility of computer-enhanced images-cleaner and, arguably, more persuasive than the typical x-ray film. Faced with such decisions, courts will need assurances that the enhanced image is, in fact, an accurate representation of the test results. It will likely prove necessary to subject computer analysis tools to verification and reliability testing analogous to that received by the DNA typing technologies themselves. (See ch. 4 for a description of the admissibility of scientific evidence.)

Also, the improvements in gel analysis offered by these technologies are not without cost. Acquisition of the equipment, materials, and skills for testing already represents a major expenditure-in time and money-for forensic science laboratories. The FBI estimates the costs for its computer analysis hardware at less than $\$ 11,000$ (not including software or the costs of operating a computer network) (34). Commercial systems are considerably more expen- 
sive (some in excess of $\$ 100,000$ ) (44). Forensic science laboratories typically have limited funds, and each one that undertakes DNA testing will have to determine whether additional analytical tools are necessary to meet its needs. Most of the forensic science laboratories surveyed by OTA (see ch. 6) have expressed an interest in database applications, however, and computers will be critical to the development of these capabilities.

\section{DATABASE CONSIDERATIONS}

The criminal justice community relies on specialized databases maintained by law enforcement groups, as well as on other government and private databases, in criminal investigations, sentencing, and parole decisions. Databanks of fingerprintsmanually maintained but increasingly automatedprovide valuable assistance in identifying and apprehending suspects. Most of the criminal justice community holds out the same hope for DNA profiles. Banks of population data will enhance the certainty of identifications based on test results and could someday be useful for investigative purposes. However, population data will be stored without reference to particular individuals so these databanks cannot be used to track suspects.

Genetic databanks are not anew idea, but their development and application to date have been limited to the medical field or research laboratories (box 5-C). Existing genetic databases provide much of the background for database proposals for forensic uses of DNA tests. Maintenance of genetic databases by law enforcement agencies is a new idea with possible positive and negative consequences extending beyond the law enforcement community.

\section{Types of Databanks}

Law enforcement proposals for DNA databanks recognize two distinct purposes for electronic storage of test results. The ability to compare greater and greater numbers of test results will enhance the legal and scientific certainty of judgments based on DNA tests. In addition, central storage of test results could 'help officials track suspects or identify repeat offenders. Several computer files and subfiles will likely result from these various needs.

\section{Population Statistics}

The value of DNA tests for forensic science purposes lies in their unique discriminatory power. If a sufficient number of probes are used in RFLP analysis, for example, the tests cannot only exclude an individual as a suspect but can show, with near certainty, that a suspect is in fact the person represented by the biological evidence. Though subject to debate, experts have testified to the existence of a match by saying, for example, that there is less than 1 chance in 3 billion that the evidence sample came from someone other than a defendant. Since many fewer than 3 billion people have been tested, these statistics are extrapolated from smaller test pools based on allele frequencies in that population (figure 5-5). Although it is possible to extrapolate these statistics from small populations, the statistics are more credible as the number of data points (i.e., the size of the tested population) increases (see ch. 3). It would be useful, then, to combine the results of as many tests as possible to create increasingly reliable statistics, either by working with existing databanks or by establishing new ones.

Population statistics based on allele frequencies must be generated for each restriction enzyme-probe combination used in RFLP analysis. Several companies maintain proprietary databases related to their testing systems, but if their systems are not adopted by forensic scientists, their data will not be useful. The FBI has developed a database of population statistics (maintained separately for Caucasians, Blacks, Hispanics, and Asians) that will be available to crime laboratories that use the FBI DNA typing method. The database is maintained centrally by the FBI and contains technical information on DNA probes and population frequency data. It does not contain information traceable to named individuals. Rather, it records the sex and race of anonymous contributors of blood specimens. The file is used to interpret the statistical significance of DNA tests on evidence and suspect samples (20). Significant regional variations in allele frequencies will lead some jurisdictions to develop population statistics specific to their area, but the central database would be available as a check on their figures and as a source of data for other jurisdictions.

A population statistics database might someday yield information useful for additional investigative purposes. Population statistics on particu- 


\section{Box 5-C-Existing Storehouses of Genetic Information}

Existing databases and repositories gather, maintain, analyze, and distribute data and materials used in genetic research that could also prove helpful to forensic uses of DNA testing. Many of the problems of information storage and networking and of sample storage and access that will confront the forensic science community are already being addressed in relation to these storehouses. Some of these resources are listed and briefly described here.

Databases

On-Line Mendelian Inheritance in Man (OMIM)-Since 1986, the Howard Hughes Medical Institute has supported computerization of this atlas of human traits that are known to be inherited As of March 1,1988,4,336 traits had been identified as genetically based, including over 2,000 diseases. The list is accessible for on-line searches free of charge.

Human Gene Mapping Library (HGML)-HGML consists of five linked database-one each for map information, relevant literature, RFLP maps, DNA probes, and contacts. All the databases are cross-referenced and linked to OMIM.

GenBank-GenBank is maintained by the Los Alamos National Laboratory and is the major U.S. database for nucleic acid sequence information from humans and other organisms. Tens of thousands of scientists now have access to the database directly or through commercial distributors.

Protein Identifiction Resource (PIR)-PIR is a resource designed to aid the research community in identtication andinterpretation of protein sequence information. It is run by the nonprofit National Biomedical Research Foundation. Users pay a small fee for access.

Protein Data Bank (PDB)-PDB is an international computerized archive for structural data on biological macro-molecules. PDB gathers structural information critical to the understanding of how proteins function, which will lead to knowledge of the mechanisms of genetic disease and directions for drug design.

Repositories

American Type Culture Collection-This repository maintains a variety of different collections of human, animal, plant, and bacterial cell lines, hybridomas, phage, and recombinant DNA vectors. It also serves as an NIH-sponsored repository of human DNA probes and chromosome libraries, The repository also maintains a database of information on the source and characteristics of the material in its collection.

Human Genetic Mutatnt Cell Repositoty-This repository maintains a collection of well-characterizedhurnan cell cultures that are available to investigators worldwide at a nominal fee.

SOURCE: Office of Technology Assessment 1990.

lar alleles are currently generated by racial and ethnic classifications, since allele size and frequency can vary widely among such groups. This information could be used by police to narrow the field of potential suspects. For instance, if it is known that an allele of size " $x$ " appears in only 0.2 percent of the U.S. Asian population, but appears in 10.0 percent of Hispanic Americans, investigators armed with test results might concentrate their efforts on Hispanic rather than Asian suspects, particularly if Asians and Hispanics are equally prevalent in the local population. However, problems such as variability y within defined population groups ("Asians" includes Chinese, Japanese, and Koreans, for instance), regional variations, and difficulty in establishing race or ethnicity (is skin color or last name controlling?) render current data insufficient to justify relying on population statistics to establish the likely race or ethnicity of a perpetrator. If law enforcement officials use this tool to develop suspects, they will also need to take measures to avoid discriminating against individuals or groups based on racial classification (e.g., using population statistics to establish probable cause).

\section{Investigative Support Data}

The law enforcement community has expressed great interest in compiling databases of convicted offenders and the results of tests performed on evidence from open cases (see ch. 6). The FBI is currently involved in the development of a theoretical model and working prototype for an investigative DNA profiling database that would include the following types of information: 


\section{Figure 5-\%--DNA Variation Among Population Groups}
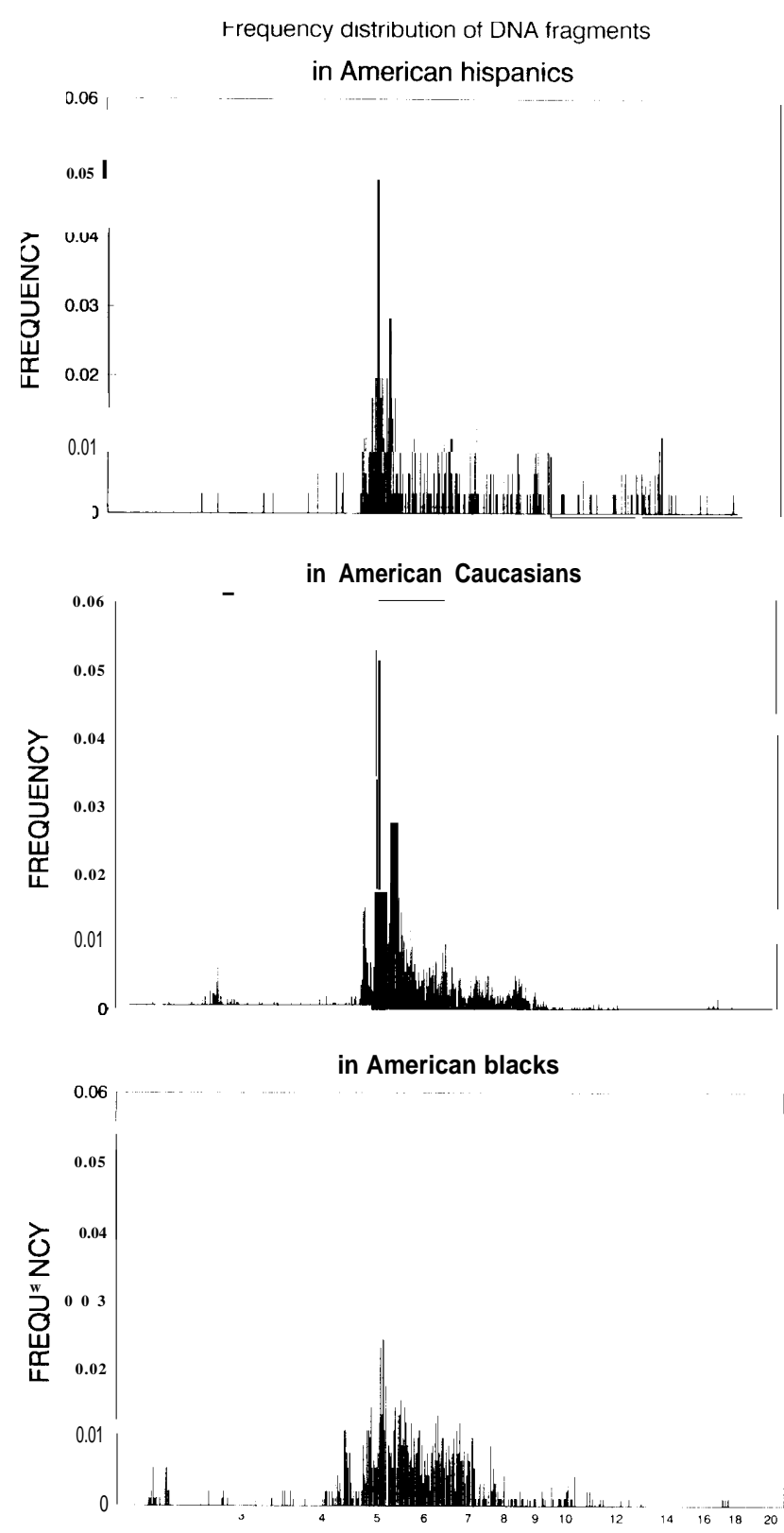

DNA FRAGMENT SIZE $(\mathrm{Kb})$

DNA testing laboratories report their population statistics according to racial and ethnic classifications because allele frequencies can vary substantially among, as with this probe, American Caucasians, Blacks, and Hispanics.

SOURCE: Lifecodes Corp., 1989.
- Open Case: The FBI would centrally maintain a file containing DNA typing information from blood, hair, or semen evidence left at a crime scene. It would be used to help investigators in the same jurisdiction, or among different ones, determine if a series of crimes were related and committed by the same person.

- Missing Persons/Unidentified Deceased: The FBI would centrally maintain this file as an aid to medical examiners and investigators where other techniques, such as fingerprints, cannot be used. The FBI suggests that the file could include DNA typing information from parents who report their children missing. As children are located, the child's DNA type could be compared with parent DNA on file to effect identification.

- Convicted Offenders: These files would be maintained b-y the individual States according to their authority, but the FBI would provide an indexing service. It would contain DNA test results of convicted rapists, murderers, and others, much as fingerprint cards are retained. States could have access to other States' files after receiving approval $(20,48)$.

The FBI established an advisory group to assist with database development in November 1988. The Technical Working Group on DNA Analysis Methods (TWGDAM) includes scientists from Federal, State, and local crime laboratories in the United States and Canada who are actively involved in the implementation of DNA typing. The FBI released TWGDAM'S report on development of the theoretical model for a database in October 1989 (48). States will now be selected to conduct pilot studies with the FBI prototype. After testing and modifications, the prototype can be used as a model in States' development of individual DNA profiling efforts.

State legislatures are responding to these technological developments and to law enforcement officials' enthusiasm for their potential to assist investigation. As of January 1990, at least 11 States (figure 5-6) have enacted laws to require some level of DNA typing of convicted offenders, including:

- Arizona: A 1989 law requires DNA testing of convicted sex offenders.

- California: 1985 and 1989 laws require all convicted sex offenders to provide blood and saliva specimens at the time of their release from prison. Samples collected to date and 


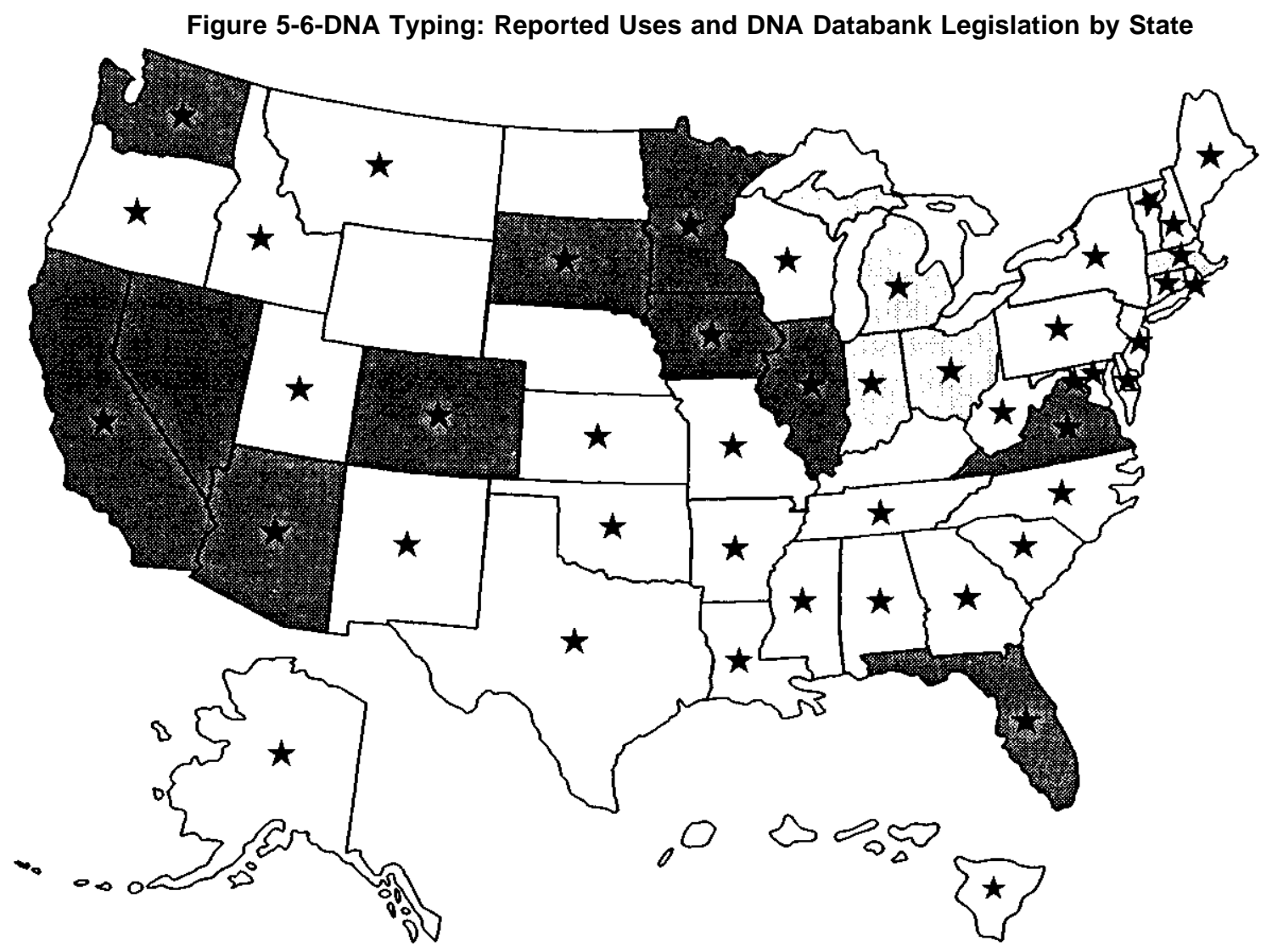

Reported use of DNA typing in that State as of January 1990 (see app. A). Gray= Legislation proposing databanking of DNA information from certain convicted offenders. Black=State law requires databanking of DNA information from certain convicted offenders.

First introduced in a United States criminal court case in 1986, DNA typing has since been applied in criminal investigations in at least 45 States and the District of Columbia as of January 1990. Interest in a means to store and exchange DNA test results across jurisdictional boundaries is also increasing, as reflected by State legislation.

SOURCE: Office of Technology Assessment, 1990.

future samples will be submitted for DNA testing, and the California attorney general's office has begun studies to determine the best methods for collecting and storing data.

- Colorado: All sexual assault offenders released on parole after May 29, 1988 will be subject to genetic testing.

- Florida: A 1989 law calls for a computer bank for genetic information on convicted sexual offenders.

- Illinois: New legislation requires those who have been convicted of sexual assault or attempted sexual assault, or who have been in an institution as a sexually dangerous person, to submit specimens of blood or saliva to the State police.
- Iowa: A law enacted in 1989 permits DNA testing in theriminal law context. The attorney general's office will issue rules about which crimes are covered and who will be required to provide DNA samples. Genetic profiling could become a condition of parole.

- Minnesota: Recent legislation requires uniform procedures for collecting DNA information in cases of criminal sexual conduct, requires that a court sentencing a person foriminal sexual conduct order a DNA analysis specimen, and provides for admission of DNA test evidence without expert testimony.

- Nevada: A new State law requires that convicted sex offenders submit to testing of their blood and saliva. The law also requires that the 
test results be maintained in Nevada's criminal history records.

- South Dakota: A 1990 law allows law enforcement agencies to perform DNA typing of people convicted of sex crimes, calling for blood and saliva samples to be taken from those convicted or arrested.

- Virginia: The State legislature passed a bill in the 1989 session that requires DNA typing of convicted sex offenders. Virginia was the first State to establish its own DNA typing laboratory and expects to be the frost State to come on-line with a DNA databank.

- Washington: State law requires a system to collect genetic descriptions of violent and sexual offenders. In addition, King County, which includes Seattle, passed an ordinance requiring DNA testing on sex offenders.

Several other States, including Connecticut, Massachusetts, Michigan, Indiana, and Ohio have proposed DNA databanking legislation that had not yet been enacted.

Some State crime laboratories have begun to contemplate the effects of this legislation and the FBI's proposals on their operations. Virginia's laboratory believes that DNA databanking will be an extremely effective investigative tool. Staff also recognize constitutional considerations (e.g., whose test results will be included) and confidentiality requirements (16). Virginia's enthusiasm for databanking may be spurred, in part, by its success in using DNA typing to apprehend a serial murderer (12; also see box 4-B). One California crime laboratory, however, cautions that forensic science laboratories will not have the resources to examine all evidence from open cases, thus the benefits of a databank for such cases is, perhaps, being oversold (6).

Open-case and known-offenders databases could assist police in identifying suspects, but prosecutors will need to be alert to problems of overreliance on database matches. The FBI believes that the databases should be used solely as information management tools, and that ideally each sample should be reanalyzed after a suspect is apprehended (20). Reanalysis is the only sure way to link a suspect to the biological evidence in a new incident, and thus adds to the strength of the DNA evidence put before the trier-of-fact (49). Some experts also believe that reanalysis should be undertaken with a new enzyme- probe system to eliminate preelection bias (25). The proposed databases are designed to assist investigation, not prosecution, which will depend on new test results.

\section{Technical Considerations}

Successful computerization of DNA test results leaves little doubt that intra- or extra-jurisdictional databases will be possible using technologies such as those under development at the FBI and within the Human Genome Project. Usefulness of population statistics or of offender and missing persons files will be limited, however, unless standardization is pursued in testing as well as analysis. Dissimilar information cannot be compared. Therefore a successful databank will require (in the case of RFLP analysis) quality control standards for electrophoresis (e.g., gel length and composition, temperature, strength of electric charge, relative humidity), use of specific restriction enzymes, and use of specific probes in the testing process. The computer analysis must be performed according to a standardized protocol, i.e., guidelines for band identification must be established and fragment lengths must be calculated and recorded using a common numerical system. Finally, the computers used must be able to communicate.

These requirements present no insurmountable technical difficulties, but institutional protocols will be needed to establish standards and oversee quality control. Some look to the FBI for a leadership role in this area. The American Society of Crime Laboratory Directors supports the establishment of a national DNA database system based on the FBI's RFLP program (1). Others resist such a strong Federal role and suggest appointment of an independent commission for oversight of these matters. A cooperative venture between Federal, State, and local government entities and the private sector might also satisfy technical requirements. In addition to its work with TWGDAM, the FBI has convened two international symposia on forensic applications of DNA analysis to facilitate cooperation. The FBI, the American Electrophoresis Society, and the International Electrophoresis Society will cohost a similar conference in summer 1990 (44).

Peer review of results will be an important part of any database system. Users will want to be sure that the data on which they rely-whether it be for population statistics or identification-have been 
carefully generated. This is likely to require that the database be in the public domain. It also could require that the database and the methodology used to create it be published and available for expert review. Particularly if the database is centralized, users will likely want to initiate review procedures and limit the ability to bypass the review procedure when adding or editing information in the system (30).

The rapid development of DNA testing technologies also leads some observers to suggest that investigatory databanks based on current testing technology would be premature. There is no consensus on how swiftly new technologies, such as PCR/dot-blot or DNA sequencing, will replace the predominant RFLP methodology, but most scientists agree that the present state-of-the-art is relatively primitive and will quickly be superseded. The FBI notes the necessity of building flexibility into any databanking system and intends to make provisions for technological developments. Yet some scientists believe that any commitment to data files based on RFLP methodology will discourage the switch to new and better testing technologies as they are proven effective, since new and old test results presumably could not be compared.

\section{Database Management}

Management of computerized DNA files will require cooperation among Federal, State, and local law enforcement agencies. Coordination of the mechanisms for information storage and retrieval will be no small task, but there is ample precedent for success.

\section{Information Exchange}

A cross-jurisdictional network will be required for a database to prove useful in detecting serial crime or repeat offenders. DNA data held in Federal, State, or local files could be exchanged through the National Law Enforcement Telecommunications System (NLETS). NLETS is a computerized messageswitching network operated by a nonprofit corporation controlled by the States. NLETS does not hold or manage data files. The FBI considers NLETS a possible vehicle for DNA data transmission, but that issue has not been fully explored (1 1). The FBI appears to favor inclusion of the DNA data in a system they maintain: the National Crime Information Center (NCIC) (24).
By statute (28 U.S.C. 534), the U.S. Attorney General may acquire, collect, classify, and preserve criminal identification and crime and other records, and exchange them with authorized officials of Federal, State, and local law enforcement agencies, and with penal and other institutions; the Attorney General delegated this authority to the Director of the FBI (28 CFR 0.85). Regulations (28 CFR 20.2) permit NCIC to store identifiable descriptions; notations of arrests, detentions, indictments, and other formal criminal charges; any dispositions arising therefrom; and details of sentencing, correctional supervisions, and release $(51,53,54)$.

In general, NCIC is used to exchange public record information among criminal justice agencies. The system includes a computer at FBI headquarters, dedicated telecommunications lines, and a network of Federal, State, and local information systems. NCIC files include information about persons who have been formally charged with criminal offenses, persons who have been formally reported as missing, and property (securities, guns, vehicles, articles, license plates, and boats) that has been formally reported as stolen. One NCIC file contains entries for persons judged to represent a potential threat to U.S. Secret Service protectees, but who have not been charged with a current criminal offense. NCIC currently contains about 20 million records (most are on property rather than people) and almost instantly answers about 75,000 inquiries a day.

The FBI has suggested that one particular NCIC file, the Interstate Identification Index (Triple I), might be an appropriate place to house DNA information (figure 5-7) (24). Triple I indexes the names and other identifiers of persons with Federal and/or State criminal history records. If a query of the index yields a result, the system indicates which jurisdiction to contact for more information. The complete records are maintained in FBI and State repositories (53).

The FBI makes decisions regarding new NCIC services with the advice of the Advisory Policy Board (APB). The APB is composed of 20 law enforcement officer members elected from the States and localities, 6 members appointed by the FBI Director (2 each from the judiciary, prosecuting agencies, and correctional institutions), and 4 members appointed by criminal justice associations (one each from the International Association of Chiefs of 


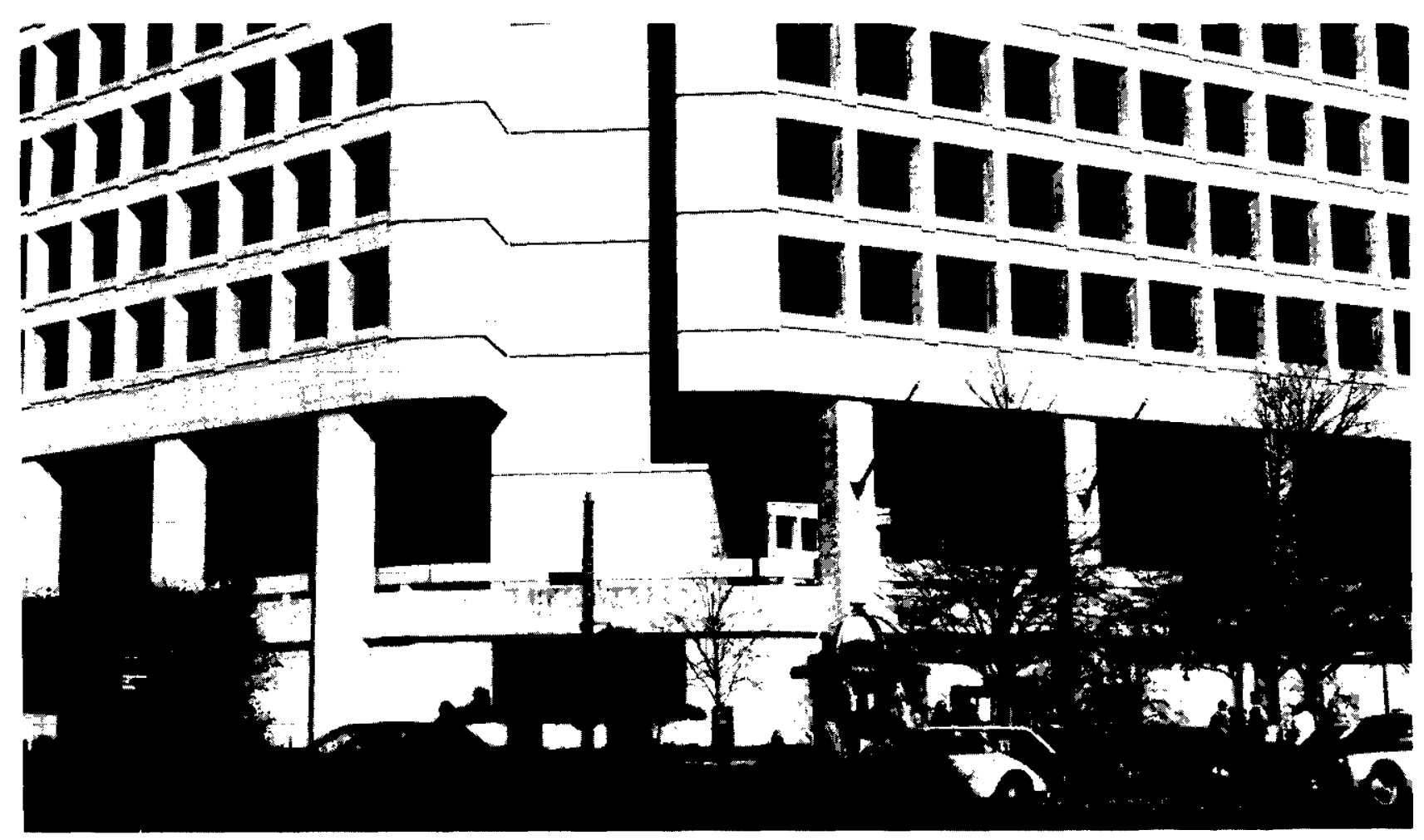

Photo credit: Kevin O'Connor

J. Edgar Hoover Building, Washington, DC: Headquarters of the Federal Bureau of Investigation.

Police, the National Sheriffs' Association, the National District Attorneys' Association, and the National Probation and Parole Association) (24).

In 1987, the APB considered adding DNA characteristics to NCIC. The NCIC 2000 Study Concept Paper (37) proposed that DNA information be stored with other personal identtifiers and descriptive information, and also stored as part of the crime scene evidence in the modus operandi data. Inquiries containing DNA information could then be searched against those individuals having corresponding data.

The NCIC report suggested that DNA information could accompany initial entry of the person or be filed by a separate transaction, with record update capability incorporated. Data would not be provided with a routine response unless the search criteria included DNA information. A routine response not based on a DNA search would contain a statement indicating the availability of DNA information that could be obtained by use of a specific message type. DNA information would be provided as part of the validation data.
The study found that the addition of DNA information would require resources for design, development, and implementation of the storage and search mechanism; operational support; training; and technical research to develop the search algorithm. State and regional systems would also have to gear up to provide for the new transaction types and lengthy display of DNA information. The greatest drawback, however, to adding DNA information to NCIC was found to be the data-handling burden. At the time the NCIC study was drafted, no known method for automated comparison of DNA information existed, but the FBI has begun software development in this area. Starting the database from scratch was also considered a hurdle. Sensitivity and security risks associated with operation of the databank were deemed to be minimal, although obtaining suspect samples was considered somewhat troublesome. (See ch. 4 for a discussion of the Fourth and Fifth Amendment limitations on requisition of biological samples for evidentiary purposes.)

After reviewing the proposals, the APB voted in December 1987 not to add DNA information to NCIC at that time. This decision comported with 
Figure 5-7-Proposed Data Files: Who Will Maintain Them?

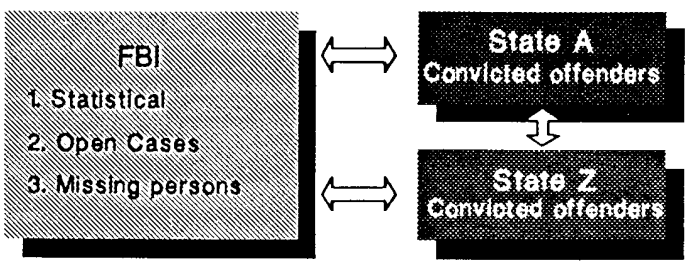

The FBI has proposed separate responsibilities for Federal, State, and local jurisdictions in creating and maintaining DNA databanks. This effort will require significant levels of coordination and cooperation to be effective.

SOURCE: Office of Technology Assessment, 1990.

concerns expressed by a variety of groups, including civil liberties advocates and computer scientists, who believed that the proposals raised substantial privacy concerns, that the need for such information was not firmly established, and that the technology was not sufficiently developed to warrant immediate acceptance. Since the 1987 vote, however, DNA testing has spread rapidly into the criminal proceedings of many States, rekindling interest in sharing test results. Given these recent developments, the APB reconsidered its action in June 1989 and voted to endorse the FBI's plan to index and match DNA profiles in NCIC. The FBI estimates that individual State costs for implementing DNA databanking will not exceed \$200,000 (11). In the TWGDAM report (48), the FBI attempts to address most of the concerns expressed by the NCIC drafters in 1987.

\section{Fair Information Practices}

Information exchanged via a DNA database would be used to assist one of the most important and sensitive government functions-law enforcement. Thus database managers in each jurisdiction will need assurances that data in the system are trustworthy and that rights of citizens are observed when data are collected and disseminated. Federal research and legislation indicate that one route to obtaining such assurances is by adherence to fair information practices $(9,53)$. A study released by the Advisory Committee on Automated Personal Data Systems (55) proposed a Federal "Code of Fair Information Practices" that included the following major principles:
- there must be no personal data recordkeeping system the existence of which is secret;

- there must be a way for an individual to find out what personal information is in a record and how it is used;

- there must be a way for an individual to prevent personal information that was obtained for one purpose from being used or made available for other purposes without his or her consent;

- there must be a way for an individual to correct or amend a record of identifiable information about himself or herself; and

- any organization creating, maintaining, using, or disseminating records of identifiable personal data must assure the reliability of the data for intended use and must take precautions to prevent misuse of the data.

This Code was the model for the Privacy Act of 1974 (5 U.S.C. 552a), which relies heavily on individual initiative to ensure that records are accurate. Since the proposed DNA files could have such major consequences for both individuals and the government, the managers of these files will probably want to take special note of the fifth principle, which speaks to management's responsibility for system integrity. Sound data management principles would include security, accountability, and data accuracy and reliability (23).

Data security is critical-both access control and control of the activities of those granted access. Throughout the private and public sectors of the economy, sensitive information is entrusted to computer networks in the belief that sufficient security controls exist. Computer "hackers" regularly manage to breach these controls. Highlevel security measures add costs to a computer system, and a judgment regarding the sensitivity of the information in the databank will be required in order to ascertain a level of adequate, cost-effective protections (52).

Accountability controls ensure that authorized users do not misuse a system. Many systems log all entries and queries by means of user identifiers, which creates an audit trail. This technique is particularly important when sensitive information, such as criminal history, is involved.

Record quality-accuracy and reliability-is also a particular concern with criminal history records. Federal courts have imposed a duty on law enforcement agencies to maintain accurate criminal records 
$(28,32,47)$, But incidents of arrest based on false or incomplete information in NCIC continue (23). If an individual is falsely arrested based on inaccurate DNA information, there may be a cause of action against NCIC or another offending government entity.

\section{DATABANKS AND INFORMATIONAL PRIVACY}

Recordkeeping is one of mankind's oldest activities (59). Governments record births, deaths, entitlements, and penalties, for example, to help dispense the privileges and protect the rights of citizenship. Constitutional principles, particularly the right of privacy and the right to due process, establish a framework for questions about what types of records are kept, on whom, and by whom they are kept, and who gets access to them. Recognition of these rights evinces a belief that individual freedom and liberty, the foundations of U.S. society, prosper when detailed information about a person's life is private (31).

Computerized databanks raise particularly sensitive issues of informational privacy. Government and private-sector entities collect vast stores of personal information for one purpose, which, with the advent of computer networks, can easily be applied to new purposes-with or without the knowledge or consent of the data subject. The way in which this personal information is then used often has a critical impact on an individual's ability to obtain employment, credit, insurance, and other valued services and benefits. Ensuring that sensitive or stigmatizing information remains private protects an individual from harm. But regardless of the substantive harm that can be done to the victim of unfair information practices, informational privacy also safeguards the interest in personal freedom. Collecting, retaining, and disclosing personal information by institutional recordkeepers can have a chilling effect on an individual's sense of autonomy and dignity (7). Standards exist for the collection, maintenance, use, and disclosure of personal information, but they vary among jurisdictions and among data types.

What is personal information? One working definition states that it is "any information that describes a natural person, and thus is defined by the reference of the information and not by its content. Thus so long as information refers to an identifiable individual-whether that reference is made by a person's name, or a number, or some other identifying characteristic-then it is personal information' (50). Name, address, social security number, credit rating, and fingerprints are personal information; so, too, are the results of DNA tests. Personal information varies in its specficity and the degree of protection it receives. Many people share the same name, but fingerprints are unique. Addresses are usually published in the telephone book, but access to credit ratings is somewhat more restricted. Information that identifies an individual is personal regardless of content, but content determines, according to social mores, the level of privacy accorded personal information.

Governments and the private sector regularly collect and "bank" personal information, ranging from a person's birthday to whether he or she has declared bankruptcy. The law enforcement community currently maintains databases including much personal information, such as a person's name and aliases, fingerprints, criminal record, eye and hair color, and some medical information, such as whether a person has epilepsy. Law enforcement officials also have access, by statute, subpoena, or voluntary cooperation, to many other public-and private-sector databases. The Privacy Act offers some protection regarding data collection and access to information about most individuals included in Federal databases, but the act specifically provides that criminal justice agencies may exempt their record systems from many of its provisions (5 U.S.C. 552a(b)(7), (c)(3), @(2)). Regulation of non-Federal databases is left to the States, but very little privacy protection exists there. State criminal history files range from being completely open matters of public record, as in Florida, where private access is permitted, to being sealed from public scrutiny (as in Massachusetts) (51).

To secure funding, any government agency seeking to establish a new database is usually asked to demonstrate a need for the information to be collected. This exercise is intended to ensure that government funds are spent wisely and to reassure those concerned about growing data collection that a valid social purpose is being served. Many observers now ask why the FBI, for instance, needs a DNA database $(14,45)$. 
The FBI cites the fact that DNA is a unique identifier; no two people share the same genetic sequence (except for identical twins). As such, DNA can enhance the ability to identify suspects in certain types of crime-particularly rape, sometimes murder-where no other physical evidence is available. If the perpetrator is a repeat offender with DNA test results on file, identification will be complete (in the absence of error) and apprehension and prosecution eased.

Law enforcement officials often cite the high rate of recidivism among convicted offenders to justify databases. The Bureau of Justice Statistics (BJS) recently announced the results of a survey of recidivism among State prisoners released in 1983 (10). The report showed that 62.5 percent of this group had been rearrested within 3 years, with 41.4 percent returning to prison. The rate of rearrest among violent offenders was 59.6 percent. Released rapists were 10.5 times more likely to be rearrested for rape than other released offenders, and released murderers were about 5 times more likely than other released offenders to be rearrested for homicide. The study also revealed that one out of every eight rearrests was for a crime committed in a different State from where the prior offense occurred. The FBI believes that DNA databases might significantly aid their efforts to solve the high number of forcible rapes $(92,486$ reported in 1988) and of murders and non-negligent manslaughter cases $(20,675$ reported in 1988) in this country, as well as a growing number of serial crimes (21).

Those less inclined to increase the amount of personal information stored in government databases could cite other aspects of the BJS study. For instance, only 6.6 percent of released murderers were rearrested for homicide and only 7.7 percent of released rapists were rearrested for rape (10). Some cite the fact that many accused rapists choose to litigate only the issue of consent, thus the source of the biological evidence-the only issue that can be addressed by DNA testing-is never in question (8). Other research shows that blood was available to link a suspect to murder in only 15 percent of cases, semen available to link a suspect to rape in 10 percent of cases, and hair available to associate a suspect to the crime in murder or rape cases only 5 percent of the time (41). These statistics make a less compelling case for a database than those presented by database advocates and suggest a need to weigh the social benefits of investigatory databases against the potential social costs.

New means to detect and deter crime generally compel great respect in this country. When a social goal, such as crime control, competes with a fundamental right, such as privacy, however, it is not a foregone conclusion that the social goal will prevail; relative weights must be established in each case (29). The effort to balance law enforcement's advocacy with counter arguments from database opponents requires a determination of the individual liberties that might be compromised by the databases $(9,19,42)$. A number of questions about where the collection of such data might lead must be posed and analyzed.

\section{Who Will Be Tested?}

Law enforcement proposals to date generally would limit test populations to violent offenders, or to the even smaller population of sex offenders. Law enforcement databases currently record much personal information, of varying sensitivity, on all offenders (figure 5-8). Some commentators view DNA information as no greater an infringement on privacy than anything currently collected. Others find DNA data increase the sensitivity of the criminal history records to unacceptable levels. These experts tend to view criminal records as a civil disability imposed in addition to the criminal penalty. A civil disability is any forfeiture of right or privilege exacted by society that hinders a person's ability to function normally after completing a criminal sentence (e.g., loss of voting rights). If adding DNA information to criminal records further discourages a decision to hire an ex-felon (e.g., because it revealed potential for a serious and costly health problem), that would bean imposition of civil disability and a potential threat to rehabilitation that should be considered (26). Imposition of a greater civil disability may or may not be a price society is willing to pay for the benefit DNA records provide.

Once violent-offender databases were established, would justification for testing all convicted offenders be found? No specific proposals for such testing have been made, but OTA's survey of State and local crime laboratories (see ch. 6) found that many labs are considering applying DNA tests in cases of suspected homicide, sexual assault, violent crime, serial crimes, hit and run, and robbery when crime scene evidence is available for comparison. Criteria 
Figure 5-8-How a Database of DNA Information Could Be Created and Used

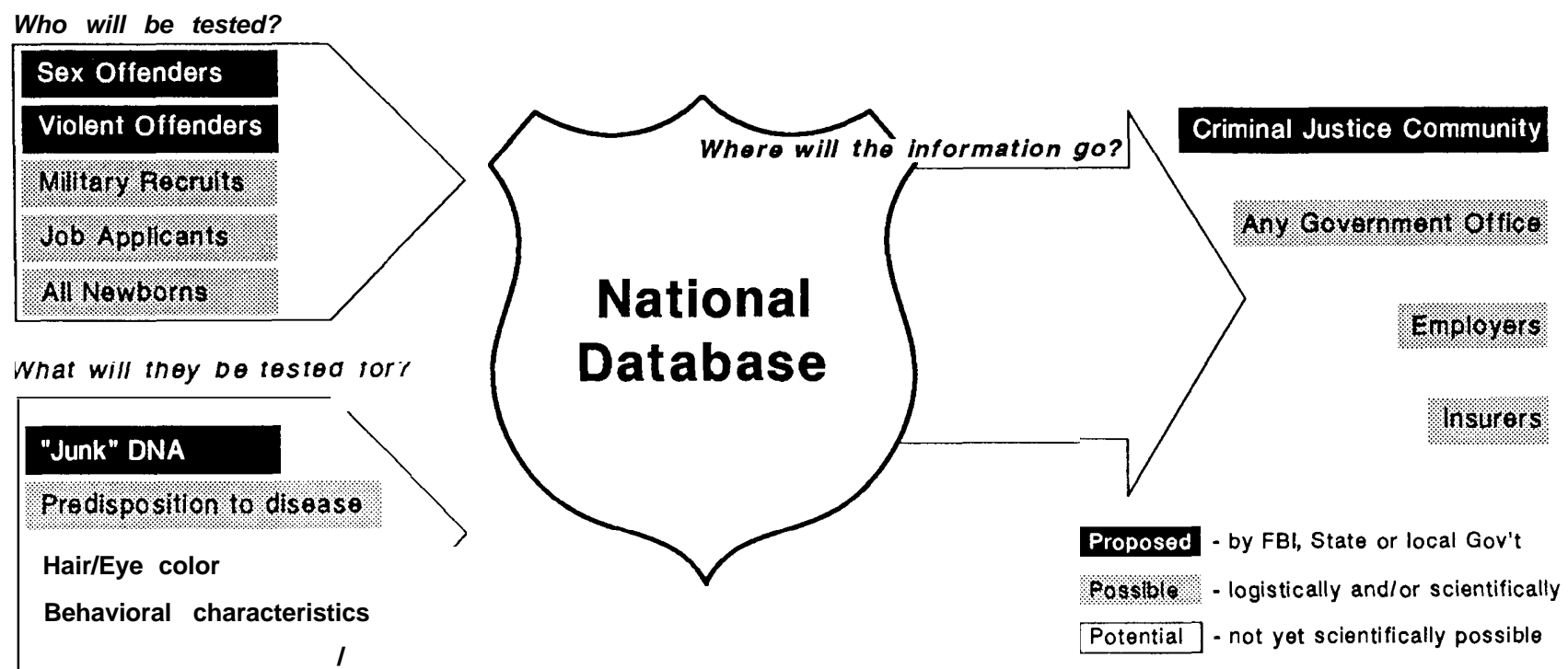

The law enforcement community cites a need for a DNA database to apprehend repeat offenders and solve serial crimes; the military for additional identification (e.g., for victims of wars and mass disasters). Civil liberties experts, however, fear that DNA testing could expand beyond legitimate identification needs, and that test results would be widely available through the de facto national database.

SOURCE: Office of Technology Assessment, 1990.

for establishing the types of crimes suitable for DNA testing include considerations of costs, whether conventional methods are adequate, and any FBI guidelines that are established. Even if test results are produced in a wide variety of crimes, they need not all be included in investigatory data files, but could be.

Proposals to establish DNA databases for identification purposes do not stop with law enforcement. The military services are considering proposals to begin using DNA tests for criminal justice purposes, and are also contemplating performing DNA tests on all current personnel and military recruits to establish a database that would enhance the ability to identify those killed in wars or the victims of mass disasters $(57,58)$. Cases like that of Cpl. Carl Houston, whose body was identified 43 years after he disappeared, might be resolved more quickly and reliably if a DNA database existed. So, too, might situations like the Gander air crash in Newfoundland, Canada, where noncomputerized dental records were destroyed in the disaster (46). (Normally records on military personnel are transported separately from the individuals to which they refer; in the Gander incident, however, troops returning from the Sinai were accompanied by their records, so identification of victims from the plane crash following refueling in Newfoundland was more difficult.) But this database might also be a permanent computer record of personal information on all military personnel. Will society consider that an appropriate use of personal information?

Should parents be able or compelled to store a DNA print of their child for use in the event of a kidnapping or to resolve allegations of switched babies? Such a step might ensure the existence of an immutable identifier, readily and scientifically attributable to an individual, unlike an assigned social security number, for instance (box 5-D). On the other hand, it might also encourage genetic discrimination if DNA samples were probed in-depth. In the mid-1960s, scientists found a high incidence of the XYY chromosome pattern in violent criminals. The press and the public, including some scientists, called for prenatal screening or newborn testing so that those genetically predestined to a life of crime could be tracked. Some innocent children were branded as inferior before this theory was discredited (15).

The Twigg case (4) also raises interesting points on this issue. The Twiggs' daughter, Arlena, suffered from a heart problem, and genetic tests performed before her death revealed that Arlena was 


\section{Box 5-D-Newborn DNA Typing}

Parents sometimes lose their children-they are kidnapped or switched; they run away. If the child and parents are separated for a period of time that renders normal, physical identification difficult or unreliable, DNA testing can assist reunification. Paternity, or parentage, testing is a frequent application of DNA typing, and well within the capabilities of current DNA technologies.

If, however, one or both parents is unavailable at the time the child is recovered, or if there is no clue to connect a child with his or her parents, accurate identification becomes more difficult. That problem has led some experts to suggest that children should acquire a DNA profile at birth, which could be stored for direct comparison with a profile taken at the time of recovery. One company recently began marketing such a service.

Lifebank, Inc., a subsidiary of Quantum Chemical Corp. and sister company of Lifecodes, was incorporated in July 1989 for the purpose of providing neonatal DNA storage services. Lifebank will extract DNA from a newborn's umbilical cord blood and create a DNA profile using Lifecodes' technology. The profile and remaining DNA sample will be preserved at Lifebank facilities for 18 years.

According to Lifebank, the DNA information will be maintained with strict confidentiality. Only a child's parent or guardian will have access to the information; access will be controlled through a passbook/code number system. The company foresees using the DNA profile only for identification purposes, e.g., to reunite parents and missing children. The company does not intend to make the umbilical cord blood available for paternity testing or further genetic testing.

Lifebank began marketing their services in December 1989 through pediatricians and obstetriciangynecologists. It hopes eventually to expand its market, perhaps by providing DNA banking services for the military or complete families.

SOURCE: Office of Technology Assessment, 1990, based onL. Kelly, Lifebank, Inc., Bridgewater, NJ, personal communication, January 1990.

unrelated to either parent. The Twiggs, seeking to learn what happened to their biological daughter, requested a judge to compel genetic testing on a child, Kimberly Mays, who was born at the same time and in the same hospital as Arlena, but who was raised by another family. Kimberly's father, Robert Mays, resisted this request, as he believed it would

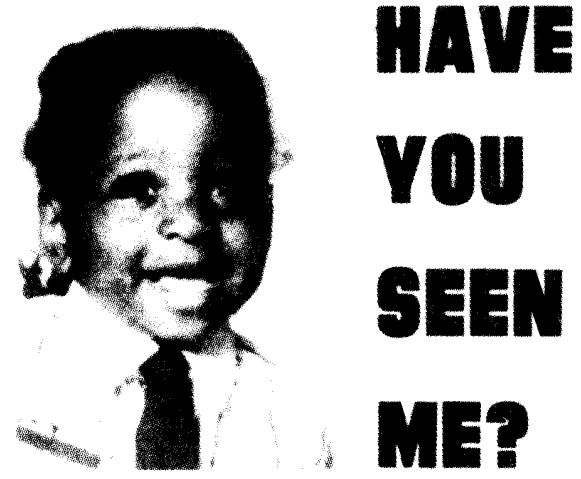

| -800-843-5678

Vational Center for Missing and Explotted Children VAME: SHANE ANTHONY WALKER DOB: 12107187 AGE: 2 tT $3^{\prime} 0^{\prime \prime}$ EVES: DOrk Brown HAR: Block WT: $23 \mathrm{los}$. SEX:M DATE MISSNG: 08/10189 FROM NEW York. New York Photo credit: National Center for Missing and Exploited Children, Arlington, VA

Some propose that DNA prints stored in a databank could be useful in missing children investigations.

unnecessarily disrupt his child's life. In 1989, the Twiggs and Mr. Mays compromised: the Twiggs agreed not to seek custody in return for Mr. Mays agreeing to the tests. Eight genetic tests performed at Johns Hopkins University confined that Kimberly is the Twiggs' biological child. If a judge approves the agreement between the Twiggs and Mr. Mays, the Twiggs intend to seek visitation rights. The Twiggs have sued the hospital where the girls were born, charging negligence, malpractice, or deliberate acts. Existence of a DNA databank might preclude the need for court intervention at the testing stage in similar cases (each child's DNA test results would be on file), but it would do little to resolve the social or moral dilemmas involved.

Would an adult be permitted to have a childhood DNA record purged from a databank, or control how that record was used? Satisfactory answers to these questions may require answers to additional, broader questions.

\section{What Do the Tests Reveal?}

Forensic RFLP probes in use and under immediate development identify highly variable, noncoding segments of the genome-sometimes called 'junk' DNA - that reveal only an individual's identity. DNA profiles in this respect resemble fingerprintsthey are unique, but otherwise uninformative. On the other hand, the $D Q X$ enzyme system used to test 
PCR-amplifed DNA can reveal important information regarding a disease condition (see ch. 3 ).

For most people, the information most likely (at this time) to be added to a criminal history record-RFLP results-probably would not escalate privacy concerns associated with those files because scientists cannot yet make disease associations with the type of information now being collected. Similarly, individuals are asked to provide personal information, from social security number to health status, for so many purposes, that files of "junk" DNA information on military recruits or newborns might be found unobjectionable.

Some are more cautious about DNA collection and storage. They include genetic data in that category of information-along with religion, votes, special confidences-that civil liberties tradition in this country protects from compelled disclosure. These observers are particularly wary of forensic science laboratories applying probes used for medical diagnosis.

DNA testing methods applicable to forensic science are the same as those used in medical diagnostics-to reveal sickle cell or Huntington's disease, for instance. Evidence of disease is personal information and normally designated as highly sensitive. If it were added to a criminal history file, any civil disability created by the file might be compounded, particularly if the information were available to prospective employers. Society might be willing to impose that disability on crimainals, but would likely be more hesitant with regard to children or military personnel.

Diagnostic tests do not reveal unique identity in the reamer of 'junk' DNA, thus no suggestion has been made to include DNA-based medical information in law enforcement or other identification databases. However, some probes used in forensic science locate alleles that lie near a disease locus, thus there may be some association between the "junk" DNA and the disease locus. The possibility exists to test DNA acquired specifically for identification purposes for disease information and to include that information in a database. This option may become more attractive over time, especially as the number and types of probes for genetic disorders increase.
Some scientists developing the DNA tests believe it will be possible to identify behavioral and other mental characteristics within a decade (e.g., genetic bases for schizophrenia and bipolar disorder have been hypothesized). Many forensic scientists do not believe a legitimate law enforcement purpose could be established for such tests and, thus, do not advocate their use in the criminal justice community. Such tests are not yet available, but the civil disabilities attached to misuse of such information, if the tests are developed, could be enormous.

Obviously, testing technologies are under rapid development, with new probes becoming available regularly. Database proponents have recognized the need to build flexibility into any system adopted to accommodate new developments. Still, a problem with the long-term value of the database will arise unless provisions are made to update test results as new testing methods become available. This dilemma leads to another broad and unresolved question.

\section{How Will DNA Information Be Stored?}

Complete genetic information on an individual resides in the DNA sample acquired for testing. Tests render portions of this basic information accessible, but are limited in scope, i.e., one test can only reveal so much about an individual's genetic makeup. Current technology permits several different probes to be used on one Southern blot, but each one has a limited lifetime and a limited amount of information on it. DNA itself can be frozen without significant degradation, and technologies exist to identify the small mutations that can occur during storage (39). Thus three levels of data storage will be available to database managers: test results, Southern blots, and a DNA sample.

Crime scene evidence and DNA samples from victims and suspects are being and will continue to be tested to help identify perpetrators. Current proposals for law enforcement databases anticipate a need only for test results of convicted offenders and unidentified crime scene evidence in investigatory databanks, which, since tests are currently limited to identification, limits the privacy concerns associated with those databanks. To further avoid privacy concerns, law enforcement officials could take specific steps to assure that test results and test materials of victims (and of suspects who are not convicted) are destroyed. Consider, though, a recent 
English case. T'he defendant voluntarily contributed a blood sample during a criminal investigation and was eliminated as a suspect in that case. Police retained the test results, however, and compared them with evidence from other cases, leading to the individual's arrest on another rape charge (17).

A Federal court has determined that NCIC'S authorizing statute (28 U.S.C. 534) only permits storage of information on individuals who axe subject to formal criminal proceedings, thus it may be illegal for NCIC to maintain victim DNA information in any form traceable to the individual (32). The databanks of population statistics may include the results of tests run on both victims and suspects, but since these data are maintained anonymously, privacy concerns again are limited.

Although many officials favor some means of storing test results, no consensus exists within the forensic science community on the issue of DNA sample storage. Two panels convened to help formulate policy in this area reached slightly different conclusions. The New York State Forensic DNA Analysis Panel recommended that DNA samples not be stored in order to avoid improper use (38). The Ad Hoc Committee on Individual Identification by DNA Analysis of the American Society of Human Genetics (ASHG) concluded that it would be appropriate to retain DNA samples if permissible uses were defined and adequate rules of access and disclosure implemented (3).

The main reason to store a DNA sample would be to facilitate retesting whenever necessary to keep up with changes in preferred testing technology or information requirements. Standardization of identity tests would eliminate the need for retesting unless new technologies were adopted or officials determined a need for additional genetic information. If retesting is required, it might also be possible to obtain new samples from convicted offenders, making storage unnecessary. Obtaining a DNA sample from an involuntary donor for purposes unrelated to a specific crime is likely to be problematic, however.

Many ethicists believe sample storage is inappropriate, primarily because it increases the likelihood that specimen DNA will be tested for information beyond unique identity. Since noncoding sections of the genome vary most between individuals, probes for "junk" DNA, rather than medical diagnostic probes, will likely continue to be applied to establish links between a suspect and a crime scene. If a suspect's sample is available for further testing, however, the opportunity arises for use of medical diagnostic probes, which would generally be considered a misapplication of the technology. Destruction of samples, except for crime scene evidence, and maintenance of only 'junk' DNA test results would resolve this issue. Again, privacy concerns are especially acute with regard to storing samples from victims and unconvicted suspects, and some suggest that the law enforcement community take special steps to assure that these samples are destroyed.

If sample storage is deemed necessary for forensic applications, forensic scientists and law enforcement officials could turn to work done by the Ad Hoc Committee on DNA Technology of the ASHG. This group has published some "Points to Consider" regarding preservation of DNA samples taken for diagnostic purposes (2). The guidelines address questions of ownership, confidentiality, release to third parties, quality assurance, and certification.

Southern blots, a middle ground, can be stored and reprobed, but contain a limited amount of information. The limit is imposed by the life of the Southern blot, which can be reused only so many times, and by the restriction enzyme used to fragment the DNA, which limits the probes that can be used. In some circumstances, Southern blot storage could be necessary to preserve the evidence. Otherwise, this storage mechanism offers few technical benefits and potentially raises many of the same privacy concerns associated with sample storage.

Legislatures appear to be wary of imposing substantive restrictions on collection or storage of personal information (7). Most legislation focuses on controlling access to information already collected. The Supreme Court, too, has seemed willing to defer to a government's perceived need for personal information if proper access controls are employed (60). Thus another question regarding a potential DNA database is raised.

\section{Who Will Have Access to DNA Information?}

Civil liberties tradition holds that sensitive information collected under government authority should not be shared indiscriminately. Noncriminal justice use of NCIC'S Triple I file is prohibited (53), thus access to information in that index is quite limited. 
However, FBI proposals for DNA databases envision maintenance of DNA information in State criminal history files, which vary in their accessibility. Concerns about some types of criminal behavior (particularly sex offenses) have led Congress to require that State criminal history files be opened to certain noncriminal justice agencies and employers. For example, in 1984 Congress required States to establish procedures to provide for nationwide criminal history checks for all operators and employees of child-care facilities (Public Law 98-473). There has also been growing interest in implementing criminal record checks for teachers, youth group leaders, and elder-care providers. In addition, there has been increased emphasis on criminal history record checks for current and prospective Federal employees (53). In a majority of States, private organizations can lawfully obtain conviction information (and often arrest information) from State criminal history record files, though conditions regarding access range from very strict (e.g., in Massachusetts) to quite liberal (e.g., in Florida).

The Supreme Court recognizes a strong privacy interest in criminal history records (56). The Supreme Court has ruled, however, that criminal justice agencies are not required to maintain confi dentiality of official records (40). The Privacy Act permits the Attorney General to exempt the FBI from its provisions, but the FBI has adopted privacy regulations for governing NCIC (28 CFR 20). States that violate privacy standards with regard to access to FBI files can be denied NCIC services, but compliance is largely voluntary since the FBI has no active enforcement process (51).

Regulation of access to files maintained by private laboratories remains an open question. Files created for criminal justice purposes may be subject to Federal or State legislation. New means of access control may be necessary if private DNA databases are established to help, for instance, parents identify their children.

\section{Investigatory Use of Population Statistics}

The preceding questions have dealt mainly with the possible informational privacy implications of investigative support databases such as those proposed by the FBI. Databases of population statistics, which do not contain information traceable to an individual, could also change the nature of law enforcement in the United States. Consider the following scenario: A rape occurs in a small community with a population equally divided between Blacks and Caucasians. Semen recovered from a vaginal swab expresses allele size characteristic of 9 percent of the Black population and 0.5 percent of the Caucasian population. No other evidence is available. The scenario raises the following questions:

- Does the entire Black male population in the community become suspect?

- Are the statistics sufficient to issue a warrant demanding blood samples from all Black males in the community?

- If a warrant could not be issued, would a general call for "voluntary' testing of Blacks be condoned? (Box 5-E describes a case involving voluntary testing.) Would failure to volunteer create probable cause for a warrant to be issued?

A Supreme Court case from 1969, Davis v. Mississippi (13), involving fingerprint evidence raised similar questions. In Davis, a rape victim described her assailant as a young, Black man, but could not identify him. Police recovered partial fingerprints from a windowsill. Over a 10-day period following the rape, police, without warrants, questioned and fingerprinted at least 24 Black youths and interrogated 40 to 50 others. Police eventually arrested, based on fingerprint evidence obtained during warrantless questioning, a youth who had done yardwork for the victim. The Supreme Court characterized police behavior in Davis as a dragnet and excluded the fingerprint evidence as obtained in violation of Fourth Amendment protections. The majority of the court refused to accept the State's argument that the inherent reliability of the fingerprinting process would exempt it from probable cause requirements.

The facts of Davis and the Pitchfork case (box 5-E) indicate that powerful identification tools can tempt police to extend their investigatory actions beyond generally accepted bounds. Observers have recognized the power of new technologies to trigger dragnets and searches where there is no specific evidence of wrongdoing. This power effectively shifts the presumption of innocence to one of guilt, with the burden of proof on the targets of the investigation (31). One State attorney general has noted the possibility that DNA typing technologies in particular may create a temptation to engage in 


\section{Box 5-E-The Leicester Case: DNA's Criminal Debut}

On November 21,1983, Lynda Mann, 15 years old, was sexually assaulted and killed on an isolated footpath in the small English county of Leicestershire. Semen recovered from an internal labial swab and a deep vaginal swab was tested. The blood tests could not positively identify the killer, and the scientific label 'Group A secretor, PGM $1+$," a blood type shared by just 10 percent of the population, was the only clue police had.

The police went to every residence in three nearby villages filling out a pro forma document on male residents between the ages of 13 and 34 (an arbitrary range). Patient records from the local psychiatric hospital were also carefully examined. The local newspaper published appeals for help, leading to many tips, all of which proved useless. The investigation team started out with 150 officers, dropped to 8 by May, and was disbanded in August 1984. One-hundred-and-fifty blood tests on potential suspects were performed with no positive results.

In a neighboring village, 15-year-old Dawn Ashworth was similarly slain on July 31, 1986. Police assumed this was a serial murder, and semen was recovered from a vaginal swab and a clothing stain.

On August 8, 1986, police arrested 17-year-old Richard Buckland, a kitchen porter from the psychiatric hospital, for Ashworth's murder. Buckland had a history of sexual behavior that would fit the pattern presumed for the murderer and had known the victim. After prolonged questioning, he made a graphic confession to killing Ashworth.

At this point, the police officer charged with investigating Mann's murder decided to try to connect Buckland to her death. He delivered the semen samples taken from Mann and Ashworth and blood from Buckland to Dr. Alec Jeffreys at Leicester University. Jeffreys, well known because of a highly publicized immigration case in which he applied his new technique of "DNA fingerprinting," accepted the request for assistance. He concluded that both girls were raped by the same man, and that Buckland was not the perpetrator. On November 21, 1986, Buckland became the first accused murderer in the world to be set free as a result of a DNA test.

A new inquiry to investigate both murders began immediately, and on January 2, 1987, police announced a "revolutionary step"-a campaign of voluntary blood testing for every male resident in the three villages. Men were requested by form letter to appear at a certain time for sampling. Collected blood and saliva was first tested for PGM 1+, A secretor characteristics; any blood meeting these criteria was forwarded to Jeffreys for the DNA test. The Police made "house calls" on those men who failed to appear. English civil liberties experts expressed concerns about coercion and the ultimate disposition of test results.

Colin Pitchfork received his notice to appear that January and told his wife he was afraid to give blood because of his criminal record for flashing. Pitchfork eventually convinced a coworker, Ian Kelly, to give under Pitchfork's name using a falsified identity card, and Pitchfork received notification of a negative test.

By May 1987, the police had taken samples from 3,653 men and boys, a 98 percent response rate, but had not found the killer. In August, Kelly admitted his act of deception to other coworkers, one of whom had also been approached by Pitchfork. Six weeks later the police were informed and Kelly was arrested. Pitchfork confessed to both murders on his subsequent arrest in September 1987.

Pitchfork received a double life sentence for the murders, a 10-year sentence for each of the rapes, 3 years each for two earlier sexual assaults, and 3 years for conspiracy, all to be served concurrently. The concurrent sentences mean he could be released within 10 to 12 years. At sentencing, the judge noted that without DNA testing, Pitchfork might still beat large.

SOURCE: J. Wambaugh, The Blooding (New York, NY: William Morrow\& Co., Inc., 1989).

genetic “fishing expeditions.' A professor of forensic science has voiced a concern that mirrors the third query in the hypothetical case, i.e., calls for massive voluntary DNA testing to solve a crime will make a suspect of everyone refusing the test (35). Existing interpretations of Fourth and Fifth Amendment protections may also control application of DNA typing technology, but the issues cannot be ignored as the technology becomes more accessible.
To date, few population statistics have been published, and these have received minimal scrutiny. Thus it maybe unlikely that police will depend on them to help direct their investigations, especially since many scientists believe that population statistics will never be sufficient to indicate reliably a perpetrator's race (36). Their very inadequacy, however, heightens concern that limits to the technology be recognized prior to reliance. 


\section{FINDINGS AND SUMMARY}

Enthusiasm for and availability of DNA typing technologies among the forensic science community grows daily. Concerns about the ability to share information collected from these tests directly follow cost and court acceptance as priority considerations. Several States are debating funding the acquisition of the testing technologies and/or ordering study of networking DNA results. Despite the rapid pace of introduction, the relative newness of the technology provides an opportunity to consider the pros and cons of databanking before making major investments.

The technical capability to network DNA information exists, but should it be used? Beyond the necessity for population statistics, the main rationale for databanking test results appears to be the desire of law enforcement agencies to catch repeat offenders and to aid investigation of serial crime. Experts point to recidivism among rapists as an illustration of a databank's usefulness-recidivists would be more quickly identified if prior test results were on file. Some experts also believe that serial crime could be far more prevalent than realized. A database permitting jurisdictions to store DNA information from unsolved crimes could enhance the ability to identify crime as serial in nature, and therefore encourage collaborative endeavors to solve such crimes.

On the other hand, collection of "junk" DNA (noncoding segments of the genome) for identification purposes will, according to some experts, start society down the slippery slope to unwarranted invasion of privacy. These experts fear that suspect samples will be tested for medical information or behavioral characteristics, and that information generally accorded privacy protections could be entered into computer files that normally are not considered sensitive.

Some experts also suggest ' 'technology-forcing' type reasons to delay databanking at this time. They believe that current tests are primitive but that technology is rapidly advancing. If extensive databasing is done using current, less sophisticated tests, there may be reluctance to adopt new and better technologies that could detract from the usefulness of the initial databases. Of course, this problem would be diminished by a decision to store DNA samples in addition to test results. The database could be constantly updated by performing the newest tests on stored specimens. Such a procedure, however, might increase the likelihood that specimens would be tested for information other than "junk" DNA as new probes are developed, which raises civil liberties concerns.

Databanks of population statistics will likely grow with or without forensic science test results (e.g., through efforts to map or sequence the genome). Since these data do not identify individuals, misuse could only occur in investigations where no suspect has been identified (e.g., to focus efforts unfairly on a particular racial or ethnic group). Such broad applicability of the technology means that possible misuse in forensic science would have to be controlled by limiting access to the population statistics, rather than by deciding not to bank the information.

If deliberation on the pros and cons of databanking are resolved in favor of its use, some technical concerns must be addressed. Successful networking will require databases built around test results derived from standardized procedures and analyzed according to standardized protocols, to be conveyed on standardized computer hardware and software. At the moment, no institutional framework exists to require such standardization, but it appears to be in the best interests of both the States and the FBI. Various means to ensure data integrity-both through peer review and security measures-also need to be integrated in any computer system.

\section{CHAPTER 5 REFERENCES}

1. American Society of Crime Laboratory Directors, "Policy Statement on Forensic Applications of DNA Typing, ' adopted by the Board of Directors, May 3, 1989.

2. American Society of Human Genetics, Ad Hoc Committee on DNA Technology, "DNA Banking and DNA Analysis: Points to Consider," American Journal of Human Genetics 12:5, 1988.

3. American Society of Human Genetics, Ad Hoc Committee on Individual Identification by DNA Analysis, "Individual Identification by DNA Analysis: Points to Consider, 'American Journal of Human Genetics 46:631-634, 1990.

4. Associated Press, "Lawyer for Twiggs Says Robert Mays Could Be Scaring Girl in Custody Case," Wauchula, FL, Jan. 2, 1989; "Genetic Tests Confirm Florida Baby Swap, "Clearwater, FL, Nov. 19,1989.

5. Balazs, I., Lifecodes Corp., Valhalla, NY, personal communication, April 1989. 
6. Bashinski, J.S., Oakland Police Department, Criminalistics Lab, personal communication, April 1989.

7. Belair, R.R., "Information Privacy: A Legal and Policy Analysis," InformationReports and Bibliographies 12:2, 1983.

8. Bereano, P.L., Professor, Engineering and Social Policy, University of Washington, testimony before U.S. House of Representatives, Subcommittee on Civil and Constitutional Rights, Committee on the Judiciary, Mar. 22, 1989.

9. Berman, J., and Goldman, J., A Federal Right of Information Privacy: The Need for Reform, Project on Communication and Information Policy Options, No. 4 (Washington, DC: Benton Foundation, 1989).

10. Bureau of Justice Statistics, A Survey of Recidivism Among Prisoners Released in 1983 (Washington, DC: U.S. Department of Justice, March 1989).

11. Castonguay, R.T., Federal Bureau of Investigation, Washington, DC, personal communication, April 1989.

12. Dabbs, D., "The Use of DNA Profiling in Linking Serial Murders," Medico-Legal Bulletin 37:6, 1988.

13. Davis v. Mississippi, 394 U.S. 721 (1969).

14. Edwards, D., "Chairman's Opening Statement," U.S. House of Representatives, Subcommittee on Civil and Constitutional Rights, Committee on the Judiciary, Mar. 22, 1989.

15. Elmer-Dewitt, P., "The Perils of Treading on Heredity," Time 70, Mar. 20, 1989.

16. Ferrara, P. B., Virginia Bureau of Forensic Science, Richmond, VA, personal communication, May 1989.

17. Gelowitz, M.A., "DNA Fingerprinting: What's Bred in the Blood," Criminal Reports (3d) 65:122-135, 1989 ,

18. Goldman, J., American Civil Liberties Union, Washington, DC, personal communication, August 1989.

19. Gray, S.H., "Electronic Databases and Privacy: Issues for the 1990' s," Science, Technology, and Human Values 14:3, 1989.

20. Hicks, J.W., Federal Bureau of Investigation, testimony before U.S. House of Representatives, Subcommittee on Civil and Constitutional Rights, Committee on the Judiciary, Mar. 22, 1989.

21. Hicks, J. W., Federal Bureau of Investigation, "Conference Summary," International Symposium on the Forensic Aspects of DNA Analysis, Quantico, VA, June 23, 1989.

22. Hicks, J.W., Federal Bureau of Investigation, Washington, DC, personal communication, August 1989.

23. Horning, J.J., Goldman, J., and Gordon, D. R., "A Review of NCIC 2000: The Proposed Design for the National Crime Information Center," prepared for the U.S. House of Representatives, Subcommittee on Civil and Constitutional Rights, Committee on the Judiciary, February 1989.
24. Johnson, D. M., Federal Bureau of Investigation, "National Database Development," International Symposium on the Forensic Aspects of DNA Analysis, Quantico, VA, June 19-23, 1989.

25. Lander, E., Whitehead Institute for Biomedical Research, Cambridge, MA, personal communication, April 1989.

26. Laudon, K. C., Dossier Society: Value Choices in the Design of National Information Systems (New York NY: Columbia University Press, 1986).

27. McDonnell, M., Automated Microbiology Systems, Inc., San Diego, CA, personal communication, May 1989.

28. Maney v. Ratcliff, 399F. Supp.760(E.D. Wis. 1975).

29. Marchand, D. A., The Politics of Privacy, Computers, and Criminal Justice Records (Arlington, VA: Information Resources Press, 1980).

29. Marr, T. G., Los Alamos National Laboratory, Los Alamos, NM, personal communication, February 1989.

31. Marx, G.T, "I'll Be Watching You," Dissent 32:26-34, Winter 1985.

32. Menard v. Saxbe, 498 F. 2d 1017 (DC. Cir. 1974).

33. Monson, K.L., "Semiautomated Analysis of DNA Autoradiograms,' Crime Laboratory Digest 15:4, 1988.

34. Monson, K. L., Federal Bureau of Investigation, Quantico, VA, personal communication, April 1989.

35. Moss, D. C., "DNA-The New Fingerprints," $A B A$ Journal 70, May 1, 1988.

36. Mueller, L.D., University of California, Irvine, Irvine, CA, personal communication, August 1989.

37. National Crime Information Center, Minutes of the Advisory Policy Board Meeting, St. Petersburg, FL, Dec. 9-10, 1987.

39. New York State Forensic DNA Analysis Panel, "DNA Report," Sept. 6, 1989.

39. Nolan, K., and Swenson, S., "New Tools, New Dilemmas: Genetic Frontiers," Hastings Center Report 18:5, 1988.

40. Paul v. Davis, 424 U.S. 693 (1976).

41. Peterson, J.L., testimony before U.S. Senate, Subcommittee on the Constitution, Committee on the Judiciary, Mar. 15, 1989.

42. Price, M. E., "Searching for a New Paradigm," National Law Journal Aug. 7, 1989, pp. 13-17.

43. Pun, T., Trus, B., Grossman, N., et al., "Computer Automated Lanes Detection and Profiles Evaulation of One-Dimensional Gel Electrophoretic Autoradiography," Electrophoresis 6:268-274, 1985.

44. Reeder, D.J., National Institute of Standards and Technology, Gaithersburg, MD, personal communication, June 1989.

45. Simon, P., "Chairman's Questions to the Panel," U.S. Senate, Subcommittee on the Constitution, Committee on the Judiciary, Mar. 15, 1989. 
46. Smith, B. C., U.S. Army Central Identification Laboratory, Ft. Shafter, HI, personal communication, January 1989.

47. Tarlton v. Saxbe, 507 F.2d 1116 (D.C. Cir. 1974).

48. Technical Working Group on DNA Analysis Methods (TWGDAM), The Combined DNA Index System (CODIS): A Theoretical Model, Federal Bureau of Investigation, Quantico, VA, Oct. 15, 1989.

49. Thompson, W. C., and Ford, S., "DNA Typing: Acceptance and Weight of the New Genetic Identification Tests," Virginia Law Review 75:45-108, 1989.

50. Trubow, G., Watching the Watchers: The Coordination of Federal Privacy Policy, Project on Communication and Information Policy Options, No. 5 (Washington, DC: Benton Foundation, 1989).

51. U.S. Congress, Office of Technology Assessment, An Assessment of Alternatives for a National Computerized Criminal History System, OTA-CIT-161 (Washington, DC: U.S. Government Printing Office, October 1982).

52. U.S. Congress, Office of Technology Assessment, Defending Secrets, Sharing Data: New Locks and Keys for Electronic Information, OTA-CIT-31O (Washington, DC: U.S. Government Printing Office, October 1987).
53. U.S. Congress, Office of Technology Assessment, Federal Government Information Technology: Electronic Record Systems and Individual Privacy, OTACIT-296 (Washington, DC: U.S. Government Printing Office, June 1986).

54. U.S. Congress, Office of Technology Assessment, "Issues Relevant to NCIC 2000 Proposals," staff paper, Nov. 12, 1987.

55. U.S. Department of Health, Education, and Welfare, Records, Computers and the Rights of Citizens: Report of the Secretary's Advisory Committee on Automated Personal Data Systems, 1973.

56. United States Department of Justice v. Reporters Committee for Freedom of the Press, No. 87-1379, decided Mar. 22, 1989.

57. Webb, J.E., Commander, U.S. Army Central Identification Laboratory, Ft. Shafter, HI, personal communication, January 1989.

58. Weedn, V., Office of Armed Forces Medical Examiner, Armed Forces Institute of Pathology, Baltimore, MD, personal communication, June 1989.

59. Westin, A. F., and Baker, M.A., Databanks in a Free Society (New York, NY: Quadrangle/The New York Times Book Co., 1972).

60. Whalen v. Roe, 429 U.S. 595 (1977). 


\section{Chapter 6}

\section{DNA Typing by Federal, State, and Local Crime Laboratories}

"DNA typing will not significantly lower the crime rate in America. At most, it will simply add to the quality ethic that pertains to the process by which guilt is decided. But then, that is quite a lot in itself. The criminal justice system needs all the help that it can get."

John I. Thorton Professor of Forensic Science University of California, Berkeley Chemical \& Engineering News

Nov. 20, 1989 


\section{CONTENTS}

FBI INVOLVEMENT IN DNA TYPING ...............................

STATE AND LOCAL CRIME LABORATORY INVOLVEMENT, $\ldots \ldots \ldots \ldots \ldots \ldots \ldots \ldots \ldots$

Crime Laboratories' Views on FBI Role in DNA Testing . . . . . . . . . . . . . . . . 146

Crime Laboratories' Plans for DNA Testing . . . . . . . . . . . . . . . . . . . . . 147

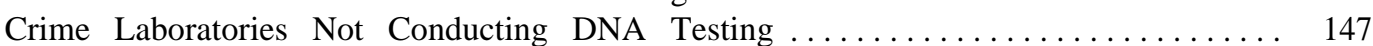

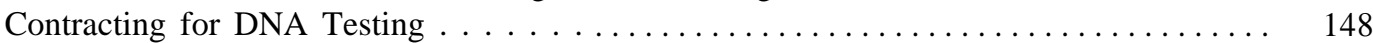

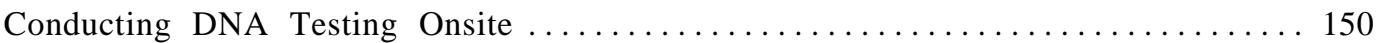

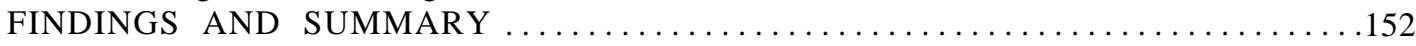

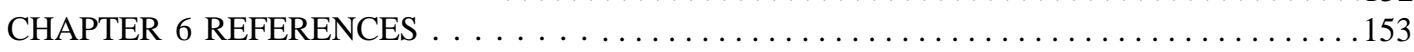

\section{Boxes}

6-A. Previous Surveys on Forensic DNA Testing . . . . . . . . . . . . . . . . . . 142

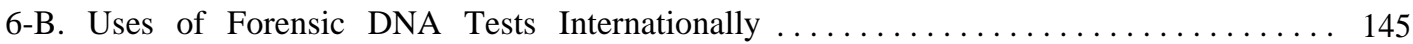

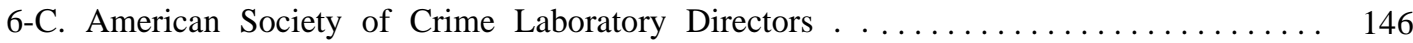

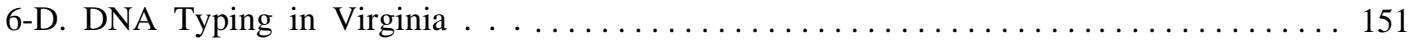

6-E. The New York State Forensic DNA Analysis Panel ................... 152

\section{Tables}

6-1. Equipment Needs To Conduct DNA Typing $\ldots \ldots \ldots \ldots \ldots \ldots \ldots \ldots \ldots \ldots \ldots \ldots$

6-2. Operating Expenses for the FBI DNA Analysis Unit . . . . . . . . . . . . . . . . . . . . 144

6-3. Ranking of Importance of DNA Typing to Crime Laboratories . . . . . . . . . . . . 146

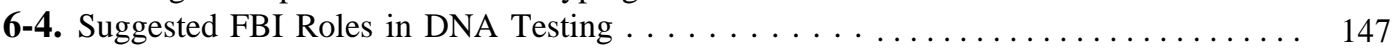

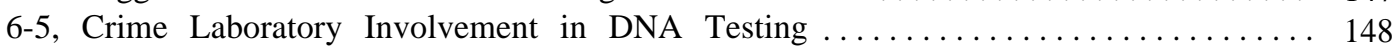

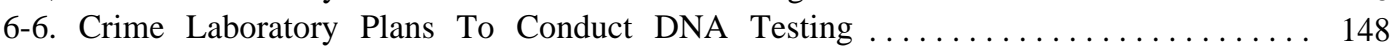

6-7. Crime Laboratory Plans To Contract for DNA Testing in the Future . . . . . . . . . . 148

6-8. Costs for Forensic DNA Testing by Private Laboratories . . . . . . . . . . . . . . 149

6-9. Costs for Paternity DNA Testing by Private Laboratories . . . . . . . . . . . . . . . . 149

6-10. Facilities Contracted With for DNA Testing . . . . . . . . . . . . . . . . . . . . . 149

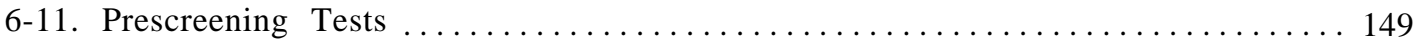

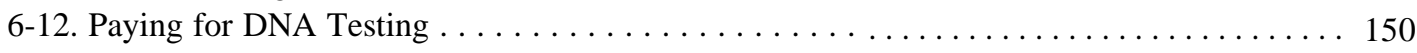




\section{DNA Typing by Federal, State, and Local Crime Laboratories}

Since November 1987, when a Florida criminal conviction based on DNA typing evidence received national attention, State and local crime laboratory interest in this technology has skyrocketed. (See app. A for descriptions of additional cases.) Immediately following this case, crime laboratories around the Nation began to explore their DNA typing options. Almost all U.S. crime laboratories have now heard of the technology. Many choose to contract with private companies currently conducting DNA testing for forensic purposes. Several others have taken the first steps necessary to provide onsite capability for DNA typing. Some States have enacted legislation requiring that certain groups of convicted offenders submit a blood or saliva specimen to be placed in a databank (see ch. 5).

This chapter reports the results of a 1989 OTA survey of State and local crime laboratories that built on earlier surveys (box 6-A; see app. B for survey instrument). Designed to determine the present and future extent of DNA typing by crime laboratories, the survey also evaluated the extent of onsite v. offsite capability. The survey population was derived from the 1988 Federal Bureau of Investigation (FBI) Directory of Crime Laboratories. The survey was mailed to 298 laboratories between February and May 1989. At least 1 survey from each of the 50 States was returned, along with surveys from the U.S. Virgin Islands and Puerto Rico. Eight States returned one questionnaire each for their entire laboratory systems, reducing the original sample by 41; in total, 221 questionnaires were completed and returned from the survey population of 257 (an 85 percent response rate).

In addition to discussing the results of the survey, this chapter presents a brief overview of the FBI's involvement in DNA typing. Survey results on crime laboratories' views on the potential role for this agency in DNA typing are analyzed in the context of the projections of the FBI. The involvement of the American Society of Crime Laboratory Directors (ASCLD) in DNA typing is also described, as are divergent approaches to forensic DNA analysis by two States: Virginia and New York.

\section{FBI INVOLVEMENT IN DNA TYPING}

The FBI, established in 1908, is the investigative branch of the U.S. Department of Justice. Charged with responsibility for investigating violations of Federal law in criminal, civil, and security fields, the FBI also oversees the National Crime Information Center (see ch. 5) and offers training to law enforcement officers and forensic scientists. FBI facilities include 59 field offices throughout the United States, the FBI Academy in Quantico, VA, and the headquarters in Washington, DC.

The FBI Academy trains agents and other law enforcement officers and also researches new methods in forensic science. The Forensic Science Research and Training Center (FSRTC) of the FBI Laboratory, opened in 1981 at the FBI Academy, performs both long- and short-term research in the areas of biochemistry, immunology, chemistry, physics, and polygraph (42 U.S.C. sec. 3744). Longterm projects usually investigate new theories or technologies, while short-term projects often evaluate current methods for their value and reliability (17). The mandated mission of FSRTC is to provide quality research and training programs plus operational assistance in the forensic sciences to the FBI and other Federal, State, and local law enforcement agencies and crime laboratories (13).

With this goal in mind, FBI research scientists began investigating DNA typing in early 1985 . Their involvement began with the cofunding of a project with the National Institutes of Health to examine rnitochondrial DNA from blood samples for ethnic markers (13). Although not originally conceptualized as a method to examine DNA for identification purposes, the FBI accelerated its efforts in this area of research after the frost scientific papers on DNA typing were published in 1985. A research scientist was assigned in early 1986 to investigate the potential of DNA technologies for forensic purposes. Site visits were made to private DNA testing labs in the United States and the United Kingdom, as well as to other institutions performing DNA research. In July 1987, the FBI decided to have a research team at FSRTC develop DNA typing for use in the headquarters' laboratory (13). 


\section{Box 6-A-Previous Surveys on Forensic DNA Testing}

At least five surveys on forensic DNA testing have been done previously, and provide a gauge of how quickly interest in DNA testing has increased. The first was conducted by the California Association of Crime Laboratory Directors' DNA Committee in September 1987. It was an informal poll given to members of the American Society of Crime Laboratory Directors (ASCLD) present at the 1987 annual meeting in Ernmitsburg, MD. At the time of the survey, levels of awareness and understanding of DNA typing among crime laboratory personnel were much lower than current levels. Respondents were asked if they did serological testing, and if so, they continued with the survey. Eighty-seven laboratories responded to the additional series of questions; 70 laboratories had discussed or considered the feasibility of DNA typing, while 17 had not. When asked if their laboratory had formed an opinion (a policy) on DNA typing, more than half (37) of the laboratories who had discussed the DNA issue had formed a policy. Of those, 20 labs responded that DNA testing was valid as a routine tool, and that they might contract out DNA typing. Seventeen felt that DNA typing was not yet appropriate for casework Of the 33 whose laboratories had not yet formed an opinion on DNA typing, 13 felt DNA typing was not yet appropriate for casework and 5 felt that it was a valid tool and that they might contract out DNA typing on selected cases.

A second small survey was conducted at a DNA workshop at the University of New Haven, CT, in spring 1988. The results indicated that respondents were planning to implement DNA typing in collaboration with university labs, blood banking centers, and DNA typing labs. This indicated that each forensic laboratory planned to implement DNA typing in cooperation with a local collaborator, which could lead to a situation where labs would use a variety of different approaches and techniques with no standardization of the methodologies. However, when asked if there should be a standardized procedure, all respondents said one should be developed. According to the respondents, the following aspects should be standardized: DNA extraction procedure, restriction enzyme used, electrophoresis, Southern blotting, definition of probes, and data analysis. All those surveyed indicated there was a need for a national DNA data center. Information that should be incorporated into such a database included restriction enzymes, DNA standards, DNA probes, autoradiograms, DNA polymorphism population distributions, and DNA typing results in digitized form.

In part to assess its projected workload for DNA testing, the FBI conducted a small survey at the September 1988 ASCLD annual meeting held at the FBI Academy in Quantico, VA. From a survey population of 168 crime laboratory directors, 75 questionnaires were received (a response rate of 45 percent). Of those who responded, 34 crime lab directors representing 31 systems anticipated implementing some form of DNA typing by January 1990. Four laboratories would not have an impact on the FBI's workload, either because they were Federal labs, Canadian, or already performing DNA typing onsite. Approximately 120 investigations had been referred to these laboratories at that time. The remaining 27 laboratories that responded positively had submitted budget requests but had not yet received approval. The FBI assumed that the 93 laboratory directors who did not respond were not planning to implement onsite DNA testing, at the time alerting them to the possibility that much of this casework could be referred to the FBI. The OTA survey, however, indicates that plans for onsite testing are more widespread than at the time of the FBI survey.

Finally, two telephone surveys were conducted at court expense in early 1989. These telephone surveys of crime laboratory directors and molecular biologists were introduced in the ease of State of Indiana v. Hopkins to raise questions about the admissibility of DNA typing results. The "Survey of Members of American Society of Crime Laboratory Directors" was responded to by 241 crime laboratories. Responses for the "Survey of Scientists Regarding DNA Typing" were elicited from 215 members of the Molecular Biology and Genetics Section of the American Society for Microbiology. Survey questions ranged from assessing whether DNA tests performed by private laboratories were ready for casework to identifying potential scientific problems with DNA typing. (The actual surveys and results were unavailable for review by OTA.)

SOURCES: Office of Technology Assessment, 1990, based in part on California Association of Crime Laboratory Directors' DNACommittee, "DNA Survey," Report \#2, Nov. 19, 1987; H. Lee and R. Gaensslen, "The Need for Standardization of DNA Analysis Methods and a National DNA Database, " paper prepared for the meeting "DNA Technology In Forensic Science," Quantico, VA, May 31-June 2, 1988; J. Kearne $r$, Federal Bureau of Investigation "FBI Survey at 16th Annual Symposium on Crime Laboratory Development," September 1988; and W.F. Rowe, "DNA Testing Not Ready for Court? A Tale of Two Surveys," Journal of Forensic Sciences 34(4):803-805, July 1989. 


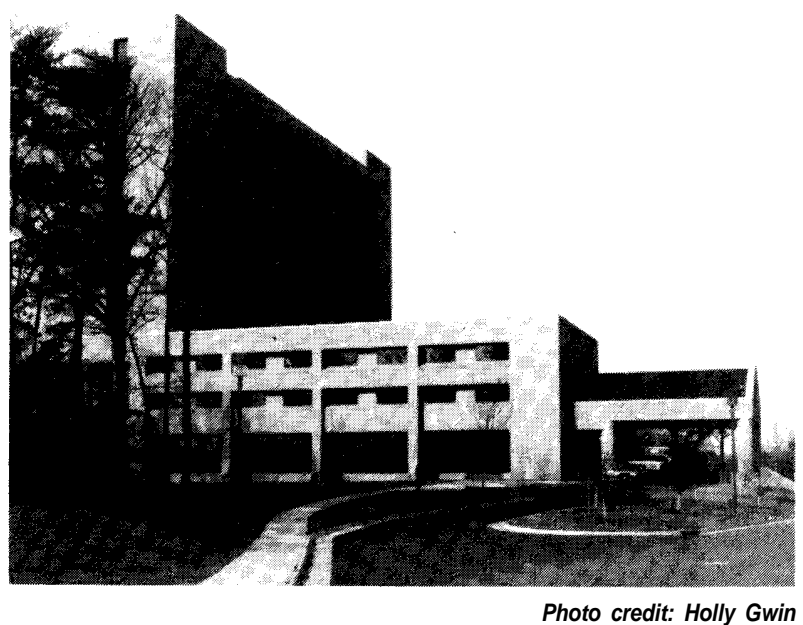

Federal Bureau of Investigation Academy: Headquarters of the Forensic Science Research and Training Center, Quantico, VA.

By January 1988, FSRTC had implemented DNA typing trials onsite. Personnel were trained and given proficiency tests through December 1988, and once the final validation process was completed, the DNA Analysis Unit, located at the FBI's headquarters facility, began accepting actual casework from other crime laboratories. The first case was reported in March 1989. A great deal of ongoing research at FSRTC still supplements DNA typing casework at the headquarters DNA Analysis Unit. Currently four laboratory personnel at FSRTC are doing DNA typing research and four others are involved in training and the development of a proficiency testing prograrn(13). The FSRTC spent 20percent $(\$ 104,200)$ of its research and training equipment budget on DNA typing and 36 percent $(\$ 143,200)$ of its supply budget on DNA typing in fiscal year 1989 (13).

As of July 1989, the FBI had received 536 case submissions consisting of 2,619 individual DNA samples (11); by November 1989, the number of cases had risen to over 1,000 (13). The FBI estimates the cost per sample to be $\$ 98.50$ (this figure includes labor but not the costs for facility use) (8). (See table 6-1 for equipment needs to perform DNA testing.) Monthly costs (excluding labor) have been estimated at $\$ 18,100$ ( $\$ 217,200$ per year). However, because the FBI expects to process 25 percent more samples in the future, the annual amount has been adjusted to $\$ 271,500$ (table 6-2). The $\$ 217,200$ figure was based on the workload of five technicians, while the $\$ 271,500$ is based on a full staff laboratory of seven technicians; currently there are
Table 6-I-Equipment Needs To Conduct DNA Typing

\begin{tabular}{|c|c|}
\hline Equipment item & $\begin{array}{l}\text { imate cost per item } \\
\text { (dollars) }\end{array}$ \\
\hline Autoclave (bench top) $\ldots \ldots \ldots$ & 4,600 \\
\hline UV spectophotometer .... & 12,000 \\
\hline UV transilluminator . . . . . . . . . . & 2,300 \\
\hline Electrophoresis power supplies . . . . . & 2,500 (minimum of 2 ) \\
\hline Electrophoresis tanks. ........... & 400 (minimum of 4 ) \\
\hline Microfuge (general use) . . . . . . . . & 1,200 \\
\hline $\begin{array}{l}\text { Microfuge (dedicated to radioactive } \\
\text { isotopes) } \ldots \ldots \ldots \ldots \ldots \ldots \ldots\end{array}$ & 1,200 \\
\hline Microliter pipettor (variable range) . . . & 250 \\
\hline Water baths $\ldots \ldots \ldots \ldots \ldots \ldots \ldots$ & 2,000 (2-3 required) \\
\hline Vacuum centrifuge $\mathrm{e}^{\star}$. & 4,300 \\
\hline Ultra-low temperature freezer & 6,300 \\
\hline Environmental rotary shaker* & 5,100 \\
\hline Vacuum oven* $\ldots \ldots \ldots \ldots$ & 1,000 \\
\hline Gel photography equipment ... & 1,000 \\
\hline X-ray film autoprocessor' . . . & 7,100 \\
\hline Platform shaker ${ }^{*} . \ldots \ldots \ldots \ldots \ldots$ & 1,000 \\
\hline Benchtop radioisotope counter OR . . & 2,400 \\
\hline Liquid scintillation counter $\ldots \ldots \ldots$ & 12,000 \\
\hline Radioactivity survey meter ... & 250 \\
\hline Intensifying screens (pair) .. & 300 (5pairminimum) \\
\hline
\end{tabular}

six technicians working in the DNA Analysis Unit (13). At the moment, one technician can extract 25 to 30 samples per week. Based on a 48-week work year, the FBI anticipates an annual processing capability of 10,000 samples (8).

The FBI is transferring DNA typing technology to State and local crime laboratories through collaborative research projects, technical training courses, seminars, and publications (10). Scientists from State and local crime laboratories can participate in the Visiting Scientist program, through which forensic examiners learn DNA typing techniques (10). Analysts from at least 16 crime laboratory systems have participated in this program and 9 other systems are scheduled to participate in fiscal year 1990. In addition, free training courses are offered by FSRTC to personnel from State and local crime laboratories. Courses run from one day to several weeks. One-day courses are taught onsite by the FBI scientists; a 4-week course held two times since January 1989 has trained 60 students, and will be offered four times in fiscal year 1990, training 120 more students (13).

Two FBI symposia on DNA typing have included presentations by research scientists from academia, private labs, and the international forensic science community. (See box 6-B for information onuses of forensic DNA typing in other countries.) In addition 
Table 6-2-Operating Expenses for the FBI DNA Analysis Unit

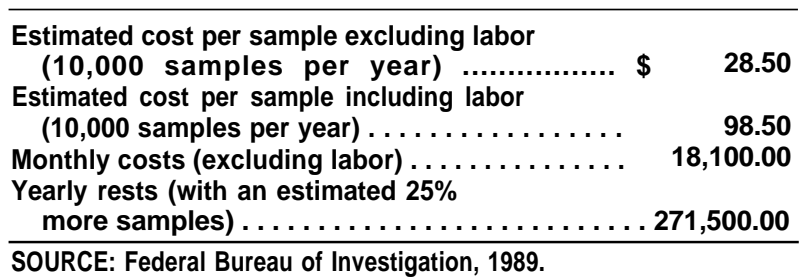

to these technology transfer mechanisms, the FBI publishes Crime Laboratory Digest quarterly, which has devoted several issues to DNA technology.

Following a suggestion at a June 1988 FBI seminar on DNA technology, an FBI Technical Working Group on DNA Analysis Methods (TWGDAM) was established. It first met in November 1988, and held three meetings in 1989, with the mission to evaluate DNA typing technologies used in State and local crime laboratories. To date, FBI, Lifecodes Corp. (a private company), and Canadian methods have all been considered. The group provides a forum for these labs to share information, protocols, and ideas related to DNA typing (12). It will also establish guidelines where appropriate (16).

Thirty-one representatives from 16 laboratories in the United States and Canada were chosen to serve on TWGDAM, based on how close the labs were to doing DNA typing. Initially, two representatives per lab were selected, although this has since been reduced to one per lab to allow other facilities to participate. Two academics were also chosen, one as a technical adviser for the polymerase chain reaction (PCR) method and the other for the restriction fragment length polymorphism (RFLP) technique.

Two TWGDAM subcommittees have been formed. One is addressing database developments and the other is considering quality control and quality assurance issues. The database subcommittee developed a theoretical model that was completed in October 1989. The FBI plans to create a working prototype of the model, to use for pilot studies with crime laboratories (4). The final report on quality assurance was published in July 1989 (16). TWGDAM will not be running a proficiency testing program. However, samples may be sent to TWGDAM members who are using the FBI method to measure the precision between laboratories.

\section{$\begin{array}{ll}\text { U.S. Department of Justice } \\ \text { Volume 15, Supplement No. I } & \text { Federal Bureas of Investigation }\end{array}$ \\ Crime Laboratory Digest}

In This Issue

DNA Implementation

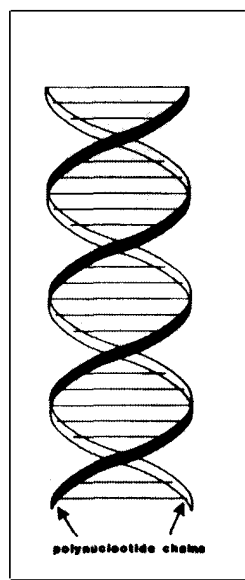

Photo credit: Federal Bureau of Investigation, Quantico, VA

An issue of the Crime Laboratory Digest devoted to DNA typing.

\section{STATE AND LOCAL CRIME LABORATORY INVOLVEMENT}

Since the 1920s, when the first U.S. crime laboratories were established in Los Angeles and Chicago, they have proliferated across the country. Over half of those now operating opened their doors after 1970, often through Law Enforcement Assistance Administration funding (15). Currently, more than half of the crime laboratories in the United States provide at least some forensic serology services (2). The OTA survey of State and local crime laboratories revealed a wide range of efforts in DNA typing. Each State and local system has set up a crime laboratory uniquely suited to their needs. More often than not, DNA typing has become apart of those needs (box 6-C).

The number of nonclerical staff members in a lab ranged from 1 to 160 , with an average staff size of 22. The OTA survey found that annual budgets ranged from $\$ 10,000$ to $\$ 12$ million, with an average of $\$ 1,269,000$. It should be noted that 18 percent of 


\section{Box 6-B-Uses of Forensic DNA Tests Internationally}

$\boldsymbol{A n}$ informal OTA survey in January 1989 of 40 countries found that at least 15 have implemented or are exploring forensic applications of DNA tests' with most expecting to perform DNA typing of forensic samples in late 1989 or 1990. Two-the Republic of Korea and Yugoslavia-reported that such use of DNA identification was not planned. South Africa indicated that DNA typing is used only for medical applications at present, but embassy staff did not say whether this might be broadened to forensic uses. Yugoslavia also reported that such tests are used for medical applications.

The extent to which DNA typing technologies have been used abroad varies. In the United Kingdom, where forensic applications of DNA typing originated, single-locus and multilocus approaches have been fully accepted for criminal, paternity, and immigration casework Over the past two years, Norway has gradually begun to use DNA typing in selected penal and civil cases. In other countries, DNA profiling is in an early, exploratory phase, with law enforcement units developing suitable systems and, in particular, collecting population data. In 1988, for example, Finland replaced traditional genetic human leukocyte antigen (HLA) typing for paternity cases with DNA-based profiling, which is now routinely used; DNA identification for criminal offenses has been on a selective basis.

The Israeli police intend to use DNA typing on a routine basis, and as of February 1989 were beginning trials on case samples. The Main Office of the Polish police and the Polish Academy of Sciences are conducting research on DNA typing for forensic applications and anticipate field applications at the end of 1989 for selected rape and murder cases. Explorations into DNA typing for paternity purposes in Poland has been discontinued due to lack of funding. In the State of South Australia, restriction fragment length polymorphism analysis is used for paternity testing, and polymerase chain reaction has been used for crime work Two of New Zealand's three forensic laboratories plan to be performing DNA analysis by early 1990. Several countries, while currently in the development phase, have contracted with commercial laboratories on a limited basis.

Full international cooperation that would result in standardization and a coordinated investigative databank, as with some current National Crime Investigation Center files (see ch. 5), appears beyond reach at the moment. On the one hand, close coordination between the Royal Canadian Mounted Police and the Federal Bureau of Investigation will likely lead to effective data sharing from the outset-especially since the FBI anticipates its system eventually will become the de facto system in the United States. On the other hand, in anticipation of a unified European Community in 1992, officials of Denmark, Italy, the Netherlands, the United Kingdom, and Federal Republic of Germany met and agreed to a series of issues pertinent to standardization, including a designated restriction enzyme (different from the United States system) and a common probe. Nevertheless, although current technologies and applications appear to have advanced too far for international standardization for the present, the situation is likely to change as future technical advances are adopted. In the interim, the Federal Government could facilitate dialogue and encourage cooperative efforts leading toward a system amenable to DNA identification among, not just within, international criminal justice entities.

\footnotetext{
${ }^{1}$ Australia, Canada, Finland, India, Ireland, Israel, Italy, Japan, New Zealand, Norway, Poland, Sweden, Switzerland, United Kingdom, and West Germany.

SOURCE: Office of Technology Assessment, 1990.
}

those surveyed did not respond to this question, often because they are covered under a State budget. In addition, some who responded may have given the total State budget, which would inflate their response and hence the average. And some may have included staff salaries, while others may not have.

Regardless of whether the responding crime laboratory was making plans to do DNA typing onsite, 78 percent of those surveyed said that DNA typing is very important to develop in order to advance the mission of their crime laboratory.
The remainder said that DNA typing was "somewhat important, but only an additional technology in an array of existing technologies" (15 percent), or that it was 'not very important' to their laboratory's mission (5 percent) (table 6-3). Of the latter, most noted the response was prompted by very narrow forensic duties (e.g., drug analysis or arson investigation).

Respondents were asked to list what they perceived as the most important issues regarding DNA typing. The issues cited most often were standardi- 


\section{Box 6-C-American Society of Crime Laboratory Directors}

Formed in January 1974, the American Society of Crime Laboratory Directors (ASCLD) is the national professional organization of crime laboratory administrators. Its mission is to use management practices to improve crime laboratory operations. Officers are elected by the 15-member Board of Directors. The group's purposes are:

. to promote and foster the development of laboratory management principles and techniques;

- to acquire, preserve, and disseminate information related to the utilization of crime laboratories;

- to maintain and improve communications among crime laboratory directors;

. to promote, encourage, and maintain the highest standards of practice in the field of crime laboratory services;

- to promote an increase in the effective utilization of crime laboratory services;

. to foster an increase in the effective utilization of crime laboratories in the criminal justice system;

. to foster the continuous improvement of the quality of services offered by the crime laboratory; and

- to offer advisory and consultant services in the forensic sciences in support of the criminal justice system.

ASCLD sponsors programs for both proficiency testing and laboratory accreditation on a voluntary basis. Annual meetings are scheduled to coincide with the FBI's yearly crime laboratory development symposiums. In recent years, technical updates on DNA analysis have been given at the meetings. The first ASCLD position statement on DNA typing, adopted at the May 1988 Board of Directors meeting, stated that "DNA typing is an additional tool in the characterization of biological evidence in criminal investigations. It must be recognized that this procedure is only one part of the scientific analysis of evidence." At the May 1989 meeting, the organization formulated another policy statement on DNA typing, in which appropriate quality control and quality assurance measures and a common database system were identific as important. The establishment of a national DNA database system using the FBI's RFLP analysis program was supported as were implementation guidelines to help transfer DNA typing to State and local crime laboratories. In September 1989, ASCLD endorsed the TWGDAM quality assurance guidelines. Finally, ASCLD believes it has both a duty and a responsibility to establish standards for the forensic science community and cites its prior experience in establishing quality assurance programs through its national crime laboratory accreditation program (see ch. 3).

SOURCES: Office of Technology Assessment, 1990, based on "ASCLD DNA Statement," adopted by the ASCLD Board of Directors, May 3, 1989; American Society of Crime Laboratory Directors, pampblet.

zation of DNA typing methods, courtroom approval and acceptance, proper training of laboratory personnel, establishment of a databank, quality assurance, and quality control. Other responses pointed to issues of developing population statistics, proficiency testing, costs and finding, continued research and development of methods, implementation and availability of the technology to local laboratories, certification, equipment needs, and confidentiality of results. It is clear that both standardization of the DNA typing process and its courtroom acceptance are of great concern to crime laboratories.

\section{Crime Laboratories' Views on FBI Role in DNA Testing}

A large majority of respondents (96 percent) indicated that research (methods development and evaluation) is an appropriate role for the FBI in DNA testing (table 6-4). Training is also seen by a large majority (95 percent) as a role for the FBI, as is the maintenance of DNA data files ( 88 percent). Other suggestions were for the FBI to be used as a
Table 6-3-Ranking of Importance of DNA Typing to Crime Laboratories

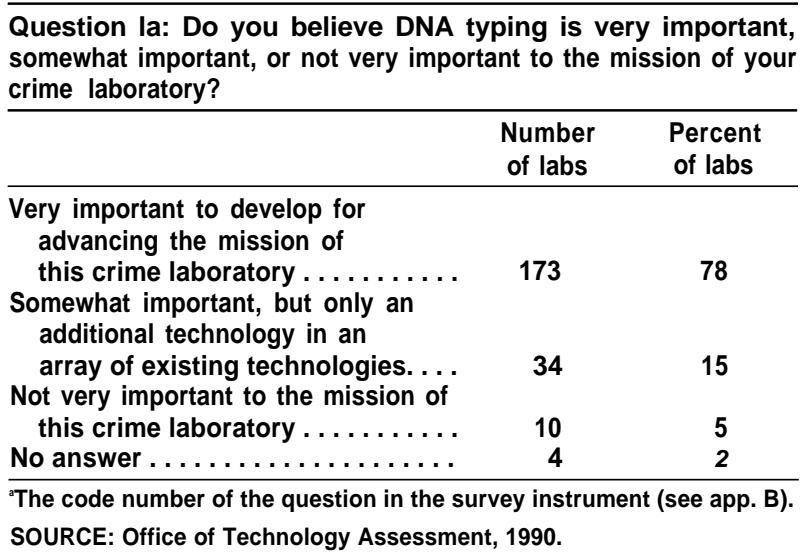

reference library (77 percent), do casework for State and local laboratories (63 percent), provide proficiency samples for quality assurance (55 percent), define standards (48 percent), and certify lab personnel (24 percent) (table 6-4). (The FBI does plan to 


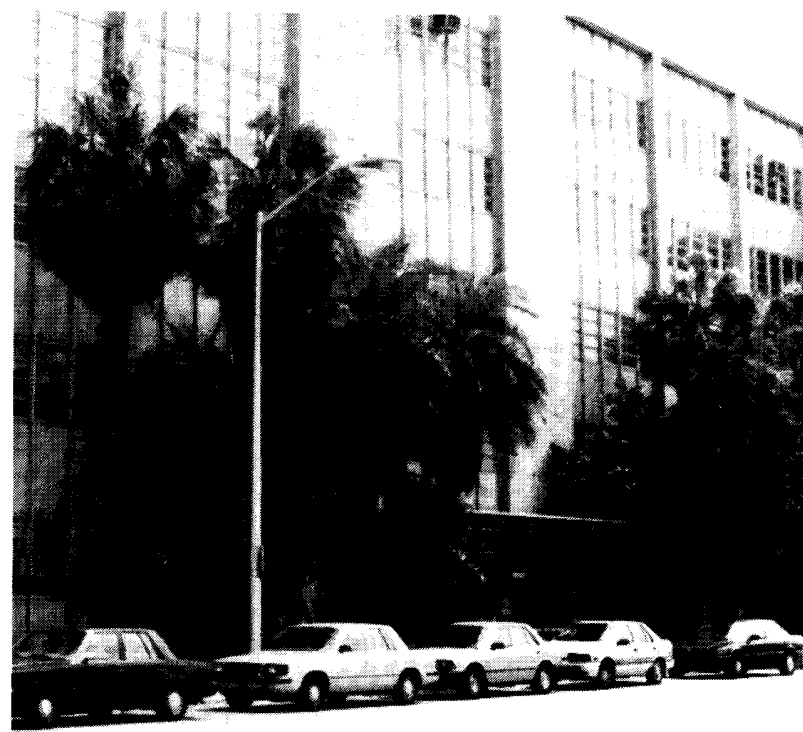

Photo credit: Kevin O'Connor

The crime laboratory of the Metro-Dade Police Department in Miami, FL.

provide some level of proficiency testing to those laboratories using the FBI's DNA typing method $(4,13$ ).) Other suggested roles include providing probes and expert testimony, being available for onsite troubleshooting, offering refresher courses, assisting in complex cases, having staff available when labs start up, and publishing updates in methods and protocols. For the issue that many believe is the most pressing one facing forensic applications of DNA typing-that of defining standards-a minority of crime laboratories responding to the OTA survey (48 percent) proposed a role for the FBI. Moreover, some laboratories expressed serious concern about FBI involvement in this issue. They indicated that professional groups and forensic science associations should handle this, with the FBI helping to coordinate. The FBI's stated position on standards is that they will facilitate their establishment through the consensus building process of TWGDAM (11). (Some respondents to the survey may not have understood this distinction and may have taken the survey question to mean FBImandated standards, hence the lower affirmative response and perhaps the small negative response.)

As discussed earlier, the FBI is already doing many of the things that were cited by respondents as appropriate for the agency. Substantial research into methods development and evaluation has been and is currently underway at FSRTC. The FBI laborato-
Table 6-4-Suggested FBI Roles in DNA Testing

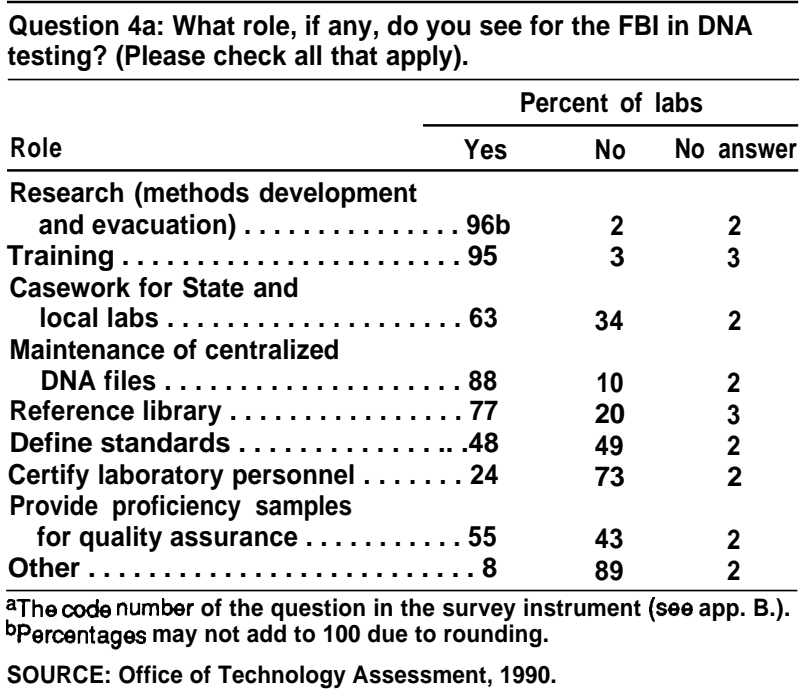

ries have devoted considerable resources to training, and casework has been accepted since late 1988. Furthermore, several of the roles cited by the respondents are still under discussion. The possibility of a national database system is being researched (see ch. 5). Policies toward mandatory proficiency testing, defining standards, and lab personnel certification programs are still undefined.

\section{Crime Laboratories' Plans for DNA Testing}

Considering how recently DNA testing has been introduced, interest and involvement in this new technology at the State and local crime laboratory level are extraordinary. The survey found that almost half of the laboratories (47 percent) presently contract with and have sent samples to either a private laboratory or the FBI, while 35 percent are not currently using DNA testing. Interest in having onsite capability for DNA testing is high among respondents (46 percent). Although more labs are scheduled to come on-line shortly, at the time of the survey only one was doing DNA tests onsite (table 6-5).

\section{Crime Laboratories Not Conducting DNA Testing}

Nearly half those not currently conducting DNA testing have plans to start it in the next 1 to 2 years (24 percent have plans or funding to contract for it in the next 12 months, and 22 percent expect to start in the next 2 years). About one-fifth (21 percent) of those not conducting DNA testing have no plans to 


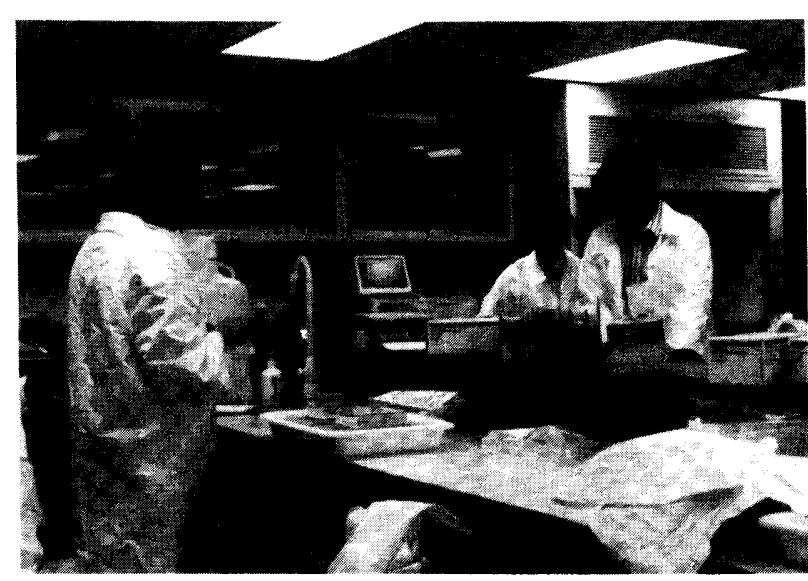

Photo credit: Robyn Nishimi

Students in forensic DNA analysis training course at the Forensic Science Research and Training Center, FBI Academy, Quantico, VA.

do so in the next 1 to $\mathbf{2}$ years, and 33 percent of those surveyed did not answer the question, probably indicating the same situation (table 6-6).

When asked if they have provisions to contract out DNA testing in the future, over one-third of the respondents (37 percent) said they will contract as necessary. Another 34 percent said that they did not intend to do so. A small number of labs (13 percent) have provisions, but may not be able to due to cost (table 6-7).

\section{Contracting for DNA Testing}

As of June $1989^{1}$, three private companies conducted DNA testing on a contract basis (Cellmark Diagnostics, Forensic Science Associates (FSA), and Lifecodes Corp.). Costs for the services of the three companies are presented in tables 6-8 and 6-9.

Cellmark Diagnostics established its Germantown, MD, laboratory in September 1987. It is a business unit of Imperial Chemical Industries Americas, Inc., which in turn is a subsidiary of the British-owned Imperial Chemical Industries PLC. Cellmark Diagnostics has the exclusive worldwide license to the "DNA fingerprinting"sM technique (based on RFLP analysis) developed by Dr. Alec Jeffreys in England and first used in the Leicester Crown Court case (see box 5-B). Cellmark has a technical staff of 20 (9). The estimated processing time is 4-8 weeks, depending on the nature of the evidence (5).
Table 6-5-Crime Laboratory Involvement in DNA Testing

Question 8a: Have you plans for utilizing or do you currently utilize forensic DNA testing? (Please check all that apply). ${ }^{\text {. }}$

\begin{tabular}{lcccc}
\hline & & \multicolumn{3}{c}{ Percent of labs } \\
\cline { 3 - 5 } & $\begin{array}{c}\text { Number } \\
\text { of labs= }\end{array}$ & Yes & No & $\begin{array}{c}\text { No } \\
\text { answer }\end{array}$ \\
Use of testing & 104 & 47 & 50 & 3 \\
\hline $\begin{array}{l}\text { Presentiy contracting . } \\
\text { DNA tests onsite..... }\end{array}$ & 1 & 0.5 & 97 & 3 \\
$\begin{array}{l}\text { Have plans for onsite } \\
\text { DNA testing....... }\end{array}$ & 101 & 46 & 52 & 3 \\
$\begin{array}{l}\text { We do not currently } \\
\text { use............... }\end{array}$ & 78 & 35 & 62 & 3 \\
\hline
\end{tabular}

aThe code number of the question in the survey instrument (see app. B). bercentages may not add to 100 due to roundi ng.

cNumber of labs cannot be totaled because respondents were asked to check all responses that may apply.

SOURCE: Office of Technology Assessment, 1990.

\section{Table 6-6-Crime Laboratory Plans To Conduct DNA Testing}

Question 9a: If you are not currently conducting DNA testing either onsite or contracting, do you have plans or funding to contract for DNA testing?

\begin{tabular}{lcc}
\hline Plans for testing & \multicolumn{2}{c}{ Number of labs Percent of labs } \\
\hline In the next 12 months $\ldots \ldots \ldots$ & 41 & 24 \\
In the next 24 months $\ldots \ldots \ldots$ & 37 & 22 \\
Neither $\ldots \ldots \ldots \ldots \ldots \ldots \ldots$ & 36 & 21 \\
No answer $\ldots \ldots \ldots \ldots \ldots$ & 57 & 33 \\
\hline
\end{tabular}

aThe code number of the question in the survey instrument (see app. B). SOURCE: Office of Technology Assessment, 1990.

Table 6-7--Crime Laboratory Plans To Contract for DNA Testing in the Future

Question 10a: Do you have provisions to contract out DNA testing if necessary in the future?

\begin{tabular}{|c|c|c|}
\hline Plans to contract & $\begin{array}{c}\text { Number } \\
\text { of labs }\end{array}$ & $\begin{array}{l}\text { Percent } \\
\text { of labs }\end{array}$ \\
\hline $\begin{array}{l}\text { Yes, we will contract out as } \\
\text { necessary } \ldots \ldots \ldots \ldots \ldots \ldots\end{array}$ & 63 & 37P \\
\hline $\begin{array}{l}\text { No, we do not intend to contract } \\
\text { Yes, we may have provisions, but } \\
\text { cost may prevent us from }\end{array}$ & .58 & 34 \\
\hline contracting $\ldots \ldots \ldots \ldots \ldots \ldots$ & 22 & 13 \\
\hline No answer $\ldots \ldots \ldots \ldots \ldots \ldots$ & 29 & 17 \\
\hline
\end{tabular}

aThe code number of the question in the survey instrument (See app.B). bPercentagesmay not add to 100 due to rounding.

SOURCE: Office of Technology Assessment, 1990.

FSA is a small firm in Richmond, CA, that processes forensic samples using the PCR method under a licensing agreement with Cetus Corp. Cetus received a patent for the PCR method in 1987 and

\footnotetext{
${ }^{1}$ Since the time of the survey, OTA has identified at least two other companies performing forensic DNA testing - Genescreen of Dallas, TX, and Gennan Corporation of Akron, OH.
} 
Table 6-8-Costs for Forensic DNA Testing by Private Laboratories

\begin{tabular}{|c|c|c|c|}
\hline Service & Cellmark & $\begin{array}{c}\text { Forensic Science } \\
\text { Associates }\end{array}$ & Lifecodes \\
\hline $\begin{array}{l}\text { DNA testing } \ldots \ldots \ldots \ldots \ldots \ldots \ldots \\
\text { Processing isolated DNA sample } \ldots \ldots \ldots \ldots \ldots \ldots \ldots \\
\text { Expert witness (daily rate }+ \text { expenses) } \ldots \ldots \ldots \ldots \ldots \ldots\end{array}$ & $\begin{array}{l}\text { \$490/sample } \\
\text { \$350/sample } \\
\text { 1,000/day (Ph.D.) } \\
\text { 50/day (non-Ph.D.) }\end{array}$ & $\begin{array}{l}\$ 1,500 / \text { case } \\
\text { Not available } \\
\$ 100-\$ 125 / h r\end{array}$ & $\begin{array}{l}\$ 325 / \text { sample } \\
\$ 200 / \text { sample } \\
\$ 750 / \text { day }\end{array}$ \\
\hline Processing of insufficient sample $\ldots \ldots \ldots \ldots \ldots \ldots$ & $\$ 210 /$ sample & $\$ 450 /$ sampie & $\$ 125 /$ sample \\
\hline
\end{tabular}

alnformation current as of June 1989.

SOURCE: Office of Technology Assessment, 1990.

markets a PCR HLA $D Q c x$ - 1 test kit for use by crime laboratories.

Established in 1982, Lifecodes Corp. is located in Valhalla, NY. They began doing research and development into the RFLP method in 1982, and started doing forensic testing commercially in early 1987 (3). Currently employing a staff of six forensic scientists, Lifecodes estimates a turnaround time for processing samples to be 2-3 months (18). Lifecodes will be marketing a test kit in early 1990 that will contain all the necessary reagents for processing a sample from DNA extraction to final hybridized Southern blot (14). This kit will follow the FBI protocol, and is viewed by some as significant on two counts: as an indication that there will be a ready supply of testing materials for crime laboratories, and because it indicates the support by a company that uses its own method for a national standardized protocol based on the FBI method (11). Additionally, one of Lifecodes' high priority development issues is to develop a test kit that will use nonradioactive probes (14).

As previously mentioned, 47 percent of laboratories have contracted for forensic DNA analysis. When asked which facilities they had contracted with, most laboratories surveyed (65 percent) had dealt with Lifecodes, nearly half (48 percent) with Cellmark, one-ftith (21 percent) with FSA, and 22 percent with other facilities (including the FBI) (table 6-10). It should be noted that users do not formally contract with the FBI, their services are available at no charge to law enforcement agencies in connection with their investigation of criminal (not civil) matters (1 1). Also, crime laboratories can contract with more than one facility. Of those who listed the number sent to each facility, 277 cases were sent to Lifecodes, 191 to Cellmark, 45 to FSA, and 40 to other facilities. Prior to sending specimens out to private laboratories, nearly three-quarters ( 74 percent) conduct a prescreening test (table 6-11).
Table 6-9-Costs for Paternity DNA Testing by Private Laboratories ${ }^{e}$

\begin{tabular}{|c|c|c|}
\hline Service & Cellmark & Lifecodes \\
\hline $\begin{array}{l}\text { DNA testing of } \\
\text { whole blood } \ldots \ldots \ldots \ldots \\
\text { DNA testing of nonblood } \\
\text { sample } \ldots \ldots \ldots \ldots \ldots\end{array}$ & $\begin{array}{l}\text { \$200/sample } \\
\$ 350 / \text { sample }\end{array}$ & $\begin{array}{c}\$ 150 / \text { sample } \\
\$ 300-450 / \text { sample }\end{array}$ \\
\hline $\begin{array}{l}\text { Expert witness (daily } \\
\text { rate }+ \text { expenses } \ldots \ldots \ldots \\
\text { Processing of insufficient } \\
\text { sample } \ldots \ldots \ldots \ldots \ldots \ldots\end{array}$ & $\begin{array}{c}\$ 500 / \text { day } \\
\$ 210 / \text { sample }\end{array}$ & $\$ 750 /$ day \\
\hline
\end{tabular}

Information current as of June 1989

SOURCE: Office of Technology Assessment, 1990.

Table 6-10-Facilities Contracted With for DNA Testing

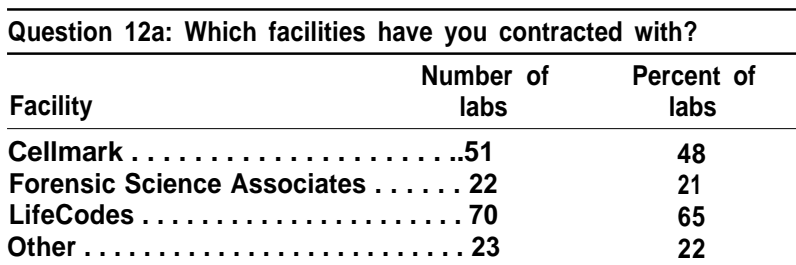

${ }^{2}$ The code number of the question in the survey instrument (see app. B.). SOURCE: Office of Technology Assessment, 1990.

Table 6-11-Prescreening Tests

Question 13a: When you send specimens out to private laboratories, do you conduct a prescreening test on them beforehand?

\begin{tabular}{|c|c|c|}
\hline Prescreening & Number of labs & Percent of labs \\
\hline \multirow{3}{*}{\multicolumn{2}{|c|}{ 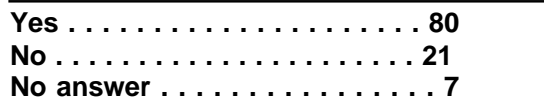 }} & 74 \\
\hline & & 19 \\
\hline & & 7 \\
\hline
\end{tabular}

aThe code number of the question in the survey instrument (See app. B). SOURCE: Office of Technology Assessment, 1990.

Respondents were asked to estimate the number of samples they anticipated sending out yearly. The results show that the expected usefulness of contract DNA testing varies widely. Estimates of the number of annual samples ranged from 2 to 3,000 with the average being 120 . Over half the laboratories (65 
percent) plan to restrict or institute a formal protocol to determine the types of crimes that DNA testing can be used on. When asked what criteria they would use to determine these crimes, cost, the failure of conventional methods, and a prescreening test were mentioned. Others said they planned to follow the FBI's criteria. Respondents indicated that homicide, sexual assault, violent crime, and serial crimes all merited use of DNA typing. Hit-and-run accidents as well as robbery were also cited. The use of DNA testing would be warranted on hit-and-run accidents that involve serious bodily injury or death, such as when a pedestrian or a child on a bicycle is struck. The technology would have no utility in a "property damage" hit-and-run accident (11).

In contrast to the large number of facilities that have contracted for forensic DNA testing, budget proposals for onsite DNA typing have not been submitted by many crime laboratories. Of the 104 laboratories contracting for outside services, nearly half (49 percent) have not submitted budget provisions to do DNA analysis onsite. This can be compared with the 38 percent that have submitted a budget but have not yet had it approved (table 6-12). The survey revealed a wide variation in budget requests. (As noted earlier, numbers may be inflated by budget requests from entire State systems.) Budget requests for DNA analysis in State and local crime laboratories range from $\$ 5,000$ to $\$ 4.6$ million (for a State system).

Many crime laboratories have devised innovative financing plans for DNA typing. For example, one State plans to use some of the proceeds from the State cigarette tax (6). Another growing source of funding for State and local crime laboratories is money, goods, and property confiscated from drug dealers (1). Problems in financing crime laboratories, in general, have arisen in other States. In one, local county law enforcement agencies are now paying for their use of the State crime laboratories, even though they never had to previously (7). These labs will run out of funds unless the counties pay up. Although this particular situation is not directly related to DNA typing costs, similar situations could arise as States try to raise funds necessary for DNA analysis.
Table 6-12-Paying for DNA Testing

Question 11a: If you are not conducting DNA analysis onsite, have you submitted budget provisions to do so that have not yet been approved?

\begin{tabular}{|c|c|c|}
\hline Budget submitted & Number of labs & Percent of labs \\
\hline $\begin{array}{l}\text { Yes } \ldots \ldots \ldots \ldots \\
\text { No } \ldots \ldots \ldots \ldots \\
\text { No answer. . . }\end{array}$ & $\begin{array}{l}\ldots 41 \\
\ldots .53 \\
\ldots \ldots 14\end{array}$ & $\begin{array}{l}38 \\
49 \\
13\end{array}$ \\
\hline
\end{tabular}

\section{Conducting DNA Testing Onsite}

The cost of submitting samples to private laboratories has been cited as the reason for pursuing onsite DNA testing by some members of the crime laboratory community. Although, for facilities without a large case load, it could be more cost-effective to continue contracting. It is apparent that there will soon be a score of crime labs conducting DNA tests onsite. Some respondents have established facilities, but have not yet begun to accept casework. For the purposes of this survey, OTA defined "labs conducting DNA testing onsite" as those actually accepting casework. Although several were close to starting up, only one laboratory was actually conducting DNA testing onsite at the time of the survey. Located in Norfolk, VA, the laboratory began casework on May 1, 1989 (box 6-D)². The annual budget in that section is $\$ 100,000$, and currently it has two forensic scientists performing DNA testing. An increase in professional staff positions is expected, and staff handling DNA samples required training above and beyond their academic and work experience. The new positions also required training in molecular biology and genetics, and courses at the FBI Academy.

When ranking factors important in the decision to pursue DNA typing onsite, the Virginia laboratory indicated that evidence control was most important, that having state-of-the-art technology was important, that the cost of contracting out was not very important, and that the least important factor was having a short turnaround time.

Although the possibility of a noncrirninal justice agency using the DNA typing facility for other purposes has been proposed in some States, this was not the case in Virginia. No noncriminal justice agencies were planning to use the crime laboratory

\%ecause confidentiality was ensured in the survey, permission to disclose the laboratory's identity was received from Paul Ferrara of the Virginia Bureau of Forensic Science. 


\section{Box 6-D—DNA Typing in Virginia}

In May 1989, Virginia became the first State in the Nation to conduct onsite DNA testing. Serving all law enforcement agencies in the State, all prosecuting attorneys, and the State medical examiner, the Bureau of Forensic Science processes over 60,000 cases a year. The Bureau began discussions on a State DNA testing facility in 1987, and in spring 1987, a representative of LifeCodes Corp. visited the headquarters facility in Richmond, VA, to propose a 1-year technology transfer program. Under the terms of the program, selected Virginia laboratory personnel received 4 weeks of training at the Lifecodes facility in New York to learn DNA typing procedures and quality control measures, and take a proficiency test. Having made a commitment to training in DNA typing procedures, the Bureau requested $\$ 85,000$ for January to July 1988 to purchase the needed equipment. An additional request of \$206,000 was made for July 1988 to June 1990. Both budget requests were granted in full by the Virginia State Legislature. A budget request for the 1990 to 1992 biennium for $\$ 1,050,000$ is pending.

DNA testing was deemed admissible in the court system of Virginia after it was submitted as evidence in the Timothy Spencer case (see ch. 4), In March 1989, the Governor signed legislation calling for mandatory samples from all convicted sex offenders. Currently, the State has 2,100 incarcerated sex offenders. Until money is received to create a databank, samples will be stored and, as of July 1989, all convicted sex offenders have been providing samples that will be stored until funding to perform these tests is available. The Tidewater Regional Forensic facility in Norfolk was chosen to be Virginia's first DNA typing laboratory. It has capacity of 300 to 400 cases per year. Turnaround time for processing samples is currently 10 to 12 weeks. It is staffed by two scientists (with a third planned) and one technician. In addition to the Lifecodes training, the scientists have also received training from the FBI.

It is important to note also that the Virginia Bureau of Forensic Science has recently decided to switch from the Lifecodes system and instead has adopted the FBI protocol for DNA testing. Although both systems rely on the same technical foundation, the step was taken by Virginia in an effort to foster and promote standardization of methods (important for a national databank) among the first forensic laboratories performing DNA analyses. The Virginia Bureau of Forensic Science also has adopted the TWGDAM guidelines for quality assurance.

SOURCE: P. Ferrara, personal communications and presentation at "International Symposium onthe Forensic Aspects of DNAAnalysis," Quantico, VA, June 22,1989.

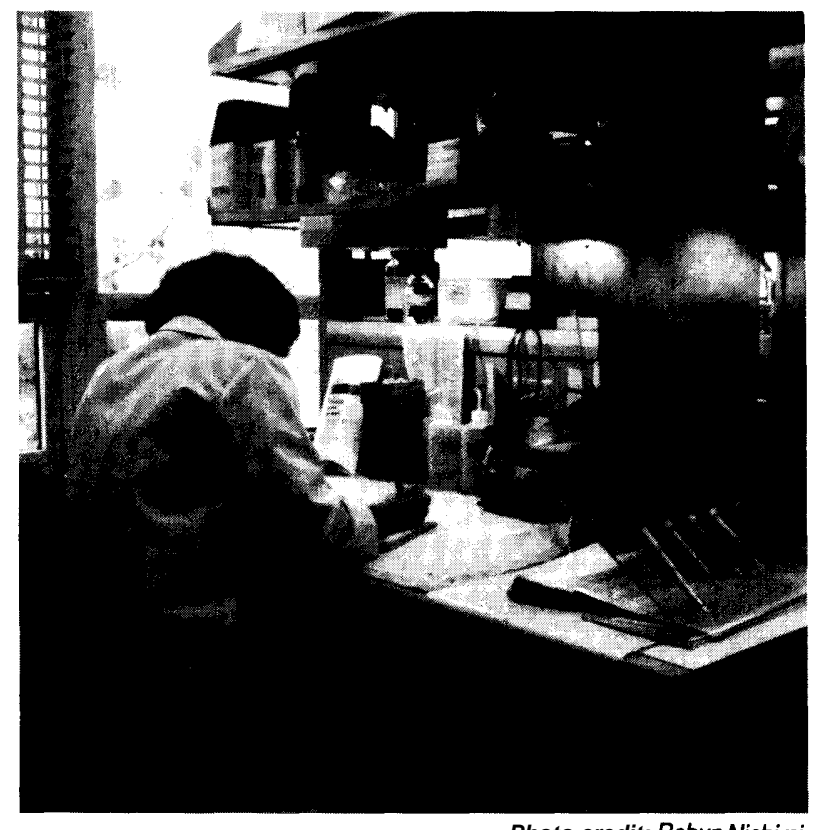

Photo credit: Robyn Nishimi

Scientist at the Tidewater Regional Forensic Laboratory in Norfolk, VA, a laboratory of the Virginia Bureau of Forensic Science. for paternity, child support enforcement, or missing persons. Virginia's crime laboratory is creating DNA data files at this time for suspects under investigation. These particular files will be maintained at the State level, and Virginia is working with the FBI on a pilot project to create a national DNA databank. Any DNA testing material not specifically related to an ongoing investigation will be stored as autoradiograms, electronically captured prints, or membranes. Virginia intends to restrict the types of crimes DNA testing can be used on.

Not all State and local crime laboratories will be able to implement DNA typing quite as smoothly, although some, such as New York, have planned extensively (box 6-E). Virginia's experience is also unique in the general lack of controversy about the privacy issues involved. In addition, money for the program was approved by the State legislature with relative ease. Nevertheless, the OTA survey indicates that crime laboratories are moving rapidly toward onsite DNA testing regardless of potential controversies. 


\section{Box 6-E-The New York State Forensic DNA Analysis Panel}

In July 1988, the State of New York formed a panel to assess issues surrounding forensic DNA testing before implementing such procedures. The panel consisted of prosecutors and defense attorneys, scientists, policymakers, legal scholars, and experts in law enforcement. In September 1989, the panel released its report on DNA testing. Included were its recommendations for a program to implement DNA testing in New York.

Scientific issues covered in the report included a discussion of the limits of traditional identification techniques, problems associated with the existing technologies and population studies, and quality control issues. The legal section covered national court rulings on DNA admissibility, as well as the different standards that should be applied when DNA results are admitted for inclusionary v. exclusionary purposes. Concerns about private and public laboratories' procedures were highlighted in the policy issues section. Finally, the report laid out a model program for forensic DNA testing implementation in New York State.

Rather than have each State and local laboratory in New York implement DNA typing on their own, the report recommended that a statewide DNA network be created. This network would eventually be served by at least three regional forensic DNA testing laboratories. Coordination on issues such as quality assurance, quality control, and safety would occur for the laboratories. In addition, there would be an accreditation process for both public and private forensic DNA typing laboratories operating in the State.

Two advisory bodies would oversee the operations of the network-an advisory committee that would establish uniform standards, and a scientific review board to assist the courts in evaluating the technologies that were used in specific cases. Members of the scientific review board could serve as expert advisers to the courts if necessary. The report acknowledged that many complex issues are associated with the creation of a DNA databank. If the privacy concerns were appropriately addressed, the report recommended legislation requiring those convicted of violent sex crimes or other designated offenses to give DNA specimens. It also recommended that the State begin preliminary developmental work to overcome any technical problems involved in creating such a databank. The innovative approach to implementation of forensic DNA analysis taken by the State of New York might enable them to avoid future problems that could have arisen in the absence of such a report.

SOURCE: Office of Technology Assessment, 1990, based on DNA: Report of New York State Forensic DNA AnalysisPanel, Sept. 6, 1989.

\section{FINDINGS AND SUMMARY}

Although DNA analysis has only been in use in the U.S. criminal justice system for a short time, it has been quickly incorporated into the array of investigative biological technologies used by State and local crime laboratories. A 1989 OTA survey of 221 crime laboratories found that over three-quarters (78 percent) believe DNA typing is very important to their mission. Nearly half (47 percent) were contracting for this service with an outside facility, and 46 percent have plans to implement onsite DNA testing. OTA found a diversity in crime laboratory budgets and staff size. Yet while some systems will be able to finance onsite DNA typing facilities, others may not even be able to cover the costs of contracting. However, if the use of DNA testing for forensic purposes continues to increase at the present rate, it is not inconceivable that all crime laboratories will reach a point where access to DNA typing will be essential.

The FBI DNA Analysis Unit began accepting casework in December 1988. Several mechanisms are used by the FBI to transfer DNA typing technologies to State and local crime laboratories. When these labs were asked about the appropriate roles for the FBI, defining standards (48 percent) and providing certification for laboratory personnel (24 percent) were ranked the lowest. Also, while it is clear that the crime laboratories feel standards should be set, who should set them is not at all clear.

A large majority of crime laboratories (95 percent) said that DNA results should be incorporated into a database for exchange among law enforcement agencies. (Efforts are currently under way in the Federal Government (see ch. 5) to create such a database.) In addition, a number of States have already passed legislation requiring blood or saliva samples from convicted sex offenders.

Three companies were providing DNA testing on a contract basis at the time of the OTA survey. OTA found that laboratories anticipated sending out anywhere from 2 to 3,000 samples annually in the future. Nearly two-thirds of the crime labs (65 percent) will restrict or institute a formal protocol to 
determine which crimes are appropriate for DNA testing. Of the 104 laboratories contracting for tests, nearly half (49 percent) have not submitted budget provisions to do their own DNA analysis onsite. Laboratories can continue contracting or use the FBI DNA Analysis Unit at no cost. It is unclear if the FBI will be able to handle the case load of those labs.

At the time of the survey, OTA found only one facility conducting onsite DNA typing. Many others were nearly ready to accept casework, however, and in the next few years large numbers of crime laboratories will probably be conducting DNA typing onsite. It would be helpful if issues such as Standardizationand courtroom approval and acceptance two issues viewed as important by survey respondentscould be settled prior to their coming on-line with DNA typing.

\section{CHAPTER 6 REFERENCES}

1. Associated Press, "State's Top Cop Wants Drug Money to Pay for New Crime Lab,"June 22, 1989.

2. Bashinski, J. S., and Fisher, B., "Methods of Genetic Marker Typing: A Survey of the Current State of the Art," American Academy of Forensic Sciences, Colorado Springs, CO, 1988.

3. California Association of Crime Laboratory Directors, "DNA Committee Report," Nov. 19, 1987.

4. Castonguay, R.T, Federal Bureau of Investigation, Washington, DC, personal communication, April 1989.

5. Cellmark Diagnostics, Forensic Testing Facts, November 1988 .

6. Conrad, D., Associated Press, "State Police Moving Toward Genetic Fingerprints,” July 7, 1989.
7. Edwardsen, E., Associated Press, “Counties to Pay Up for State Police Lab Work," July 5, 1989.

8. Eubanks, B., "DNA Operational Up-Date," paper presented at the American Society of Crime Lab Directors Board of Directors Meeting, Quantico, VA, May 2, 1989.

9. Forman, L., Cellmark Corp., Germantown, MD, personal communication, September 1989.

10. Hicks, J.W., Federal Bureau of Investigation, testimony before U.S. Senate, Subcommittee on the Constitution, Committee on the Judiciary, Mar. 15, 1989.

11. Hicks, J.W., Federal Bureau of Investigation, Washington, DC, personal communication, August 1989.

12. Kearney, J., "Summary of the First Meeting of the Technical Working Group on DNA Analysis Methods," Crime Laboratory Digest 15(4), October 1988.

13. Kearney, J., Federal Bureau of Investigation, Quantico, VA, personal communications, April, August, October, and December 1989.

14. Page, L. A., Lifecodes Corp., personal communication, November 1989.

15. Peterson, J., "The Crime Lab," Thinking about the Police: Contemporary Readings (New York NY: McGraw Hill, 1983).

16. Technical Working Group on DNA Analysis Methods (TWGDAM), Quality Assurance Subcommittee, "Guidelines for a Quality Assurance Program for DNA Restriction Fragment Length Polymorphism Analysis," Crime Laboratory Digest 16(2):41-59, April-July 1989.

17. U.S. Department of Justice, Federal Bureau of Investigation, FBI Academy, Forensic Science Research and Training Center, Annual Report, 1988.

18. Winkler, J.K., Lifecodes Corp., personal communication, April 1989. 
Appendixes 


\section{Reported Uses of DNA Testing in Criminal Investigations and Proceedings}

This appendix lists reported uses of DNA testing in criminal investigations and proceedings. It originates form material collected from a number of sources:

- private laboratories (Cellmark Diagnostics, Forensic Science Associates, and Lifecodes Corp.) that have provided DNA analysis of evidence for criminal investigations;

- the Federal Bureau of Investigation (FBl);

- State Attorney Generals' offices;

- Office of Technology Assessment (OTA) advisory panel members and reviewers; and

- news reports and wire services.

Where possible, the following information is provided for each entry in this appendix:

- name of case/investigation;

- date of case/investigation (e.g., date the information was provided to OTA or date of trial, hearing, or report);

- location of case/investigation (county or city);

- information about the case/investigation; and

- the laboratory involved in conducting the testing and/or providing expert testimony.

This appendix catalogues over 200 reported uses of DNA testing in criminal investigations and proceedings reported to OTA as of January 1, 1990. DNA evidence has been admitted by courts in 38 States and by the U.S. military. Judicial recognition of the admissibility of DNA evidence was pending in two additional States, and in one State had been used to obtain a plea without a hearing as to the evidence's admissibility. Uses of DNA testing in criminal investigations and proceedings were reported in 45 States and the District of Columbia. No State court has found that DNA testing per se fails to meet established tests for admissibility, although in several cases the admissibility of DNA evidence has been limited or barred. This appendix reports the use of DNA testing:
- in cases where such evidence was admitted by a court or used to obtain a plea prior to an admissibility hearing (185 cases);

- in cases where the admissibility of DNA evidence is pending (26 cases);

- as a tool in an ongoing criminal investigation (13 cases);

- to exculpate a defendant (12 reported instances);

- in cases where the DNA test results were inconclusive (7 reported instances);

- in two cases where such evidence was given only limited admissibility by a court (Pennell in Delaware and Castro in New York);

- in two cases where such evidence was ruled to be inadmissible (Martinez in California and Schwartz in Minnesota);

- in one case where such evidence was withdrawn by the prosecution prior to its introduction (McLeod in Maine); and

- as it involves two cases (Woodall in West Virginia and Hinton in Connecticut) where defendants sought to use such evidence to re-open prior convictions.

The number of reported uses in this appendix is conservative. The vast majority of criminal investigations, suspect/defendant exculpations, and plea bargains are not widely reported. For example, in 37 percent of the more than 500 rape and homicide investigations completed by the FBI through January 1990, the primary suspect was excluded. In addition, this appendix generally covers only those cases reported by the primary private laboratories and the FBI. Although impossible to precisely determine, OTA estimates that, to date, DNA tests have been used by law enforcement in over 2,000 investigations. All trends indicate that the number of cases will continue to increase dramatically in the near term. 


\author{
Alabama \\ State of Alabama v. Moore \\ April 1989 \\ Prattville \\ DNA evidence admitted in rape case. Defendant \\ convicted. (Lifecodes)
}

State of Alabama v. Perry

December 1988

Scottsboro

DNA evidence admitted in rape case. Defendant

convicted. (Lifecodes)

State of Alabama v. Pettway

November 1989

Mobile

DNA evidence admitted in rape case. Defendant convicted. (Lifecodes)

State of Alabama v. Snowden

November 1989

Bay Minette

DNA evidence admitted in rape case. Defendant convicted. (Lifecodes)

State of Alabama v. Wallace

December 1989

Birmingham

DNA evidence admitted. Defendant accused of rape. Trial ended in a hung jury. (Lifecodes)

State of Alabama v. Yelder

March 1989

Montgomery County

DNA evidence admitted. Jury convicts Timothy Yelder of seven felony counts of rape, burglary, and sodomy associated with three rapes that occurred in 1988.

\section{Alaska}

Admissibility of DNA evidence pending in criminal trial in Kodiak.

\section{Arizona}

State of Arizona v. Bible

May 1989

Coconino county

In February 1989, a Superior Court judge ruled to allow the introduction of DNA evidence in the murder trial of Richard Bible. Bible was charged with murder, kidnapping, and child molestation in the June 1988 disappearance and death of a 9-year-old girl, (Cellmark)

State of Arizona v. Dazen

August 1989

Apache County

DNA test matches suspect to semen stain. Suspect pleaded guilty to rape. (Lifecodes)
State of Arizona v. Kiles

December 1989

Yuma County

Judge orders the FBI to release all laboratory notes and proficiency tests for the defense to examine, or the prosecution would be barred from using DNA evidence in the case.

State of Arizona v. Martin

August 1989

Mesa City

Results of DNA test lead to arrest of suspect in the 1988 sexual assault and murder of a 13-year-old girl.

State of Arizona v. Stutler

August 1989

Yavapai County

Upon learning of results of DNA analysis on semen/ vaginal fluid mixture, defendant pleaded guilty to attempted murder, burglary, sexual assault, kidnapping, and arson. Sentenced to a total of 74 years in prison. (Cellmark)

Associated Press report, Oct. 29, 1989

Scottsdale

Detectives in this celebrity-conscious city hope that DNA blood testing will help them crack the 1 1-year-old murder of former 'Hogan's Heroes' star Bob Crane. Blood samples from a suspect's car have been sent to Cellmark Diagnostics. Blood samples taken from the car in 1978 confirmed that the blood was Type B, which matches Crane's and is found in 10 percent of the population. Now, with DNA testing, it is hoped that a more positive physical identification can be made.

\section{Arkansas}

DNA evidence was admitted in a Little Rock rape case following a pretrial hearing in November 1989. Trial pending. (FBI)

\section{California}

State of California v. Axell

August 1989

Ventura County Superior Court

Court rules Cellmark's DNA test results admissible.

Defendant is convicted of first-degree murder in

September 1989. (Cellmark, FBI)

State of Calfornia v. Barney

December 1989

Alameda County

DNA evidence admitted. Defendant waived jury trial and was convicted in December 1989 of kidnapping, robbery, and attempted rape. (Cellmark) 
State of California v. Black

March 1989

Santa Ana

Defendant enters guilty plea to sexual molestation of two step-daughters after being told of prosecution plans to seek DNA analysis of fetal remains from an abortion performed on the 17-year-old victim.

State of California v. Cathcart

November 1989

Santa Ana

DNA evidence admitted. Trial pending. (Lifecodes)

State of California v. Chavez

June 1988

San Mateo County

Prosecutors dismiss rape charges against defendant, in custody for 7 months, after polymerase chain reaction analysis (PCR) excludes the defendant. (Forensic Science Associates)

\section{State of California v. Davis}

December 1989

Ventura County

DNA evidence admitted. Defendant convicted in fall 1989 of first-degree murder, sodomy, and sexual assault. (Cellmark)

State of California v. Harris

June 1989

Santa Ana

Hearing. Orange County prosecutors seek to introduce DNA evidence in rape trial. Admissibility pending.

\section{State of California v. Littleton}

December 1989

San Diego

Hearing held in December 1989 to admit DNA evidence in rape case. Decision pending. (Cellmark)

State of California v. Luna

November 1989

Ventura County

DNA evidence admitted. Defendant convicted of rape in November 1989. (FBI)

State of California v. Marlow

November 1989

Hollister

DNA evidence offered at pretrial hearing. Defendant is charged with double murder and multiple rapes.

Admissibility ruling and trial pending. (Cellmark)

State of California v. Martinez

1988

I.os Angeles

Introduction of DNA evidence successfully opposed by the District Attorney's office. (Forensic Science Associates)
State of California v. Mend

Riverside County

PCR case. (Forensic Science Associates)

State of California $v$. Wilds

December 1989

Los Angeles County

DNA evidence ruled admissible in rape-robbery case.

Prosecutors said they waited a year before settling on what they considered the best case to use DNA evidence in. Jury selection began in January 1990.

Associated Press report, Jan. 26, 1989

DNA analysis used to identify skull of a 3-year-old who disappeared in 1984 during a desert camping trip at Joshua Tree National Monument.

\section{Colorado}

State of Colorado v. Fishback

November 1989

Denver

DNA evidence admitted. Defendant convicted of rape. (Cellmark)

State of Colorado v. Gallagher

November 1988

El Paso County

DNA evidence admitted. After a 4-day, nonjury trial, the defendant was convicted of sexual assault. (Cellmark)

State of Colorado v. Groves

September 1989

Castle Rock

Suspected serial killer charged with 3 murders; a suspect in 14 murders.

State of Colorado v. Lindsey

February 1989

El Paso County

DNA evidence admitted, but not considered by jury in sexual assault and burglary case. DNA evidence was linked to first of two attacks on the victim; however, charges related to first incident were dismissed.

Defendant convicted and sentenced to life in prison. (Cellmark)

State of Colorado v. Richardson

June 1989

Jefferson County

Defendant found not guilty of murder, but guilty of accessory to murder. DNA evidence not found on defendant, but was found on companion also charged with murder (see State of Colorado v. Rivera).

State of Colorado v. Rivera

December 1989

Jefferson County

Defendant was tried for murder in December 1989. DNA testing admitted. Defendant convicted. (Lifecodes) 
State of Colorado v. Robinson

Lifecodes testifies at evidentiary hearing. Defendant exculpated of murder charge. (Lifecodes)

State of Colorado v. Sandoval

March 1989

Jefferson County

DNA test admitted as evidence in case of sexual assault, kidnapping, and robbery. (Cellmark)

State of Colorado v. Wortham

February 1989

Pitkin County

Jury convicted defendant of rape and burglary. Prosecution relied on DNA test of semen sample. Defendant convicted.

Associated Press report, Aug. 31, 1989

A headless, handless torso found in December 1988 was found to be that of a missing woman. Cellmark's DNA test confirmed that the body was related to the father and sister of the missing woman. Arapahoe County Sheriff said this is the first case in Colorado, and possibly the Nation, in which DNA was used to identify an unknown body.

\section{Connecticut}

\section{State of Connecticut v. Green}

November 1989

Hartford

DNA testing admitted. Defendant pleaded guilty to first-degree assault, and was sentenced in November 1989 to a 20 -year prison term.

State of Connecticut v. Hinton

October 1989

New London

Arguments were heard in October 1989 on a State prison inmate's request for DNA tests to prove his claim that he was wrongfully convicted of rape in 1982. Judge said he would issue a decision on the request in early 1990.

\section{State of Connecticut v. Sivri}

October 1989

Trumbull

Pre-trial hearing re: DNA testing.

State of Connecticut $v$. Williams

June 1989

Stamford

PCR test conducted fails to show a link between defendant and woman stabbed to death in a shopping center parking lot. (Forensic Science Associates)

\section{Delaware}

State of Delaware v. Pennell

December 1989
Wilmington

DNA evidence admitted, but population statistical data not admitted. Defendant convicted of two counts of first-degree murder. Hung jury on third count.

\section{District of Columbia}

\section{Green v. District of Columbia}

Convicted in June 1989, Green pursued DNA testing, which revealed that he was not the individual whose semen had stained the victim's clothing. Rape, kidnapping, and sodomy charges were dropped in early 1990.

\section{Florida}

State of Florida v. Andrews

October 1988

Orange County

DNA evidence admitted. Andrews convicted in November 1987 of raping and slashing a woman. The use of such evidence upheld by 5th District Court of Appeals in October 1988.

\section{State of Florida v. Beene}

February 1989

Okaloosa County

DNA evidence admitted. Defendant convicted of multiple counts of sexual assault. (Cellmark)

State of Florida v. Bentzel

January 1989

Jacksonville

DNA evidence admitted in rape case. Defendant convicted. (Lifecodes)

\section{State of Florida v. Bishop}

December 1988

Bay County

DNA test admitted in case charging armed burglary and assault with a firearm. Judge found defendant guilty on both counts. (Cellmark)

\section{State of Florida v. Burroughs}

November 1989

Miami

DNA evidence admitted in rape case. Defendant convicted. (Lifecodes)

\section{State of Florida v. Forrest}

January 1989

West Palm Beach

Defendant, the suspect in the so-called Congress Avenue rapes, was convicted of rape by a jury after DNA evidence showed defendant had fathered the victim's aborted fetus. (Lifecodes) 
State of Florida v. Helton

September 1989

Escambia County

DNA evidence admitted. Defendant convicted of six counts of rape, one count of attempted rape, attempted first-degree murder with a weapon, and petty theft. (Cellmark)

State of Florida v. Herndon

December 1989

Miami

DNA evidence admitted in rape case. Defendant convicted. (Lifecodes)

State of Florida v. Hill

January 1988

Broward County

DNA evidence admitted in rape case. Defendant convicted. (Lifecodes)

State of Florida v. James

November 1988

Ft. Lauderdale

DNA tests conducted. No result from testing. Lifecodes provided testing and was called to testify at trial.

(Lifecodes)

State of Florida v. Jenkins

June 1988

Orange County

DNA evidence admitted in rape case. Defendant con-

victed. (Lifecodes)

State of Florida v. Jones

March 1988

Putnam County

DNA evidence admitted. Defendant convicted of murder, robbery, and sexual battery. This was the first capital case using DNA evidence. Case submitted for review to Florida's appellate court. (Cellmark)

State of Florida v. Jones and Griffin

September 1989

Leon County

DNA evidence admitted in murder case. Both defendants convicted. (Cellmark)

State of Florida v. Martinez

April 1988

Deland

DNA evidence admitted in rape case. Defendant convicted. (Lifecodes)

State of Florida v. McGriff

November 1988

Quincy

DNA evidence admitted in murder-rape case. Defendant convicted of murder; hung jury on rape charge. (Lifecodes)
State of Florida v. Moore

September 1989

Broward County

DNA evidence admitted. Defendant charged with rape and armed kidnapping; convicted of assault. (Cellmark)

State of Florida v. O'Connor

May 1989

Miami

DNA testimony offered at pretrial hearing of murder case.

Defendant pleaded guilty prior to trial. (LifeCodes)

State of Florida v. Palmer

September 1988

Ft. Lauderdale

DNA tests conducted. No result from testing. Lifecodes provided testing and was called to testify at trial.

(Lifecodes)

State of Florida v. Partain

September 1988

Ocala

DNA tests conducted. No result from testing. Lifecodes provided testing and was called to testify at trial.

(Lifecodes)

State of Florida v. Power

June 1989

Sanford

DNA evidence used to prosecute defendant in three rapes. Sentenced to 125 years in prison. (Lifecodes, Forensic Science Associates)

State of Florida v. Reid

April 1989

Clearwater

DNA evidence admitted in rape case. Defendant convicted. (Lifecodes)

State of Florida v. Robinson, Coleman, and Frazier June 1989

Escambia County

DNA evidence admitted in trial of three men charged with drug-related murders of four people and the attempted murder of fifth. DNA evidence linked one of the defendants to the rape. Defendants were found guilty of rape and murder. (Cellmark)

State of Florida v. Rogers

May 1989

St. Petersburg

DNA evidence admitted in sexual battery case. Defendant convicted. (Lifecodes)

State of Florida v. Russell and Johnson

January 1989

Flagler County

DNA evidence admitted. Defendants convicted of sexual battery and child abuse and sentenced to life imprisonment. (Cellmark) 
State of Florida v. Savage

November 1989

Titusville

DNA evidence admitted after expert testimony at pretrial hearing. Defendant convicted of murder. (Lifecodes)

State of Florida v. Weed

July 1989

Pinellas County

DNA evidence admitted. Defendant convicted of kidnapping and rape. (Cellmark)

State of Florida $v$. Wike

June 1989

Milton

Defendant found guilty of murdering 6-year-old girl and slashing the throat of and raping her 8-year-old sister.

\section{Georgia}

State of Georgia v. Caldwell

October 1989

Marietta

Pretrial hearings in May and October 1989 to determine admissibility of DNA tests. Case pending. (Lifecodes)

State of Georgia v. Grier

December 1989

Bibb County

DNA evidence admitted. Defendant convicted of raping a 91-year-old woman. Sentenced to life in prison. (FBI)

State of Georgia v. Redding

September 1988

Decatur

DNA evidence admitted after pretrial hearing in rape case.

Defendant pleaded guilty. (Lifecodes)

State of Georgia v. Smith

November 1988

Gainesville

DNA evidence admitted after pretrial hearing. Defendant pleaded guilty to rape. (Lifecodes)

State of Georgia v. Whitner

March 1989

Conyers

DNA evidence admitted in rape case. Defendant convicted. (Life-codes)

\section{Hawaii}

State of Hawaii v. Lohr

March 1989

Honolulu

Defense proposes, prosecution and court agree, to DNA testing of defendant in sexual assault case. Case pending. (FBI)

State of Hawaii v. Manning

April 1989

Wailuku
DNA evidence is admitted. Defendant found guilty of three cases of assault and burglary. (FBI)

\section{Idaho}

State of Idaho v. Horsley

May 1988

Sandpoint

DNA evidence admitted in rape case. Defendant convicted. (LifeCodes)

Illinois

State of Illinois v. Daniels

December 1989

Cook County

DNA evidence admitted. Defendant convicted in October 1989 of rape and murder. Sentenced to life term in prison in December 1989.

Case of Gary Dotson

August 1989

Cook County

Cook County judge vacates 1979 rape conviction after

DNA test exculpates defendant. Dotson had been convicted in a 1977 rape, for which he spent 6 years in jail. Alleged victim recanted story in 1985 , and Governor James Thompson granted clemency, but rape conviction remained on his record. Dotson had requested that the case be reopened for new trial after PCR tests excluded him. (Forensic Science Associates)

State of Illinois v. Dugan

May 1989

Du Page County

Pre-trial hearing set for 1983 case of abduction, rape, and murder. Tests link defendant to 1983 kidnapping, rape, and murder of girl. Pending.

State of Illinois v. Lipscornb

October 1989

Champaign

Lifecodes provides testing and expert witness for pretrial hearing in rape case. Admissibility pending. (Lifecodes)

\section{Indiana}

State of Indiana v. Hopkins

April 1989

Fort Wayne

Cellmark's DNA test results admitted in case charging rape, sodomy, and murder. Defendant convicted and sentenced to 60 years in prison. Lifecodes expert also testified. (Cellmark, Lifecodes)

State of Indiana $v$. Jones

August 1989

Marion County

DNA evidence admitted. Defendant convicted of rape and robbery. (Cellmark) 
State of Indiana v. Lockhart

August 1989

Crown Point

DNA evidence admitted. Defendant found guilty of rape and murder. Jury recommended death penalty. Defendant sentenced to death. (Cellmark)

\section{Iowa}

State of Iowa v. Brown

August 1989

Polk county

DNA evidence admitted. Defendant convicted of firstdegree murder. (Cellmark, Lifecodes)

State of Iowa $v$. Vargason

February 1989

Johnson County

DNA evidence admitted. Defendant convicted of thirddegree sexual abuse.

\section{Kansas}

State of Kansas v. Pioletti

May 1988

Wichita

DNA evidence admitted. Defendant convicted of murder.

State of Kansas v. Searles

PCR case. (Forensic Science Associates)

State of Kansas v. Smith

February 1989

Marion County

Defendant convicted of first-degree murder and rape in which DNA typing was used as evidence. Trial of defendant, who is Black, was moved to Junction City from Marion County because all Black residents of that county were relatives or acquaintances of the defendant. Sentenced to life in prison. (Lifecodes)

State of Kansas v. Thomas

October 1989

Johnson County

DNA evidence admitted. Defendant convicted of firstdegree murder. (FBI)

State of Kansas v. Wilson

December 1989

Saline County

FBI report on DNA admitted. Judge rules that defendant is to stand trial on charges of rape and aggravated burglary. (FBI)

\section{Louisiana}

State of Louisiana v. Quatrevingt

January 1990

New Orleans

DNA evidence admitted in murder-rape case. Defendant convicted. (Lifecodes)

\author{
Maine \\ State of Maine v. McLeod \\ December 1989 \\ Portland \\ The prosecution, in a sexual molestation case, withdrew \\ DNA evidence during a preliminary hearing on the \\ reliability of the data. (Lifecodes)
}

State of Maryland v. Abbott

September 1988

Anne Arundel County

DNA evidence admitted. Defendant pleaded guilty to assault and battery charges after tests linked him to the 1987 rape of a relative.

State of Maryland v. Bailey

November 1988

Baltimore

Rape and armed robbery charges against defendant dropped after DNA tests proved he could not have been the man who raped and robbed a guest at a Baltimore City hotel in July 1988.

\section{State of Maryland v. Benton}

March 1989

Montgomery County

DNA evidence admitted. Defendant convicted of rape and other charges; sentenced to life term in prison. (Cellmark)

State of Maryland v. Cobey

July 1989

Montgomery County

Defendant found guilty of rape after DNA evidence ruled to meet the Frye standard. Defendant sentenced to life, plus 10 years. The case was submitted for appellate review, and the Court of Special Appeals affirmed the use of DNA evidence in July 1989. This was Cobey's third trial. The first ended in a mistrial, and his conviction in the second trial (where evidence based on chromosome variant analysis was introduced) was overturned on appeal. Appeals Court subsequently upheld the admissibility of the DNA evidence.

\section{State of Maryland v. Edwards}

May 1989

Montgomery County

Trial pending on July 1989 sex offense.

\section{State of Maryland v. Hargrove}

January 1989

Montgomery County

Rape case. DNA evidence admitted following pretrial hearing. Defense stipulated to the DNA testing results. The trial resulted in a hung jury. Defendant was scheduled to be retried. (Cellmark) 
State of Maryland v. Jenkins

October 1987

Charles County

Rape case. Charles County Circuit Court judge orders DNA testing to be performed. DNA sample too degraded, however, to successfully perform the testing. (Cellmark)

State of Maryland v. Lee

May 1989

Montgomery County

DNA evidence admitted. Defendant convicted of rape. (Cellmark)

State of Maryland v. Rager

September 1989

Anne Arundel County

DNA evidence admitted. Defendant (who "dreamed" he raped his neighbor) convicted of rape and sentenced to 12 years in prison.

State of Maryland v. Stavrakas

August 1989

Prince George's County

DNA evidence admitted. Defendant convicted of rape. (FBI)

State of Maryland v. Tasker

September 1988

Anne Arundel County

Defendant pleads guilty to second-degree rape and draws 5 -year prison sentence in case where DNA evidence was introduced.

State of Maryland v. Tu

November 1989

Montgomery County

DNA evidence admitted. Defendant convicted of murdering his common law wife; no body was recovered.

(Cellmark)

State of Maryland v. Wilkenson

November 1989

Baltimore County

Defendant arrested for kidnapping. DNA tests indicate identification of the stolen 16-pound baby.

State of Maryland v. Williams

May 1989

Montgomery County

DNA evidence admitted. Defendant pleads guilty to first-degree murder. (Cellmark)

State of Maryland v. Yorke

September 1988

Baltimore County

DNA evidence admitted in rape case.

\section{Massachusetts}

Commonwealth of Massachusetts v. Curnin

September 1989

Worcester

DNA evidence admitted. Defendant convicted of rape. (Cellmark)

\section{Michigan}

State of Michigan v. Adams et al.

October 1989

Oakland County

Expert testimony at pretrial hearing in rape and serial rape case. Judge rules that DNA is admissible. Trial pending. (Cellmark)

\section{State of Michigan v. DuJardine}

September 1989

Ottawa County

DNA evidence admitted following a Frye hearing.

Defendant convicted; sentenced in September 1989 to life in prison. (Lifecodes)

\section{State of Michigan v. Fagan}

September 1988

Flint

DNA evidence admitted in rape case. Defendant convicted.

State of Michigan v. McMillan

September 1989

Ingharn county

Rape-murder case in which DNA identification from hair follicles is awaiting acceptance by the court.

State of Michigan v. Perkins

April 1989

Oakland County

DNA evidence admitted. Defendant awaiting trial on rape and murder charges. (Cellmark)

State of Michigan v. Szeman

October 1989

Oakland County

DNA evidence admitted in October 1989 following pretrial hearing. Defendant faces 49 charges in connection with 10 sexual assaults.

\section{Minnesota}

State of Minnesota v. Nielson

September 1989

Ramsey County

DNA evidence admitted. Defendant convicted of firstdegree murder and sentenced to life imprisonment.

(Cellmark) 
State of Minnesota v. Plaster

September 1989

Ramsey County

DNA evidence admitted in first-degree murder case.

Defendant convicted. (FBI)

\section{State of Minnesota v. Schwartz}

Minnesota Supreme Court ruled in November 1989 that DNA tests performed by Cellmark did not meet guidelines for scientific reliability and cannot be used against defendant, who was charged with first-degree murder.

$\quad$ Mississippi
State of Mississippi v. Jenkins
September 1989
DeSoto County
DNA evidence admitted. Defendant convicted of capital
murder and sentenced to death by injection. (Cellmark)

State of Mississippi v. Mettetal

June 1989

Union County

DNA evidence admitted. Defendant convicted of murder. (Cellmark)

State of Mississippi v. Parker

October 1989

Neshoba County

DNA evidence admitted. Defendant convicted of capital murder and sexual assault. (Cellmark)

State of Mississippi v. Weaver

February 1989

Hinds County

DNA evidence admitted. Defendant convicted of rape and sentenced to life without parole. (Cellmark)

\author{
Missouri \\ State of Missouri v. Davis \\ August 1989 \\ Boone County \\ DNA evidence admitted. Defendant was found guilty of \\ murder. (Cellmark)
}

\section{State of Missouri v. Thomas \\ March 1989}

St. Louis

DNA evidence admitted in rape case. Defendant convicted. (Lifecodes)

Associated Press report, Nov. 11, 1989

Investigators in Columbia looking into the rape and murder of a 5-year-old girl seek to obtain samples from six suspects. Child's body was recovered in November 1989.

\section{Montana}

State of Montana v. Drummond

September 1989

Jefferson County

Sexual intercourse without consent allegedly committed by a State institution attendant against a developmentally disabled patient. The victim gave birth and DNA comparisons were done by Lifecodes. Defendant pleaded guilty to the offense. (Lifecodes)

\section{New Hampshire}

State of New Hampshire v. Barnaby

September 1989

Hillsborough County

DNA analysis admitted, according to State Attorney

General's Office.

State of New Hampshire v. Chase

September 1989

Rockingham County

DNA analysis admitted, according to State Attorney

General's Office.

State of New Hampshire v. Parker

September 1989

Merrimack County

DNA analysis underway, according to State Attorney

General's Office.

\section{New Jersey}

State of New Jersey v. Beard

December 1989

Union County

Nearly 3 months after being charged with murder, the defendant was released after a judge ruled that authorities arrested the wrong man. The primary suspect in a 1975 Georgia murder disappeared after the crime. Mistakenly, his cousin (the defendant in this case) was arrested. DNA tests conducted by Lifecodes proved the jailed man was not the father of a man known to be the son of the suspect. (Lifecodes)

Associated Press report, Dec. 14, 1988

It seemed to be an open-and-shut case against a man charged with sexual assault. DNA testing by showed defendant's sample did not match semen taken from victim. (Lifecodes)

Associated Press report, Mar. 25, 1989

Unidentified female head discovered at a golf course in a Hopewell Township. DNA testing to be conducted once police get an idea of identity. 


\section{New Mexico}

State of New Mexico v. Collins

October 1989

Santa $\mathrm{Fe}$

A man once charged with killing his step-daughter was released from prison in October 1989 pending the outcome of DNA testing. Open murder charges against the defendant were dismissed in the interim.

\author{
New York \\ State of New York v. Arashi \\ November 1988 \\ New York \\ DNA evidence admitted in rape case. Defendant con- \\ victed. (Lifecodes)
}

State of New York v. Bailey

July 1988

Albany

Rape case. DNA evidence admitted after expert testimony at pretrial hearing. Defendant pleaded guilty. (Lifecodes)

State of New York v. Berries

November 1989

Defendant charged with rape. No result from DNA test. (Lifecodes)

State of New York v. Burton

March 1989

New City

DNA evidence admitted in murder case. Defendant convicted. (Lifecodes)

State of New York v. Buxton

December 1988

Albany

Defendant charged with rape. No result from DNA test. (Lifecodes)

State of New York v. Castro

August 1989

Bronx

Life-codes' test found to meet Frye standard and is ruled admissible for exclusion purposes, inadmissible for inclusion purposes. Defendant pleaded guilty to murder. (Lifecodes)

State of New York v. Davis

May 1989

Queens

DNA evidence admitted in rape case. Defendant convicted. (Lifecodes)

State of New York v. Drozic

November 1989

Erie County

Defendant indicted in rape case submits to DNA testing.
According to files released to media, defendant linked to series of rapes. Defendant pleaded guilty to three rapes in November 1989.

State of New York v. Golub

November 1989

Nassau County

Hearing held in October 1989, regarding admissibility of DNA evidence. Defendant charged with second-degree murder. (Lifecodes)

State of New York v. Gonzales

May 1989

Riverhead

DNA evidence admitted in murder case. Defendant pleaded guilty. (Lifecodes)

State of New York v. Hwang

October 1989

Mineola

DNA evidence admitted in murder case. Defendant convicted. (Lifecodes)

State of New York v. Jones

October 1989

Albany County

A thrice-convicted felon pleaded guilty in October 1989 to rape after DNA tests implicated him.

State of New York v. Lawrence

November 1989

White Plains

DNA evidence admitted in murder case. Defendant convicted. (Lifecodes)

State of New York v. Lolisco

December 1989

Suffolk county

Defendant arrested in December 1989 after DNA tests

implicated him in the rape and homicide of a teenage girl.

State of New York v. Lopez

October 1988

Queens

Defendant convicted in 1988 of three rapes and one robbery after DNA evidence was admitted. (Lifecodes)

State of New York v. Predmore

December 1988

Binghamton

DNA evidence admitted. Defendant pleaded guilty to murder. (Cellmark)

State of New York v. Rhem

July 1989

Albany County

DNA evidence admitted in murder case. Defendant convicted. (Lifecodes) 
State of New York v. Scheff

January 1989

White Plains

Westchester County man accused of rape exonerated by

DNA test. Charges dismissed. (Lifecodes)

State of New York v. Smith

October 1989

New York City

Man charged with raping and killing a doctor in her

Bellevue Hospital office agrees to DNA testing aimed at determining whether he acted alone. DNA test implicated him; defendant convicted. (Lifecodes)

State of New York v. Walker

March 1989

Jamaica

Rape case. No result from DNA testing. (Lifecodes)

State of New York v. Wesley

August 1988

Albany

DNA evidence admitted in murder-rape case. Defendant convicted. (Lifecodes)

State of New York v. Williams

PCR case. (Forensic Science Associates)

State of New York v. Zambrana

October 1987

New City

DNA evidence admitted. Defendant convicted of murder.

\section{Central Park Wilding Case}

October 1989

New York City

Youths charged in the beating and rape of a female jogger during a "wilding" rampage ordered to give samples of hair, blood, and saliva for DNA testing. FBI tests proved inconclusive.

\section{North Carolina}

State of North Carolina v. Hamrick

September 1989

Forsythe County

Defendant was released, and rape and kidnapping charges were dismissed after DNA tests exculpated him.

\section{State of North Carolina v. McCarty}

December 1989

Duplin county

Rape-incest case. A DNA paternity test was admitted at trial. Defendant was convicted. (Cellmark)

State of North Carolina v. Mills

March 1989

Salisbury

DNA evidence admitted. Defendant convicted of murder. (Cellmark)
State of North Carolina v. Pennington

December 1989

Forsythe County

DNA evidence admitted. Defendant convicted of rape. In December 1989, the North Carolina Supreme Court agreed to hear an appeal regarding the admissibility of the DNA test results. (Cellmark)

State of North Carolina v. Satterfield

September 1989

Alamance County

DNA evidence admitted at trial. Defendant was convicted of rape and kidnapping. (Cellmark)

$$
\text { Ohio }
$$

State of Ohio v. Biddings

March 1989

Columbus

DNA tests resulted in 21 additional charges against the defendant in a series of attacks known as the "handcuff rapes." Defendant now faces 123 charges in connection with sexual attacks on 35 women from October 1984 to August 1988.

State of Ohio v. Blair

September 1989

Clark County

DNA evidence admitted. Defendant convicted of murder. (Cellmark)

State of Ohio v. Borgmann

June 1989

Hamilton County

DNA testing was performed for the defense in this case. Judge ruled test results admissible. Defendant was found guilty of rape. (Cellmark)

State of Ohio v. Burgette

May 1989

Toledo

Defendant pleads guilty to rape and kidnapping charges after DNA tests link him to the crimes.

\section{State of Ohio v. Dascenzo}

July 1988

Montgomery County

Cellmark testified at motion hearing and jury trial where DNA evidence was admitted in aggravated murder case. Defendant was found guilty. (Cellmark)

State of Ohio v. Gordon

January 1989

Franklin County

DNA evidence admitted. Defendant convicted of five counts of rape and kidnapping. (Cellmark) 
State of Ohio v. Kinley

March 1989

Springfield

Defendant charged in two murders after DNA tests linked the man to the incident.

State of Ohio v. McWhite

September 1989

Lucas County

DNA evidence admitted. DNA from tissue scraped from victim's fingernails did not match the defendant. However, the defendant was convicted of two counts of 'aggravated murder. (Cellmark)

State of Ohio v. Pierce

July 1989

Delaware County

DNA evidence admitted. Defendant convicted of rape.

(Cellmark)

State of Ohio v. Reese

October 1989

Cuyahoga County

DNA evidence admitted. Defendant convicted of rape, aggravated burglary, and theft; sentenced 40 to 100 years. (Cellmark)

State of Ohio v. Tague

June 1988

Montgomery County

Judge assigned from Perry County rules that DNA evidence will be admitted in Montgomery County trial

where defendant is charged with aggravated murder and kidnapping.

\section{State of Ohio v. Thomas}

September 1989

Montgomery County

DNA evidence introduced in rape-murder case. Defendant found guilty of all charges and was sentenced to life in prison, plus 10 to 25 years. (Cellmark)

United States v. Yee, Veri, and Bonds

October 1989

U.S. District Court, Toledo

Three members of the Hell's Angels motorcycle gang were arrested on murder charges. Admissibility of DNA evidence pending. (FBI)

Associated Press report, Dec. 7, 1989

Pike County Sheriff's Department awaiting DNA test results from FBI so suspect can be arrested. According to local authorities, FBI reported a backlog of 60 cases, and that results in this case would not be issued for 3 months.

State of Oklahoma v. Hunt

\section{Oklahoma}

September 1987

Norman
First time Lifecodes testifies regarding DNA evidence in criminal case. Defendant acquitted of murder charges. (Lifecodes)

State of Oklahoma v. Reed

May 1988

Oklahoma City

DNA evidence admitted in rape case. Defendant convicted. (Lifecodes)

State of Oklahoma v. Taylor

January 1989

Oklahoma City

DNA evidence admitted. Defendant convicted of rape, burglary, oral sodomy, and robbery. (Lifecodes)

Associated Press report, Sept. 26, 1989

DNA tests implicated a suspect in four rapes. However, the suspect was slain by police following a robbery in April 1989. (FBI)

\section{Oregon}

State of Oregon v. Dorson

November 1989

Lincoln County

DNA evidence admitted in aggravated murder case.

Defendant convicted in November 1989.

State of Oregon v. Futch

May 1989

Clatsop County

DNA test results offered for admission at 7-month pretrial hearing, which concluded in December 1989. (Lifecodes)

\section{Pennsylvania}

Commonwealth of Pennsylvania v. Conyers

August 1989

Dauphin County

DNA evidence admitted. Defendant convicted of murder and rape; sentenced to two consecutive life terms, plus 5 to 10 years. (Cellmark)

Commonwealth of Pennsylvania v. James

PCR case. (Forensic Science Associates)

Commonwealth of Pennsylvania v. McCullum

June 1989

Allegheny County

DNA evidence admitted in murder-rape case. Defendant convicted. (Cellmark)

Commonwealth of Pennsylvania v. Osellanie

July 1989

Lackawanna County

DNA test inconclusive in case against defendant, who was charged with murder. Authorities said DNA was not the primary evidence, and that the test results would have no adverse impact on the case. (Cellmark) 
Commonwealth of Pennsylvania v. Pestinikas

First criminal DNA case in the United States (1986). PCR case. (Forensic Science Associates)

Commonwealth of Pennsylvania v. Smith

August 1989

Harrisburg

DNA evidence admitted in rape-burglary case. Defendant convicted. (Cellmark)

\section{Commonwealth of Pennsylvania $v$. Thomas}

September 1989

Cannonburg DNA evidence offered at pretrial hearing in rape case. Defendant pleaded guilty. (Lifecodes)

Commonwealth of Pennsylvania v. Trubia

December 1988

Lackawanna County

DNA evidence accepted in murder-rape case. Defendant convicted.

Commonwealth of Pennsylvania v. Whitman

October 1989

Lebanon County

Defendant pleads guilty to first-degree murder, but mentally ill to charges of rape and involuntary deviate sexual intercourse. DNA evidence would have been offered had the case gone to trial.

Commonwealth of Pennsylvania v. Woodson March 1989

Allegheny County

Defense stipulates to DNA test results. Defendant found guilty of rape. (Cellmark)

Associated Press report, Feb. 23, 1989

Police in State College released new details of a Pennsylvania State University student's 1987 murder, including information that police have a DNA test of the killer. Police released information in hopes of generating new leads in the case.

\section{Rhode Island}

In re: Juvenile

September 1989

Case involving rape of a nursing home resident. Lifecodes conducted test. Juvenile admitted sufficient facts to establish the charge against him; sentenced to 3 years at a juvenile facility. (Lifecodes)

State of Rhode Island v. Otero

September 1989

Testing by Lifecodes. Trial pending.

State of Rhode Island v. Scurry

September 1989

Testing by FBI. Trial pending.

\section{South Carolina}

State of South Carolina v. Daniels

July 1989

DNA tests reveal that defendant's blood did not match

DNA patterns in semen samples taken from rape victims.

Police were looking for a man wearing a stocking mask who was believed to be responsible for 12 rapes over a 2-year period. Defendant said his troubles began when he jokingly donned a Halloween mask one day and walked from his sister's house in Summerville to his home in Lincolnville. Authorities were not convinced of first DNA tests. Second tests were negative and defendant was released.

\section{State of South Carolina v. Evans}

April 1989

Charleston County

DNA evidence admitted in rape-burglary case. Defendant convicted. (Lifecodes)

\section{State of South Carolina v. Ford and Fraser}

April 1989

DNA evidence admitted. Defendant convicted on charges of criminal sexual conduct, kidnapping, and conspiracy. (Lifecodes)

State of South Carolina v. Mitchell

August 1989

Columbia

DNA evidence admitted. Hung jury on rape charges.

(Lifecodes)

State of South Carolina v. Sellers

December 1989

Orangeburg

DNA evidence admitted in rape case. Defendant convicted. (Lifecodes)

\section{South Dakota}

State of South Dakota v. Wimberly

December 1989

Meade County

Defendant found guilty of rape. (FBI)

\section{Tennessee}

FBI testimony in rape case in Blountville, Tennessee on Dec. 11, 1989, results in admission of DNA evidence. Trial pending.

\section{Texas}

State of Texas v. Balawajder

PCR case. (Forensic Science Associates)

State of Texas v. Bethune

January 1989

Harris County

Defendant convicted of raping a 74-year-old woman after introduction of DNA evidence. (Lifecodes) 
State of Texas v. Clarke

PCR case. (Forensic Science Associates)

State of Texas $v$. Danzinger

PCR case. (Forensic Science Associates)

State of Texas v. Fuller

PCR case. (Forensic Science Associates)

State of Texas v. Kelly

November 1988

Tarrant County

Defendant convicted in the slaying of a 63-year-old woman following a trial in which DNA testing was admitted into evidence. (Lifecodes)

State of Texas v. Glover

October 1988

Dallas

DNA evidence admitted in rape case. Defendant con-

victed. (Lifecodes)

State of Texas v. Hicks

January 1989

Fairfield

DNA evidence admitted in murder-rape case. Defendant convicted. (Lifecodes)

State of Texas v. Leon

May 1989

Henderson County

DNA tests completed. The 15-year-old defendantcertified to stand trial as an adult for capital murder, aggravated sexual assault, and two armed robberiespleads guilty.

State of Texas v. Lockhart

October 1988

San Antonio

DNA evidence linking defendant to a Florida murder victim was admitted at a Texas sentencing hearing on Oct. 17-18, 1988. The defendant, convicted of murdering a Beaumont policeman, received the death penalty. Defendant was accused of going on a nationwide killing spree, and was also charged with capital murder in slayings in Indiana and Florida.

State of Texas v. Lopez

PCR case. (Forensic Science Associates)

State of Texas v. Mandujano

May 1989

Bryan

DNA evidence admitted in rape case. Defendant convicted. (Lifecodes)

State of Texas v. McFarland

PCR case. (Forensic Science Associates)
State of Texas $v$. Perryman

June 1989

Piano

DNA evidence admitted in sexual assault case. Defendant convicted. (Lifecodes)

State of Team v. Schultze

September 1989

Palestine

DNA evidence admitted in murder case. Defendant convicted. (Lifecodes)

State of Texas $v$. Trimboli

April 1988

Tarrant County

A DNA test that triple-murder defendant Ronald Trimboli had hoped would clear his name instead gave prosecutors additional evidence against him. The tests concluded that semen found on the bedspread where one of the three victims was raped matched a sample Trimboli had given for the test. Trimboli's two earlier trials for the three murders both ended in mistrials, first because of jury misconduct and later because a jury deadlocked, 6 to 6 . In February 1989, defense lawyers, who had earlier demanded the tests, announced plans to seek exclusion of the tests at trial. Presiding judge granted a defense motion requiring prosecutors to furnish detailed data related to the tests, and to send the defense team to Lifecodes, where the tests were done, at State expense. The third trial began on Mar. 27, 1989, and the defendant was found guilty of three murders in April 1989. (Lifecodes, Forensic Science Associates)

State of Terns v. Vickers

July 1989

Beaumont

DNA evidence admitted in rape case. Defendant convicted. (Lifecodes)

State of Texas $v$. Williams

August 1988

Bryan

DNA evidence admitted in rape case. Defendant convicted. (Lifecodes)

Associated Press report, Feb. 22, 1989

DNA testing was reported in two investigations. In one, a police officer in Houston, arrested and charged with kidnapping and rape, provided a blood sample that was to be used in DNA matching. The other, an immigration case, involves a woman who was indicted by Federal authorities on kidnapping charges for taking a child from Mexico and bringing him to the United States, according to the FBI. Blood tests were taken to determine the relationship between the woman and the child. 


\section{Utah}

State of Utah v. Bickmore

April 1989

Ogden

DNA evidence admitted. Mistrial declared on other grounds.

Associated Press report, Mar. 4, 1989

DNA tests conducted on severed legs found in supermarket trash container in Salt Lake City area.

\section{Vermont}

United States v. Jakobetz

November 1989

U.S. District Court, Burlington

Admissibility hearing pending in rape case. Defense attorney has filed request that genetic evidence not be used in court. In August 1989, judge ruled that hair, blood, and saliva samples could be taken from defendant for testing.

\section{Virginia}

Commonwealth of Virginia v. Breer

October 1989

Arlington County

Defendant is charged with two rapes. DNA evidence expected to be introduced at trial.

Commonwealth of Virginia v. Copeland June 1989

Portsmouth

DNA evidence admitted in murder case. Defendant convicted of murder. (LifeCodes)

Commonwealth of Virginia v. Ford

February 1989

Henrico County

Case involving charges of rape, breaking and entering, and abduction. DNA testing admitted. (Cellmark)

Commonwealth of Virginia v. Johnson

June 1989

Rockingham County

Defendant pleads guilty just prior to trial; DNA evidence had been ruled admissible after a motions hearing.

(Cellmark)

Commonwealth of Virginia v. Reynolds

February 1988

Henrico County

Murder case. DNA evidence admitted. (Cellmark)

Commonwealth of Virginia v. Spencer

January 1990

Arlington County and Richmond

Defendant convicted four times-July 1988, September 1988, January 1989, and May 1989-of capital murder and rape where DNA test was admitted into evidence. Spencer received the death sentence, which is automatically reviewed. Virginia Supreme Court upheld the admission of DNA tests. In January 1990, the U.S. Supreme Court refused to hear Spencer's appeal, thus allowing the Virginia High Court ruling to stand.

Commonwealth of Virginia v. Trent

January 1989

Roanoke

Judge dismissed charges of statutory rape against defendant because, although DNA tests showed the man had sex with a 14-year-old girl, there was insufficient evidence of criminal intent. Defendant claimed he was drunk at the time, and thought he was having sex with his wife.

Commonwealth of Virginia v. Vasquez.

January 1989

Richmond

Vasquez, who had earlier pleaded guilty to second-degree murder, was released from prison in January 1989 after being granted executive clemency by Virginia Governor Baliles. DNA testing in Commonwealth of Virginia $v$. Spencer led authorities to believe that Spencer, not Vasquez, was responsible for the homicide to which Vasquez had pleaded guilty.

Associated Press report, May 13, 1989

Authorities in Campbell County plan to use DNA tests in seeking identification of the mother of a suffocated baby found in the Campbell County landfill.

Washington
State of Washington v. Buckner
February 1989
Stevens County

DNA evidence admitted. Defendant convicted of firstdegree murder and rape. (Lifecodes)

State of Washington $v$. Cauthron

May 1989

Everett

Jury finds defendant guilty of seven counts of rape. DNA evidence was recovered from six of the seven attacks. Defendant sentenced to 51 years in prison. (Cellmark)

State of Washington v. Chapple

May 1989

Spokane County

Defendant charged with two murders. Trial pending.

State of Washington v. Evans

October 1989

Pierce County

DNA evidence admitted. Defendant convicted of rape and robbery. (FBI) 
State of Washington v. Kalakowsky

June 1989

Spokane County

DNA evidence admitted. Defendant convicted of four counts of first-degree rape and one count of attempted first-degree rape. Sentenced to 54 years in jail. (Lifecodes)

State of Washington v. Shriner

October 1989

Pierce County

Judge rules that DNA testing is to proceed in sexual assault case. (Cellmark)

State of Washington v. Young

February 1989

Snohomish County

DNA tests exclude Young, who had been identified by the victim as the rapist. Charges dropped.

\section{West Virginia}

State of West Virginia v. Ferrell

January 1989

Petersburg

DNA evidence admitted in murder case. Defendant convicted. (Lifecodes)

State of West Virginia v. Woodall

July 1989

Defendant, serving 335 years and two life terms for kidnapping and raping two women, undergoes DNA testing after several attempts are denied. DNA tests showed that samples were too degraded for testing to be accurate. West Virginia Supreme Court admitted test results in July 1989; rules that Woodall can follow normal appeals process. (Cellmark)

\section{Wisconsin}

State of Wisconsin v. Banks

February 1989

Kenosha County

DNA evidence admitted, defendant convicted of rape.

(Cellmark)

\section{Military}

United States v. Luke

March 1988

Us. Army

Defendant charged with murder, robbery, and sexual battery. DNA evidence admitted. Defendant pleaded guilty.

United States v. Scott

January 1988

U.S. Marine Corps

Rape case. Military judge approved request for DNA tests, but DNA in sample too degraded to perform the testing. 


\section{Survey Instrument for OTA Survey of State and Local Crime Laboratories}

As part of this assessment, OTA surveyed all State and local crime laboratories identified in the 1988 U.S. Department of Justice, Federal Bureau of Investigation Directory of Crime Laboratories Representing Local, State and Federal Systems (see ch. 6).
The following is a reproduction of the survey questionnaire. 


\title{
SURVEY OF STATE AND LOCAL CRIME LABORATORIES
}

\author{
Survey by the Biological Applications Program \\ Office of Technology Assessment \\ U.S. Congress \\ Washington, D.C. $20510-8025$
}

Please Respond by March 13,1989

The Office of Technology Assessment is conducting a survey of U.S. state and local crime laboratories as part of an assessment of Forensic Uses of Genetic Tests. Please read each question and mark the space below the question that corresponds to your answer. After each answer continue with the next question unless there is an instruction to skip to a particular question or section. Only aggregate data will be presented in the report, so individual information will not be identified with any particular facility. Please call Margaret Anderson if you have any questions (202)228-6695.

\section{SECTION 1: GENERAL QUESTIONS}

1. Do you believe DNA typing is:

very imporlant to develop for advancing the mission of this crime laboratory? (1)

somewhat important, but only an additional technology in an array of existing technologies? (2) not very important to the mission of this crime laboratory?

2. What is the total number of non-clerical staff members in your facility?

3. What is your crime laboratory's annual budget?

4. What role, if any, do you see for the FBI in DNA testing? (Please check all that apply)
research (methods development and evaluation)
training
casework for state and local labs
maintenance of centralized DNA data files
reference library
define standards
certify laboratory personnel
provide proficiency samples for quality assurance

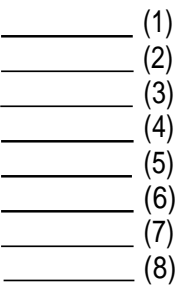

other, what?

5. Do you believe that DNA testing results should be incorporated into a database (e.g., local, state, or national) so that they can be exchanged among law enforcement agencies?
yes (1)
no (2) SKIP to Q 7 
6. What types of data files would be most useful? (Please rank from $1=$ most useful to $4=$ least useful. Ignore our code numbers such as (I), (2)) population data crime scene evidence from cases in which

a subject hasn't been identified known offender files

missing persons/unidentified deceased

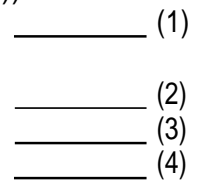

7. What do you see as the most important issues involving DNA testing?

8. Have you plans for utilizing or do you currently utilize forensic DNA testing? (Please check all that apply)

yes, presently contracting

yes, DNA tests on site

yes, have plans for on-site

DNA testing

no, we do not currently use
(1) Please answer SECTION III

(2) Please answer SECTION IV

(3) Please answer SECTION II (4) Please answer SECTION II

\section{SECTION 11: NOT CURRENTLY CONDUCTING DNA TESTING}

9. If you are not currently conducting DNA testing either on-site or contracting, do you have plans or funding to contract for DNA testing:

in the next 12 months?

in the next 24 months?

10. Do you have provisions to contract out DNA testing if necessary in the future?

yes, we will contract as necessary

no, we do not intend to contract (1)

yes, we have provisions, but cost may prevent us from contracting

IF YOU ARE NOT CURRENTLY CONDUCTING DNA TESTS OR CONTRACTING FOR THEM, THIS COMPLETES YOUR SURVEY. THANK YOU VERY MUCH. 


\section{SSECTION III: CONTRACTING FOR DNA TESTING}

II. If you are not conducting DNA analysis on-site, have you submitted budget provisions to do so that have not yet been approved?
yes
If yes, how much?
(3)

no

12. Which facilities have you contracted with? Please list all facilities and the number of for each facility. Include any test or trial samples as well.

specific cases

13. When you send specimens out to private laboratories, do you conduct a pre-screening test on them beforehand?

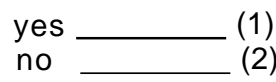

14. Based on the types of crimes that you would or are currently using DNA testing on, how many samples do you anticipate sending out annually in the future?

15. Do you intend to restrict or institute a formal protocol to determine the type of crimes that DNA testing can be used on?<smiles>[Te][Te]</smiles>

If yes, what type and/or criteria? (3)

IF IN ADDITION TO CONTRACTING, YOU ARE CONDUCTING ON-SITE DNA TESTING, PLEASE ANSWER SECTION IV. IF NOT, THIS COMPLETES YOUR SURVEY. THANK YOU VERY MUCH.

\section{SECTION IV: ON-SITE}

16. How many non-clerical staff members are there in the section performing DNA testing?

17. What is the annual budget in the section performing DNA testing? 
18. If you are conducting DNA testing on-site, have you or do you anticipate an increase in professional staff positions to coordinate or to conduct DNA analysis?

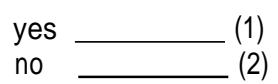

19. Will positions handling DNA samples require extra training above and beyond the existing academic and work experience of these personnel?

$$
\begin{array}{ll}
\text { yes } & (1) \\
\text { no } & (2)
\end{array}
$$

If yes, what?

20. Please rank the following factors for relative importance in your decision to pursue DNA typing onsite. (Use 1 = most important to 4 = least important. Ignore our code numbers such as (I), (2))

cost of contracting out

wanted the shortest turnaround time for samples control of evidence is important

it's important that we have state-of-the-art technology
(1)

21. Are any non-criminal justice agencies in your state currently using the crime laboratory for other purposes (e.g., paternity, child support enforcement, missing persons)?

$\begin{array}{ll}\text { yes } & (1) \\ \text { no } & (2)\end{array}$

If yes, please name the type of agency and purpose:

22. Are you creating or contributing to any DNA testing data files at this time?

yes (1)

no (2) SKIP to Q 25

If yes, please describe: (3)

23. If yes, will these files be maintained and regulated:
at the local level at the state level (1)
at the national leve
(2) (3)

24. How do you plan to store DNA testing material not specifically assigned to an ongoing investigation? After completing this question, SKIP to $Q 26$.
DNA samples
gels
autoradiographs electronically captured prints other (Please describe) (1) 
25. [f you are not creating files, do you have plans to computerize the results of DNA testing, and what stage have those plans reached? (Please check all that apply)
still preliminary
hardware in place
software in place

other (Please explain)

26. Do you currently have an NRC license for use of radioactive markers? If not, are you applying for one?

yes
no
applying for a license (3)

27. Do you intend to restrict or institute a formal protocol to determine the type of crimes that DNA testing can be used on?
yes (1)
no (2)

If yes, what type and/or criteria? 
OTA would like to thank the members of the advisory panel who commented on drafts of this report and the many individuals and organizations that supplied information for the study. In addition, OTA acknowledges the following individuals who reviewed drafts of this-report:

Ronald T. Acton

University of Alabama, Birmingham

Birmingham, AL

Dan Adams

Office of the Attorney General of Massachusetts

Boston, MA

Robert C. Allen

Medical University of South Carolina

Charleston, SC

Sue Anderson

Chicago, IL

Jeffrey Ashton

Assistant State's Attorney

Orlando, FL

Bernard Auchter

National Institute of Justice

Washington, DC

John Ballantine

Office of the Medical Examiner, Suffolk County

Hauppauge, NY

Jan S. Bashinski

California DNA Lab

Berkeley, CA

Peter G. Beeson

Office of the Attorney General of New Hampshire

Concord, NH

Robert P. Bennett

Office of the Attorney General of North Dakota

Bismarck, ND

Robert A. Bever

Genetic Design, Inc.

Greensboro, NC

Paul R. Billings

New England Deaconess Hospital

Boston, MA

Edward T. Blake

Forensic Science Associates

Richmond, CA

Bruce Budowle

Federal Bureau of Investigation

Quantico, VA
Brian L. Burgess

Office of the Attorney General of Vermont

Montpelier, VT

Beverly J. Burke

Office of the Corporation Counsel of the

District of Columbia

Washington, DC

John E. Burris

National Academy of Sciences

Washington, DC

R. Alta Charo

University of Wisconsin

Madison, WI

Byron Chatfield

Office of the Attorney General of Oregon

Salem, OR

James J. Coman

Office of the Attorney General of North Carolina

Raleigh, NC

Catherine T. Comey

Federal Bureau of Investigation

Quantico, VA

John P. Connor

Office of the Attorney General of Montana

Helena, MT

Edward L. Dance

Crime Laboratory, Kentucky State Police

Frankfort, KY

Steven D. Ebert

Office of the Attorney General of Wisconsin

Madison, WI

John Edward Farley

Office of the Attorney General of Rhode Island

Providence, RI

Paul B. Ferrara

Virginia Bureau of Forensic Science

Richmond, VA

Robert I. Field

Dilworth, Paxson, Kalish \& Kauffman

Philadelphia, PA 
Barry A.J. Fisher

Scientific Services Bureau, Los Angeles County

Sheriff's Office

Los Angeles, CA

William Fitzgerald

Office of the Attorney General of Guam

Agana, GU

Theodore Friedmann

University of California, San Diego

La Jolla, CA

R.E. Gaensslen

University of New Haven

West Haven, CT

Daniel D. Gamer

Cellmark Diagnostics

Germantown, MD

Barry D. Gaudette

Central Forensic Laboratory,

Royal Canadian Mounted Police

Ottawa, Ontario, Canada

Andrew Geiser

Gaithersburg, MD

Paul L. Gimenez

Office of the Attorney General of the Virgin Islands

St. Thomas, VI

Jo Ann Given

Naval Investigative Services

Norfolk, VA

Richard Givens

Attorney-at-Law

New York NY

Dorothy Gordimer

Crime Laboratory, Union County Prosecutor's Office

Westfield, NJ

Lionel H. Grundy

Home Office

London, England

Laura Lee Hall

Office of Technology Assessment

Washington, DC

Dan Hanaway

Attorney General, Wisconsin

Madison, WI

Rockne P. Harmon

District Attorney's Office, Alameda County

Oakland, CA
Linda F. Harrison

School of Law, Georgia State University

Athens, GA

John W. Hicks

Federal Bureau of Investigation

Washington, DC

Theodore Holder

Office of the Attorney General of Arkansas

Little Rock, AR

Edward E. Hueske

Northern Regional Laboratory,

Arizona Department of Public Safety

Flagstaff, AZ

Robert Ianni

Office of the Attorney General of Michigan

Lansing, MI

Edward Imwinkelried

School of Law, University of California, Davis

Davis, CA

Dirk Janssen

Crime Laboratory, Wisconsin Department of Justice Milwaukee, WI

Kathleen Jennings

Office of the Attorney General of Delaware

Wilmington, DE

Donald M. Johnson

National Crime Information Center

Washington, DC

Randolph N. Jonakait

New York Law School

New York NY

Roger Kahn

Crime Laboratory, Metro-Dade Police Department

Miami, FL

Michael Katzer

Office of the District Attorney, Albany County

Albany, NY

James J. Kearney

Federal Bureau of Investigation

Quantico, VA

Frank J. Kelley

Attorney General, Michigan

Lansing, MI

Margaret Kuo

Orange County Sheriff-Coroner's Crime Laboratory

Santa Ana, CA 
Terry L. Laber

Minnesota Bureau of Criminal Apprehension

St. Paul, MN

Timothy D. Leathers

U.S. Department of Agriculture

Peoria, IL

John N. Linssen

Crime Laboratory, Wisconsin Department of Justice

Milwaukee, WI

Don MacClaren

Crime Laboratory, Washington State Patrol

Seattle, WA

Michael T. McDonnell

Automated Microbiology Systems, Inc.

San Diego, CA

Gary T. Marx

Massachusetts Institute of Technology

Cambridge, MA

Frederick R. Millar, Jr.

Office of the Attorney General of California

San Diego, CA

Keith L. Monson

Federal Bureau of Investigation

Quantico, VA

Laurence Mueller

University of California, Irvine

Irvine, CA

Peter J. Neufeld

New York, NY

Kenneth W. Nimmich

Federal Bureau of Investigation

Washington, DC

Kathleen Nolan

The Hastings Center

Briarcliff Manor, NY

Carla M. Noziglia

Crime Laboratory, Las Vegas Metro Police Department

Las Vegas, NV

Shannon Odelberg

University of Utah

Salt Lake City, UT

Linley E. Pearson

Attorney General, Indiana

Indianapolis, IN

Rickie L. Pearson

Office of the Attorney General of Kentucky

Frankfort, KY
Joseph L. Peterson

University of Illinois, Chicago

Chicago, IL

James M. Pollock

Crime Laboratory, Florida Department of Law Enforcement

Jacksonville, FL

Warren Price, III

Attorney General, Hawaii

Honolulu, HI

Noreen F. Purcell

New Mexico State University

Las Cruces, NM

Christopher Pyle

Mount Holyoke College

South Hadley, MA

Carlos L. Rabren

Alabama Department of Forensic Sciences

Auburn, AL

Lisa J. Raines

Industrial Biotechnology Association

Washington, DC

Emmet A. Rathbun

Federal Bureau of Investigation

Washington, DC

Richard M. Rau

National Institute of Justice

Washington, DC

Dennis J. Reeder

National Institute of Standards and Technology

Gaithersburg, MD

Priscilla M. Regan

George Mason University

Fairfax, VA

Philip R. Reilly

Shriver Center for Mental Retardation

Waltham, MA

Rex E. Riis

Office of the Attorney General of South Dakota

Pierre, SD

Ira Robbins

Washington College of Law, American University

Washington, DC

Richard Roberts

Cold Spring Harbor Laboratory

Cold Spring Harbor, NY 
Stanley D. Rose

Perkin Elmer Cetus

Emeryville, CA

Anthony Sarcione

Office of the Attorney General of Pennsylvania

Harrisburg, PA

George F. Sensabaugh

University of California

Berkeley, CA

Donna-Marie Seyfried

The Perkin-Elmer Corp.

Norwalk, CT

David T.Stafford

University of Tennessee

Memphis, TN ,

David A. Stoney

University of Illinois, Chicago

Chicago, IL

Richard L. Tanton

Palm Beach Sheriff's Crime Laboratory

West Palm Beach, FL

Enrico N. Togneri

Washoe County Sheriff's Crime Laboratory

Reno, NV

Richard E. Tontarski, Jr.

Bureau of Alcohol, Tobacco, and Firearms

Rockville, MD

George L. Trainor

E.I. du Pent de Nemours \& Co.

Wilmington, DE

John K. Van de Kamp

Attorney General, California

Sacramento, CA
Clifton VanderArk

Central Regional Crime Laboratory, Arizona Department of Public Safety Phoenix, AZ

Victor Weedn

Armed Forces Institute of Pathology

Washington, DC

Steven Westheimer

Office of the Attorney General of New Mexico

Santa Fe, NM

Raymond L. White

Howard Hughes Medical Institute

Salt Lake City, UT

Jerry Williams

Office of the Attorney General of American Samoa

Pago Pago, AS

Luther S. Williams

National Science Foundation

Washington, DC

Jan Witkowski

Banbury Center

Cold Spring Harbor, NY

Fred C. Wood

Office of Technology Assessment

Washington, DC

Harold Young

Office of the Attorney General of Iowa

Des Moines, IA

Marc Zimmerman

University of Michigan

Ann Arbor, MI

Additionally, OTA gratefully acknowledges the assistance of two contractors who provided material for this assessment:

Eric S. Lander, The Whitehead Institute for Biomedical Research, Cambridge, MA, "Reliability and Validity of DNA Typing For Forensics," October 1989.

Susan Sanford, MedSciArtCo, Washington, DC. 


\section{Acronyms}

\begin{tabular}{|c|c|}
\hline A & —adenine \\
\hline $\mathrm{AABB}$ & —American Association of Blood Banks \\
\hline AAFS & -American Academy of Forensic Sciences \\
\hline AFIS & $\begin{array}{l}\text {-Automated Fingerprint Identification Sys- } \\
\text { tems }\end{array}$ \\
\hline APB & —Advisory Policy Board (NCIC) \\
\hline ASCLD & $\begin{array}{l}\text {-American Society of Crime Laboratory } \\
\text { Directors }\end{array}$ \\
\hline ASHG & —American Society of Human Genetics \\
\hline ASHI & $\begin{array}{l}\text {-American Society of Histocompatibility } \\
\text { and Immunogenetics }\end{array}$ \\
\hline BJS & —Bureau of Justice Statistics (DOJ) \\
\hline c & -cytosine \\
\hline CAC & —California Association of Criminalists \\
\hline CACLD & $\begin{array}{l}\text { - California Association of Crime Laboratory } \\
\text { Directors }\end{array}$ \\
\hline CLIA & $\begin{array}{l}\text { - Clinical Laboratory Improvement Amend- } \\
\text { ments of } 1988\end{array}$ \\
\hline CTS & —Collaborative Testing Services \\
\hline DHHS & $\begin{array}{l}\text {-U.S. Department of Health and Human } \\
\text { Services }\end{array}$ \\
\hline DNA & —deoxyribonucleic acid \\
\hline Doc & —U.S. Department of Commerce \\
\hline DOJ & —U.S. Department of Justice \\
\hline FBI & -Federal Bureau of Investigation (DOJ) \\
\hline FSA & -Forensic Science Associates \\
\hline FSF & —Forensic Science Foundation \\
\hline FSRTC & $\begin{array}{l}\text {-Forensic Science Research and Training } \\
\text { Center (FBI/DOJ) }\end{array}$ \\
\hline G & -guanine \\
\hline HCFA & - HealthCareFinance Administration (DHHS) \\
\hline HGML & —Human Gene Mapping Library \\
\hline HLA & -human leukocyte antigen \\
\hline ISFH & $\begin{array}{l}\text {-International Society for Forensic Haemo- } \\
\text { genetics }\end{array}$ \\
\hline mtDNA & —mitochondrial DNA \\
\hline NCIC & -National Crime Information Center \\
\hline NIH & —National Institutes of Health \\
\hline NIJ & —National Institute of Justice \\
\hline NIST & $\begin{array}{l}\text { - National Institute of Standards and Tech- } \\
\text { nology (DOC) }\end{array}$ \\
\hline NLETS & $\begin{array}{l}\text { - National Law Enforcement Telecommuni- } \\
\text { cations System }\end{array}$ \\
\hline 0MIM & -On-Line Mendelian Inheritance in Man \\
\hline OTA & —Office of Technology Assessment \\
\hline PCR & —polymerase chain reaction \\
\hline PDB & -Protein Data Bank \\
\hline PIR & —Protein Identification Resource \\
\hline RFLP & —restriction fragment length polymorphism \\
\hline $\mathrm{SSN}$ & —social security number \\
\hline
\end{tabular}

T - thymine

Triple I - Interstate Identification Index (NCIC)

TWGDAM-Technical Working Group on DNA Analysis Methods (FBI/DOJ)

VNTR - variable number of tandem repeats

\section{Glossary of Terms}

Allele: Alternative form of a genetic locus (e.g., at a locus for eye color there might be alleles resulting in blue or brown eyes); alleles are inherited separately from each parent.

Autoradiogram: An x-ray film image showing the position of radioactive substances. Sometimes called "Autocad."

Autoradiograph: See autoradiogram.

Autoradiography: A technique for identifying radioactively labelled molecules or fragments of molecules.

Autosome: Chromosome not involved in sex determination. In a complete set of human chromosomes, there are 44 autosomes (22 pairs).

Band shift: The phenomenon of DNA fragments in one lane of a gel migrating slower or faster than identical fragments in another lane. As visualized on an autoradiogram, the overall patterns would be the same, but out of register. Factors responsible for band shift include contaminants, salt concentration, and DNA concentration.

Base pair: Two complementary nucleotides (adenosine and thymidine or guanosine and cytidine) held together by weak bonds. Two strands of DNA are held together in the shape of a double helix by the bonds between base pairs.

Blot: See Southern blot.

Cell: The smallest component of life capable of independent reproduction and from which DNA is isolated for forensic analysis.

Chromosome: A threadlike structure that carries genetic information arranged in a linear sequence. In humans, it consists of a complex of nucleic acids and proteins.

Controls: Tests designed to demonstrate that a procedure worked correctly and performed in parallel with experimental samples. Controls yield certain expected results; when the observed results for the controls deviate from what is expected, then the results for the case samples cannot be considered reliable.

Deoxyribonucleic acid (DNA): The molecule that encodes genetic information. DNA is a doublestranded helix held together by weak bonds between base pairs of nucleotides.

DNA: See deoxyribonucleic acid.

DNA band: Referring to the visual image, e.g., on a autoradiograrn or an ethidium bromide stained gel, that represents a particular DNA fragment. 
DNA probe: Short segment of DNA that is labeled with a radioactive or other chemical tag and then used to detect the presence of a particular DNA sequence through hybridization to its complementary sequence.

DNA sequence: Order of nucleotide bases in DNA.

Electrophoresis: Technique used to separate molecules such as DNA fragments or proteins. In forensic uses of DNA tests, electric current is passed through a gel, usually composed of a substance called agarose, and the fragments of DNA are separated by size. Smaller fragments will migrate farther than larger pieces.

Enzyme: A protein that acts as a catalyst, speeding the fate at which a biochemical reaction proceeds, without being permanently altered or consumedly the reaction so that it can be used repeatedly.

Gel: The semi-solid matrix used in electrophoresis to separate molecules. In forensic DNA analysis, the substance usually used is agarose, although acrylamide can also be used

Gene: The fundamental unit of heredity; an ordered sequence of nucleotide base pairs to which a specific product or function can be assigned.

Genome: All the genetic material in the chromosomes of a particular organism; its size is generally given as its total number of base pairs.

Genotype: The genetic constitution of an organism, as distinguished from its physical appearance, or phenotype.

Hardy-Weinberg equilibrium: In a large, random, intrabreeding population, not subjected to excessive selection, migration, or mutation, the gene and genotype frequencies will remain constant overtime, so that for most single-locus probe analyses, the likelihood of being a homozygote (one band) with genotype $\mathrm{a}_{1} \mathrm{a}_{1}$ will be (pl)2, where $\mathrm{p}_{1}$ is the frequency in the population of allele $\mathrm{a}_{1}$. For heterozygotes with two bands, the chance that a person will have genotype $\mathrm{a} / \mathrm{a}_{2} \sim$ will be $2 \mathrm{p}_{1} / 2 \mathrm{p}_{2}$, where $\mathrm{p}_{1}$ and $\mathrm{p}_{2}$ are the respective frequencies of how often bands $\mathrm{a}_{1}$ and $\mathrm{a}_{2}$ occur.

Heterozygous: Having two different alleles at a particular locus. For most forensic DNA probes and individuals, if the person is heterozygous at the locus the probe detects, the autoradiogram displays two bands.

HLA: See human leukocyte antigen.

Homozygous: Having the same allele at a particular locus. For most forensic DNA probes and individuals, if the person is homozygous at the locus the probe detects, the autoradiogram displays a single band.

Human leukocyte antigen (HLA): Located on the surface of most cells, except blood cells, these protein-sugar structures differ among individuals and are important for acceptance or rejection of tissue or organ grafts and transplants. The locus of one particular class of these antigens, HLA $D Q x-1$, is useful for forensic analysis using PCR.
Hybridization: The process of joining two complementary strands of DNA, or of DNA and RNA, together to form a double-stranded molecule.

Junk DNA: Sequence of DNA for which no specific coding function has yet been assigned. Also called noncoding DNA.

Linkage disequilibrium: The phenomenon of a specific allele of one locus being associated with an allele of another locus on the same chromosome with a frequency greater than expected by chance.

Locus: A specific, physical position on a chromosome.

Marker: A gene with a known location on a chromosome and a clear-cut phenotype that is used as a point of reference when mapping another locus; or, referring to DNA fragments of known base pair length run on gels from which the size of unknown DNA sample fragments can be determined.

Mitochondria: Structures, or organelles, found within a cell that are responsible for generating the cell's (and hence organism's) energy. Mitochondria contain DNA molecules that are inherited only from an individual's mother. An individual and his or her siblings will share the same mitochondrial DNA pattern-the pattern of their mother (and other maternal relatives, including the maternal grandmother and maternal aunts and uncles).

Multilocus probe: DNA probe that detects genetic variation at multiple sites in the genome. An autoradiogram of a multilocus probe application yields a complex, stripe-like pattern of 30 or more bands per individual. Compare Single-1ocus probe.

Nucleotide: The unit of DNA consisting of one of four bases-adenine, guanine, cytosine, or thymineattached to a phosphate-sugar group. The sugar group is deoxyribose in DNA. (In RNA, the sugar group is ribose and the base uracil substitutes for thymine.)

Phenotype: The appearance of an individual or the observable properties of an organism that result from the interaction of genes and the environment.

Polymerase chain reaction (PCR): An in vitro process, through which repeated cycling of the reaction reproduces a specific region of DNA, yielding millions of copies from the original.

Polymorphism: The existence of more than one form of a genetic trait.

Probe: In forensic applications, a short segment of DNA tagged with a reporter molecule, such as radioactive phosphorus (32P), used to detect the presence of that particular complementary DNA sequence.

Protein: A biological molecule whose structure is determined by the sequence of nucleotides in DNA. Proteins are required for the structure, function, and regulation of cells, tissues, and organs in the body. Some traditional forensic genetic markers are proteins.

Recombinant DNA technology: Processes used to form a DNA molecule through the union of different DNA 
molecules, but now commonly used to refer to any techniques that directly examine DNA.

Replication: The synthesis of new DNA from existing DNA. PCR is an in vitro technology based on the principles of replication.

Restriction endonuclease: An enzyme that has the ability to recognize a specific DNA sequence and cut it at that sequence.

Restriction enzyme: See restriction endonuclease.

Restriction fragment length polymorphism (RFLP): Variations in the size of DNA fragments produced by a restriction endonuclease at a polymorphic locus.

RFLP analysis: DNA technique using single-locus or multilocus probes to detect variation in the DNA sequence by revealing size differences in DNA fragments produced by the action of a restriction enzyme. See restriction fragment length polymorphism.

Serology: Scientific discipline concerned with the study of body fluids.

Single-locus probe: DNA probe that detects genetic variation at only one site in the human genome. An autoradiogram using one single-locus probe usually displays one (homozygote) or two (heterozygote) bands. Compare multilocus probe.

Southern blot: The nylon membrane to which DNA has adhered after the process of Southern blotting.

Southern blotting: The technique for transferring DNA fragments separated by electrophoresis from the gel to a nylon membrane, to which DNA probes that detect specific fragments can then be applied.

Standardization: In forensic uses of DNA tests, refers to a national system that uses a single restriction endonuclease with, in whole or part, certain designated DNA probes; critical to databanking considerations. Compare standards.

Standards: Criteria established for quality control and quality assurance; or, known test reagents, such as molecular weight standards. Compare standardization.

Tandem repeats: Multiple copies of the identical (or nearly identical) DNA sequence arranged in direct succession at a particular site on a chromosome. See variable number of tandem repeats.

Tag polymerase: DNA polymerase-the enzyme used to form double-stranded DNA from nucleotides and a single-stranded DNA template-isolated from the bacterium Thermus aquaticus, which normally lives in hot springs. Taq polymerase can withstand the high temperatures required in the repeating cycles of PCR.

Variable number of tandem repeats (VNTR): Repeating units of a core DNA sequence, for which the core number varies between individuals, thus providing the basis for RFLP analysis. See tandem repeats. 


\section{Index}


Accreditation, 77-79

Admissibility

DNA tests, 14, 16-17,98-101, 103-105, 107, 157-172

DNA tests, limited or barred, 16, 103, 105, 108, 157

scientific evidence, 14, 15, 91, 93, 95-\%

State statutes for DNA testing, 107

Advisory Committee on Automated Personal Data Systems, Federal Code of Fair Information Practices, 127

Advisory Policy Board (APB)-NCIC, 20, 125-127

Alabama

number of DNA cases in, 15

reported uses of DNA typing in, 16, 158

Alaska

number of DNA cases in, 15

reported uses of DNA typing in, 16, 158

American Academy of Forensic Sciences (AAFS), 72

American Association of Bioanalysts, clinical laboratory regulation, 13,78

American Association of Blood Banks (AABB)

proficiency testing program, 79

quality assurance standards for paternity testing of, 72

American Association of Trial Lawyers, 73

American Bar Association, 73

American Board of Criminalistics, 76

American Civil Liberties Union, 73

American Osteopathic Association, clinical laboratory regulation, 13,78

American Society for Microbiology, survey of membership in Hopkins case, 142

American Society of Crime Laboratory Directors (ASCLD), $72,141,146$

accreditation program, 12, 77-78, 146

proficiency testing program, advisory capacity of, 72 , 146

support for national databank based on FBI RFLP protocol, 124

survey of members, 142

American Society of Histocompatibility and Immunogenetics (ASHI), quality assurance guidelines of, 72

American Society of Human Genetics (ASHG) preservation of DNA samples, points to consider by, 133

quality assurance guidelines, points to consider by, 72

American Type Culture Collection, 121

Andrews, Tommie Lee, 99, 108, 105, 160

Antitrust Division (U.S. Department of Justice), 78

Argentina, 51

Arizona

law establishing DNA databank in, 16,20, 122, 123

number of DNA cases in, 15

reported uses of DNA typing in, 16, 158

Arkansas number of DNA cases in, 15

reported uses of DNA typing in, 16, 158

Army (U.S.)

reported use of DNA typing in, 172

see also Military

Ashton, Jeffrey, 99

Attorney General (U. S.)

oversight and setting of standards, 29-30

role in crime-related information exchange, 125

Australia, 24, 145

Automated Fingerprint Identification Systems (AFIS), 114

Band shift, 10-11,63,65

Beirne, D., 119

Biotechnology Science Coordinating Committee, monitoring DNA technologies, 81

Brandeis, Justice, 111

Bureau of Justice Statistics (BJS), study of rates of recidivism, 22, 129

California

law establishing DNA databank in, 16,20, 122-123

Martinez case, 157, 159

number of DNA cases in, 15

reported uses of DNA typing in, 16, 157, 158-159

California Association of Crime Laboratory Directors (CACLD), 72

proficiency test administered by, 79-80,105

survey of interest in DNA typing conducted by, 142

California Association of Criminalists (CAC), 72,76

California Department of Justice, 72

Canada

Gander, Newfoundland incident, 130

Royal Canadian Mounted Police, 24, 145

Casselman, Murrel, 89

Castro, Jose, 103

Cellmark Diagnostics (Maryland), 148

costs of services, 25,149

crime laboratories contracting with, 149

criminal cases and investigations examined by, 157172

testimony as expert witnesses by, 98

Certification, 76-77

Cetus Corp. (California)

Forensic Science Associates' licensing agreement with, 148

patent for PCR, 148-149

test kit marketed by, 149

Civil liberties, 21-23

policy options for, $35-38$

see also Privacy

Clinical laboratories 
Federal regulation of, 12-13,29,71,78

proficiency testing in, 80

State regulation of, 75-76

see also Clinical Laboratory Improvement Amendments of 1988

Clinical Laboratory Improvement Amendments of 1988 (CLIA), 12-13,78

Cobey, Kenneth, 108

Collaborative Testing Services (CTS), proficiency testing program, 79

College of American Pathologists, clinical laboratory regulation, $13,77,78$

Colorado

law establishing DNA databank in, 16,20, 123

number of DNA cases in, 15

reported uses of DNA typing in, 16, 159-160

Computers

analyzing DNA tests using, 18-21, 113, 114-120

cost-effectiveness in court, 118-120

cross-jurisdictional networks of, 19-20, 125-128

FBI model system, 119

interpretation of PCR test results, 117-118

interpretation of RFLP analysis, 114-117, 118

interpretation of RFLP analysis, potential problems, 18,119

storing DNA results in, 19-21, 120-128

verification and reliability of, 18, 119

see also Databanks

Congress, U. S., policy issues and options for, 26-38

Connecticut

Hinton case, 157, 160

number of DNA cases in, 15

proposed law establishing DNA databank in, 16, 20, 124

reported uses of DNA typing in, 16, 160

Consensus Development Program (NIH), 28,73-74

Constitution, U. S., 75,80,81,82

considerations in obtaining biological evidence, 97-98

Fifth Amendment, 17,97-98

Fourteenth Amendment, 17,98

Fourth Amendment, 17,98, 108

Right to privacy, 128

Sixth Amendment, 17,98

see also Privacy

Controls

for PCR, 69-71

for single-locus probe analysis, 62-64

costs

FBI equipment and computer, 118-120

FBI estimates of DNA typing, 25, 143-144

forensic services by private laboratories, 25,149

of DNA typing, impact on defense, 17-18, 26, 101

onsite DNA testing, 23-25

paternity services by private laboratories, 149

quality assurance, 14,79

savings to courts in, 17, 100 to States of implementing DNA databank networks, 127

Council on Forensic Science Educators, 72

courts

DNA in, 14, 16-17,98-100, 157-172

pretrial hearings of DNA evidence in, 101, 103-105

role in quality assurance, 82

scientific evidence in, 14, 16, 91, 93, 96

trial strategy when using DNA in, 107

Crime laboratories

budgets of, 144-145

budget requests for DNA testing of, 150

contracting by, $148-150$

involvement in DNA testing of State and local, $147-152$

not currently using DNA testing, 147-148

onsite DNA testing by, 150-151

OTA survey of, 23-26, 129, 141, 144-153

plans for DNA testing by, 23-25, 147, 148

Databanks

access to information in, 133-134

accessibility to State criminal history files in, 22-23, 128,134

creation and use of, 19, 120-128

crime laboratories' interest in, 19, 146-147, 152

de facto national, 21, 113

ethnic and racial data collected in, 20-21,68, 120-121, 122

existing storehouses of genetic information, 121

fair information practices, 127-128

FBI plans for types of, 19, 120-124, 151

information exchange via, 20, 125-128

information proposed for storage in, 131-132

investigatory uses of, 19-21, 120, 121-124, 134-135

maintenance and management of, 20, 125-128

policy options for advisability of, 32-34

policy options for standardization for, 34-35

population statistics in, 19, 120-121

privacy of DNA information in, 21-23, 128-135, 136

proposed use to locate missing children, 130-131

recidivism as a justification for, 22,129

role of NCIC, 20, 125-127

security and accountability, 127

standardization, 14,21,46, 83, 124, 136

State laws for establishing DNA, 16,20, 122-124

technical considerations in establishing, 124-125

see also Computers; Privacy

Davis, Aubrey J., 101

Davis v. Mississippi, 134

Delaware

number of DNA cases in, 15

Pennell case, 157, 160

reported uses of DNA typing in, 16, 160

Denmark 24, 145

Department of Commerce (U.S.), 28,75 
Department of Health and Human Services (U. S.) clinical laboratory regulation, 13, 78

Consensus Development Program (NIH), 73 quality assurance and performance under Medicare, 81

Department of Justice (U.S.). See Federal Bureau of Investigation; Attorney ,General (U. S.)

District of Columbia number of DNA cases in, 15 reported uses of DNA typing in, 16, 160

DNA composition and structure of, 3-4, 6,41-43 sources of, 4, 15,42, 104 variability and uniqueness of, 3,4143,59, 83

DNA analysis. See DNA testing, terminology DNA databanks. See Databanks

DNA fingerprinting. See DNA testing, terminology DNA identification. See DNA testing, terminology

DNA markers

population genetics and variation of, 7,43-44, 122 variable number of tandem repeats, 44 see also DNA; Population genetics; Restriction fragment length polymorphism; Statistics

DNA patterns

in murder casework $11,50,65$

in paternity casework 9,61

in rape casework $7,50,60,117$

revealed by multilocus probes, 47

revealed by single-locus probes, 4,47

using PCR/HLA $D Q x-1,50$

DNA prints. See DNA testing, terminology

DNA profiling. See 20DNA testing, terminology

DNA sequencing, 50

DNA testing

advantages of, 17,50, 100

considerations for declaring a match in, 63-64 controversies over setting standards for, 10-11, 82, 85 courtroom use of, 14-17, 98-100, 157-172

crime laboratories' interest in, OTA survey, 23-26,141, 144-153

criminal investigations using, 14, 157-172

criticisms and limitations of, 17-18, 101

defense-initiated use of, 99-100

equipment needs for, 143

exclusion through, 157

impact on murder cases of, 51-52

impact on rape cases of, 51-52

international uses of, 24, 145

medically informative, 19, 37-38, 130-132

newborn infants, 130-131

novel applications of, 7, 51

paternity disputes, 14,52

quality assurance considerations for, 11-14,71-82

reliability of, 7-8, 60, 83

State laws addressing admissibility of, 14, 107

surveys to assess interest in (non-OTA), 142

terminology of OTA report, 3,41 uses of, present and future, 6-7, 8, 50-52,53

Validity of, 7-8, 10, 59-60, 83, 103

DNA typing. See DNA testing

Dotson, Gary, 119, 162

Drug testing laboratories, Federal regulation of, 12,29,71

Due process, $17,98,128$

Economics. See Costs; Funding

Einstein, Albert, 57

Electrophoresis Society, 73, 124

Everhart, Jeffrey L., 101

Evidence

biological, 96-98

DNA as, 96-109

DNA as exculpatory, percent by FBI laboratory, 157

rules and standards concerning the law of, 91

standards for admitting scientific, 91,93,95-96

statistical, 104-105, 107

Expert testimony

costs of, 25, 149

provided by FBI and commercial laboratories, 14,98

requirements under the Frye test, 93,95

requirements under the relevancy test, 96

use of, 91,93

Fair Information Practices, 127-128

Federal Bureau of Investigation (FBI)

cases and samples handled by, 23

computer networks and databanks, advisory role of, $122,125-129,151$

criminal cases and investigations examined by, 157172

DNA Analysis Unit, 23-24, 143, 152

DNA databank types proposed by, 19, 120-122

percent suspects excluded in cases by, 157

proficiency testing, role of, 144

responsibilities for data files, 20,22, 127

roles suggested by crime laboratories for, 26, 146-147 survey of interest in DNA typing conducted by, 142 testimony as expert witnesses, 23,98

see also Forensic Science Research and Training

Center; National Crime Information Center; Technical Working Group on DNA Analysis Methods

Federal Rules of Evidence. See Relevancy test

Federal Trade Commission (U.S.), 78

Fifth Amendment to U.S. Constitution, 17,97-98, 135

Finland, 24, 145

Florida

Andrews case, 99, 108, 160

law establishing DNA databank in, 16,20, 123

number of DNA cases in, 15

private access to criminal history files in, 22, 128,134

reported uses of DNA typing in, 16, 160-162

Forensic science

education and training in, 76-77

policy options for funding in, 30-32 
professional societies in, 72

Forensic Science Associates (FSA)-California, 148-149 costs of services, 25, 149

crime laboratories contracting with, 149

criminal cases and investigations examined by, 157172

licensing agreement with Cetus. Corp., 148

testimony as expert witnesses by, 98

Forensic Science Foundation (FSF), proficiency testing program, 79

Forensic Science Research and Training Center (FSRTC) mission of, 141

research by, 141,143

training by, 23, 143

validation studies of DNA testing by, 23, 143

Visiting Scientist Program of, 23, 143

see also Federal Bureau of Investigation

Fourteenth Amendment to U.S. Constitution, 17,98, 128

Fourth Amendment to U.S. Constitution, 17,98,108,135

Frye case, 93

Frye, James Alfonso, 93

Frye test, 93-95

advantages and drawbacks of, 95

comparison to relevancy test, 16, 96

Funding

mechanisms by crime laboratories for DNA testing, 150

policy options for, 30-32

Gander, Newfoundland, 130

GenBank, 121

General Accounting Office (U.S. Congress), quality assurance in drug testing laboratories, 12,71

GeneScreen (Texas), 148

Genetic markers, traditional, 6,41,50,83

Genetics Society of America, 73

Gennan Corp. (Ohio), 148

Georgia

number of DNA cases in, 15

reported uses of DNA typing in, 16, 162

Guidelines

TWGDAM, 74

voluntary professional, 72-73

Hardy-Weinberg equilibrium, 67

Hawaii

number of DNA cases in, 15

reported uses of DNA typing in, 16, 162

Health Care Finance Administration (HCFA), clinical laboratory regulation, 13,78

Holmes, Justice, 57

Houston, Cpl. Carl, 130

Human Gene Mapping Library (HGML), 121

Human Genetic Mutant Cell Repository, 121

Human Genome Mapping Project computer spin-off technologies from, 113, 117 identification of loci for DNA sequencing from, 50

Human leukocyte antigen (HLA)--HLA $D Q x-1$

casework using, 50

discrimination power of, 48

PCR examination at, 48-49

Idaho

number of DNA cases in, 15

reported uses of DNA typing in, 16, 162

Illinois

Dotson case, 119, 162

law establishing DNA databank in, 16,20, 123

number of DNA cases in, 15

reported uses of DNA typing in, 16, 162

Imperial Chemical Industries PLC (United Kingdom), 148

India, 24, 145

Indiana

Hopkins case, 142, 162

number of DNA cases in, 15

proposed law establishing DNA databank in, 16, 20, 124

reported uses of DNA typing in, 16, 162-163

International Association of Chiefs of Police, 125-126

International Electrophoresis Society, 124

International Society for Forensic Haemogenetics (ISFH), quality assurance guidelines of, 72

Interstate Identification Index (Triple 1)-NCIC, 22, 125

Iowa

law establishing DNA databank in, 16,20, 123

number of DNA cases in, 15

reported uses of DNA typing in, 16, 163

Ireland, 24, 145

Israel, 24, 145

Italy, 24, 145

Jack, Melanie, 100

Japan, 24, 145

Jeffreys, Alec, 148

Joint Commission on Accreditation of Healthcare Organizations, clinical laboratory regulation, 13,77,78

"Junk" DNA, 19,38, 131-132

Kansas

Mosley case, 100

number of DNA cases in, 15

reported uses of DNA typing in, 16, 163

Kentucky, number of DNA cases in, 15

Korea, Republic of, 24, 145

Law Enforcement Assistance Administration, 144

Law Enforcement Standards Laboratory (National Institute of Justice), 75

Legislation

State admissibility of DNA tests, 14, 107

State DNA databanking, 16, 19,20, 122-124 
Leicester case, 8, 134-135, 148

Licensing of personnel, 74-76

of facilities, 77

Lifebank Inc. (New York), 131

Lifecodes, Corp. (New York), 149

costs of services, 25, 149

crime laboratories contracting with, 149

criminal cases and investigations examined by, 157172

testimony as expert witnesses by, 98

Louisiana

law addressing the admissibility of DNA in, 14, 107

number of DNA cases in, 15

reported uses of DNA typing in, 16, 163

Maine

McLeod case, 157,163

number of DNA cases in, 15

reported uses of DNA typing in, 16, 163

Marine Corps (U. S.)

reported use of DNA typing in, 172

see also Military

Maryland

clinical laboratory licensing in molecular biology, 75-76

Cobey case, 108, 163

law addressing the admissibility of DNA in, 14, 107

number of DNA cases in, 15

reported uses of DNA typing in, 16, 163-164

Massachusetts

number of DNA cases in, 15

private access to criminal history files in, 22, 128, 134

proposed law establishing DNA databank in, 16, 20, 124

reported uses of DNA typing in, 16, 164

Match (DNA patterns), considerations for declaring and reporting, 63-66

Mays, Kimberly, 131

Mays, Robert, 131

Mendel, Gregor, 41

Michigan

number of DNA cases in, 15

proposed law establishing DNA databank in, 16, 20, 124

reported uses of DNA typing in, 16, 164

Military (Us.)

number of DNA cases in, 15

potential use of DNA typing and DNA databanks by, 130

reported uses of DNA typing in, 157, 172

Minnesota

law addressing the admissibility of DNA in, 14, 107

law establishing DNA databank in, 16,20, 123

number of DNA cases in, 15

reported uses of DNA typing in, 16, 164-165
Schwartz case, 105, 108, 157, 165

statistical evidence in, 105, 107

Mississippi

number of DNA cases in, 15

reported uses of DNA typing in, 16, 165

Missouri

number of DNA cases in, 15

reported uses of DNA typing in, 16, 165

Mitochondrial DNA (mtDNA), 51

Moennsens, Andre A., 89

Montana

number of DNA cases in, 15

reported uses of DNA typing in, 16, 165

Mosley, Johnny D., 100

Multilocus probes, 68-69

patterns revealed by, 47

population genetics of, 69

Murder

DNA patterns from actual cases of, 11,50,65

impact of DNA on, 17, 51

incidents reported (1988), 17, 51

recidivism statistics for, 22,129

National Academy of Sciences, 28,73

National Association of Criminal Defense Lawyers, 73

National College of District Attorneys, 73

National Conference of Commissioners on Uniform State Laws, role in quality assurance of, 27

National Crime Information Center (NCIC)

DNA information, policy of, 126-127

DNA profiles indexed in, 20, 125

records held by, 125

role in exchanging criminal history information, 125 127

safeguards for databanks of, 22, 134

National District Attorneys' Association, 126

National Institute of Justice (NIJ), 31-32,73,75

National Institute of Standards and Technology (NIST), role in quality assurance of, 28-29, 75

National Institutes of Health $(\mathrm{NIH})$

Consensus Development program, 28,73-74

FBI joint project with, 141

Recombinant DNA Advisory Committee, monitoring DNA technologies, 13, 81

National Law Enforcement Telecommunications System (NLETS), 20,125

National Probation and Parole Association, 126

National Sheriffs' Association, 126

Nebraska, number of DNA cases in, 15

Negligence litigation, 76

Netherlands, the, 24, 145

Nevada

law addressing the admissibility of DNA in, 14, 107 law establishing DNA databank in, 16,20, 123-124 number of DNA cases in, 15

New Hampshire 
number of DNA cases in, 15

reported uses of DNA typing in, 16, 165

New Jersey

number of DNA cases in, 15

reported uses of DNA typing in, 16, 165

New Mexico

number of DNA cases in, 15

reported uses of DNA typing in, 16, 166

New York

Castro case, 103, 157, 166

Forensic DNA Analysis Panel, 152

number of DNA cases in, 15

reported uses of DNA typing in, 16, 166-167

New Zealand, 24, 145

North Carolina

number of DNA cases in, 15

reported uses of DNA typing in, 16, 167

North Dakota, number of DNA cases in, 15

Norway, 24, 145

Office of Technology Assessment (OTA)

findings on validity and reliability of DNA tests by, 7-8,59-60

instrument for survey by, 173-178

reports on human genetics and biotechnology by, 41

results of survey of crime laboratories, 23-26,129,141, 144-153

Ohio

number of DNA cases in, 15

proposed law establishing DNA databank in, 16, 20, 124

reported uses of DNA typing in, 16, 167-168

Oklahoma

number of DNA cases in, 15

reported uses of DNA typing in, 16, 168

Olmstead v. United States, 111

On-Line Mendelian Inheritance in Man (OMIM), 121

Oregon

number of DNA cases in, 15

reported uses of DNA typing in, 16, 168

Paternity cases, 99

child support enforcement, 52

cost savings to court in, 52

DNA patterns from, 9,61

number of facilities handling, 52

Pennsylvania

number of DNA cases in, 15

reported uses of DNA typing in, 16, 168-169

Pitchfork case, 8, 134-135

Poland, 24, 145

Policy, issues and options for Congress, 26-38

Polymerase chain reaction (PCR)

amplification of DNA using, 4,47-50,69-71

computer technologies used with, 117-118

contamination as a problem of, 69-70 controls for, $69-71$

HLA DQx+1 amplification using, 48-50,70-71, 119

misincorporation with, 70

mitochondrial DNA amplification using, 51

novel applications using, 48,50,51

population genetics considerations for, 70-71

possible technical standards for, 10,69-70

schematic of DNA using, 6,48

use in actual casework, 50, 119

validity and reliability, 59-60

Ponce, Vilma, 103

Popper, Sir Karl R., 57

Population frequencies. See Population genetics; Statistics

Population genetics

disagreement about, 10,66

ethnic and racial considerations in databanks, 20-21, $37,68,120-122$

interpreting DNA test results using, 8-10, 62, 66-71

role in forensic investigations, $6,134-135$

validity of underlying principles applied to forensic casework, 66

see also Statistics

Privacy, 21-23, 128-136

debates about storing DNA v. storing DNA test results, $21,132-133$

medically informative DNA tests, 21-22, 37-38, 130132

personal information and, 128

policy options to address issues in, 35-38

regulations by NCIC to ensure, 22, 134

Privacy Act of 1974

Code of Fair Information Practices as a model for, 127

exemptions for criminal justice agencies, 22, 128, 134

protection of information in Federal databases, 22,128

Probes. See Multilocus probes; Single-locus probes

Proficiency testing

AABB program, 79

controversy over availability and use of results of, 80

controversy over CTS-FSF program, 79

FBI plans for, 80

United Kingdom program, 79

Protein Data Bank (PDB), 121

Protein Identification Resource (PIR), 121

Quality assurance, 83-85

clinical laboratories, 12-13,29,71, 75-76,78, 80

costs of, 14,79

drug testing laboratories, 12,29,71

Federal role in, 14-16,73-75, 80-82

flexibility in programs for, 14,79

mechanisms for, 11-14, 71-82

policy options for, 27-30

professional societies' role in, 12,72-73

State role in, 12,75-77

see also Regulation; Standards 
Quality control, 62,71

Rape

DNA patterns from actual cases of, 7,50,60, 117

impact of DNA on, 17, 52, 99

incidents reported (1988), 17, 52

recidivism statistics for, 22,129

Recidivism, 22, 129

Regulation

accreditation, 77-79

certification, 76-77

clinical laboratories as a model for, 12-13, 29, 71, $75-76,77,78,80$

drug laboratories as a model for, $12,29,71$

Federal role in, 80-82

licensing, 75-76,77

policy options for, 27-30

proficiency testing, 79-80

State role in, 75-77

see also Quality assurance; Standards, setting of

Relevancy test, 14, 16-17,96

comparison to Frye test, 16, 96

expert testimony under, 96

Reliability

increasing challenges to, 8

of DNA test results, 60

of DNA tests per se, 7-8,60

Research, funding for forensic, 31-32

Restriction enzymes, used by FBI and commercial laboratories, 46

Restriction fragment length polymorphism (RFLP)

analysis and interpretation, 4,4347, 60-68

basis for, 43-44

population genetics, 66-68

see also Multilocus probes; Single-locus probes; Southern blotting; Variable number of tandem repeats

Rhode Island

number of DNA cases in, 15

reported uses of DNA typing in, 16, 169

Right to counsel, 17,98

Schmerber v. California, 97-98

Schwartz, Thomas, 105

Scientific evidence

expert testimony, 91, 93

Frye test, 93,95

relevancy test, 96

standards for admitting, 91, 93

see also Evidence; Statistics

Search and seizure, 17,98, 135

Cobey case, 108

Secret Service (U.S.), 125

Self-incrimination, 17,97-98, 135

Senate Committee on Labor and Human Resources (U.S.), 3

Sessions, William S., 1, 111
Sexual assault. See Rape

Sheindlin, Judge Gerald, 103

Single-locus probes

analysis and interpretation using, 44-47,60-68

computer analysis of DNA tests using, 114-117, 118

considerations for choosing, 62

controls for test using, 61,62-64

evidence size limitation for analysis with, 47

patterns revealed by, 4,47

population genetics of, 66-68

possible technical standards for, $60-66$

reporting that patterns match using, 63-66

schematic using, 5,45

Sixth Amendment to U.S. Constitution, 17,98

Social security number (SSN), use as a nat.ional identifier, $21,113,115$

Society of Heredity and Evolution, 73

South Africa, 24, 145

South Carolina

Ford case, 89, 169

number of DNA cases in, 15

reported uses of DNA typing in, 16, 169

South Dakota

law establishing DNA databank in, 16,20, 123-124

number of DNA cases in, 15

reported uses of DNA typing in, 16, 169

Southern Association of Forensic Scientists, 77

Southern blotting, 44,4647,60-61

Spencer, Timothy W., 101, 108

Standardization

as distinct from standards, 83

importance to crime laboratories of, 145-146

importance to DNA databanking of, $14,21,46,83,124$, 136

international cooperation on, 24, 145

policy options for, 34-35

role in quality assurance of, 83

Standards

controversies over setting, 10-11, 82, 85

crime laboratories' view of FBI role in, 25, 147

for legal admissibility of scientific evidence, 14,16-17, 91,93,95-96

for PCR, possible technical, 10,69-70

for RFLP analysis, possible technical, 10-11,60-66

operational, 10, 82

policy options for setting, 27-30

technical, 10, 82

see also Guidelines; Quality assurance

Statistics

as evidence in court, 101, 104-105, 107

calculating for RFLP analysis, 67

database considerations of population, 120-122

see also Population genetics

Supreme Court, U.S.

privacy of criminal history records, 134

refusal to hear appeal in Spencer case, 101 
ruling on congressional authority to impose conditions on funds, 81

Sweden, 24, 145

Switzerland, 24, 145

TJ. Hooper, The, 57

Teale, Edwin Way, 39

Technical Working Group on DNA Analysis Methods (TWGDAM)-FBI

computer database model of, 13, 122, 127, 144

members of, 144

quality assurance program of, 13-14,74-75,77, 144 statistics, 13

Tennessee

number of DNA cases in, 15

Texas

number of DNA cases in, 15

reported uses of DNA typing in, 16, 169-170

Trimboli case, 100, 170

Thompson, Governor James (Illinois), 162

Thorton, John I., 139

Training

policy options for funding, 31

education and requirements for, 76-77

Trimboli, Ronald Stephen, 100, 170

Triple I. See Interstate Identification Index

Twigg, Arlena, 130-131

Twigg case, 130-131

Uhrig, Hal, 39,99

United Kingdom

DNA typing in, 24, 145

DNA's criminal debut, Leicester case, 8, 135

immigration case, first use in forensic context, 68

multilocus probe analysis in, 47, 68

proficiency testing in, 79

United States v. Williams, 89

University of New Haven (Connecticut), survey of
Utah

interest in DNA typing conducted by, 142

number of DNA cases in, 15

reported uses of DNA typing in, 16, 170-171

Validity

DNA tests per se, 7-8,59-60

principles of population genetics, 10,66

Variable number of tandem repeats (VNTR), 44

Vermont

number of DNA cases in, 15

reported uses of DNA typing in, 16, 171

Virginia

child support enforcement and DNA testing in, 52

law establishing DNA databank in, 16,20, 123-124

number of DNA cases in, 15

onsite DNA testing in, 150-151

reported uses of DNA typing in, 16, 171

Spencer case, 101, 108, 171

Washington

law establishing DNA databank in, 16,20, 123-124

number of DNA cases in, 15

reported uses of DNA typing in, 16, 171-172

Webb, Cathleen Cromwell, 119

West Germany, 24, 145

West Virginia

number of DNA cases in, 15

reported uses of DNA typing in, 16, 172

Woodall case, 108, 157, 172

Williams, John, 39

Wisconsin

number of DNA cases in, 15

reported uses of DNA typing in, 16, 172

Wyoming, number of DNA cases in, 15

Yugoslavia, 24, 145 